\title{
Conceptualization of a
} Hypothetical High-Level Nuclear Waste Repository Site in Unsaturated, Fractured Tuff

Manuscript Completed: December 1990

Date Published: January 1991

Prepared by

A. M. Parsons, N. E. Olague, D. P. Gallegos

Sandia National Laboratories

Albuquerque, NM 87185

Prepared for

Division of Engineering

Office of Nuclear Regulatory Research U.S. Nuclear Regulatory Commission

Washington, DC 20555

NRC FIN A1266
This report was prepared as an account of work sponsored by an agency of the United States Government. Neither the United States Government nor any agency thereof, nor any of their employees, makes any warranty, express or implied, or assumes any legal liability or responsibility for the accuracy, completeness, or usefulness of any information, apparatus, product, or process disclosed, or represents that its use would not infringe privately owned rights. Reference herein to any specific commercial product, process, or service by trade name, trademark, manufacturer, or otherwise does not necessarily constitute or imply its endorsement, recommendation, or favoring by the United States Government or any agency thereof. The views and opinions of authors expressed herein do not necessarily state or reflect those of the United States Government or any agency thereof.

\section{MASTER}




\section{DISCLAIMER}

Portions of this document may be illegible in electronic image products. Images are produced from the best available original document. 


\begin{abstract}
Under the sponsorship of the U.S. Nuclear Regulatory Commission (NRC), Sandia National Laboratories (SNL) is developing a performance assessment methodology for the analysis of long-term disposal and isolation of high-level nuclear waste (HLW) in alternative geologic media. As part of this exercise, SNL created a conceptualization of ground-water flow and radionuclide transport in the far field (i.e., outside the disturbed. zone) of a hypothetical HLW repository site located in unsaturated, fractured tuff formations. This study provides a foundation for the development of conceptual, mathematical, and numerical models to be used in this performance assessment methodology.
\end{abstract}

This conceptualization is site specific in terms of geometry, the regional ground-water flow system, stratigraphy, and structure in that these are based on information from Yucca Mountain located on the Nevada Test Site. However, in terms of processes in unsaturated and saturated, fractured, porous media, the model is generic. This report also provides a review and evaluation of previously proposed conceptual models of unsaturated and saturated flow and solute transport.

This report provides a qualitative description of a hypothetical HLW repository site in fractured tuff. However, evaluation of the current knowledge of flow and transport at Yucca Mountain does not yield a single conceptual model. Instead, multiple conceptual models are possible given the existing information. 


\section{CONTENTS}

ABSTRACT $\ldots \ldots \ldots \ldots \ldots \ldots \ldots \ldots \ldots \ldots \ldots \ldots \ldots \ldots \ldots \ldots \ldots \ldots \ldots$ iii

1.0 INTRODUCTION $\ldots \ldots \ldots \ldots \ldots \ldots \ldots \ldots \ldots \ldots \ldots \ldots \ldots \ldots \ldots \ldots \ldots \ldots \ldots$

1.1 Definition of Conceptual Model $\ldots \ldots \ldots \ldots \ldots \ldots \ldots \ldots \ldots, 1$

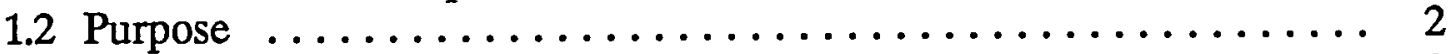

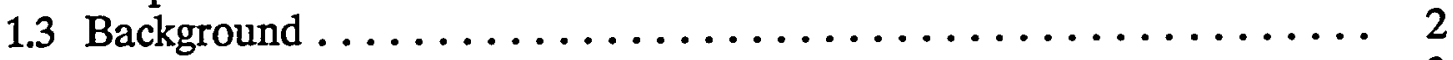

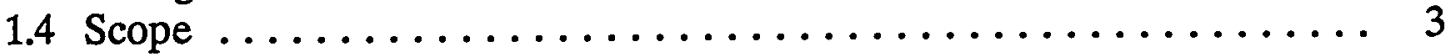

2.0 GENERAL DESCRIPTION $\ldots \ldots \ldots \ldots \ldots \ldots \ldots \ldots \ldots \ldots \ldots$

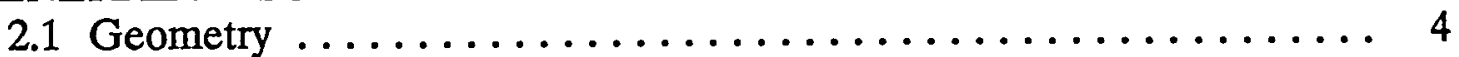

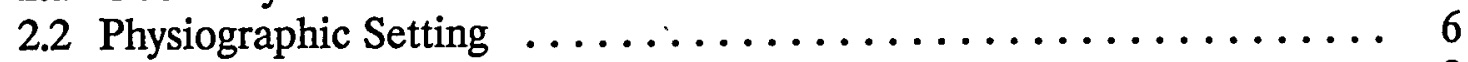

2.3 Climate $. \ldots \ldots \ldots \ldots \ldots \ldots \ldots \ldots \ldots \ldots \ldots \ldots . \ldots . \ldots . \ldots \ldots$

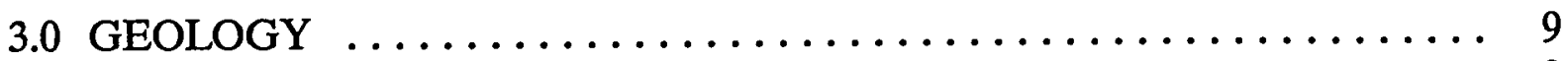

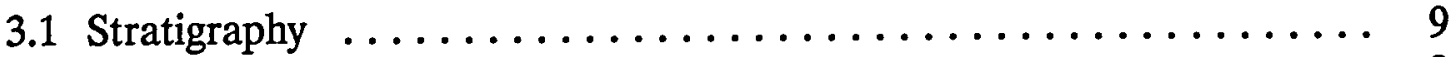

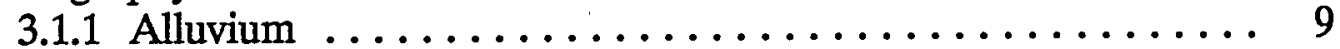

3.1 .2 Volcanic Tuff ........................ 9

3.1.3 Upper Carbonates $\ldots \ldots \ldots \ldots \ldots \ldots \ldots \ldots \ldots \ldots \ldots \ldots$

3.1 .4 Upper Clastics ....................... 18

3.1.5 Lower Carbonates .................... 18

3.1 .6 Lower Clastics ...................... 19

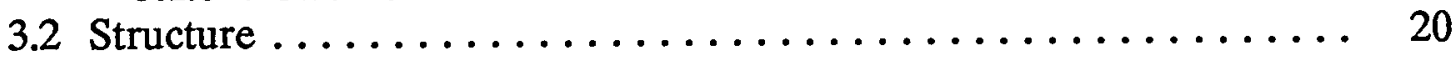

4.0 GROUND-WATER FLOW SYSTEM PROCESSES $\ldots \ldots \ldots \ldots \ldots \ldots 25$

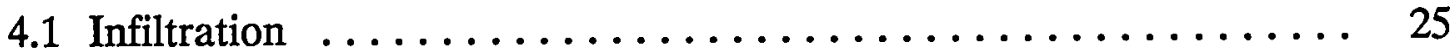

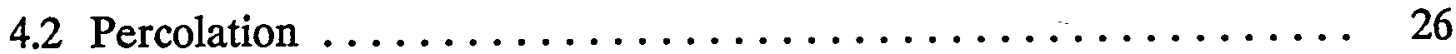

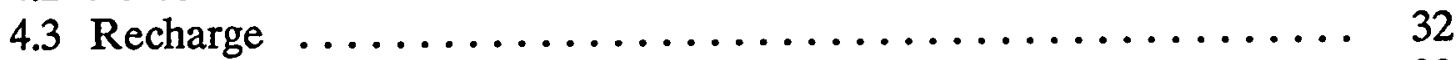

4.4 Vapor and Air Movement ....................... 33

4.5 Saturated Ground-Water Flow .................. 36

5.0 TRANSPORT SYSTEM PROCESSES $\ldots \ldots \ldots \ldots \ldots \ldots \ldots \ldots \ldots, 37$

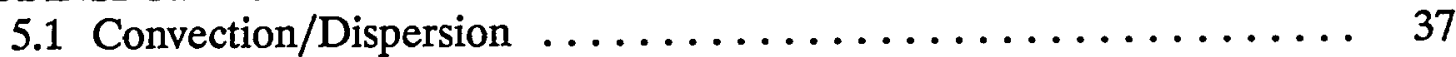

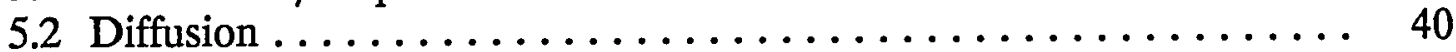

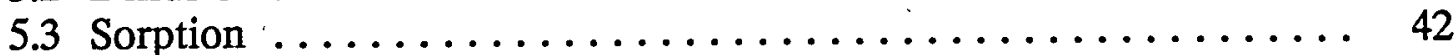

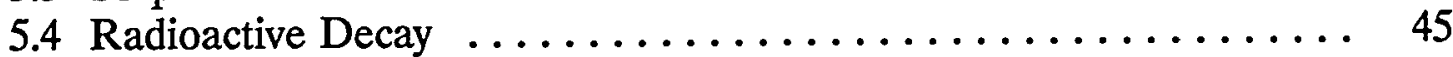

5.5 Leaching, Dissolution, and Precipitation ............ 46

5.6 Complexation ......................... 46

5.7 Gas Phase Transport $\ldots \ldots \ldots \ldots \ldots \ldots \ldots \ldots \ldots \ldots \ldots \ldots \ldots$

5.8 Colloids $\ldots \ldots \ldots \ldots \ldots \ldots \ldots \ldots \ldots \ldots \ldots \ldots \ldots, 50$

6.0 GROUND-WATER FLOW SYSTEM $\ldots \ldots \ldots \ldots \ldots \ldots \ldots \ldots \ldots$

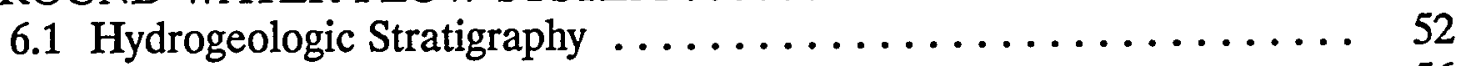

6.2 Regional Flow System $\ldots \ldots \ldots \ldots \ldots \ldots \ldots \ldots \ldots \ldots \ldots \ldots$

6.3 Local Flow System $\ldots \ldots \ldots \ldots \ldots \ldots \ldots \ldots \ldots \ldots \ldots$ 


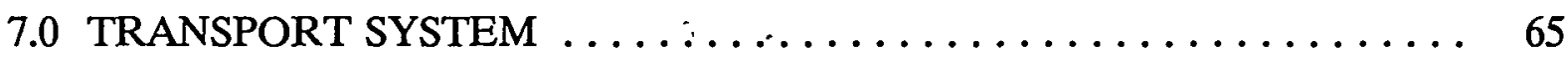

7.1 Physical Transport Stratigraphy .................. 65

7.2 Geochemical Transport Stratigraphy ................66 66

7.3 Stratigraphic Comparison . . . . . . . . . . . . . . 73

7.4 Hydrochemistry Related to Radionuclide Transport .......... 77

8.0 PREVIOUS CONCEPTUAL MODELS FOR FRACTURED TUFF . . . . 80

8.1 Unsaturated Ground-Water Flow $\ldots \ldots \ldots \ldots \ldots \ldots \ldots \ldots \ldots$

8.1.1 Montazer and Wilson (1984) $\ldots \ldots \ldots \ldots \ldots \ldots \ldots \ldots . \ldots \ldots$

8.1.2 Peters and others $(1986) \ldots \ldots \ldots \ldots \ldots \ldots \ldots \ldots . \ldots \ldots$

8.1.3 Lin and others $(1986) \ldots \ldots \ldots \ldots \ldots \ldots \ldots \ldots . \ldots \ldots$

8.1.4 Wang and Narasimhan (1985) $\ldots \ldots \ldots \ldots \ldots \ldots \ldots 87$

8.1 .5 Wang and Narasimhan (1986) $\ldots \ldots \ldots \ldots \ldots \ldots \ldots . \ldots . \ldots$

8.1.6 Wang and Narasimhan (1988) $\ldots \ldots \ldots \ldots \ldots \ldots \ldots . \ldots \ldots$

8.1.7 Travis and others $(1984 a, b) \ldots \ldots \ldots \ldots \ldots \ldots \ldots 9 . \ldots \ldots$

8.1.8 Ross (1984) . . . . . . . . . . . . . . . . . 94

8.1.9 Discussion of Unsaturated Ground-Water Flow Assumptions

8.2 Saturated Ground-Water Flow . . . . . . . . . . . . . . . 103

8.2.1 Rice (1984) .......................... 105

8.2.2 Waddell (1982) . . . . . . . . . . . . . . . . 107

8.2.3 Czarnecki and Waddell (1984) .............. 110

8.2 .4 Czarnecki (1985) . . . . . . . . . . . . . . . . . 110

8.2.5 Barr and Miller (1987) ................. 113

8.2.6 Discussion of Saturated Ground-Water Flow Assumptions . 115

8.3 Solute Transport $\ldots \ldots \ldots \ldots \ldots \ldots \ldots \ldots \ldots \ldots \ldots \ldots, 122$

8.3.1 Sinnock and others $(1984) \ldots \ldots \ldots \ldots \ldots \ldots \ldots, 122$

8.3.2 Travis and others $(1984 \mathrm{a}, \mathrm{b}) \ldots \ldots \ldots \ldots \ldots \ldots \ldots \ldots \ldots \ldots$

8.3.3 Lin and others $(1986) \ldots \ldots \ldots \ldots \ldots \ldots \ldots \ldots \ldots \ldots$

8.3.4 Dudley and others $(1988) \ldots \ldots \ldots \ldots \ldots \ldots \ldots \ldots . \ldots \ldots$

8.3.5 Ross (1988) ......................... 135

8.3.6 Discussion of Assumptions Used in Previous Solute Transport Conceptual Models ............. 136

9.0 SUMMARY AND CONCLUSIONS $\ldots \ldots \ldots \ldots \ldots \ldots \ldots \ldots \ldots$

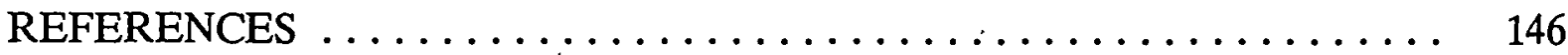


Figure $\quad$ Page

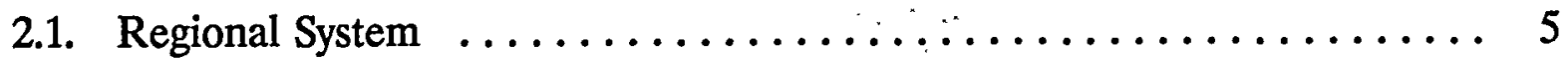

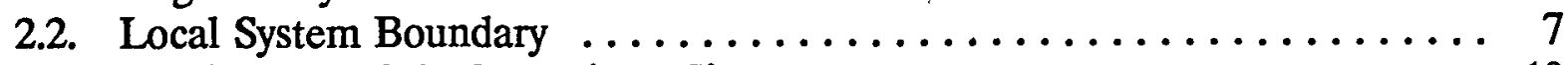

3.1. Stratigraphy of the Repository Site $\ldots \ldots \ldots \ldots \ldots \ldots \ldots \ldots \ldots . \ldots \ldots$

3.2. Generalized Geology of the Region $\ldots \ldots \ldots \ldots \ldots \ldots \ldots \ldots$

3.3. General Stratigraphic Relationships Among Geologic Units in the Repository Region ........................ 14

3.4. Generalized Cross-Section of a Typical Ash-Flow Tuff Sequence ............................... 16

3.5. Walker Lane and Major Associated Faults ............... 21

3.6. Faults at Yucca Mountain Interpreted from Geologic Mapping $\ldots \ldots .22$

3.7. Schematic Geologic Cross-Section E-E at Yucca Mountain ........ 24

4.1. Distribution of Pressure Head in Static Subsurface Water ........ 27

4.2. Effect of Texture on the Moisture Retention Relationship ........ 29

4.3. Moisture Content Distribution in a Stratified Soil $\ldots \ldots \ldots \ldots . \ldots 31$

4.4. Conceptualized System Where Convective Air Flow Occurs Due to a Topographic Effect .......................... 34

4.5. Conceptualization of Barometric Pressure Effects on Air Flow in Boreholes Open in the Unsaturated Zone ............... 35

6.1. Designated Hydrogeologic Units Based on Work by Montazer and Wilson (1984) and Winograd and Thordarson (1975) Compared to the Geologic Units at the Repository Site $\ldots \ldots \ldots \ldots \ldots \ldots \ldots \ldots . \ldots . \ldots$

6.2. Local, Intermediate and Regional Systems of Ground-Water Flow . . . . 57

6.3. Approximate Ground-Water Basin Locations, Recharge and Discharge Zones, and Boundary Conditions for the Regional Ground-Water Flow

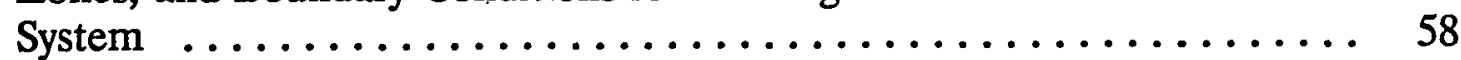

6.4. General Direction of Ground-Water Flow in the Region ........ 60

6.5. North-South Hydrogeologic Cross-Section of the Alkali Flat-Furnace Creek Ranch Ground-Water Flow Basin ................ 61

6.6. General Geographic Distributions of Hydrostratigraphic Units ...... 63

6.7. Preliminary Potentiometric Surface of the Local Ground-Water Flow

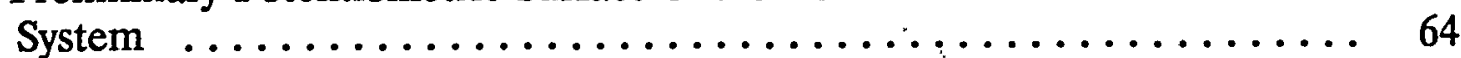

7.1. Location of Exploration Block and Exploratory Boreholes for

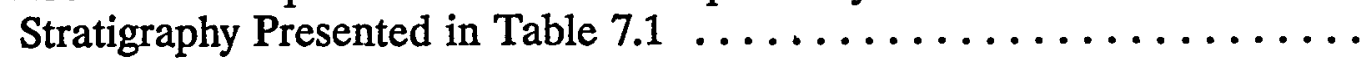

7.2. One-Dimensional Stratigraphic Comparison of Hydrogeologic, Geologic, and Geochemical-Transport Systems .................. 75

7.3. Hypothetical Example of Combined Transport Layering

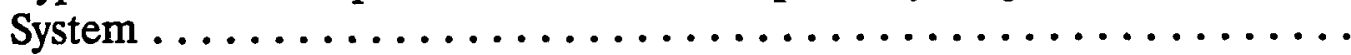

8.1. Conceptual Model Framework Assumed by Montazer and Wilson

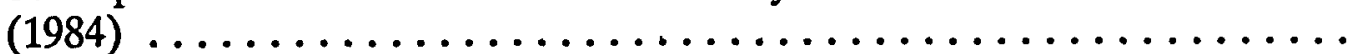

8.2. One-Dimensional Column Used in Travel Time Calculations (from

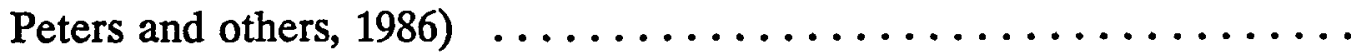

8.3. Schematic Diagram Showing the Three-Dimensional Geometry for Modeling Ground-Water Travel Time (from Lin and others, 1986) ..... 
FIGURES (cont.)

Figure

Page

8.4. General Hydrogeologic Cross-Section at Yucca Mountain (from Lin and others, 1986) . . . . . . . . . . . . . . . . . . . . . . .

8.5. Conceptual Model of Partially Saturated, Fractured, Porous Medium Showing Schematically the Flow Lines Moving Around the Dry Portions of the Fractures (from Wang and Narasimhan, 1985) .......... 88

8.6. Vertical Grid of the One Dimensional Conceptual Models Assumed by Wang and Narasimhan (1986) ...................... 90

8.7. Hydrogeologic Cross-Section at Yucca Mountain Assumed in the Conceptual Model of Wang and Narasimhan (1988) ........... 92

8.8. Conceptual Model Geometry Used for the Fracture Slug Flow Analysis by Travis and others $(1984 a, b) \ldots \ldots \ldots \ldots \ldots \ldots \ldots$

8.9. Locations of Drilled Monitoring Boreholes and Core Sampling Boreholes in the Unsaturated Zone at Yucca Mountain (modified from DOE, 1988) ............................... 104

8.10. Flow Boundaries of the Regional Ground-Water Flow Model of Rice (1984) . . . . . . . . . . . . . . . . . . . . . .

8.11. Discharge Areas of the Regional Ground-Water Flow Model of Rice (1984) . . . . . . . . . . . . . . . . . . . . . . .

8.12. Mesh and Zones Used in Regional, Two-Dimensional Ground-Water

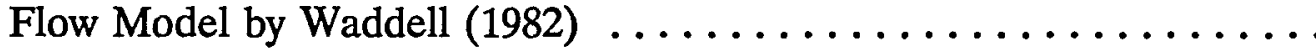

8.13. Location of Regional and Subregional Modeled Areas, With Generalized Ground-Water Flow Directions, and Generalized Geology (Czarnecki and Waddell, 1984)

8.14. Model Zone Numbers, Parameter Groupings, and Model Boundary Fluxes Assumed by Czarnecki and Waddell (1984) . . . . . . . . .

8.15. Location of the Local System Studied by Barr and Miller (1987) Compared to the Subregional System Studied by Czarnecki (1985) ... .

8.16. Local Region Modeled Around the Repository Block and the Grid of Elements and Nodes Assigned for Calculations in the Conceptual

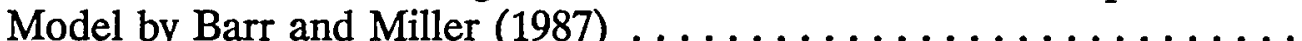

8.17. Preliminary Composite Potentiometric Surface Map of the Saturated Zone, Yucca Mountain (modified from DOE, 1988) ........... 121

8.18. Transport Paths Assumed by Sinnock and others (1984) . . . . . . . 124

8.19. Transport Path Assumed by Travis and others (1984a,b) . . . . . . . 127

8.20. Transport Path Assumed by Lin and Others (1986) . . . . . . . . 129

8.21. Transport Path Assumed by Dudley and Others (1988) . . . . . . . 132 


\section{TABLES}

Table

Page

3.1. Description of the Stratigraphy of the Hypothetical Repository Site. . . . 11

7.1. Depth and Thickness of Sorption-Based Stratigraphy Beneath

Exploration Block at Yucca Mountain

74

8.1. Conceptual Model Assumptions for Unsaturated Flow at a HLW

Repository in Fractured Tuff . . . . . . . . . . . . . . . . . 95

8.2. Conceptual Model Assumptions for Saturated Flow at a HLW

Repository in Fractured Tuff . . . . . . . . . . . . . . . . . . 117

8.3. Conceptual Model Assumptions for Solute Transport at a HLW

Repository in Fractured Tuff ...................... 137 


\subsection{INTRODUCTION}

Under the sponsorship of the U.S. Nuclear Regulatory Commission (NRC), Sandia National Laboratories (SNL) is developing a performance assessment methodology for the analysis of long-term disposal and isolation of high-level nuclear waste (HLW) in unsaturated, fractured tuff. Assessment of a given site's ability to show compliance with the Environmental Protection Agency's (EPA) containment requirements (40 CFR 191.13; EPA, 1985) and the NRC's ground-water travel time requirement (10 CFR 60.113; NRC, 1986) by application of this methodology will require the use of conceptual models, and the implementation of mathematical and numerical models to analyze ground-water flow and radionuclide transport. Therefore, SNL has developed a conceptualization of ground-water flow and radionuclide transport in the far-field (i.e., outside the disturbed zone) of a hypothetical HLW repository site located in unsaturated, fractured tuff formations to provide a foundation for the development of conceptual, mathematical and numerical models.

The results of this study have been termed a "conceptualization" rather than a "conceptual model" because a single conceptual model has not been defined. Given the existing information, it is recognized that multiple conceptual models are possible. As a result, this conceptualization provides a basis for the development of alternative conceptual models through a site description and a discussion of flow and transport processes. Nevertheless, the ideas expressed here are built upon some fundamental definitions of "conceptual model."

\subsection{Definition of Conceptual Model}

For a HLW repository, the NRC (1984) defines "conceptual model" as:

A pictorial and/or narrative description of a repository system or subsystem which represents all relevant components and structures contained within the system or subsystem, the interactions between the components and structures, and any internal or external processes which affect the overall performance of the subsystem.

Essentially, a conceptual model is the set of assumptions and simplifications used to understand and describe the system for the purpose intended. Specifically, as applied to this report, a conceptual model is a description of the processes controlling groundwater flow and radionuclide transport, the system geometry, the initial conditions for the system, and the boundary conditions for the system. A mathematical model, on the other hand, is a set of equations which quantitatively describe the conceptual model 
processes. A numerical model or code is simply the tool used to solve the mathematical model. Although not always recognized, a conceptual model must be assumed prior to performing any flow or transport analyses.

\subsection{Purpose}

The conceptualization described here should provide a foundation for the development of specific conceptual models, and the development and subsequent application of mathematical and numerical models used to predict ground-water flow and contaminant transport in both the unsaturated and saturated zones at a hypothetical HLW repository site located in unsaturated, fractured tuff. In doing so, this report reflects the current understanding of flow and transport in unsaturated and saturated, fractured rock.

In general, a conceptual model should (1) make and recognize simplifying assumptions about the physical and chemical structure of the system, (2) decide, or provide a basis for deciding, to what degree given flow and transport processes should be included for a given site, (3) implicitly provide direction as to which existing mathematical models are appropriate to describe these processes, and (4) indicate those areas where new mathematical models may need to be developed. The conceptual model itself does not include any mathematical models or data that will be used in the application of mathematical models.

\subsection{Background}

This report is based on relevant information available in the literature. The hypothetical HLW repository site is referred to as the "repository site" in subsequent text. Yucca Mountain, located on the Nevada Test Site (NTS) in Nevada, is the only tuff site that has been studied on a regional basis. The geometry, stratigraphy, structure, and regional ground-water flow system for the conceptual model are, therefore, based on information from Yucca Mountain. Conversely, the processes controlling ground-water flow and radionuclide transport in unsaturated and saturated, fractured tuff have been studied in the field and laboratory on tuffs from Yucca Mountain (Nevada) the Apache Leap Tuff Site (near Superior, Arizona), and the Bandelier Tuff (near Los Alamos, New Mexico). All of these studies are included in the conceptual model process description so that in terms of processes, the conceptual model is generic. 


\subsection{Scope}

A conceptualization of the ground-water flow and contaminant transport systems is described in terms of general properties, as well as specific flow and transport mechanisms that depend upon these properties. This report identifies and describes specific mechanisms, although these mechanisms are not quantified. Potential stratigraphic representations of the geohydrologic and transport systems are proposed based upon published data and information. Finally, a review and evaluation of previously developed conceptual models for flow and transport at a repository site located in unsaturated, fractured tuff, are discussed in this report. These previous conceptual models were chosen for review because their purpose was perceived to be that of assessing the performance of a HLW repository site. This common purpose was the basis for evaluating the conceptual model assumptions.

The review of previously developed conceptual models includes detailed discussion of each assumption that was implemented in the modeling study, since this is, by definition, a conceptual model. By including this section in the report, the authors wish to emphasize and illustrate that, regardless of the objective of a modeling study, whenever modeling is conducted, a conceptual model is assumed.

This report provides a qualitative description of a hypothetical repository site in fractured tuff; however, no definitive, single conceptual model has been chosen. Instead, a basis for the development of possible conceptual models is provided based on a description of properties and processes in general and at the site. Although a single hydrogeologic stratigraphy and a single geochemical-transport stratigraphy have been described, it is recognized that other alternatives are possible since there exist several possible methods and criteria for determining stratigraphy. Nevertheless, this study shows that although the hydrologic and transport stratigraphies are closely related, they can be quite different. 


\subsection{GENERAL DESCRIPTION}

This section describes the site geometry, physiographic setting, and climate. This portion of the conceptual model is based on data from Yucca Mountain and the Nevada Test Site.

\subsection{Geometry}

The proposed repository is located about $1200 \mathrm{~m}$ above sea level in a thick unsaturated zone composed of fractured tuff. The repository is located beneath a north-south trending mountain, approximately $300 \mathrm{~m}$ below the land surface and approximately 200 to $300 \mathrm{~m}$ above the water table.

In this report the repository site is described on three different scales: (1) a regional scale, (2) a local scale, and (3) and the scale of the repository controlled area as defined by 40 CFR Part 191 (EPA, 1985). Note that the accessible environment is defined to begin at the repository controlled area boundary. A regional system and local system are defined for the purpose of subsequent numerical modeling activities, while the repository controlled area is defined here solely for the purpose of describing site characterization results. In subsequent text, the repository controlled area is referred to as the "repository site." Data supporting designation of the regional and local systems is based on a compilation of hydrologic field work and ground-water flow numerical modeling studies performed mainly by the U.S. Geological Survey (USGS) and Pacific Northwest Laboratory (PNL), in addition to other researchers in the Yucca Mountain region.

The definition of the regional system is based the physical ground-water flow system characteristics primarily as interpreted by Waddell (1982). The regional system includes an area of approximately $6 \times 10^{4} \mathrm{~km}^{2}$ (see Figure 2.1) which contains several mountain ranges and basins. Lateral boundaries for the regional system were determined by the ground-water flow system. The boundary locations were designated by physical properties of the flow system such as ground-water divides (i.e., no flow) or constant inflow and outflow locations. Potentiometric contours were used to infer the general ground-water flow directions. Section 6.2 describes the regional ground-water flow system in detail.

The local system boundaries do not necessarily coincide with physical boundaries of the ground-water flow system. Instead, the local system is defined to provide reasonable boundaries for subsequent performance assessment computer modeling, because it is 

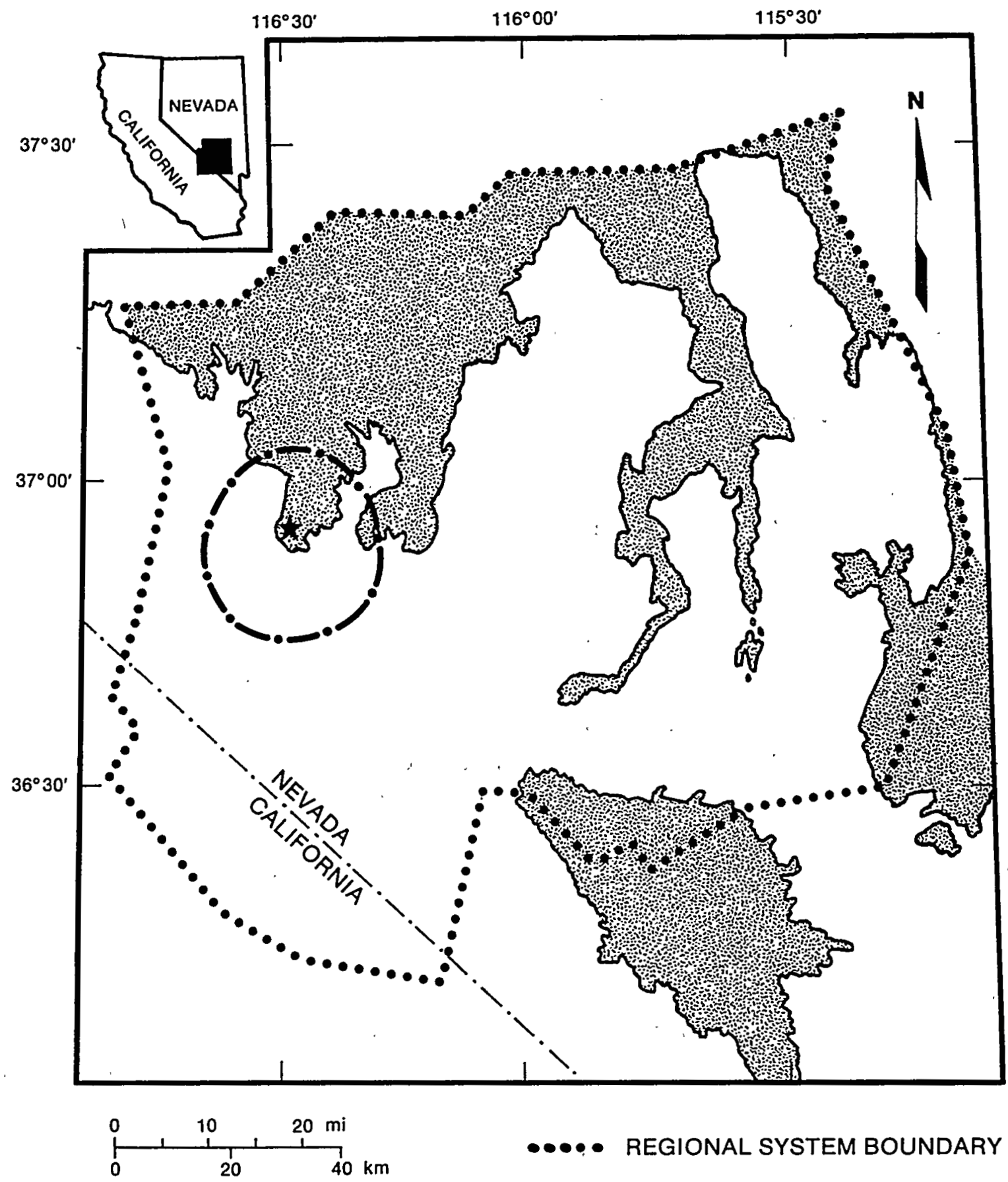

$\bullet \bullet \bullet \bullet$ REGIONAL SYSTEM BOUNDARY

- LOCAL SYSTEM BOUNDARY

$\star \quad$ REPOSITORY LOCATION

Figure 2.1. Regional System (modified from Waddell, 1982) 
computationally inefficient to model the regional system in detail. The local system, based on a conceptualization by Waddell and others (1984), includes Yucca Mountain and adjacent basins and highlands covering approximately $1600 \mathrm{~km}^{2}$ (see Figure 2.2). The lateral boundary conditions for the local system are defined by the regional groundwater flow system. Note that the repository controlled area of approximately $100 \mathrm{~km}^{2}$ is significantly smaller than the local system area. Using the definition of a local system that is significantly larger than the repository controlled area allows for the treatment of scenarios that may affect hydrologic conditions at the EPA accessible environment boundary, such as faulting in the repository area.

\subsection{Physiographic Setting}

The repository site is located in a region of rugged topography composed of north-south trending ranges and intermontane sedimentary basins with over $900 \mathrm{~m}$ of relief. The ranges can be up to $150 \mathrm{~km}$ long and $25 \mathrm{~km}$ wide. These are fault-bounded blocks created in an extensional environment. Often, the range is tilted with only one range flank bounded by a major high-angle fault (Stewart, 1985). Intermontane basins are deep, sediment-filled structural depressions between ranges. Many of the basins are closed, containing a nearly level or gently sloping basin floor surrounded by moderately sloping piedmont surfaces extending from the basin floor to the range front. The floors are typically covered with fine-grained playa, distal fan, and eolian deposits. Open basins are more deeply incised, locally exposing basin-fill deposits of late Tertiary and Quaternary periods (DOE, 1988). Piedmonts are composed of complex coalescing alluvial fans and pediments.

The local repository area includes six distinct physiographic subdivisions (see Figure 2.2). Yucca Mountain is an irregularly shaped highland 6 to $10 \mathrm{~km}$ wide and $40 \mathrm{~km}$ long. The crest altitude ranges from 1500 to $1930 \mathrm{~m}$, which is about $650 \mathrm{~m}$ above adjacent basins. West of Yucca Mountain, Crater Flat is a structural basin surrounded by highlands. Bear Mountain is an upthrown fault block that bounds the western edge of Crater Flat. East of Yucca Mountain, Fortymile Wash is a linear north-south trending trench that is 150 to $600 \mathrm{~m}$ wide, and up to $25 \mathrm{~m}$ deep (Swadley and others, 1984). Jackass Flats is an asymmetrical alluvial basin (Byers and Warren, 1983) located east of Fortymile Wash. Pinnacles Ridge is a triangularly shaped upland with similar structural and lithologic characteristics to Yucca Mountain (Carr, 1984). 

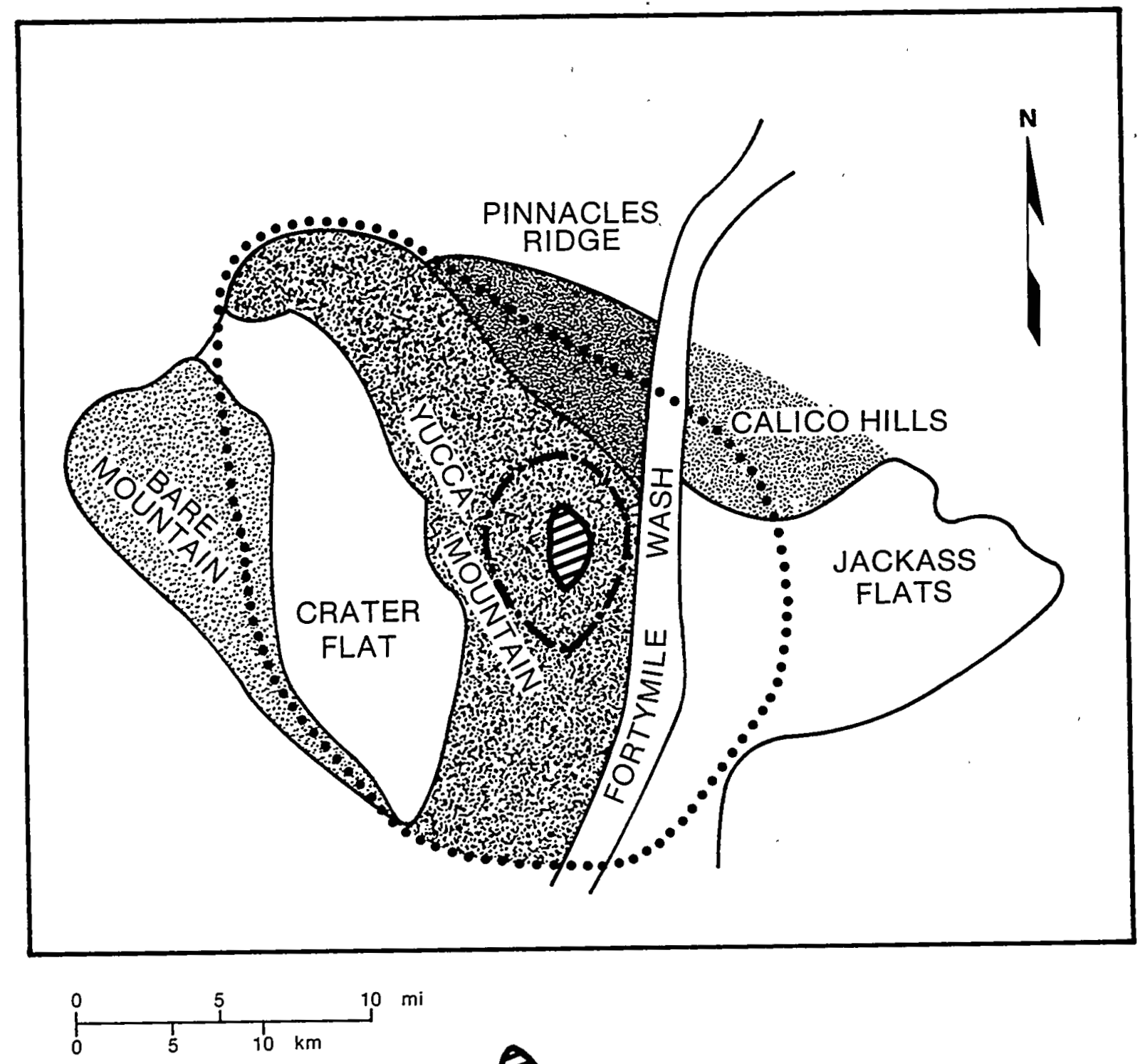

REPOSITORY LOCATION

APPROXIMATE ACCESSIBLE ENVIRONMENT BOUNDARY

•.. LOCAL SYSTEM BOUNDARY

— PHYSIOGRAPHIC SUBDIVISION BOUNDARY

Figure 2.2. Local System Boundary (from Waddell and others, 1984) 


\subsection{Climate}

The repository site is located in a semi-arid to arid environment with sparse vegetation, characterized by short mild winters and long, hot, dry summers. The area has very low annual precipitation, low humidity, high evaporation, and, during the spring high, wind velocities.

The precipitation distribution is highly variable over space and time. In general, the amount of precipitation is a related to the elevation (Quiring, 1983), ranging from an average of $40 \mathrm{~mm}$ annual rainfall in the lowest basins to $760 \mathrm{~mm}$ on the highest mountain peaks. Three-fourths of the precipitation occurs as thunderstorms during the cool season from about October through April. The storms may vary in local intensity and duration (Nichols, 1987). Light snow falls during the winter and generally melts or sublimates within a few days (Waddell and others, 1984). The seasonal pan evaporation exceeds the annual rainfall by 5 to 25 times (Rice, 1984). However, the pan evaporation rate may not be a reliable indicator for the actual evaporation in the extremely arid portions of the region.

The consequences of climatic variations must be addressed when evaluating scenarios at the repository site. For example, the repository performance may be impacted if a climatic change causes increased precipitation and decreased evaporation. Paleoenvironmental evidence (e.g., the vegetation record, lake level variations, pack rat middens, glacial cycles) indicates that significant climatic variations have occurred within the past 2 million years. These climatic variations of the past suggest that such variations will continue to occur in the future, and that a significant change could take place within the next $10^{4}$ years, the regulatory time period of interest. 


\subsection{GEOLOGY}

This section describes the stratigraphy of the region. The physical properties, petrology, and mineralogy of each geologic unit is described. A brief discussion of the structure of the local area is also given.

\subsection{Stratigraphy}

This section provides a general description of the geologic stratigraphy of the repository site. The stratigraphy is determined from field work performed in the Yucca Mountain region by the USGS and other investigators using data from borehole logs, well logs, and outcrops (Winograd and Thordarson, 1975). The stratigraphy of the repository site was divided according to the major rock types (see Figure 3.1). Table 3.1 contains a description of the lithology of each geologic formation according to work by Winograd and Thordarson (1975).

The general geologic surface exposures in the region are shown in Figure 3.2. The repository site is composed of a thick sequence of volcanic rocks overlying carbonate and clastic deposits. In this region, two structural blocks are underlain by thick sections of upper clastic sediments (see Figure 3.3). The upper volcanic rocks are described with the most detail, because they control the unsaturated flow paths from the repository to the water table. The lower carbonate and clastic rocks comprise the regional aquifer system, and less detail is necessary to describe the region. The general subsurface stratigraphic relationships of the geologic units is depicted in Figure 3.3.

\subsubsection{Alluvium}

The alluvium is comprised of Quaternary unconsolidated alluvial fan, fluvial, and fanglomerate deposits, primarily consisting of sand and gravel. Interbedded laucustrine and mudflow deposits are composed of much finer clay-sized material. Alluvial deposits are up to $610 \mathrm{~m}$ thick. The alluvial deposits are often found in the basins as the uppermost stratigraphic unit.

\subsubsection{Volcanic Tuff}

The volcanic rock sequence is comprised of a wide variety of rock types including densely welded devitrified and vitric ash-flow and ash-fall tuffs, nonwelded vitric ash-flow tuffs, vitric bedded tuffs, nonwelded zeolitized and argillized ash-flow tuffs, zeolitized and argillized bedded tuffs, as well as minor basalt and rhyolite flows (Scott and others, 


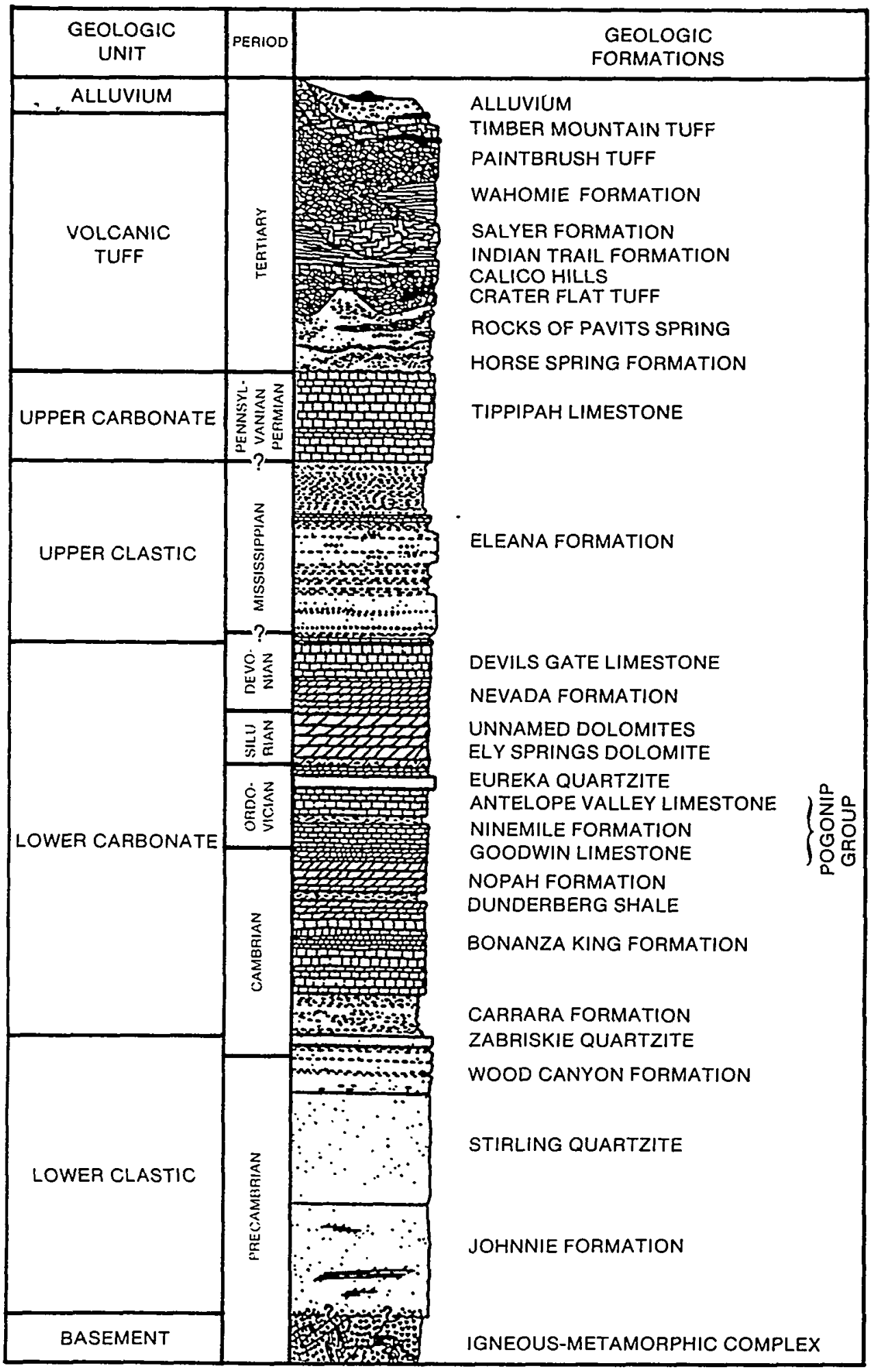

Figure 3.1. Stratigraphy of the Repository Site (modified from Sinnock, 1982) 
Table 3.1. Description of the Stratigraphy of the Hypothetical Repository Site (modified from Winograd and Thordarson, 1975).

$\begin{array}{llll}\text { Geologic } & \text { Geologic } & \text { Lithology } & \text { Maximum } \\ \text { Unit } & \text { Formation } & & \text { Thickness (m) }\end{array}$

Alluvium

Volcanic Tuff
Alluvium

Timber Mtn Tuff Paintbrush Tuff (Tiva Canyon and Topopah Spring Members)

Paintbrush Tuff (Bedded Tuff Member)

Wahomie Formation

Salyer Formation

Indian Trail Formation Grouse Canyon Member

Tub Spring Member

Informal units

Tuffaceous beds of Calico Hills

Tuff of Crater Flat
Alluvial fan, fluvial, fanglomerate, lakebed and mudflow deposits.

Interbedded nonwelded to densely welded ash-flow tuff, and thin ash-fall tuff deposits.

Ash-fall tuff and fluvial

305 reworked tuff.

Interbedded ash-fall tuff, tuffaceous sandstone, tuff breccia, matrix clayey and zeolitic.

Breccia flow, lithic breccia, interbedded with ash-fall tuff, sandstone, siltstone, claystone, matrix clayey or calcareous.

Ash-fall tuff, nonwelded to semi-welded ash-flow tuff, tuffaceous sandstone, siltstone, and claystone all massively altered to zeolite or clay minerals.

Nonwelded and welded ash-flow and ash-fall tuff, tuff breccia, tuffaceous sandstone, matrix of tuff and sandstone commonly clayey or zeolitic.

Ash-flow tuff, nonwelded and welded 
Table 3.1. (continued)

\begin{tabular}{llll}
$\begin{array}{l}\text { Geologic } \\
\text { Unit }\end{array}$ & $\begin{array}{l}\text { Geologic } \\
\text { Formation }\end{array}$ & Lithology & $\begin{array}{l}\text { Maximum } \\
\text { Thickness (m) }\end{array}$ \\
\hline
\end{tabular}

Rocks of Pavits

Spring

Volcanic Tuff

Upper Carbonate

Upper Clastic

Lower Carbonate

Basement

Lower Clastic

Zabriskie Quartzite

Tippipah

Limestone

Eleana

Formation

Devils Gate

Limestone

Nevada Formation

Unnamed Dolomites

Ely Springs Dolomite

Pogonip Group

Nopah Formation

Bonanza King Formation

Carrara Formation

Wood Canyon Formation

Stirling Quartzite

Johnnie Formation

Igneous-Metamorphic

Complex
Tuffaceous sandstone and siltstone,

425

claystone, fresh water limestone and conglomerate, minor gypsum, matrix clayey, zeolitic, or calcareous.

Fresh water limestone, conglomerate, and tuff.

300

Limestone

2000

Argillite, quartzite, conglomerate, and conglomeratic limestone.

Limestone, dolomite, and minor quartzite.

Dolomite

$>1000$

Interbedded limestone, dolomite, quartzite, and claystone.

$>840$

Dolomite, limestone, shale.

2000

Interbedded siltstone and

610 limestone.

Quartzite, siltstone, and minor

2800 limestone and dolomite.

? 


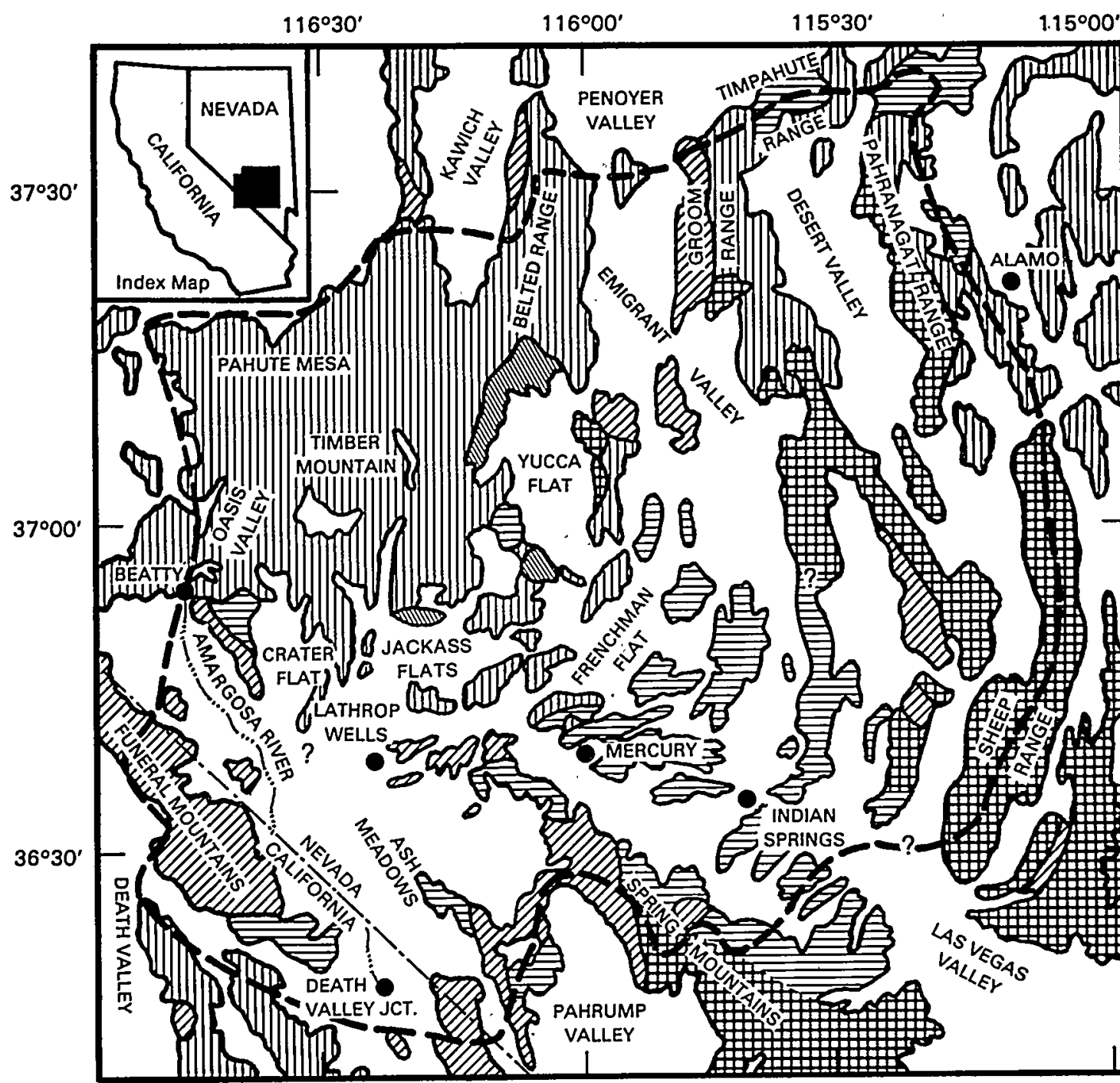

\section{N}
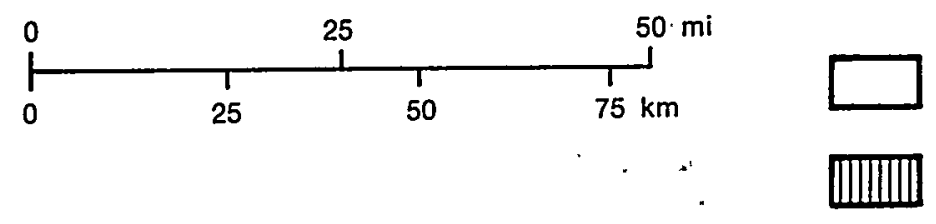

QUATERNARY

ALLUVIUM

TERTIARY

VOLCANIC ROCKS

MESOZOIC (Minor--not shown)

PALEOZOIC

SYMBOLS

UNDIFFERENTIATED UPPER CLASTIC

AND LOWER AND UPPER CARBONATES

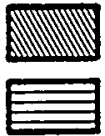

upper clastic

THRUSTFAULT

- APPROXIMATE BOUNDARY OF REgIONAL GROUNDWATER SYSTEM

Lower CARBonate

PALEOZOIC (CAMBRIAN)-PRECAMBRIAN LOWER CLASTIC

Figure 3.2. Generalized Geology of the Region (from Waddell, 1982) 


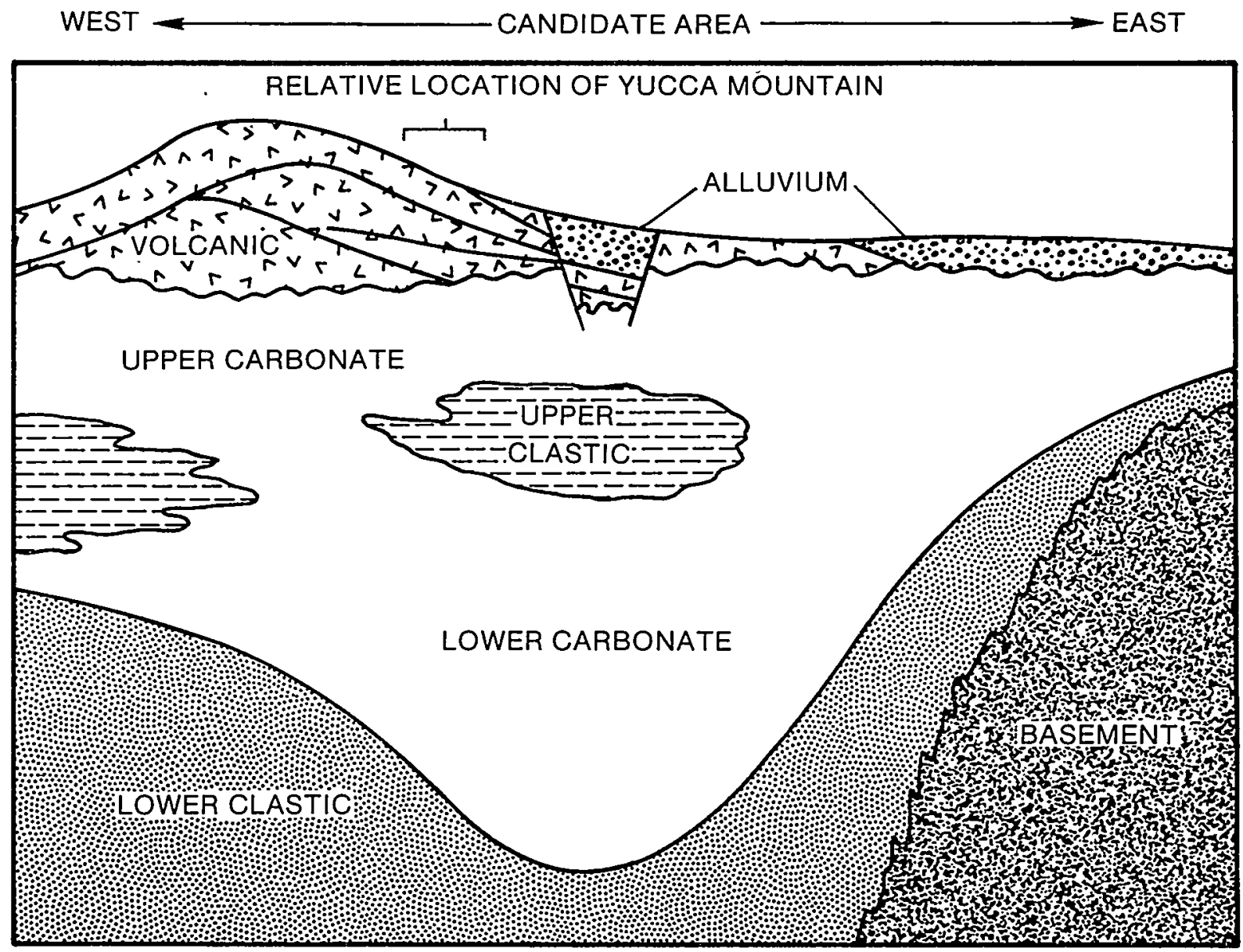

VERTICAL EXAGGERATION $\times 17$

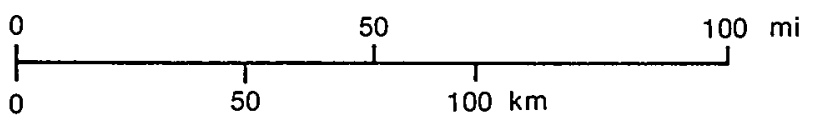

$\because \because \because \because 9$ ALLUVIUM

CARBONATE ROCKS

LOWER CLASTIC

E- UPPER CLASTIC

Ar. VOLCANIC ROCKS

BASEMENT

Figure 3.3. General Stratigraphic Relationships Among Geologic Units in the Repository Region (from Waddell and others, 1984) 
1983). These deposits are derived from volcanic activity that occurred west of the repository site during Tertiary time. The aggregate thickness of the volcanic rocks exceeds several thousand meters.

As previously stated, the majority of the volcanic rocks are a classic alternating welded and nonwelded ash-fall and ash-flow tuff sequence. Ash falls form a continuous deposit over extensive areas. The deposits exhibit a distinct horizontal and vertical size distribution that depends on fragment size and sorting. According to Smith (1960), ash flows result from a nuee ardente composed of a basal avalanche containing the bulk of erupted material and an overriding cloud of expanding gas and dust (Peterson, 1968). Most ash-flow tuffs are tongue-like sheets resulting from a series of magmatic pulses. If the fragments are extruded over a short period at high temperatures, the individual sheets effectively weld together into one sheet called a "simple cooling" unit (Scott and others, 1983). Each simple unit consists of basic zones that are based on degree of welding: an upper and lower chilled zone of no welding, upper and lower zones of partial welding, and an interior zone of dense welding (see Figure 3.4). Superimposed on all but the base of the sheet are effects of devitrification in the slowly cooled interior, and vapor-phase crystallization in the partially welded margins. Alternatively, if the cooling periods are of sufficient duration between individual magmatic pulses, decreases in the degree of welding within the interior of the cooling unit can occur, creating a "compound cooling" unit (Scott and others, 1983).

Heiken and Bevier (1979), Waters and Carroll (1981), Carroll and others (1981), Bish and others (1982), Scott and others (1983), Broxton and others (1986) describe the tuff petrology in detail.

Primary minerals in ash-flow tuffs are grouped into the groundmass phase, the phenocryst phase, and vapor phase. The groundmass consists of pyroclastic material less than $4 \mathrm{~mm}$ in diameter (Ehlers and Blatt, 1982) which often spontaneously devitrifies to cristobalite, feldspar, and tridymite (Abeele and others, 1981). Quartz, sanidine, plagioclase, and biotite are common phenocryst minerals. Vapor-phase minerals, resulting from the presence of gases concentrated in the upper part of the cooling unit, are zeolites, cristobalite, tridymite, and sanidine (Tien and others, 1985). The base of the cooling unit often contains lithic fragments from the country rock.

Secondary alteration of the tuff occurs by zeolitization, introduction or replacement by a zeolite mineral; or devitrification, the conversion of a glassy texture to a crystalline texture (Tien and others, 1985). The secondary alteration results in anhydrous minerals such as feldspar, calcite, and quartz, or hydrous phases such as smectites, zeolites, and 

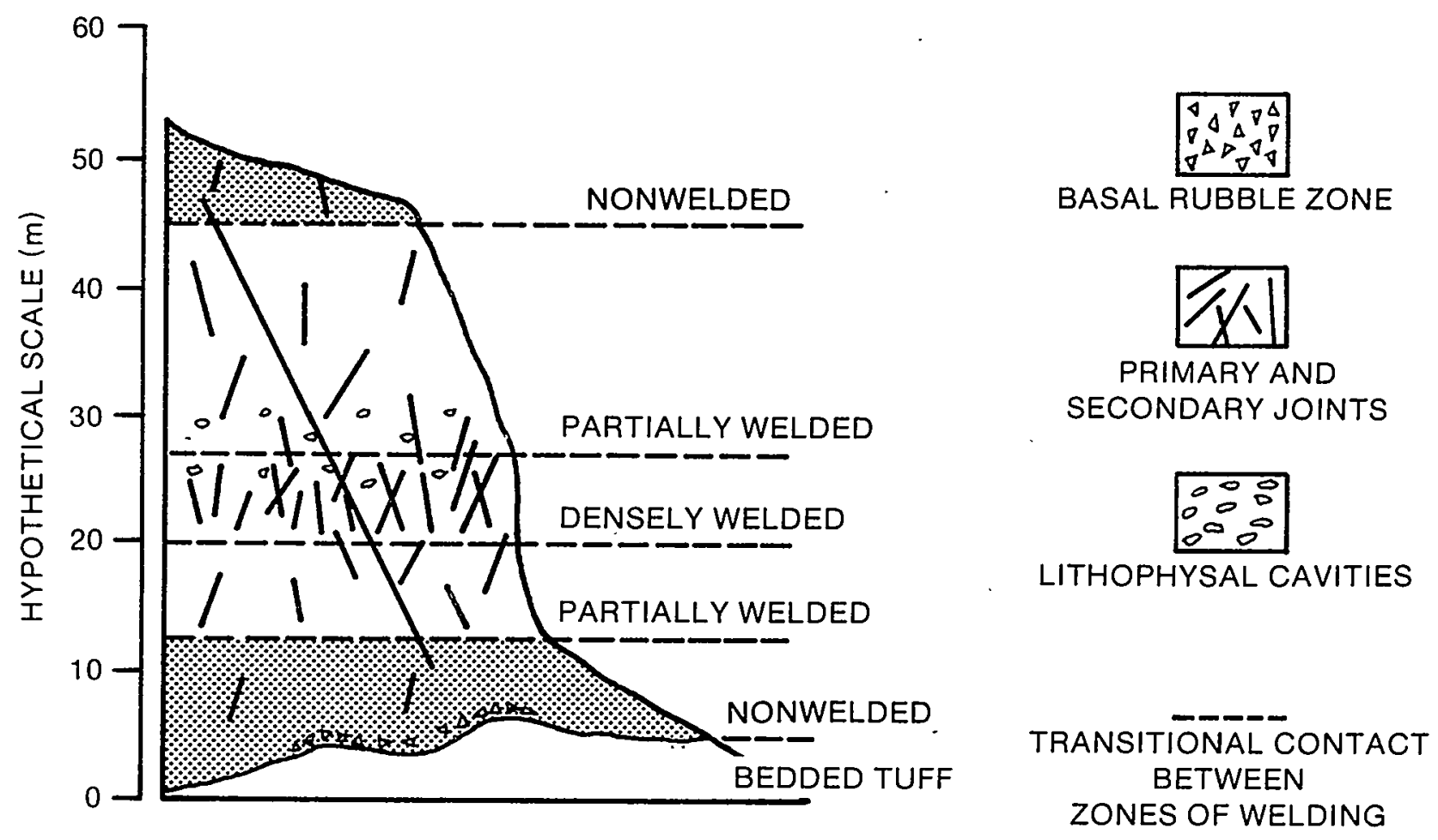

Figure 3.4. Generalized Cross-Section of a Typical Ash-Flow Tuff Sequence 
manganese minerals (Bish and others, 1983). Five zeolitic zones are found in the volcanic rock sequence (Table 3.1, Section 4.2).

The degree of welding directly affects the matrix porosity of tuff. Densely welded tuff has up to ten times lower porosity than nonwelded tuff. The reduction in porosity often results in prominent foliation in the rock. Gases within the densely and partially welded zones form cavities, or lithophysea; these are roughly circular and can measure up to a few centimeters in diameter. Lithophysea are usually unconnected or poorly connected (Winograd and Thordarson, 1975). Conversely, the bulk density is proportional to the degree of welding: densely welded tuff is about twice as dense as nonwelded tuff.

Fractures are present in all the volcanic rocks at the repository site. These fractures were produced by cooling, tectonism, and unloading due to removal of overburden (Barton, 1984). Based on core information, fractures occur more frequently in brittle, welded tuff than in nonwelded tuff. In moderately to densely welded tuff, fracture frequencies are about 10 times higher than in partially welded or nonwelded tuff (Scott and Castellanos, 1984). Subsequently, the vertical extent of fractures is often limited to individual stratigraphic units. Cooling fracture spacing ranges from centimeters to meters, where the highest frequency is found in densely welded tuffs (Winograd and Thordarson, 1975). The orientation of cooling fractures tends to be random. Conversely, the fractures formed by tectonic stresses are oriented in a dominant direction of strike (Scott and others, 1983). The dominant tectonic fracture strikes appear to be oriented parallel to the north-northwest-striking faults (Scott and others, 1983), indicating that these fractures may be due to large-scale regional extensional faulting. In general, fracture frequency tends to decrease with depth, independent of welding (Scott and Castellanos, 1984). Below several hundred meters in depth, the fracture frequency decreases abruptly by up to an order of magnitude (DOE, 1988).

The fracture faces are commonly covered with coatings or fillings. Spengler and others (1984) describe the fracture coatings and fillings observed from core collected from the northern portion of the repository site (USW G-4). The main types of fracture filling and coating, listed in order of abundance, are (1) manganese oxides (pyrolusite), manganates (cryptomelane and hollandite), iron oxides (hematite, maghemite) and iron hydroxides (goethite), (2) silica (quartz, cristobalite, opaline silica, and trydimite), (3) zeolites (mordenite and clinoptilolite), and (4) smectites (montmorillonite and illite), and (5) carbonates (calcite and siderite) (Spengler and others, 1984). In general, the percentage of fracture surfaces coated with secondary mineralization tends to decrease with depth. 


\subsubsection{Upper Carbonates}

The carbonate rocks are found in two major deposits with clastic strata differentiating the upper and lower units. The upper Pennsylvanian to Permian carbonate unit is a massive fractured limestone measuring more than $1000 \mathrm{~m}$ thick. Deformation of the carbonate rocks results in regions of high fracture density (Winograd and Thordarson, 1975). The upper carbonate rocks have been eroded away from most of the repository area.

\subsubsection{Upper Clastics}

There are two clastic deposits below the repository area. The upper clastic unit is an argillitic rock containing a large fraction of clay minerals, with minor quartzite and limestone beds that are approximately $2400 \mathrm{~m}$ thick. The upper clastic strata is a series of depositions occurring within an elongate trough as a result of a late Devonian to late Mississippian orogenic event. The deposit in the Syncline Ridge area is $99 \%$ argillite and contains minor quartzite beds. Lappin and others (1981) describe the argillite petrology and mineralogy in more detail.

The argillites have moderate matrix porosity (Winograd and Thordarson, 1975). Secondary porosity, such as solution cavities along fractures, is poorly developed due to the low solubility of shales. These rocks respond plastically to deformation by shearing and tight folding. In general, sections of high-quartz argillite have lower fracture frequencies than those that are mainly low-quartz argillite (Lappin and others, 1981).

\subsubsection{Lower Carbonates}

The lower carbonate strata are up to $4500 \mathrm{~m}$ thick, comprised of limestone and dolomite, commonly interbedded with siltstone, claystone, or quartzite. The lower carbonates exhibit highly variable physical properties. The matrix porosity of the lower carbonate rocks is very low. The rocks are fine grained to coarsely crystalline, and calcite or dolomite crystals are tightly intergrown. Vugs have been observed, but no interconnected vuggy porosity has been observed (Winograd and Thordarson, 1975).

The lower carbonate rocks are highly fractured and locally brecciated. Brecciation occurs along faults with only a few meters displacement. The strike and frequency of the fractures is significantly different from one area to another, particularly from fault block to fault block. Local fractures are confined to a particular bed or group of beds. The local fractures exhibit consistent trends over areas tens of meters in diameter. Most 
local fractures are perpendicular to bedding planes. Conversely, large-scale throughgoing fractures cut through many beds without changing direction or frequency. The through-going fractures are oriented parallel to associated fault sets and are located with trends, within areas up to hundreds of meters in diameter with uniform spacing (Winograd and Thordarson, 1975).

Fracture density is dependent on rock type. Fine-grained carbonate rocks have the highest fracture density, while coarse-grained carbonate rocks are the least fractured. Most fractures are filled with secondary calcite, calcareous clay, or calcareous clay with iron oxide (Winograd and Thordarson, 1975). Fractures in cores are filled with breccia or clayey gouge, slickensides, sealed with calcite, dolomite, or other minerals, or are partially filled with calcite or dolomite.

Secondary bedding-plane openings, due to sub-aerial mechanical weathering or solution of the rock in the saturated or unsaturated zone, are not common. Drilling records do not indicate the presence of major solution caves in the lower carbonates, but a few major solution features, on the order of tens of meters in dimension, are present at the land surface (Winograd and Thordarson, 1975). Examples of large scale solution features include Devils Hole located along a major fault zone, Gypsum Cave, and several large caves in the Spring Mountains.

Small isolated spherical to rectangular caves of a few meters dimension are found in all the lower carbonate rock formations. Locally, they tend to develop along major fault zones. The disconnected nature of the caves suggests that they originated as weatheredout joints or fault blocks (Winograd and Thordarson, 1975).

\subsubsection{Lower Clastics}

The lower clastic deposits are composed of all siltstone, quartzite, shale, and sandstone of Precambrian through Early Cambrian age, forming an aggregate thickness of about $3000 \mathrm{~m}$ in some areas.

In outcrop, the lower clastic strata have small matrix porosity. They are highly fractured and locally brecciated similar to the lower carbonates. Quartzite units are more fractured than the more porous siltstone, shale, and sandstone (Winograd and Thordarson, 1975). 
Clastic rocks are less soluble than carbonates. Secondary solution induced porosity rarely develops along bedding planes of these rocks composed of quartz, mica, and clay minerals.

Due to differences in rock strength, the mode of deformation differs significantly according to rock type. In outcrop, siltstone, shale, and sandstone exhibit tight folding, slaty cleavage, and shearing while carbonate rocks and quartzite are highly fractured and tend to form relatively broad folds. When quartzites are interbedded with argillaceous strata, open fractures in the quartzite tend to be isolated or sealed by the plastic deformation of the weaker argillite (Winograd and Thordarson, 1975).

At depth, the lower clastic rocks are highly fractured. Fractures are commonly lined with micaceous and chloritic selvage or marked by slickensides. Most fractures are tightly sealed by selvage minerals or quartz or calcite veinlets.

\subsection{Structure}

The Precambrian crystalline basement rocks of the region result from tectonic, metamorphic, and intrusive activity that occurred during the Proterozoic period. The Paleozoic was a time of slow subsidence and deposition. Mesozoic tectonic activity resulted in low angle thrust or detachment faulting. Mesozoic deformation appears to have been gentle; creating ductile folds of large amplitude beneath the thrusts. Early Tertiary activity included normal block faulting (Reynolds, 1969) contemporaneous with volcanic activity. For the last 15 million years, extensional forces have been present in the repository area. Late Tertiary structural history was dominated by normal and major strike-slip faulting.

The repository site is located in a northwest-trending belt of right-lateral faults that is juxtaposed against the overall structural trends (Figure 3.5). Many north-trending structures and ranges bend markedly near this belt. Faulting in this belt may have occurred as early as Jurassic time, with evidence of activity through Quaternary time (Albers, 1967).

Localized areas in the region contain heterogeneous and complex structures. Comparatively, the local conceptual model study area appears relatively simple. Yucca Mountain is bound on the east and west by major range front normal faults (see Figure 3.6). However, the mountain block is not solely uplifted along the range front faults, but broken by several north-northeast-striking and westward-dipping normal faults with tens to hundreds of meters of displacement, forming blocks that tilt 5 to 10 degrees eastward 


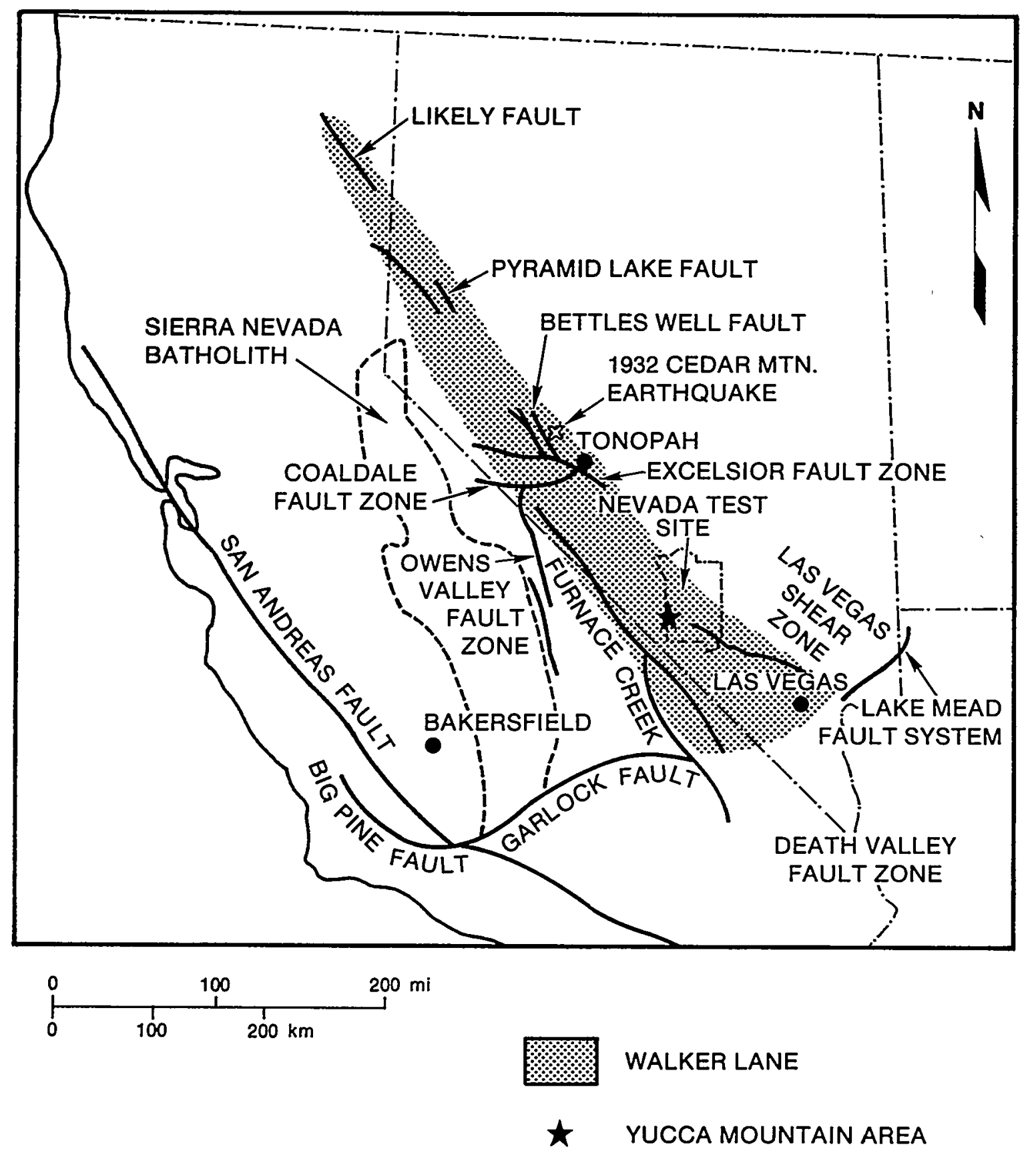

Figure 3.5. Walker Lane and Major Associated Faults (modified from Stewart, 1985) 

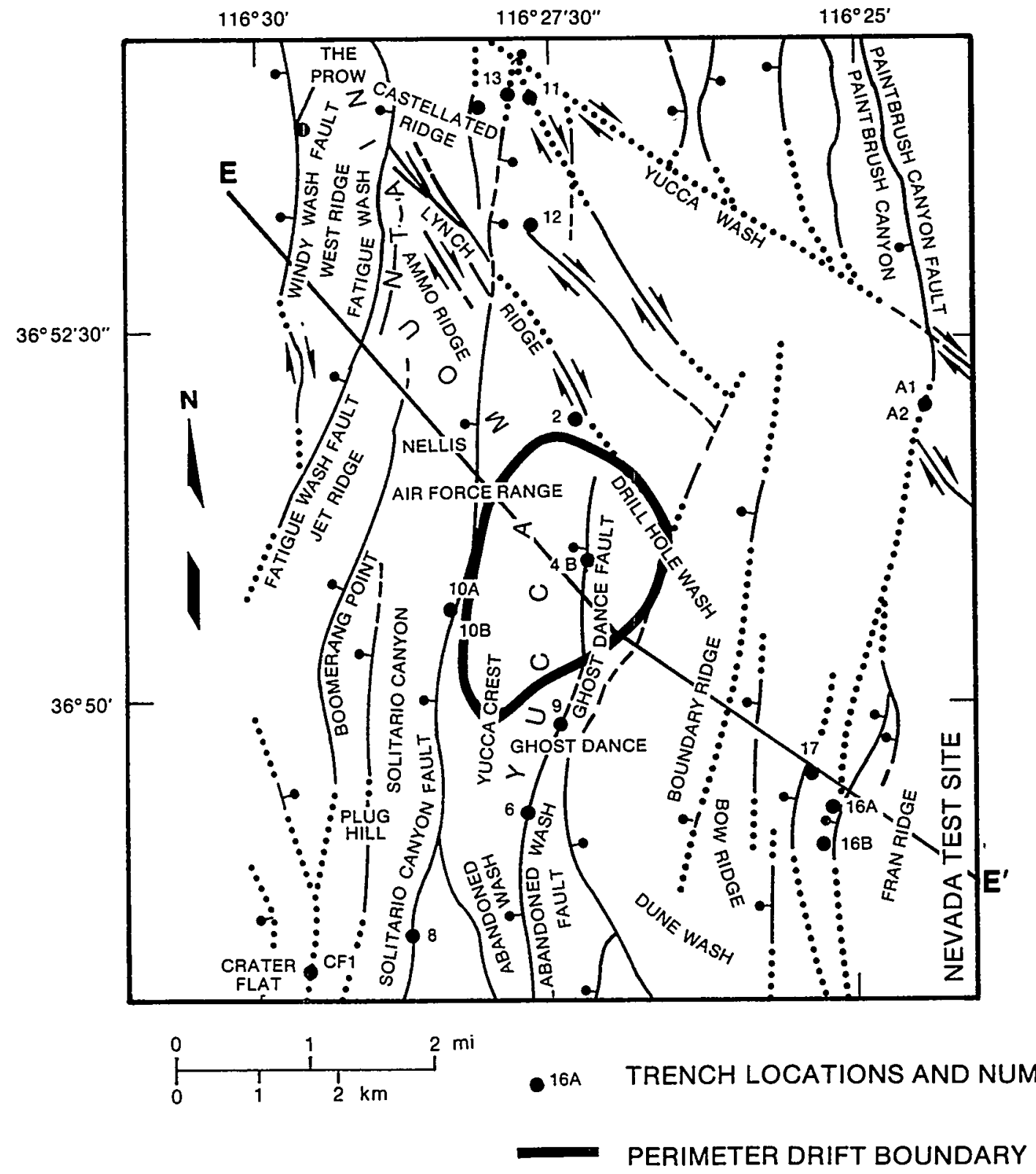

FAULT SYMBOLS

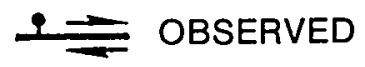

- - INFERRED IN BEDROCK

INFERRED COVER OF SURFICIAL DEPOSITS

Figure 3.6. Faults at Yucca Mountain Interpreted from Geologic Mapping (modified from USGS, 1984) 
(Scott and Bonk, 1984; Scott and others, 1983; Stewart, 1978). Approximately $2 \mathrm{~km}$ east and west of Yucca Mountain are zones of imbricate normal faults that dip west with vertical offsets of 2 to $5 \mathrm{~m}$ (see Figure 3.7). Brecciated zones that are hundreds of meters wide represent drag zones next to the major normal faults. The imbricate normal faults decrease in displacement and density to the north. A northwest strike slip fault, with less than $200 \mathrm{~m}$ of horizontal offset, is present to the north of the repository site.

The three major local fault zones transect the full thickness of the unsaturated zone (Montazer and Wilson, 1984). In fracture zones, the ductile nonwelded tuff units produce a sealing gouge material, as opposed to the welded, brittle units, which fracture more readily. On a regional scale, the lower carbonate units are compartmentalized by major structural features.

Gibbons and Guzowski (1989) discuss the structural framework of the Yucca Mountain region in the context of scenario probability. In addition, their report describes the tectonics of this area in greater detail.

"Gibbons, J.F., and Guzowski, R.V., 1989. Representative Disruptive Scenarios for Use in the Development and Demonstration of a Performance Assessment Methodology for Unsaturated Tuff: U.S Nuclear Regulatory Commission, NUREG/CR-4770, Washington DC, and Sandia National Laboratories, SAND86-7170, Albuquerque, NM, Draft submitted to the U.S. Nuclear Regulatory Commission. 


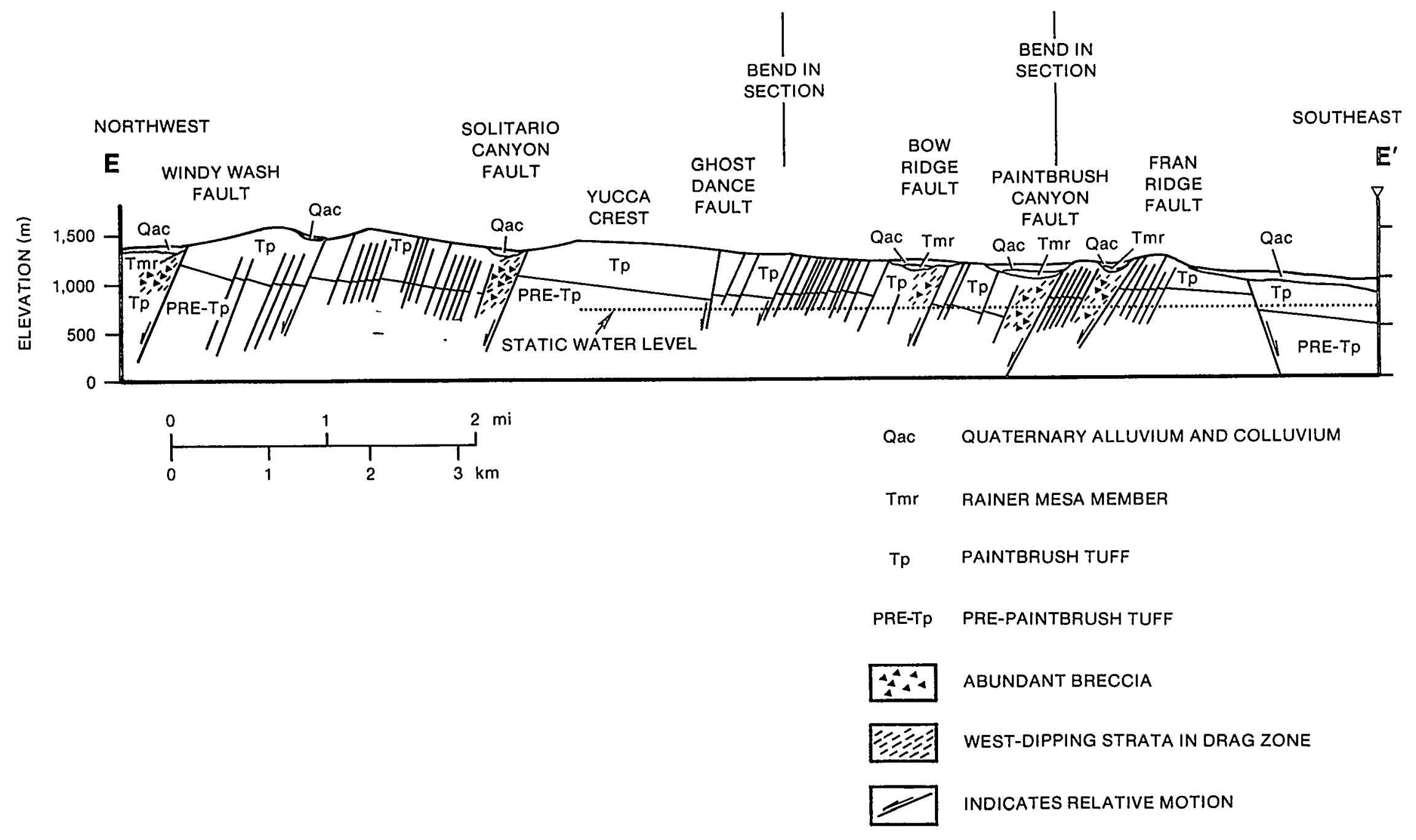

Figure 3.7. Schematic Geologic Cross-Section E-E at Yucca Mountain (modified from Scott and Bonk, 1984) 


\subsection{GROUND-WATER FLOW SYSTEM PROCESSES}

The following sections describe the processes controlling ground-water flow through the unsaturated and saturated zones.

\subsection{Infiltration}

Infiltration is the process of water entry through the land surface/atmosphere interface. The rate of infiltration varies with time and space, and depends on the initial moisture and pressure conditions as well as the texture, structure, and uniformity of the geologic profile (Hillel, 1980a). The frequency, rate, and duration of precipitation events are factors in determining how much infiltration occurs. High-intensity thunderstorms most likely exceed the soil/rock's ability to imbibe water, resulting in surface runoff to ephemeral stream channels where infiltration may occur. Degree of vegetation, slope, and surface soil/rock type are controlling factors in surface runoff rates. Conversely, if the rainfall rate is smaller than the soil/rock infiltrability, the infiltration process is supply-controlled, and water infiltrates as fast as it reaches the surface (Hillel, 1980a). Once water has penetrated the land surface/atmosphere interface, it may be stored in surface soil or rock deposits, become interflow, or undergo evapotranspiration. The water that is not lost to these processes is considered net infiltration. Information on rainfall, runoff, and evaporation for the area, however, are not available to determine the rainfall runoff infiltration relationships in the region (DOE, 1988).

The most probable areas for infiltration to occur are at high elevations that receive the highest annual precipitation. If bare tuff rock is exposed, pulses of water can enter the rock fractures. Fractures are most abundant near the land surface, and may be filled with weathered material of higher infiltrability than the rock matrix. If soil is covering the rocks, the soil properties and thickness dictate the infiltration rate. A significant soil cover on the mountain would dampen rapid pulses of water entering the fracture system. In this case, more water can infiltrate the soil than it can the tuff. However, evaporation or storage in the soil layer may reduce the amount of infiltration to the fractured tuff unit.

The potential for infiltration is high in areas of low elevation that consist of alluvial valley fill. However, the precipitation is less and the evaporation rate is higher in these regions. It is likely that only a small amount of water actually enters the flow system through the thick valley fill deposits. Norris and others (1985) inferred that no infiltration occurred below a depth of about $2 \mathrm{~m}$ in valley fill alluvial deposits northeast of the repository site (Yucca Flat), according to ${ }^{36} \mathrm{Cl}$ infiltration studies. 
Flowing ephemeral stream channels are also areas where infiltration may be likely to occur. The stream provides a hydraulic head that is the driving force for infiltration. A saturated or partially saturated profile beneath the channel also facilitates the infiltration process. In arid and semiarid environments, ground-water mounds have been observed beneath ephemeral stream channels, even when the ground water elevation is disconnected from the channel by tens of meters of unsaturated zone (Cox, 1988). The observed mounding was attributed to infiltration through the ephemeral stream channel. In addition, at the repository site, there is a possibility that the channels may be aligned with underlying faulted or fractured zones that provide a highly permeable zone where infiltration could occur.

Overall, the amount of water that infiltrates the soil/rock profile in the region is highly variable. Localized storms, variations in annual precipitation by location, and localized soil of varying thickness covering the rock surface control where rapid pulses of water are allowed to enter the profile. Net infiltration (water that does not remain in shallow storage, evapotranspire, or interflow in the washes) is considered to be very small. The rugged topography, bedrock exposed at the surface, and sparse vegetation cover enhance surface runoff at the repository site after intense storms. Subsequent flow in ephemeral stream channels may allow infiltration to occur.

\subsection{Percolation}

Percolation is the flow of net infiltration through the unsaturated zone. The percolation rate varies according to heterogeneities in the system and within each hydrogeologic unit, and due to movement from one hydrogeologic unit to another. In a system of unsaturated, fractured rocks, fracture flow, matrix flow, and the interactions between the fractures and matrix must be considered.

The unsaturated zone consists of three phases: liquid, air, and solid. The liquid phase is subjected to capillary and adsorptive forces. The water potential in the unsaturated zone is less than atmospheric. Under static conditions, the pressure head at points above the water table is equal to the elevation above the water table, independent of the porous medium:

$$
Z=\psi / \rho g
$$

where $\mathrm{Z}$ is the elevation or vertical coordinate measured positive downward from the water table, $\psi$ the pressure, $\rho$ the density of water, and $g$ the gravitational constant (see Figure 4.1). 


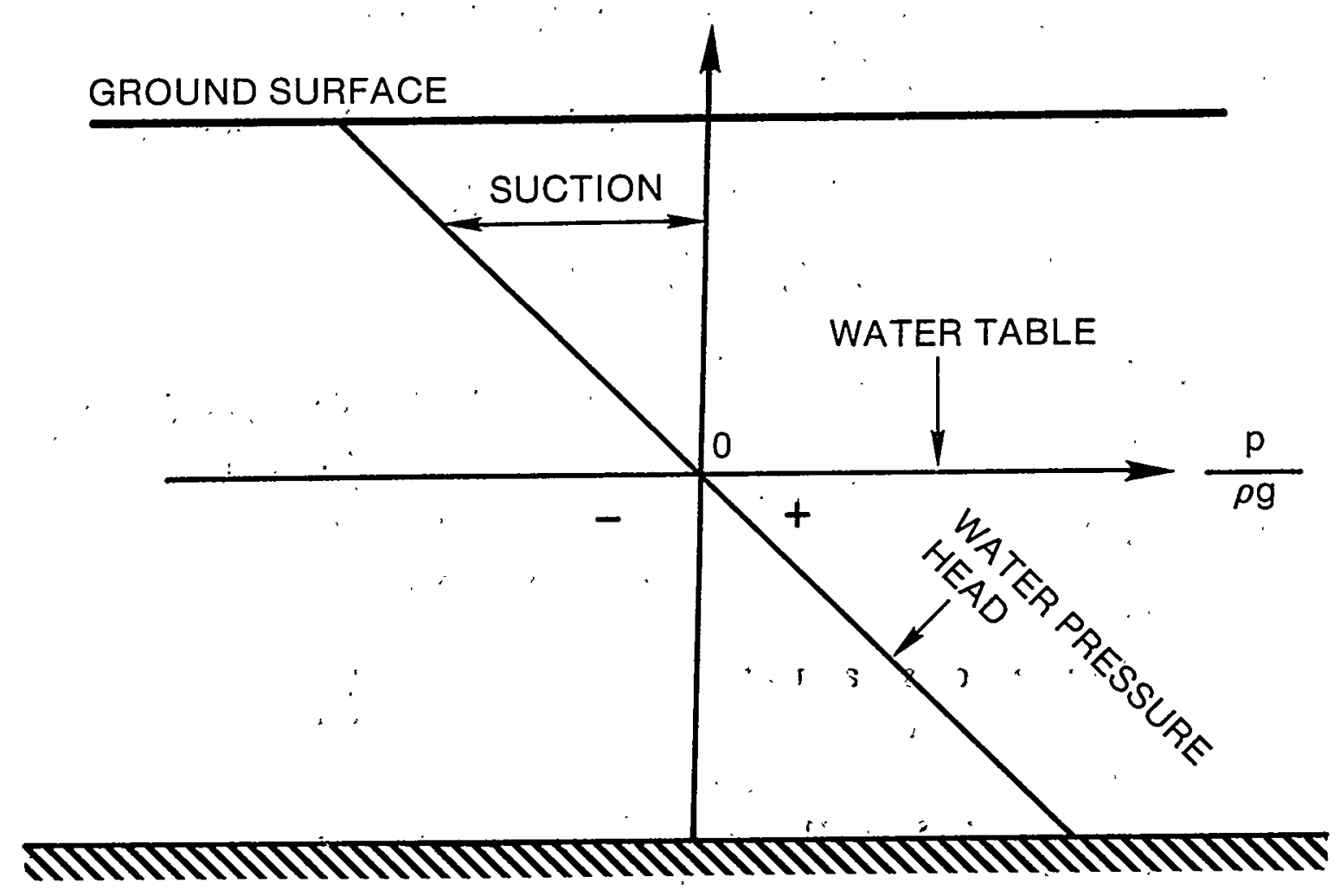

Figure 4.1. Distribution of Pressure Head in Static Subsurface Water (from McWhorter and Sunada, 1977). Permission to use this copyrighted material was granted by Water Resources Publications. 
Capillary forces determine the negative pressure head at which a given pore or fracture will drain. As the water content decreases, the pressure head becomes smaller (i.e., becomes more negative). The relationship between the pressure head and the moisture content, or the moisture retention curve, is dependent on rock type (see Figure 4.2).

Fracture flow may occur in the unsaturated zone as saturated fracture flow, film flow, or slug flow. The mode of fracture flow is an important factor in determining flux through the unsaturated zone. Saturated fracture flow is the fastest route for moisture to move through the unsaturated zone. When a saturated fracture drains, a thin film of water may be left along the walls of the fracture. Flow could continue through the film, but the flux rate of the fracture flow would be reduced by orders of magnitude. Fracture slug flow may occur from pulse infiltration into fractures at the land surface. If the fracture flow moves as a slug, the flux rate would be faster than for film flow and slower than for saturated flow.

The contrast between the fracture hydraulic conductivity and the matrix hydraulic conductivity is an important factor in understanding the interactions between fracture and matrix flow. The conductivity relationships are controlled by the amount of moisture in the fracture and matrix networks. For water to enter a fracture from the porous rock, the pressure in the matrix must be greater than the pressure in the fracture. Conversely, for water to flow from the fracture into the matrix, the pressure in the matrix must be less than the pressure in the fracture. Upon drainage of a saturated fracture and matrix system, the fractures will drain first because they have a larger aperture than the matrix pores. Due to variations in fracture aperture, it is possible for "islands" of moisture to be trapped within the narrow portions of a fracture. In this case, flow could occur across the fracture from one matrix block to another instead of along the fracture (Wang and Narasimhan, 1985).

Fracture coatings may have a significant effect on flow interactions between the fracture and matrix. Preliminary results from water uptake experiments performed in the laboratory indicate that the degree to which the fracture coatings affect imbibition may vary by several orders of magnitude (Thoma and others, 1990). Thoma and others found that the effective permeability of the composite medium (fracture coating plus matrix) was less than the matrix permeability from a factor of three to up to seven orders of magnitude.

Velocity effects are another concern pertaining to fracture flow. Commonly, the momentum term is not accounted for. Depending on the size of the fracture apertures, 


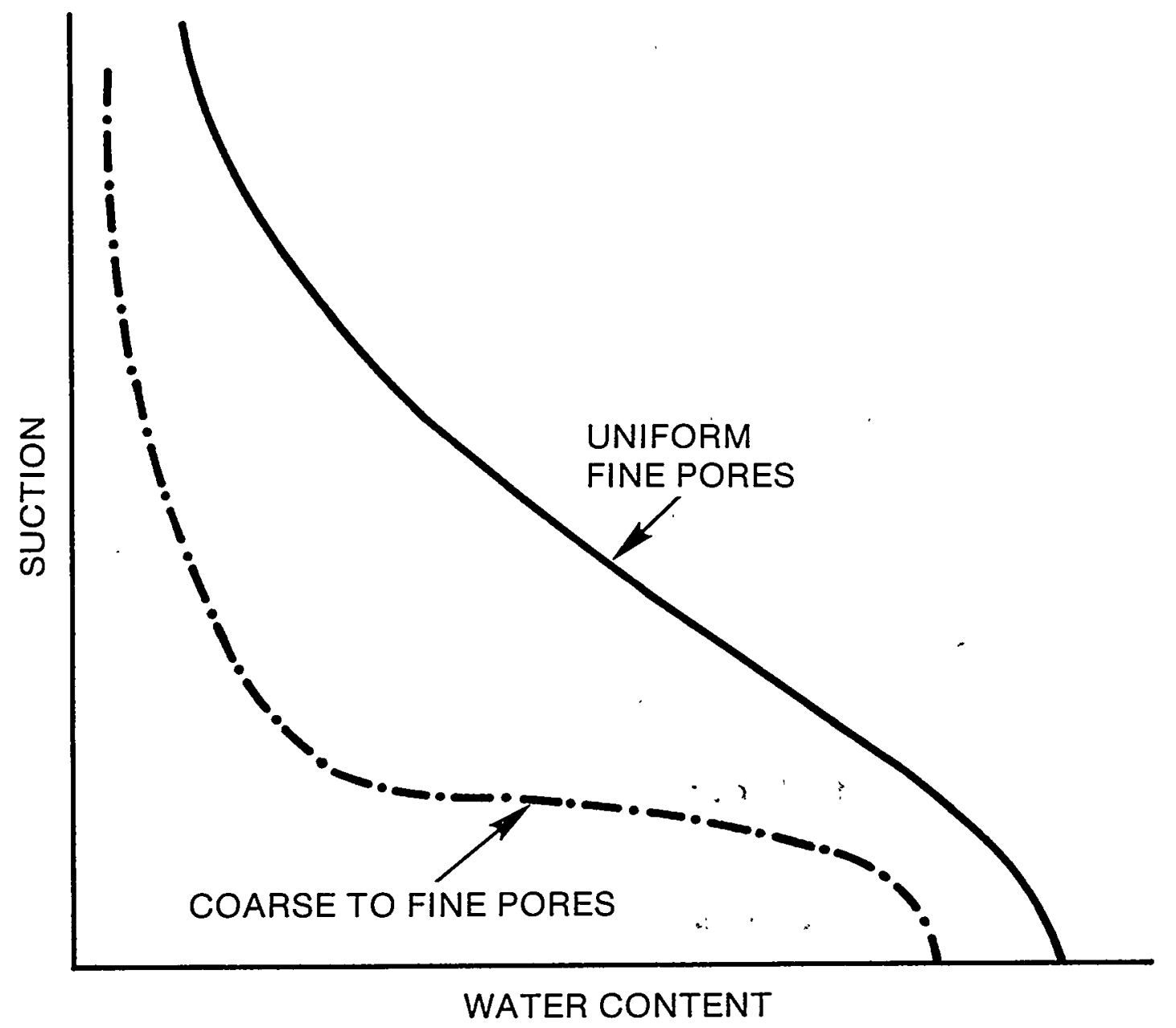

Figure 4.2. Effect of Texture on the Moisture Retention Relationship (from Hillel, $1980 \mathrm{~b}$ ). Permission to use this copyrighted material was granted by Academic Press. 
however, it may be possible for high fracture flow velocities to occur under saturated flow conditions.

Under unsaturated flow conditions, stratification of different rock types can have a strong effect on the downward movement of water. In a layered profile, the pressure head is continuous across textural boundaries, thereby forcing a discontinuity in moisture content (see Figure 4.3) (Bear, 1972). When a coarse layer overlies a finely textured layer, moisture movement is controlled by the upper layer until it reaches the textural boundary. Moisture will enter the lower layer, and, over a long time period, the layer of least conductivity will control the process. For the opposite case of a fine layer over a coarse layer, the moisture movement is controlled by the upper fine layer. However, as the water reaches the interface above the coarse layer, the advance of the wetting front may be impeded as observed in laboratory experiments by Miller and Gardner (1962). The pressure head at the wetting front àbove the interface is too small to permit entry into the larger pores of the underlying coarse layer. The vertical advance of the moisture is impeded until the pressure head at the interface increases to the water-entry pressure head of the coarse material. The increased pressure head at the interface can lead to an increase in moisture content over time. The moisture may also move laterally above the coarse layer at this time; this was observed by Palmquist and Johnson (1962).

Alternating layers of welded and non-welded tuff in the unsaturated zone at the repository site may enhance the inhibition of vertical moisture movement in the manner previously described. The extent of the capillary barrier effect depends on the contrast in pore sizes of both the fractures and matrix, state of flux, and moisture content distribution between units. The dipping beds may further enhance a horizontal component of the gravitational gradient along the contacts between layers, if nearly saturated conditions occur. Due to the moisture movement impedance and lateral flow, the existence of perched water is possible in the stratified profile beneath the repository site.

Inhibition of vertical moisture movement, lateral spreading, or perched water may also be caused by a vertical fracture intersecting a horizontal fracture. Faults intersecting the unsaturated zone similarly may impede moisture movement. However, it is not known whether the faults behave as a conduit for flow or a barrier to flow in the unsaturated zone at the repository site.

The percolation rate is very difficult to measure directly in deep unsaturated zones that are hundreds of meters thick. The deep percolation rate can be estimated indirectly using geothermal flux information. However, this is complicated by movement in both 


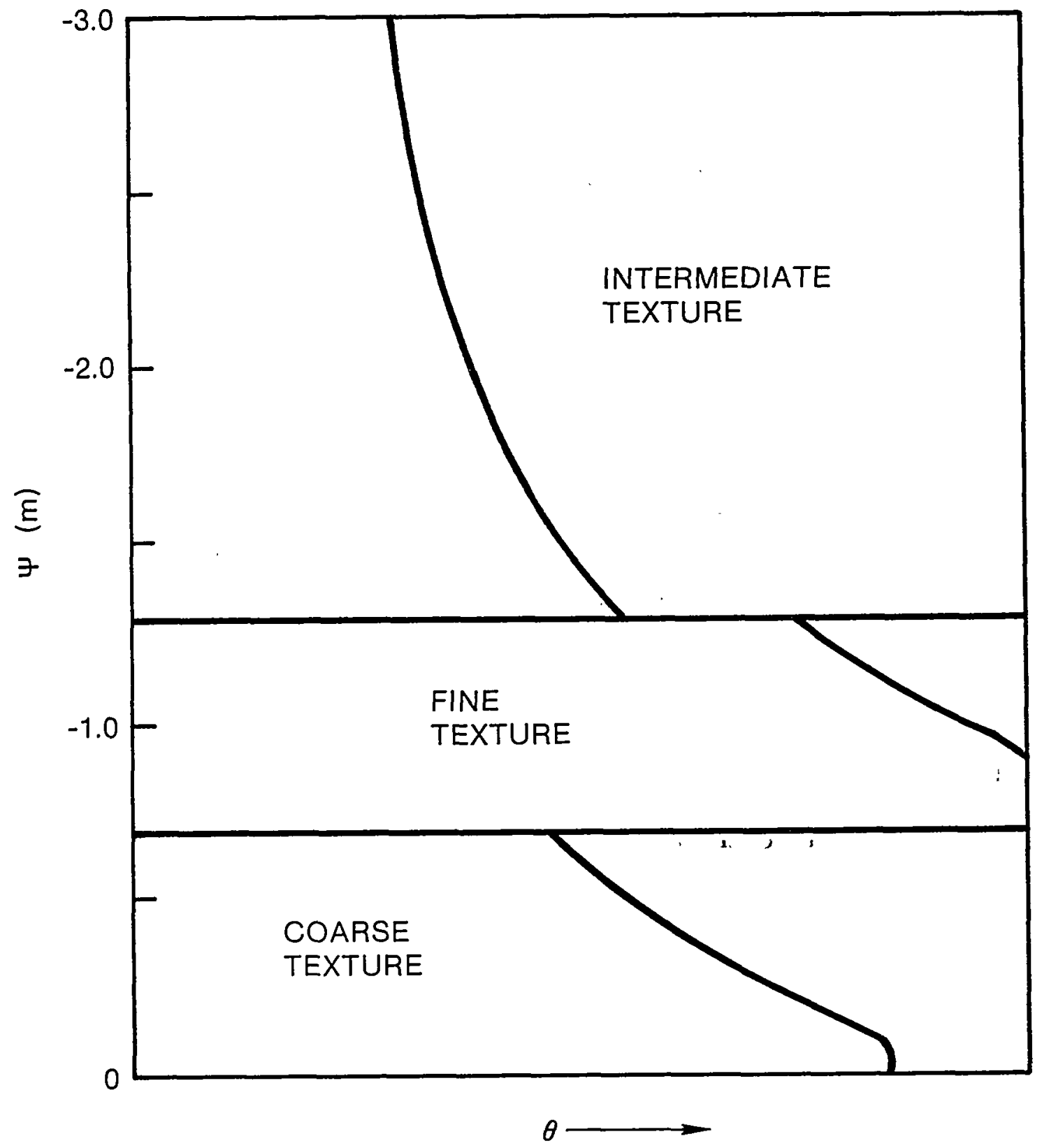

Figure 4.3. Moisture Content Distribution in a Stratified Soil (modified from McWhorter and Sunada, 1977). Permission to use this copyrighted material was granted by Water Resources Publications. 
liquid and vapor phases (Montazer and Wilson, 1984). Alternatively, the flux has been estimated by applying Darcy's law, assuming that an effective unsaturated permeability term can be applied, and that a unit gradient is present (Weeks and Wilson, 1984). The applicability of the unit gradient assumption will be discussed in detail in Section 8.1.

In general, the flux and distribution of percolation through the unsaturated zone in the region are not well understood. Due to the heterogeneities of the stratified tuff sequence, it is highly likely that the flow patterns are not simple.

\subsection{Recharge}

Recharge is the process of water entering the saturated zone from the unsaturated zone. The amount of recharge that occurs over space and time cannot be measured directly. Several different methods have been used to estimate the recharge that occurs beneath the repository site.

Eakin and others (1951) and Malmberg and Eakin (1962) developed a method to estimate recharge for ground-water basins based on regional relationships established between recharge, altitude, and precipitation. The geothermal flux method has been used to estimate the recharge rate by assuming that the percolation rate equals the recharge rate (Montazer and Wilson, 1984; Sass and Lachenbruch, 1982). That is, the vertical water flux, as determined from geothermal data, was estimated by separating the conductive and convective components of the heat flux (Sass and others, 1980) and assuming that this flux is equal to the recharge rate. Difficulties with this method arise because the geothermal flux in the saturated zone is complicated by the horizontal ground-water flow component, which varies under varying hydrogeologic conditions (Montazer and Wilson, 1984). Lastly, a basic water balance method can be used to estimate the amount of recharge that occurs in a ground-water flow system (Freeze and Cherry, 1979). Inaccuracies and uncertainties in measuring the water balance components, particularly the evapotranspiration term, are major drawbacks of the first and third methods.

It is not surprising that the recharge rates estimated by the geothermal heat-flux method and the water balance method are not similar. For a thick, unsaturated zone with long travel times, a relatively large geologic time span is involved. The water balance method measures present-day precipitation, while the actual water recharging the system may be thousands of years old. Conversely, the geothermal heat-flux method provides recharge estimates that may be the result of paleoclimatic conditions (Montazer and Wilson, 1984). 
Recharge to the saturated zone in the present day arid environment is not known. However, based on low annual precipitation and high evaporation rates, the overall average recharge appears to be small, and it seems that this condition will continue until the next major climatic change.

\subsection{Vapor and Air Movement.}

Vapor movement is a factor for consideration in thick, unsaturated zones where a thermal gradient is likely to exist at depth. Convective transport of vapor is likely to occur at shallow depths as dense vapor saturated air moves downward through the fractures. At depth, as the vapor is subjected to higher temperatures, it would become less dense and move upward until it cools. It then becomes dense and moves downward again. An equilibrium is assumed to occur between the vapor phase and liquid phase adsorbed between the vapor phase and liquid adsorbed in the matrix. Due to convective flow, this equilibrium may not exist and vapor flow could occur between the fractures and the matrix (Montazer and Wilson, 1984).

Air flow at shallow depths may occur due to orogenic and topographic effects. Some investigators have observed air to flow out of wells in unsaturated, fractured rock during cold winter months (Weeks, 1987). It is hypothesized that a column of cold dry air extending from the valley floor to the hill crest (where the top of the borehole is located) outweighs the warm, moist air that extends through the fractured rock into the entire borehole. The potential pressure difference between the atmosphere and the borehole causes air to flow from the open borehole (see Figure 4.4). Significant topographically induced air flow will only occur from wells that tap highly permeable fractured rock (Weeks, 1987).

The effect of diurnal barometric pressure changes may be superimposed over topographic effects. The transmission of an atmospheric pressure change at the land surface through the unsaturated zone to a point at depth is delayed by resistance to flow through the medium. However, the pressure change is instantaneously imposed at the same depth in the borehole, imposing a temporary pressure difference across the borehole face (Weeks, 1987). Thus, the borehole intakes air during periods of rising barometric pressure and exhales air during periods of falling barometric pressure (see Figure 4.5) (Ferris and others, 1962). Although the air flows through boreholes that tap highly fractured units, it is not understood to what degree the topographically and barometrically induced air flow actually occurs in fractures. 


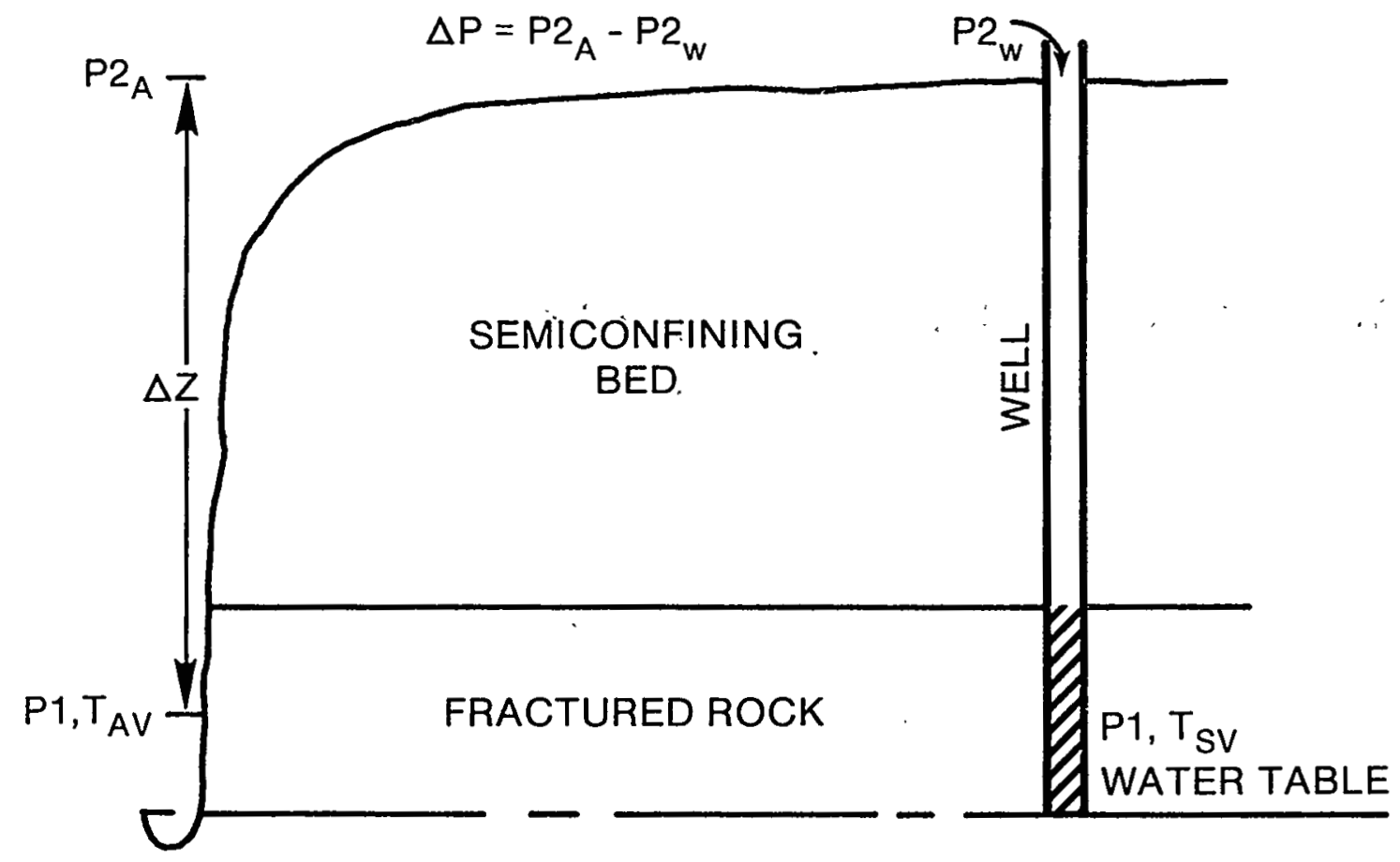

$\triangle P$ - PRESSURE DIFFERENCE, Pa;

$P_{1}$ - ATMOSPHERIC PRESSURE

AT OUTCROP, $\mathrm{Pa}$;

$g$ - ACCELERATION DUE TO GRAVITY, $\mathrm{ms}^{-2}$;

$Z$ - DIFFERENCE INALTITUDE BETWEEN OUTCROP

AND TOP OF WELL CASING, $m$;

$R_{A}$ - AIR-SPECIFIC GAS CONSTANT, J/kgK;

$T_{S V}$ - VIRTUAL TEMPERATURE OF SOIL GAS, K; and

$T_{A V}$ - VIRTUAL TEMPERATURE OF ATMOSPHERIC AIR, K.

Figure 4.4. Conceptualized System Where Convective Air Flow Occurs Due to a Topographic Effect (from Weeks, 1987) 


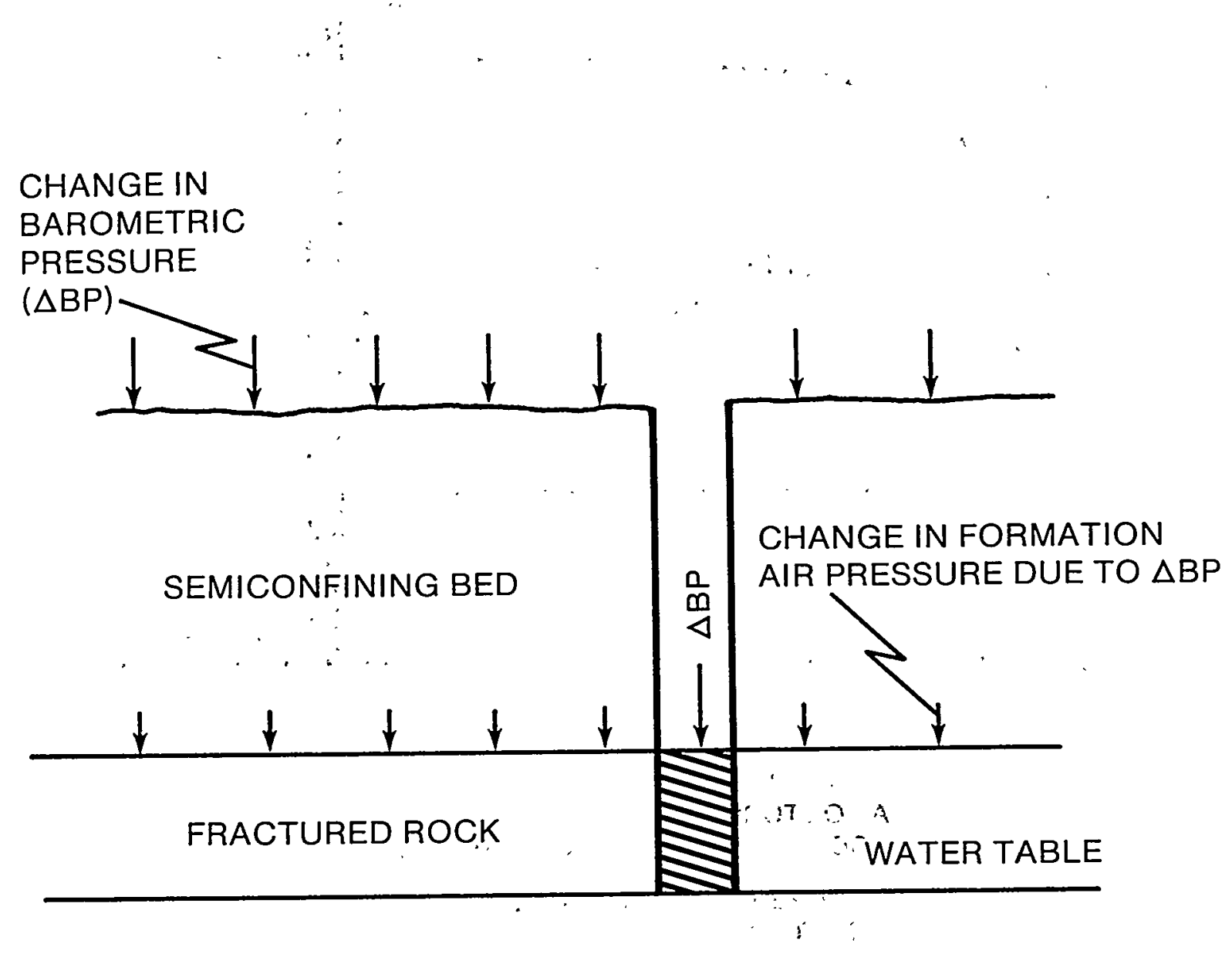

Figure 4.5. Conceptualization of Barometric Pressure Effects on Air Flow in Boreholes Open in the Unsaturated Zone (from Weeks; 1987) 


\subsection{Saturated Ground-Water Flow}

In the saturated zone, capillary forces are no longer dominant. Gravity forces cause the pressure head. The pressure head distribution, in turn, determines the ground-water gradient, the driving force behind ground-water flow. The flow system through the saturated zone is often conceptualized to be horizontal (see Section 3.2). In reality, vertical movement also occurs in recharge and discharge zones. The structural framework and the location of high and low permeability units complicates the threedimensional saturated flow field in the region. The saturated zone is comprised of two fractured aquifers that are sometimes separated by an aquitard. Thus, saturated fracture flow is a dominant process for water movement through the saturated zone. Sections $6.2,6.3$, and 8.2 describe the characteristics of the saturated zone at the repository site in more detail. 


\subsection{TRANSPORT SYSTEM PROCESSES}

To define a conceptual model (see Section 1.2), a description of the transport processes affecting the repository system is necessary. The following sections identify important processes related to transport of radionuclides from the repository to the accessible environment (i.e., through the geologic medium in the far-field region). Since the primary mode of radionuclide transport may be as dissolved solutes in the ground water, the migration of radionuclides must be consistent with the ground-water flow system that will be discussed in detail in Section 6. These transport system processes apply to both transport in the unsaturated and saturated zones. These processes are convection, dispersion, diffusion, radioactive decay, and sorption. Other processes will be discussed in terms of how they affect or are related to these important transport processes (i.e., dissolution and its effect on sorption). Gas phase transport will be discussed, because it is a possible migration path due to the presence of the gas phase in the unsaturated zone. Colloid transport will also be described, since there is the possibility of radionuclide colloid transport in a ground-water flow system. The processes will first be described in general terms, then the discussion will be extended to unsaturated and saturated, fractured rock.

\subsection{Convection/Dispersion}

The physical processes that govern the flux of solute in a ground-water system are convection and hydrodynamic dispersion. Transport by the bulk motion of the flowing fluid is known as convection. The rate of solute transport by convection alone is equal to the average linear velocity of the flowing fluid. Therefore, to conceptualize convective solute transport in a porous medium, information about the velocity field must be known. Hydrodynamic dispersion is the tendency of the solute to spread out from the path it is expected to follow due to convection, or is the macroscopic outcome of the actual movement of individual solute particles through the porous medium (Bear, 1972). If investigators knew the exact flow path of every solute particle through the porous medium, then it would not be necessary to include dispersion as a transport process. Since this microscopic information is not available, however, it becomes necessary to represent this macroscopic phenomenon as the physical process of dispersion. This process is important because dispersion causes dilution of the solute, and, therefore, dispersion affects the concentration of radionuclides in the ground water.

Hydrodynamic dispersion includes two processes: mechanical dispersion and molecular diffusion (Bear, 1972). Although hydrodynamic dispersion is defined in this manner, mechanical dispersion and molecular diffusion are two distinct processes. However, 
classical dispersion theory (Taylor, 1953) maintains that the mechanical dispersive flux can be represented in a way that is similar to the diffusive flux (i.e, Fick's law of diffusion). Consequently, mechanical dispersion and molecular diffusion are typically combined, and the resultant process is called hydrodynamic dispersion. Analyses of ground-water flow systems traditionally follow classical dispersion theory: hydrodynamic dispersion is represented by defining a dispersion coefficient that is a function of mechanical dispersion and diffusion.

The driving force for mechanical dispersion is mechanical mixing. Mechanical mixing occurs during convection and, when viewed on the microscopic level, is caused by the roughness of pore surfaces, the differences in pore sizes along the flow paths, and the branching of pore channels. Molecular diffusion is solute particle (ionic or molecular constituents) movement in the direction of a concentration gradient. This movement is due to the thermal-kinetic energy of the solute particles (random motion). Solutes tend to move outward from a concentrated source, even in the absence of fluid movement. Therefore, it is possible that radionuclides may migrate by diffusion only and may not be coupled with ground-water movement. Diffusion is the dominant process of hydrodynamic dispersion at relatively low velocities, and mechanical dispersion dominates at high velocities.

The dispersive process causes spreading of the solute in the longitudinal flow direction as well as directions transverse to flow. Because the spreading of the solute concentration is larger in the direction of flow compared to directions transverse to flow, the dispersion process is anisotropic, even if the porous medium through which flow occurs is isotropic (de Marsily, 1986).

In traditional analysis, mechanical dispersion is treated as a function of the product of ground-water velocity and a dispersivity coefficient. The dispersivity has generally been assumed to be constant for a specific porous medium. This was experimentally verified on small samples by Pfankuch (1963). However, more recent studies (Lallemand-Barres and Peaudecerf, 1978; and Dieulin and others, 1981a, 1981b) have indicated that the dispersivity may be both scale and time dependent. Lallemand-Barres and Peaudecerf found that, for published values of dispersivities, the dispersivity increased with distance between the source and the observation point. The data presented was for several rock types and ranged between distances of a few meters to $10 \mathrm{~km}$. As an approximation, the dispersivity was found to be one-tenth of the distance traveled and, therefore, the dispersivity increased with distance. Dieulin and others found that, during a short time interval, measurements at different distances from the source implied a constant dispersivity; however, for a longer time interval, they obtained a larger dispersivity value. 
Gelhar and others (1979) and Gelhar and Axness (1983) postulated that the dependence of dispersivity on scale and time can be explained by a stochastic approach. This stochastic approach assumes that the hydraulic conductivities for a porous medium are spatially correlated. As summarized by de Marsily (1986), the results of this stochastic approach are that dispersivity is a function of time and space, the dispersivity value eventually approaches an asymptotic value, and the dispersivity is a function of statistical properties of the velocity field (i.e., the hydraulic conductivities).

Convection is more complicated when more than one phase is present, as is the case for radionuclide transport in the unsaturated zone. It is conceivable that convection can transport the chemical species in both the gas and liquid phases. The bulk movement (i.e., average linear velocity) in the gas and liquid phase is not necessarily the same. Also, the flow paths of the two phases will be different, and this tends to complicate the convection process for unsaturated zone transport.

Dispersion is also more complicated when more than one fluid phase is present. The presence of each phase can deny pore space to the other phase and thus alter flow and transport paths significantly. As saturation decreases for a phase, that phase ultimately loses its continuity because of capillary instabilities within a complex pore structure. Sahimi and others (1983) indicate that, for two immiscible fluids, the distribution of phases in the pore space is dictated by the pore space morphology, the capillary and viscous forces at the interfaces, and the stability of the shape that the interfaces assume in response to these capillary and viscous forces. Other factors that can influence the distribution of the two phases are the saturations, volume fractions, and the saturation history (i.e., the way the saturations were reached).

Sahimi and others (1983) consider the case where one phase strongly wets the pore walls (the contact angle is much less than 90 degrees) and the other is nonwetting. This may correspond to water (wetting fluid) and air (nonwetting fluid) in the unsaturated zone. In this case, the saturation history is important because the larger pores control flow and transport rates during imbibition and for drainage, and the smaller pores control flow and transport rates. Using a network model, Sahimi and others also found that in twophase flow, longitudinal dispersion in a given phase increases greatly as the saturation of that phase approaches its percolation threshold. Transverse dispersion also increases, but increases more slowly. Smiles and others (1981) presented laboratory evidence indicating that, for transport in the unsaturated zone, the dispersion coefficient (both longitudinal and transverse) is a function of water content. 
In general, convection in fractured, geologic media is more complicated, compared to unfractured media. Ground water in the unsaturated zone is preferentially drawn into the smallest pores due to surface tension forces (capillarity). This leads to greater constrictivity and lower permeability in the matrix compared to the fractures. Although some researchers have indicated that fracture flow in unsaturated tuff will not occur due to the high matrix potential, there have been no conclusive studies involving experimental laboratory and/or field data to support this assertion. One area that has not been investigated thoroughly is the possibility of short intense rain storms that may induce fracture flow and transport. It is typically assumed that if this flow occurs, it will be transferred to the matrix due to capillary suction. However, mineral layers on the fracture surfaces can possibly impede capillary uptake into the matrix (Thoma and others, 1990). Because dominant matrix flow cannot be established at this time, fracture flow cannot be ruled out as a possible path for radionuclide migration.

Hydrodynamic dispersion in fractured geologic media may be more complicated than it is in unfractured media. Fractured geologic media are highly anisotropic with respect to the orientation and frequency of fractures and hence, dispersion becomes more complex. For example, the classical assumption that the principal direction of dispersion is in the direction of the velocity is questionable for fractured media, because fractured media are anisotropic (de Marsily, 1986). It is also conceivable that the connectivity of the fracture network would have a significant influence on the magnitude of the dispersive effects in fractured media.

\subsection{Diffusion}

As indicated earlier, molecular diffusion will be the dominant transport process at relatively low flow velocities. For unsaturated zone transport, molecular diffusion can occur in both the liquid and gas phase. For a fractured geologic medium, molecular diffusion can occur within the fractures in the matrix or between the fracture/matrix system.

Diffusion within the unfractured matrix will be affected by resistance from pore constrictions and branching pore channels. Characteristics that will decrease diffusion due to the porous medium are usually accounted for by using an effective diffusivity. The effective diffusivity is typically defined in terms of a tortuosity factor, a molecular diffusion coefficient, and the porosity of the porous medium. The tortuosity factor accounts for the resultant tortuous path that the solute particles follow as a result of migration in the porous medium. Porosity accounts for the decrease in cross-sectional area for diffusion to occur due to the porous medium. 
Walters (1982) has investigated diffusion in a tuffaceous rock matrix and reported tortuosity values for this type of medium, as well as effective diffusivity values. Unfortunately, the reproducibility of the diffusion experiments is questionable and, therefore, the resultant effective diffusivities are also questionable. This indicates how difficult it is to predict effective diffusivity values based on physical properties (such as tortuosity and porosity) of the tuff. Walters also concluded that coupling of the diffusive fluxes of all ionic species is important and should be considered in a model of diffusion in the unfractured matrix.

Since fracture flow in fractured tuff (unsaturated or saturated) is possible, diffusion from the bulk fluid in the fracture to the matrix fluid (which is commonly called matrix diffusion) should also be considered. This transport mechanism is often classified as a physical retardation process. The reasoning is that when the solute diffuses into the matrix from the fracture, its migration to the accessible environment is delayed. In a sense, the rock matrix acts as a storage volume; thus, the concentration of radionuclides discharged to the accessible environment for a specified time is reduced.

The driving force for matrix diffusion is a concentration gradient and net diffusion into the rock matrix will occur until the matrix concentration equals the fracture concentration (at equilibrium, net diffusion equals zero). Consequently, after the solute in the fracture passes, the solute in the matrix may diffuse back into the fracture because the driving force is reversed.

When considering transport of solutes from the fracture to the porous matrix, the mass flux at the fracture/matrix interface must be accounted for. This is often referred to as film-type mass transfer resistance (Satterfield, 1970) and a mass-transfer coefficient is needed to describe the boundary condition at the fracture/matrix interface. This coefficient may depend on the chemical composition of the fracture wall; therefore, fracture coating may be important when considering matrix diffusion. Because of this film-type resistance, mass transfer of a radionuclide from bulk flow in the fracture into the matrix becomes a two-step process (i.e., film mass transfer is followed by diffusion into the matrix). The slower of these two steps controls the overall rate of mass transfer. The relative time-scale for each step should be estimated and compared to the timescale of flow. Local equilibrium may be assumed if the time scale of a particular step is significantly shorter than the step preceding and following it. Hence, external mass transfer resistance may be insignificant in the overall mass transfer of radionuclides to the matrix from the fracture. 


\subsection{Sorption}

There are many chemical processes that can result in the loss or gain of a solute in a ground water system. These chemical processes can occur in the liquid phase, gas phase or both, and in both the unsaturated and saturated zones. For fractured media, the chemical reactions can take place in the fracture system or porous matrix or both.

When considering solute transport, one of the most significant chemical processes that occurs is sorption. Sorption is herein considered a general term for adsorption/ desorption reactions. Adsorption is the transfer of solute mass from the ground water to the solid part of the geologic medium. Desorption is the opposite phenomenon. Solute species adsorb to the solid by forming bonds with molecules on the solid surface. The strength of these bonds and kinetics of the surface reactions depend on the size and charge of both solute and surface species, the degree of saturation of surface bonding sites, the acidity $(\mathrm{pH})$, the oxidation/reduction potential $(\mathrm{pE})$, and the temperature and pressure of the system (Morel, 1983).

Adsorption can occur by two different processes: physical adsorption and chemical adsorption. Physical adsorption is exothermic, and the heat of adsorption is relatively small (1-15 kcal $/ \mathrm{mol}$ ) (Fogler, 1986). With physical adsorption, the forces of attraction between the adsorbed atoms or molecules and the solid surface are weak (van der Waals forces). Consequently, physical adsorption is often reversible. Physical adsorption can also occur between the molecules adsorbed on the surface and other molecules; thus, multilayers of adsorbed molecules can be formed. For chemical adsorption, the adsorbed atoms or molecules are held to the surface by valence forces. These valence forces are of the same type as those between bonded atoms in molecules and the heats of adsorption are generally of the same magnitude, $10-100 \mathrm{kcal} / \mathrm{mol}$, as the heat of a chemical reaction (Fogler, 1986). Chemical adsorption, therefore, is often irreversible. Chemical adsorption occurs only with surface atoms; consequently, only a monolayer of adsorbed molecules is formed. Similar to physical adsorption, chemical adsorption is an exothermic process.

The sorption process in a ground-water system is often described by means of a distribution coefficient $\left(\mathrm{K}_{\mathrm{d}}\right)$. A distribution coefficient relates the distribution of solutes between the liquid and solid phases in a porous medium. Researchers make several typical assumptions when using distribution coefficients. These assumptions include instantaneous and reversible adsorption and desorption (equilibrium), linear sorption isotherms, and single-valued sorption isotherms (i.e., no hysteresis effect). If solute adsorption/desorption cannot be described by equilibrium relations $\left(K_{d}\right.$ 's), then 
information on the rates of the sorption reactions must be known or empirical sorption ratios may be used.

A sorption ratio is typically found from a measurement of an element's distribution between phases under specific conditions. Different conditions (such as oxidizing, reducing, adsorbing, desorbing) can produce different sorption ratios for the same system. For sorption ratios, no approach to equilibrium is assumed. If equilibrium was established, sorption ratios would be the same as distribution coefficients. Many studies (Johnstone and Wolfsberg, 1980; Tien and others, 1985; and Daniels and others, 1982) report data as sorption ratios. These studies were performed on tuffaceous rock and showed large positive values for sorption ratios. These large values indicate that the tuffaceous rock has a potential for significantly retarding radionuclide migration to the accessible environment. This indicates that sorption is a mechanism that is critical in modeling radionuclide transport in unsaturated, fractured tuff. Daniels and others also conclude that sorption on tuff is nonlinear, that sorption ratios from desorption experiments are higher than those from adsorption experiments, and that lack of agreement of experimental and theoretical models suggest a more complex sorption mechanism than simple linear sorption. Polzer and others (1987) conducted field scale transport studies in tuffaceous rock and found the presence of sorbing and nonsorbing tracers on the tuff at some locations and not at others, suggesting preferential transport paths.

When considering radionuclide transport in fractured, unsaturated media there are several elements of $\mathrm{K}_{\mathrm{d}}$ 's or sorption ratios that are relevant for this type of media. For unsaturated-zone transport, Dykhuizen (1988) has postulated that the distribution coefficient or sorption ratio will be a function of moisture content. This functional relationship is due to the assumption that the liquid phase does not have access to all adsorption sites because of the presence of the gas phase. The complex relationship between sorption and saturation will depend on parameters such as ground-water chemistry, pore shape and size distribution, fracture shape and size distribution, and the distribution of liquid and gas phases in the geologic medium.

For fractured porous media, as suggested by Burkholder (1976), it is more appropriate to express the distribution coefficient on a per-unit fracture surface area basis as opposed to the per-unit mass basis for porous media. This is reasonable because sorption reactions are more closely related to the surface area of the medium than the mass. Fracture surface areas are often approximated by assuming a planar fracture surface. Due to surface roughness and irregularities, the actual surface area with which the radionuclides interact could be significantly larger than that representing this planar 
approximation. This assumption is not necessarily harmful in that, by assuming a planar surface, a conservative approach to sorption is achieved.

Another aspect of sorption that has been found to be very important in terms of radionuclide discharge (Neretnieks, 1980; Bonano and others, 1988) is sorption coupled with matrix diffusion. Diffusion of the solute from the fracture to the porous matrix can cause sorption to occur on a much larger surface area than if the solute stayed entirely in the fracture. Therefore, when considering fracture flow, solute transport may be retarded due to both matrix diffusion and matrix sorption. Hence, migration to the accessible environment may be delayed significantly.

Sorption is considered a chemical retardation process because the transport of solute to the accessible environment is retarded due to the sorption process. This chemical retardation by sorption is often described by a retardation equation. The retardation equation defines a retardation factor which represents the ratio of the average velocity of the ground water to the average solute velocity. Therefore, if sorption does not occur, the retardation factor is equal to unity; if sorption occurs, the retardation factor is greater than unity.

Defining a retardation factor as the ratio of the mean ground-water velocity to the mean solute velocity seems like a reasonable approximation. However, since these velocities would have to be measured for each type of porous medium and solute, the retardation factor is typically defined in terms of the bulk density of the porous medium, the porosity of the porous medium, and a distribution coefficient (i.e., quantities that are relatively easy to measure). There is some question concerning this definition of a retardation factor. The first assumption embodied in this definition is that all chemical processes that can retard radionuclides are represented by the sorption distribution coefficient. This is done because many of the chemical processes associated with solute transport are complex and difficult to model. Second, this $K_{d}$-based retardation is typically assumed to be constant for a specific radionuclide (i.e., it does not vary with time, space, or concentration). This assumption is usually made because of lack of site specific sorption data. Third, the porosity is used to quantify how much surface area of the porous medium is available for chemical retardation to occur. In doing so, a volume-based measurement, porosity, is used to represent surface area. Currently, for unsaturated transport, researchers replace the porosity by the water content in defining the retardation factor (to quantify how much surface area of the porous medium is available for sorption to occur). This replacement is not based on conclusive field or laboratory studies and, therefore, the relationship between retardation and water content cannot be established at this time. Fourth, there is question concerning how researchers 
typically measure $K_{d}$ 's. This question arises from the fact that researchers often find $K_{d}$ 's by using crushed rock samples and measuring the amount adsorbed in a batch system. This is in contrast to the actual physical system, which is dynamic (i.e., ground water flowing through the rock). Also, the surface area available for sorption to occur is quite different in the actual system than that of the ground up rock sample; consequently, these measurements may not be conservative.

Another chemical process that can occur in a ground-water system that is related to sorption is ion exchange. In fact, some studies define ion exchange as a form of sorption (Travis and Etnier, 1981). In a repository setting, it is difficult to discern between sorption and ion exchange because the result of each process (i.e., retardation of solutes) is the same. One main difference between the two processes is that sorption is often considered reversible (physical adsorption); whereas ion exchange is often considered irreversible (chemical adsorption).

One aspect of ion exchange that can be applied to the unsaturated, fractured tuff is that the zeolites that are in the tuff show high selectivity for specific cations (Drever, 1982). Consequently, zeolites could immobilize specific radionuclide elements and therefore contribute to the chemical retardation process. However, because zeolites have a rigid structure and the pore sizes are relatively small (on the order of $3 \times 10^{-9} \mathrm{~m}$ to $9 \times 10^{-9}$ $\mathrm{m})$, counter ions are not very mobile. Consequently, zeolites can act as molecular sieves and ions that are larger than the pore sizes are excluded from the ion exchange process. For example, Helfferich (1962) states that in zeolites, ion exchange can occur with $\mathrm{Na}^{+}$ for $\mathrm{Li}^{+}, \mathrm{K}^{+}$, and $\mathrm{Ag}^{+}$, but not for $\mathrm{Cs}^{+}$. This molecular sieve effect may exclude some of the larger radionuclide ions from exchanging with counter ions contained on the zeolite surface in the porous matrix.

\subsection{Radioactive Decay}

Another important process that is specific to transport of radionuclides in a ground-water system is radioactive decay. Radioactive decay is the spontaneous transformation of a nuclide into one or more different nuclides, accompanied by either the emission of particles from the nucleus, nuclear capture, ejection of orbital electrons, or fission. Radioactive decay is important because many of the transport mechanisms depend on the concentration of the radionuclide elements. For example, a daughter nuclide may be sorbing while its parent may not, or vice versa. Radioactive decay is a first-order reaction, where the amount of radioactive element decaying is proportional to the amount present. The proportionality constant is called the decay constant and is specific for each radionuclide. 
Radioactive decay results in radioactive decay chains (a succession of nuclides) that transform by radioactive disintegration each one into the next, until they form a stable nuclide. Because a short-lived radionuclide parent can decay into a long-lived radionuclide daughter, including radionuclide chains in the conceptual model is very important for determining which radionuclides reach the accessible environment (i.e., assessing compliance with the EPA Standard). Also, for this same reason, the transport of multiple species must be examined. The presence of more than one radionuclide would affect all the transport processes that occur in the ground-water system and a governing equation for each species would be needed. With the presence of multiple radioactive species, multiple decay chains are likely, and need to be considered.

\subsection{Leaching, Dissolution, and Precipitation}

In a ground-water system, the water comes in contact with the minerals in the rock and leaching, dissolution, and precipitation of these minerals can occur. These chemical processes continue until equilibrium concentrations are obtained in the ground water or until all the minerals are consumed. The surface of the rock is altered due to these chemical processes. Long-term dissolution can diminish or completely remove reactive mineral phases from the surface, and precipitation of minerals may coat the surface. Because the surface is altered, sorption of the radionuclides onto the rock is affected and therefore, radionuclide migration is also influenced. For tuff, when the ground water interacts with the rock minerals, the formation of any number of zeolite phases can occur (Apps and others, 1982). Polzer and others (1987), conducted field scale transport studies in tuff and then analyzed the tuff materials for the presence of tracers and freshly precipitated material. The results indicated no presence of freshly precipitated material that would retard tracer movement. In a fractured geologic system, precipitation of minerals can occur in the fractures to the point where the fractures become filled. As noted earlier, this fracture-coating phenomenon could effect fracture/matrix flow and matrix diffusion as well as sorption on the fracture walls.

\subsection{Complexation}

Complexation involves the bonding of ligands to a metal atom or ion due to the valence of the metal atom. Many metal radionuclide ionic species form very strong complexes with materials contained in ground water (e.g., polycarboxylic and amino carboxylic compounds) (Apps and others, 1982). Transport of radionuclides complexed with these ligands may be significantly different than transport of uncomplexed radionuclides. For example, radionuclides in complex form may have different propensities for sorption compared to uncomplexed radionuclides. Also, the mobility of the radionuclide complex 
may change depending on the solubility of the complex formed relative to its constituents. There is also the possibility that the radionuclide species will form a complex with solid phase molecules (a form of chemisorption). The formation of organic radionuclide complexes will depend on the concentration of organics in the ground water. Unfortunately, the basic chemistry of complexation of radionuclides with ligands and migration of these complexes is poorly understood and, therefore, radionuclide transport by complexation cannot be evaluated at this time.

\subsection{Gas Phase Transport}

The presence of a gas phase in unsaturated tuff implies that radionuclides may be transported in the gas phase to the accessible environment. This may occur in several different ways. First, there is the possibility that dissolved radionuclides will become volatile and will be transported in the gas phase. Second, there is the possibility that aerosols will form due to the heat generated by the nuclear waste, and that radionuclides will be transported as aerosols in the gas phase. Third, radionuclides that are already in gaseous form (such as ${ }^{14} \mathrm{C}$ and ${ }^{129} \mathrm{I}$ ) may also migrate in the gas phase. In general, the significance of gas phase transport in unsaturated, fractured rock is an important research question that investigators need to address. For example, if there is a continuous path for gas phase transport from the repository to the land surface (the accessible environment), then there is also a continuous path for water infiltration. This may prove to have a greater impact than gas phase transport. The following discussion reviews current research on gas phase transport in unsaturated, fractured tuff.

Smith and others (1986) assessed radionuclide gas phase transport in unsaturated tuff. They examined aerosol formation and gas phase convection/diffusion of volatile species. For aerosol transport, they considered the formation of aerosols from the liquid phase contained on a fracture wall. This was reasonable because aerosol formation will not occur in the rock matrix, since a liquid film and air space overlying the liquid film is required for aerosol production. To form an aerosol, the ground water must become supersaturated with air components, and, if the degree of supersaturation is high enough, gas bubbles form. These air bubbles will then migrate to the surface of the liquid film (if the film thickness is large as compared to the air bubble size). Then, if the bubble velocity is high enough, the bubble will collapse and aerosols will be produced.

For repository conditions, it is possible that the ground water will become supersaturated with air during the "heat pipe" effect that may occur near the high-level nuclear waste. This effect consists of liquid film ground-water movement towards the nuclear waste where high temperatures exist, vaporization of the ground water, and movement of the 
vapor away from the waste to a region of lower temperatures. The solubility of air components in the liquid ground water will decrease as the temperature increases, and, if the air components cannot diffuse quickly enough into the vapor phase, the liquid film may become supersaturated with the air components as the liquid cools.

Smith and others (1986) analyzed air diffusional transport in a stagnant liquid film to determine the degree of supersaturation in the liquid ground water film. This was a conservative analysis in that, by assuming a stagnant liquid film and transport by molecular diffusion only, they did not account for the effects of turbulence and other transport mechanisms. These other processes would only increase transport in the liquid film. From their analysis, Smith and others concluded that the air transport rate is so high that supersaturation does not occur, so gas bubbles are not formed and aerosols are not produced. They reached this conclusion for all expected repository conditions. Green and Evans (1987) also concluded that aerosol production from bubble formation should not exist under expected repository conditions. However, they believe that processes other than bubble formation may exist to produce aerosols. One process they suggest is the rupture of thin films (films of thickness $5 \times 10^{-8} \mathrm{~m}$ to $5 \times 10^{-7} \mathrm{~m}$ ). Unfortunately, they do not give any information on the processes involved. It is yet to be determined whether or not this phenomenon will occur and if it does, under what conditions does it occur.

It should be noted that Smith and others (1986) also point out that if gas bubbles actually did form, it is unlikely that the liquid film would be of adequate thickness for bubbles to accelerate to sufficient velocities for aerosol production. Day (1964) used a diffusion cloud chamber to determine that aerosol particles are not ejected by gas bubbles that have a radius less than $1 \times 10^{-4} \mathrm{~m}$. Therefore, the minimum film thickness needed for bubble formation to occur is $1 \times 10^{-4} \mathrm{~m}$, which corresponds to a minimum fracture aperture on the order of $2 \times 10^{-4} \mathrm{~m}$. Ogard and others (1983) measured fracture apertures for six tuff samples in the range of approximately $6 \times 10^{-5} \mathrm{~m}$ to $2.5 \mathrm{x}$ $10^{-4} \mathrm{~m}$. From these measurements, the possibility of adequate liquid film thickness is greatly reduced. However, Green and Evans (1987) point out that the six core samples tested by Ogard and others do not adequately characterize the entire zone of canister placement for a high-level nuclear waste repository. They also state that the heat from the nuclear waste could alter the fractures in such a way that the apertures are enlarged significantly. This question of aerosol formation is primarily relevant for the near-field and not for far-field radionuclide migration. However, if radionuclide aerosols are formed in the near-field region then their transport in the far-field region to the accessible environment becomes relevant. 
Smith and others (1986) also analyzed the transport of volatile radionuclides in the gas phase by convection/diffusion. They performed conservative bounding calculations on the gas flow rate relative to the liquid flow rate (mobility ratios) due to convection/diffusion for expected repository conditions. From the magnitude of these mobility ratios they concluded that, except for the immediate region near the canister, transport in the liquid phase will be dominant for radionuclides as heavy as or heavier than cesium. The authors also note that near the waste canister, gas phase transport of ${ }^{129}$ I may be important.

As indicated previously, transport of gaseous radionuclides (such as ${ }^{14} \mathrm{C}$ in the form of $\mathrm{CO}_{2}$ or $\mathrm{CH}_{4}$, or ${ }^{129} \mathrm{I}$ ) may also occur in the unsaturated zone. This is a research area where little work has been done to ascertain its importance, although recently, some investigators have done preliminary studies concerning gaseous ${ }^{14} \mathrm{C}$ migration (van Konynenburg and others, 1985; Amter and others, 1988; Ross, 1988).

There are several different driving forces for gas flow. Diffusion occurs along a concentration gradient. Density differences drive convective gas flow. The density difference between gases below the surface and gases in the atmosphere are caused by temperature and pressure differences. Because of seasonal temperature fluctuations, gas moves up in the winter and down in the summer. Daily pressure changes can also cause upward and downward gas movement. Researchers have inferred that air moves in and out of boreholes at Yucca Mountain (Weeks, 1987) and at the Apache Leap Tuff Site (Evans and Rasmussen, 1988), and they have postulated that this movement is due to density differences. Gas phase radionuclide migration to the surface due to these oscillating flows may be possible. However, Amter and others (1988) conclude that, for $\mathrm{CO}_{2}$ migration at Yucca Mountain, transport due to the seasonal gas flow is much less than migration of $\mathrm{CO}_{2}$ due to diffusion, and is therefore negligible. This conclusion is based on physical assumptions about the Yucca Mountain system under present-day conditions. These assumptions include gas transport in an equivalent porous media, steady-state gas flow during any season (with the air pressure at the surface an average over diurnal and weather-related fluctuations), and a retardation factor of 70 for gaseous ${ }^{14} \mathrm{CO}_{2}$.

In high-level nuclear waste (spent fuel) ${ }^{14} \mathrm{C}$ is found on the interior of fuel rods and on the interior and exterior of fuel assembly structural components (van Konynenburg and others, 1985). Initially, when the waste package is breached and the contents contact air, the ${ }^{14} \mathrm{C}$ contained in the external structural components will be released rapidly in the form of gaseous $\mathrm{CO}_{2}$. Van Konynenburg and others (1985) conclude that this initial release of ${ }^{14} \mathrm{C}$ will not exceed the proposed EPA standard, but that further research is 
needed to account for slower ${ }^{14} \mathrm{C}$ release (oxidation of the internal components of the fuel assembly) and transport of this ${ }^{14} \mathrm{CO}_{2}$ through the geosphere.

In addition to diffusion and convection, there are several chemical processes that can occur with $\mathrm{CO}_{2}$ gas phase transport. These chemical processes include isotopic exchange, radioactive decay, sorption, and water-carbonate mineral reactions. These water-carbonate mineral reactions may provide a sink for removal of ${ }^{14} \mathrm{C}$ from the gas phase (Ross, 1988). Due to these complicated chemical processes, analyzing gaseous $\mathrm{CO}_{2}$ migration becomes very involved.

Analyses of $\mathrm{CO}_{2}$ gas transport that have been done for Yucca Mountain (Amter and others, 1988; Ross, 1988) assume that gas transport occurs only in the porous matrix. These analyses also assume an immobile liquid phase. By making this assumption it is implied that liquid and gas phase transport are independent of each other or decoupled.

\subsection{Colloids}

Colloids are defined as having at least one dimension within the size range $10^{-9}$ to $10^{-6}$ m (Shaw, 1970; van Olphen, 1977; and Yariv and Cross, 1979). A colloidal system consists of these relatively large molecules or small particles suspended in a solvent. Because of the size of the colloid particles, interfacial forces control their behavior and they stay in suspension by Brownian motion. Colloids are good adsorbents because of their high ratio of surface area to volume, and ion-exchange occurs easily because colloids have a large electrical charge relative to their surface area. Besides facilitating ion-exchange, colloid particles can coalesce and may precipitate.

Naturally occurring colloids are often found in ground-water systems. These include clay minerals, which are of colloidal size, and geochemical weathering products of rocks which are often inorganic, amorphous (uncrystallized or poorly crystallized) colloids in a metastable state. Ferric and aluminum hydroxide, and silicic acid polymers are also frequently found suspended as colloids in ground water (Apps and others, 1982).

Because colloid formation is possible in ground-water systems, radionuclides could adsorb onto the surface of these particles, or form colloids themselves and be transported to the accessible environment. Chemically and physically, colloids behave differently from dissolved species and the mechanisms controlling transport of colloids are quite different from those controlling dissolved species. In fact,a number of investigators (Apps and others, 1982; Champ and others, 1982, and Bonano and Beyeler, 1985) have concluded that radionuclides in colloidal form can be transported faster than 
in dissolved form. On the other hand, colloids might be retarded by filtration in the porous matrix.

Colloid filtration depends on the relative sizes of the colloids and the pores. Colloid particles must be smaller than the fractures and/or pores in the geologic medium to pass through them. Preliminary experimental work (Smith, 1988) indicates that pore sizes in welded tuff matrix are relatively small (radii ranging from $5 \times 10^{-9} \mathrm{~m}$ to $1 \times 10^{-7} \mathrm{~m}$ ). Consequently, transport of radioactive colloids will probably occur primarily in the fractures of the tuff. This conclusion is consistent with the conclusions of Tsang and Mangold (1984). Colloidal particles may also aggregate into larger particles due to flocculation. By forming larger particles, the efficiency of colloid filtration increases.

The critical parameters when considering colloid transport include flow rate, ionic strength, particle size, and surface charge (Binnall and others, 1987; Bonano and Beyeler, 1985). Unfortunately, due to lack of experimental data, the exact nature, stability, and properties of radioactive colloids are difficult to predict. Apps and others (1982) concluded, from the small amount of available data, that concentrations of colloids are very low, and, therefore, not a significant path for radionuclide transport. Bonano and Beyeler (1985) showed that if the rate of appearance of colloids increases along the transport path so does their rate of capture and vice versa. This may be the reason colloid concentrations have been found to be low. For the unsaturated zone, if one assumes transport occurs predominately in the matrix system, ground-water flow rates will be relatively low, and colloid transport is probably not a significant path for radionuclide migration. However, for the saturated zone where fracture flow is dominant or for unsaturated fracture flow, colloid transport becomes more significant. This is because of the relatively higher flow rates in the fractures and the possibility of radioactive colloids reaching the accessible environment in a relatively short time period. 


\subsection{GROUND-WATER FLOW SYSTEM}

This section defines the hydrogeologic stratigraphy, and subsequently describes the regional and local ground-water flow systems at the hypothetical repository site.

\subsection{Hydrogeologic Stratigraphy}

The movement of fluids through rocks is fundamentally a physical process governed by the pore geometry of the medium. It is therefore appropriate to define the hydrogeologic stratigraphy according to physical differences in the rock which affect the flow regime. Thus, the hydrogeologic units do not necessarily coincide with designated geologic divisions which are generally based on mineralogy and petrology.

The upper $500 \mathrm{~m}$ of volcanic rocks in the unsaturated zone have been commonly divided according to degree of welding. As previously discussed, for tuff units the degree of welding has a direct effect on the fracture frequency and density, matrix porosity, grain density, and dry bulk density. Beneath the alluvium, one of the possible hydrogeologic stratigraphies in the volcanic tuffs has been identified by Montazer and Wilson (1984). They identified five hydrogeologic units in the unsaturated zone; the Tiva Canyon welded unit, the Paintbrush non-welded unit, Topopah Spring welded unit, Calico Hills nonwelded unit, and Crater Flat unit (see Figure 6.1). However, the degree of welding is a qualitative term. For example, the "welded" tuff and "nonwelded" tuff described by investigators at Yucca Mountain have porosities of approximately $12 \%-14 \%$ and $31 \%$ 46\%, respectively (Anderson, 1981; Rush and others, 1983; Weeks and Wilson, 1984). In contrast, the "slightly welded" tuff from the Apache Leap Tuff Site in Arizona has a porosity of about $13 \%$ - 17\% (Vogt, 1988), which is comparable to the "welded" tuff from Yucca Mountain. The porosity differences may be due to secondary mineralization, vapor-phase crystallization, and formation of lithophysal cavities. Zones containing abundant lithophysal cavities or gas pockets may significantly affect the physical properties of ash-flow tuffs. Ideally, all available properties of the unsaturated rocks that will affect flow should be utilized to designate the unsaturated zone hydrogeologic stratigraphy. This includes hydraulic properties such as in situ moisture content, the moisture retention curves, and saturated hydraulic conductivity.

Winograd and Thordarson (1975) defined a possible hydrogeologic stratigraphy in the saturated zone based on the transmissivity of the rock units. The saturated rocks are divided into the upper and lower carbonate aquifers and the upper and lower clastic aquitards (see Figure 6.1). Again, it is desirable to include additional information about the saturated rock units, such as effective porosity, when designating the hydrogeologic 


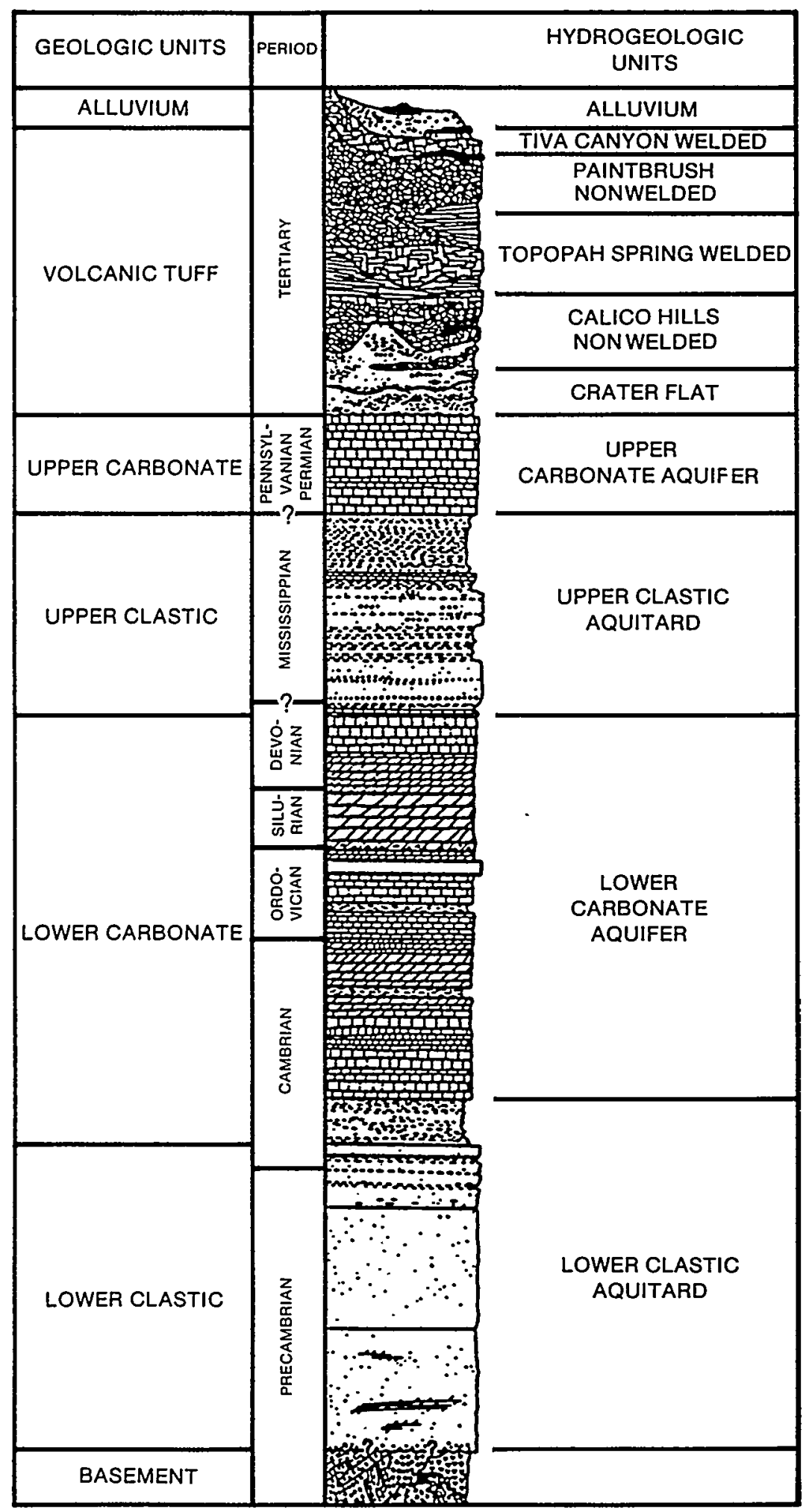

Figure 6.1. Designated Hydrogeologic Units Based on Work by Montazer and Wilson (1984) and Winograd and Thordarson (1975) Compared to the Geologic Units at the Repository Site (modified from Sinnock, 1982) 
stratigraphy of the saturated zone.

Only one hydrogeologic stratigraphy is presented here, mainly based on work by Montazer and Wilson (1984) and Winograd and Thordarson (1975). There are actually an infinite number of hydrogeologic stratigraphies, depending on which physical characteristics are chosen as the criteria for selecting the divisions. The following discussion presents the hydrogeologic stratigraphy in only one- and two-dimensional format, recognizing that the true hydrogeologic system is not well understood in threedimensions.

Alluvium is present in washes that dissect Yucca Mountain, and form surficial deposits in the inter-ridge and flats in the vicinity. The thickness, lithology, and sorting of the alluvium deposits vary substantially, but overall, the alluvium hydrogeologic unit is more permeable than the tuff units (Montazer and Wilson, 1984). The alluvium is unsaturated in the immediate repository area. The alluvium is saturated only beneath the structurally deep parts of the region near recharge or discharge zones. The alluvium is the principal aquifer of the Amargosa Desert (Waddell and others, 1984).

The Tiva Canyon welded unit is the uppermost unit at the surface of Yucca Mountain. On the central block this unit dips to the east at an angle of 5 to 10 degrees and is exposed at the land surface in several areas (Montazer and Wilson, 1984). The Tiva Canyon welded unit ranges from 0 to $150 \mathrm{~m}$ in thickness (Scott and Bonk, 1984). This unit has a large fracture density and a low matrix permeability (Scott and others, 1983; Anderson, 1981).

The Paintbrush nonwelded unit consists of thin ash-flow sheets and bedded tuffs that thin to the southeast in the repository area from a maximum thickness of $100 \mathrm{~m}$ to about $20 \mathrm{~m}$ (Scott and Bonk, 1984). The unit dips to the east at angles of 5 to 25 degrees. These tuffs are vitric, nonwelded, highly porous, contain low fracture densities, and have high matrix permeabilities (Montazer and Wilson, 1984).

The Topopah Spring welded unit is the proposed host rock for the repository. It is characterized by dense fracturing and low matrix permeability (Weeks and Wilson, 1984; Scott and Bonk, 1984). The Topopah Spring unit is the thickest and most extensive ashflow tuff in the repository area (290 to $360 \mathrm{~m}$ ) (Scott and Bonk, 1984). The Topopah Spring welded unit is devitrified throughout the central portion of the deposit. The Topopah Spring unit contains several lithophysal cavity zones that are laterally continuous, varying in thickness and stratigraphic location. East of the repository block, 
the water table is located within the base of the Topopah Spring welded unit (Montazer and Wilson, 1984).

The Calico Hills nonwelded unit varies in unsaturated zone thickness because of the location of the water table. The thickness of the Calico Hills nonwelded unit ranges from 140 to $250 \mathrm{~m}$ (Scott and Bonk, 1984). Both vitric and devitrified facies occur within the Calico Hills nonwelded unit (Montazer and Wilson, 1984). The vitric facies have substantially larger permeability than the devitrified facies, and thus have an effect on flow within and through the hydrogeologic unit.

The Crater Flat tuff unit consists of welded and nonwelded tuff layers. However, no differentiation was made between the two layers because the Crater Flat tuff is located beneath the water table within the majority of the repository area (Montazer and Wilson, 1984). The thickness of the Crater Flat tuff ranges from zero to $160 \mathrm{~m}$ (Scott and Bonk, 1984).

Beneath the water table, the upper carbonate aquifer is more than $1000 \mathrm{~m}$ thick at several locations. The upper carbonate aquifer has been eroded from the eastern part of the region, or occurs in ridges at altitudes above the water table (Winograd and Thordarson, 1975). The only area where the upper carbonate aquifer is saturated is in the western part of Yucca Flat (Waddell and others, 1984). Therefore, the upper carbonate aquifer has minor significance to the regional ground-water flow system.

The upper clastic aquitard is present in the Yucca Flat area. The upper clastic aquitard is composed of argillite with minor quartzite and limestone. It is approximately $2400 \mathrm{~m}$ thick and has a very low permeability. The presence of the upper clastic aquitard is responsible for local steep horizontal hydraulic gradients.

The lower carbonate aquifer is widespread in the eastern portion of the region. It is the primary transmitter of water in the saturated zone. As discussed previously (Section 3.1), the lower carbonate aquifer is highly fractured and saturated fracture flow is a dominant flow process in this unit. The total aquifer thickness exceeds $4700 \mathrm{~m}$, and the effective transmissivity of the aquifer is very large (Waddell and others, 1984).

The lower clastic aquitard is comprised mainly of quartzite and shales. It is up to three orders of magnitude less permeable than the lower carbonate aquifer. The lower clastic aquitard is often treated as the lower boundary of the hydrogeologic system (Winograd and Thordarson, 1975). The low permeability of this unit most likely has a significant 
effect on the distribution of hydraulic potentials and the location of discharge zones (Waddell and others, 1984).

\subsection{Regional Flow System}

The regional surface and ground-water flow systems are described here. As discussed previously, the regional flow system is defined for the purpose of subsequent numerical modeling activities. Section 3.1 contains an explanation of the regional system geometry.

The surface water system of the region consists of topographical basins containing ephemeral stream channels. Several ephemeral stream channels, such as Forty-Mile Wash and the Amargosa River, flow following significant precipitation events, but few ephemeral stream-flow data are available in the area (DOE, 1988). No perennial streams or other sources of surface water are found in the region.

In general, the flow regime at the repository site consists of infiltration and percolation through a thick unsaturated zone, composed of fractured tuff. Upon reaching the water table hundreds of meters below the ground surface, water travels through carbonate, volcanic tuff, and alluvial aquifers according to the regional and local ground-water flow paths.

A regional ground-water flow system encompasses one or more topographic basins (see Figure 6.2). Interbasin flow is common and important with respect to the total volume of water transported within the boundary of the system. The regional ground-water flow system in the repository area is composed of three alluvial basins; Ash Meadows, Oasis Valley, and Alkali Flat-Furnace Creek Ranch (see Figure 6.3).

The regional ground-water flow system has been delineated using potentiometric data (Walker and Eakin, 1963; Nichols and Akers, 1985; Waddell and others, 1984; Waddell, 1984; Rice, 1984; Czarnecki and Waddell, 1984; Robison and others, 1988) and hydrochemical studies (Schoff and Moore, 1964; Maxey and Mifflin, 1966; Classen and White, 1979; Grove and others, 1969; Clebsch, 1961; Winograd and Friedman, 1972). The regional system boundary primarily follows the outer ground-water basin boundaries (see Figure 6.3). In general, the main recharge zones are north and west of the repository site, in the highlands. A constant flux boundary was designated by Waddell (1982) on the eastern side of the region to account for inflow from the adjacent valley to the east (Pahranagat Valley). All other external boundaries of the region have been treated as no flow boundaries based on topographic and ground-water divides (Waddell, 1982). Discharge occurs in springs to the south and southwest (Figure 6.3). The 


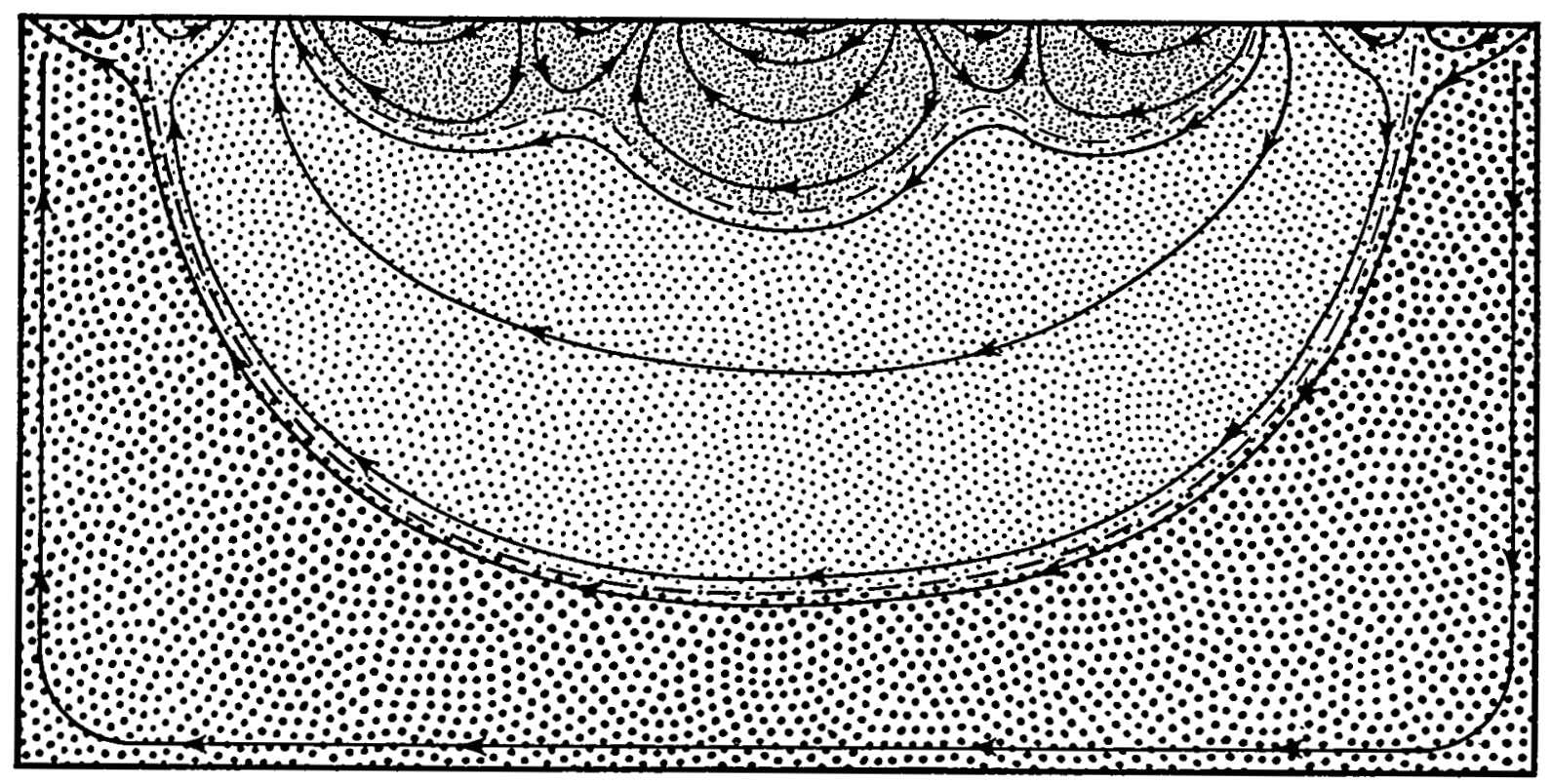

REGION OF LOCAL SYSTEM OF GROUNDWATER FLOW

REGION OF INTERMEDIATE SYSTEM OF GROUNDWATER FLOW

O0. REGION OF REGIONAL SYSTEM OF GROUNDWATER FLOW

Figure 6.2. Local, Intermediate and Regional Systems of Ground-Water Flow (from Toth, 1963). Permission to use this copyrighted material was granted by Gordon and Breach Science Publishers, Inc. 

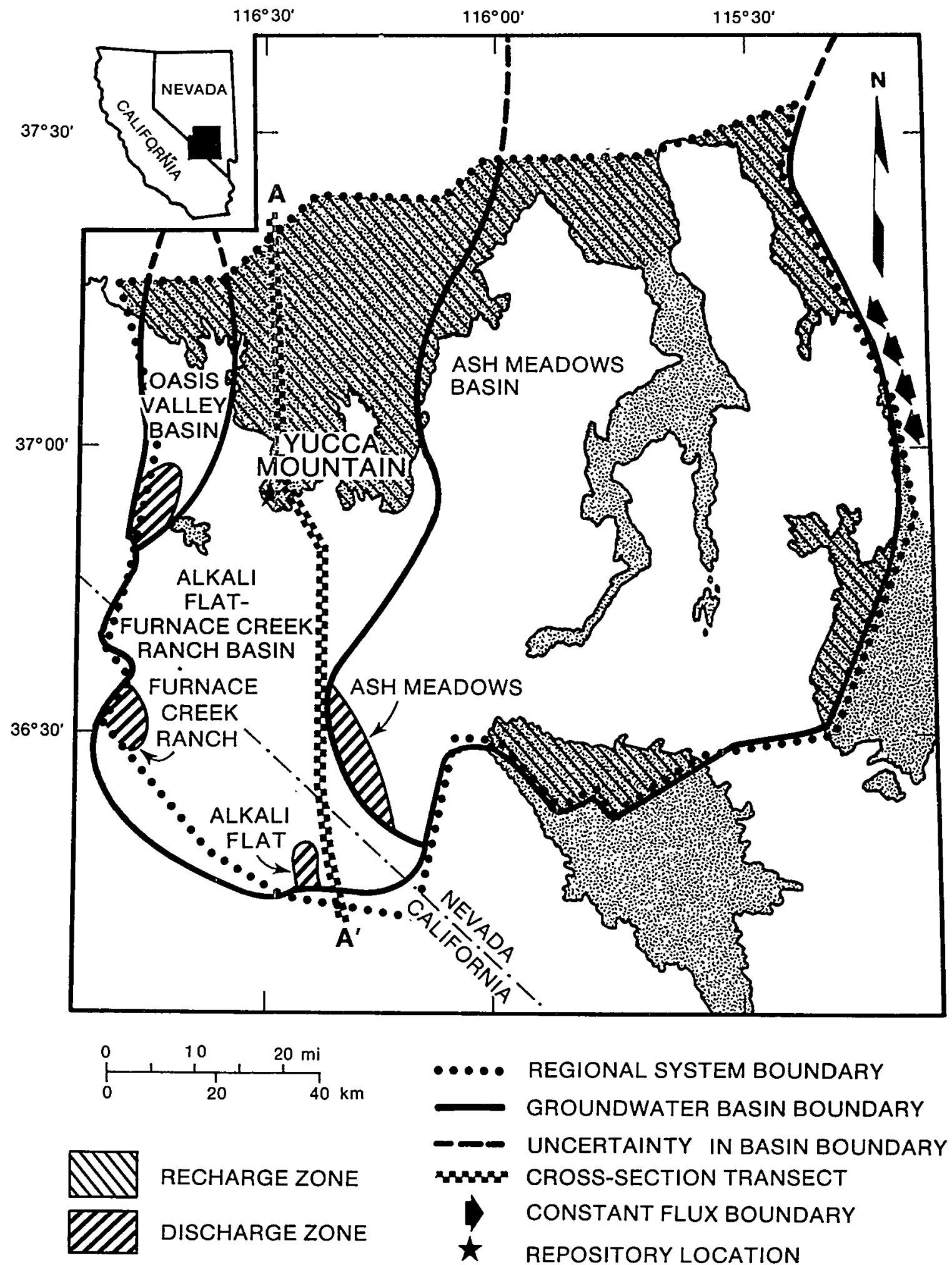

Figure 6.3. Approximate Ground-Water Basin Locations, Recharge and Discharge Zones, and Boundary Conditions for the Regional Ground-Water Flow System (modified from Waddell, 1982; Winograd and Thordarson, 1975; Waddell and others, 1984) 
discharge areas in Ash Meadows and Alkali Flat are caused by underlying rocks of low hydraulic conductivity forcing water levels high enough to intersect the ground surface (Waddell, 1982).

The regional ground-water flow system is controlled by the lower carbonate aquifer where fracture flow dominates. Tritium tracer tests indicate that in localized regions up to hundreds of meters, the fractures are hydraulically connected in the lower carbonates (Claassen and Cordes, 1975). The regional aquifer system is confined in the deepest portions of valleys and unconfined beneath mountain ridges. The regional ground-water flow paths follow a general southwest direction (see Figure 6.4).

Juxtaposition by faulting or folding of thick clastic strata against carbonate rocks results in barriers to ground-water flow (Winograd and Thordarson, 1968). Interbasin groundwater flow tends to occur where the lower carbonate rocks are present (Rice, 1984) and ground-water flow is significant between subbasins in the region (Claassen and White, 1979; Eakin, 1966; Maxey and Mifflin, 1966).

The local system of the repository site is located within the Alkali Flat-Furnace Creek Ranch ground-water basin (see Figure 6.3). The northern part of the basin is underlain by volcanic tuff, while the southern end of the basin is underlain by primarily alluvium (see Figure 6.5). The depth to the water table gradually decreases from north to south until the depth to the water table is only a few meters below the land surface in Death Valley. Springs discharge up to several hundred meters above the floor of Death Valley from the carbonate rocks or from alluvium which overlie the carbonate rocks (Waddell, 1982; Czarnecki and Waddell, 1984; Czarnecki, 1985). The origin of water discharged from the Furnace Creek Ranch area is not certain, but the water chemistry indicates that it comes from the Amargosa Desert (Winograd and Thordarson, 1975). Waddell (1982) hypothesizes that the discharging water is a mixture from all three hydrologic basins. Water discharges from the basin through evapotranspiration at Alkali Flat (Walker and Eakin, 1963). Ground water beneath the repository site flows toward the Ash Meadow Spring discharge area in the Amargosa Desert (Schoff and Moore, 1964).

\subsection{Local Flow System}

Local ground-water flow systems are characterized by the majority of the water discharges within the associated hydrologic basin (see Figure 6.2). Local flow systems in this region occur in numerous intermontane valleys and basins and in the valley-fill aquifers composed of alluvial material. Boundary conditions for the local ground-water flow system are controlled by the regional ground-water flow system. 

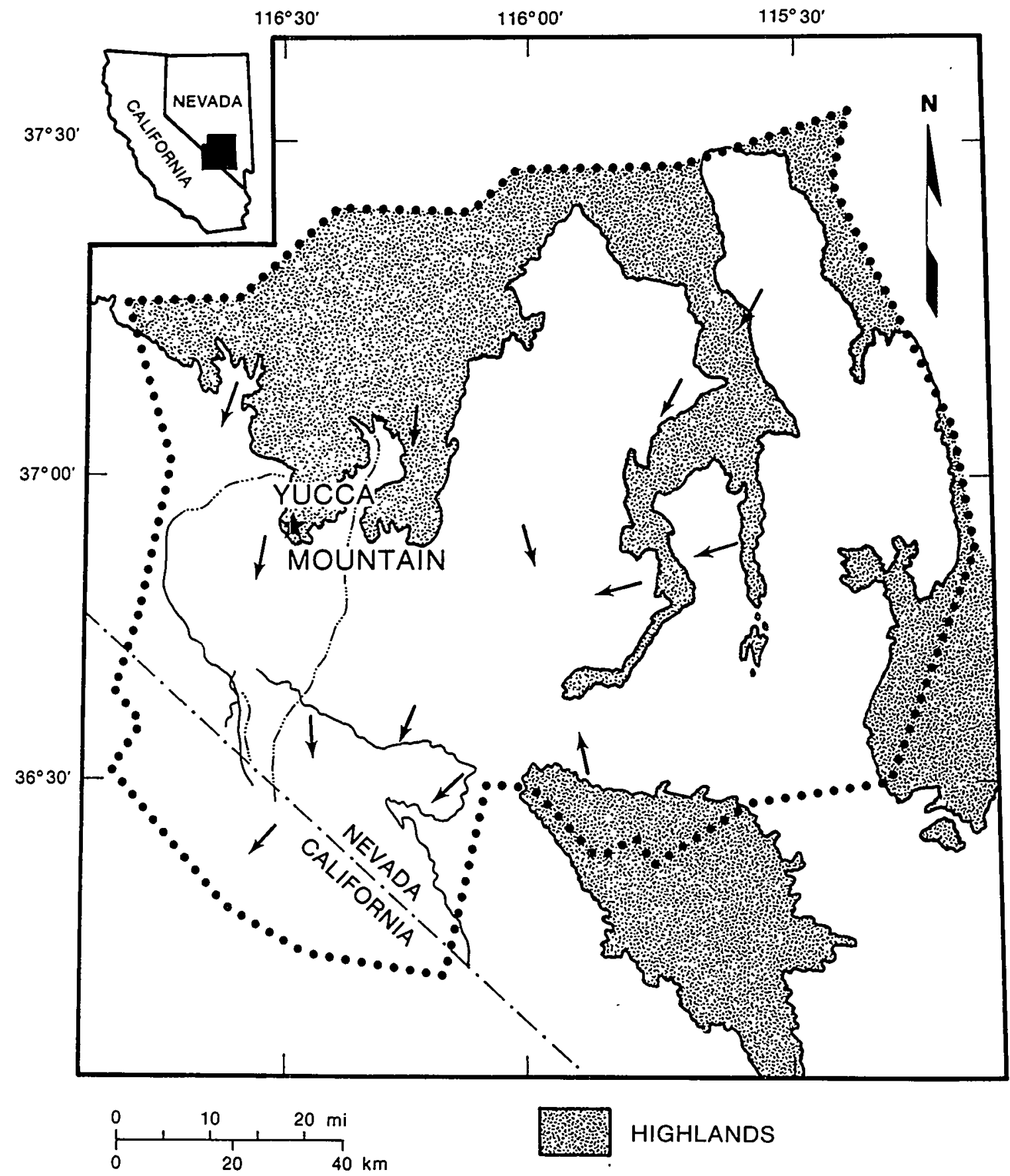

HIGHLANDS

$\bullet \cdots$ REGIONAL SYSTEM BOUNDARY

$\leftarrow$ APPROXIMATE GROUNDWATER FLOW DIRECTION

^ REPOSitory location

Figure 6.4. General Direction of Ground-Water Flow in the Region (modified from Waddell, 1982; Czarnecki and Waddell, 1984) 


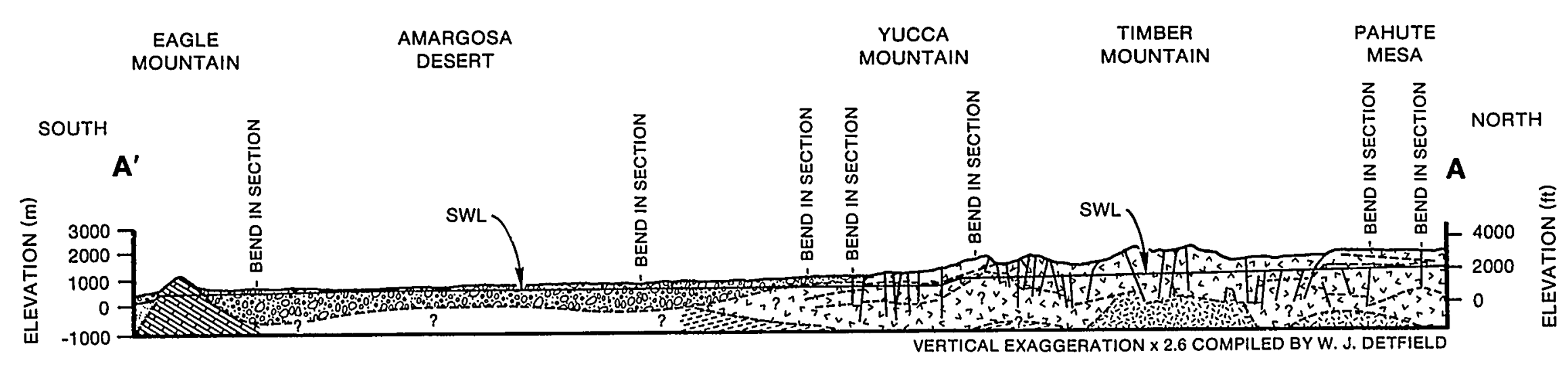

$\stackrel{9}{9}$

TRANSMISSIVE ROCKS

(only part of zone shaded)

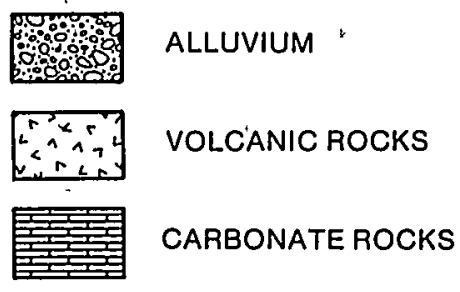

AQUITARDS AND BARRIERS

(entire zone shaded)

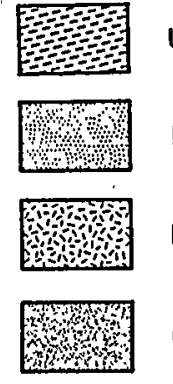

UPPER CLASTIC AQUITARD

LOWER CLASTIC AQUITARD

INTRUSIVE ROCKS

OTHER HYDROLOGIC BARRIERS
SWL = STATIC WATER LEVEL

Figure 6.5. North-South Hydrogeologic Cross-Section of the Alkali Flat-Furnace Creek Ranch Ground-Water Flow Basin (from Waddell, 1982) 
The hydrogeologic units of the local system include saturated volcanic rocks in the western portion. To the east volcanics overlying carbonates and the upper clastic aquitard are found (see Figure 6.6).

The local ground-water flow system at the repository site is characterized by a steep hydraulic gradient to the north, and a fairly flat gradient to the south (see Figure 6.7). The steep gradient is probably indicative of a low permeability zone located in these areas below the water table. The cause of the low permeability zone has not been determined. Sinton (1989) suggests several causes of the low permeability zone: a fault or fault zone; an intrusive dike; a change in lithologic facies or pinch-out; a change in fracture orientation, density, aperture, or fracture fillings; or some combination of the above. The flat gradient is due to highly permeable tuff units located below the water table.

There is evidence that perhaps both upward and downward flow occurs in the areas with shallow hydraulic gradients (Blankennagel and Weir, 1973). At this time, the field data is inconclusive as to the extent and cause of the vertical movement. However, Czarnecki (1989) has proposed that a multi-aquifer system exists in the repository area in which flow occurs through two different aquifers at nearly right angles. 


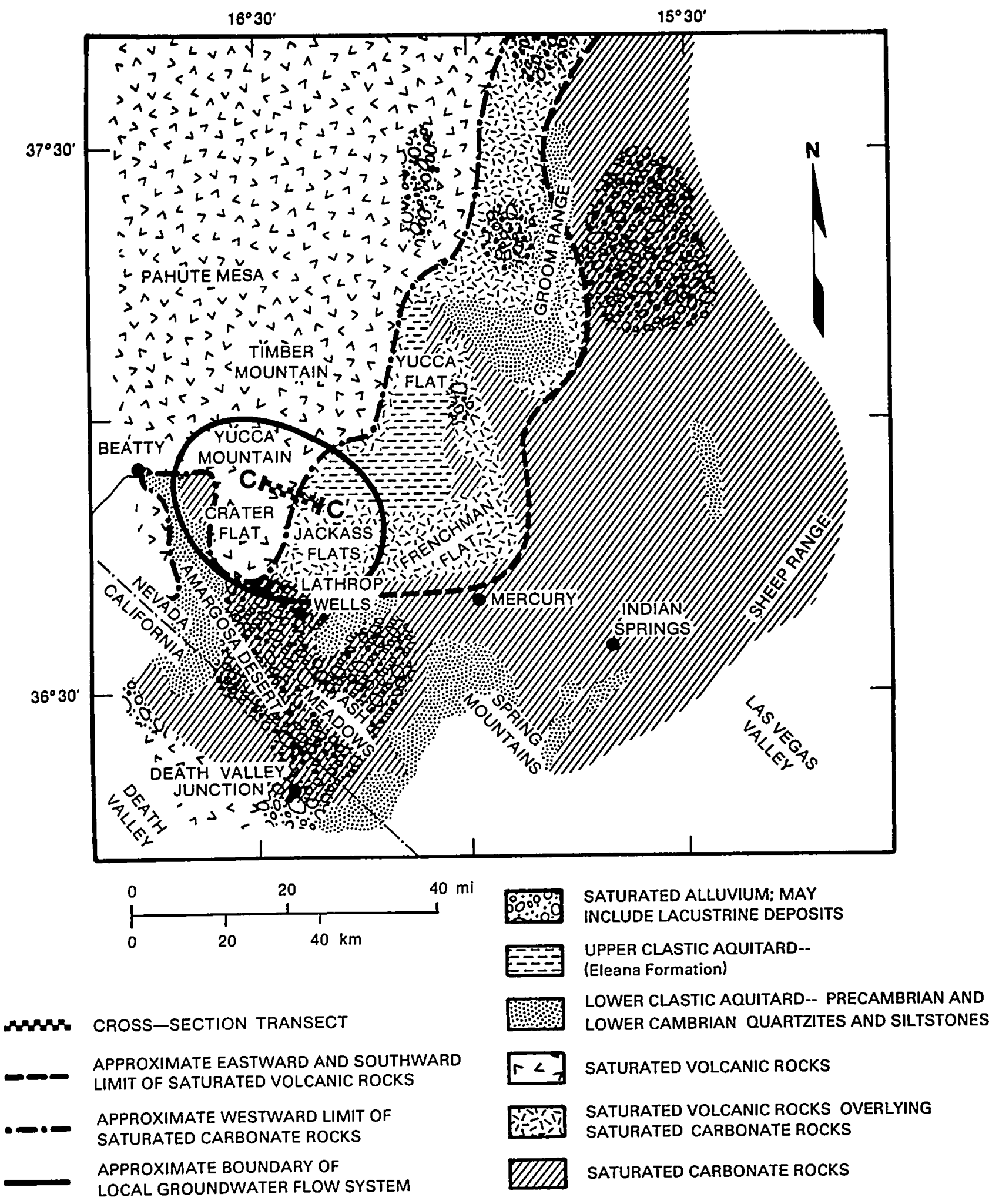

Figure 6.6. General Geographic Distributions of Hydrostratigraphic Units (from Waddell and others, 1984) 

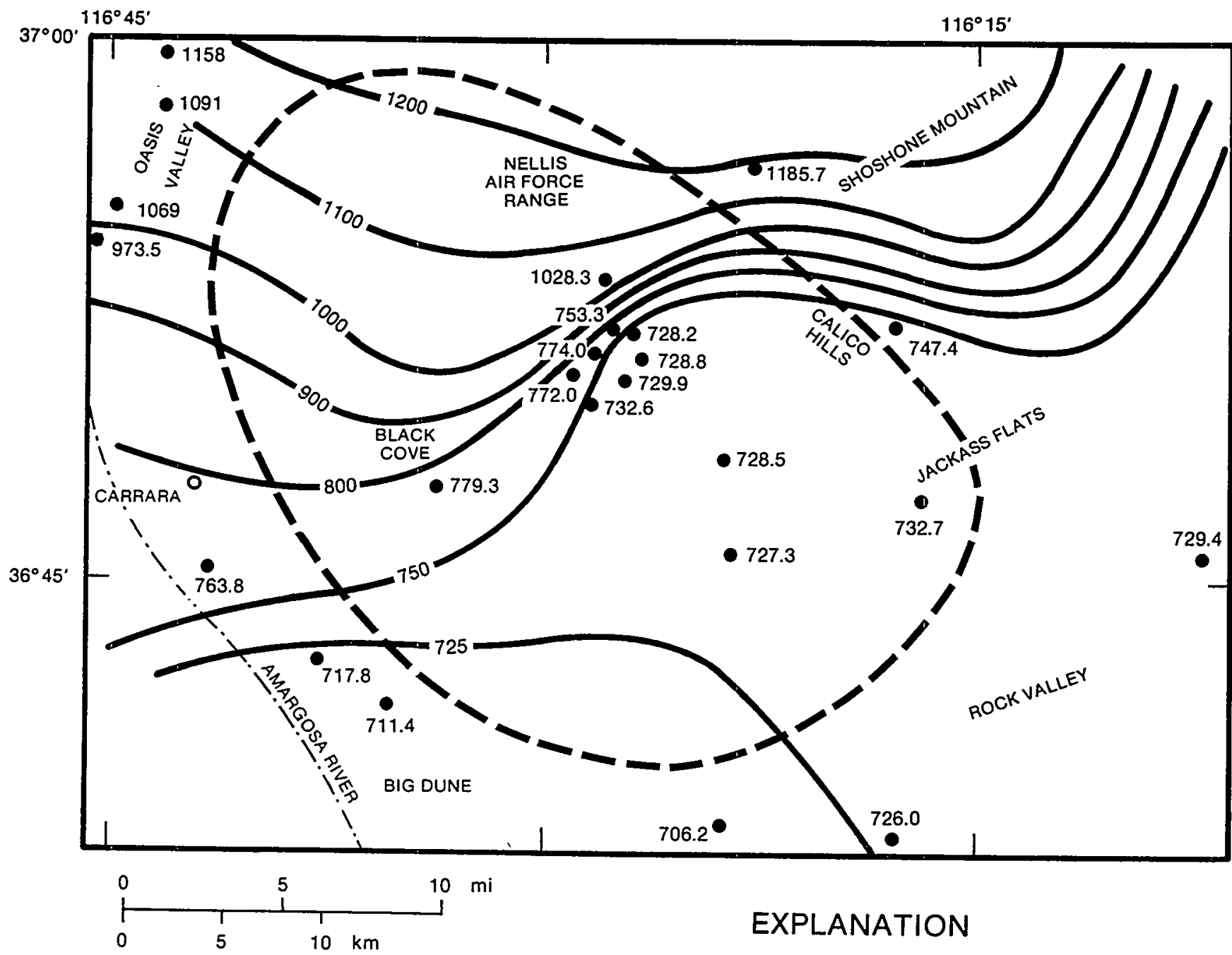

\section{EXPLANATION}

-900- POTENTIOMETRIC CONTOURSHOWS ALTITUDE OF POTENTIOMETRIC SURFACE, 19--. CONTOUR INTERVAL, IN METERS, IS VARIABLE. DATUM IS SEA LEVEL.

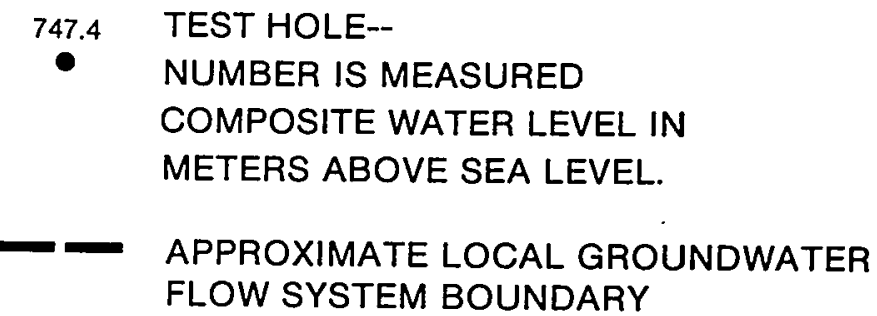

Figure 6.7. Preliminary Potentiometric Surface of the Local Ground-Water Flow System (from Waddell and others, 1984) 


\subsection{TRANSPORT SYSTEM}

Transport "of radionuclides from the repository, through the unsaturated and saturated zones, to the accessible environment will occur through a complex, spatially varying sysțem. For a conceptual model, these variations in the vertical direction are $\therefore$ represented as a sèries of discrete layers. The location and thickness of each of these layers, for the purposes of transport modeling, will be a function of the nature of the dominant transport mechanisms considered. In the following section, a possible stratigraphic"representation of the repository site based on radionuclide transport processes is proposed. For this discussion, transport is divided into physical (convection, diffusion, dispersion) and chemical (sorption) components.

As will be discussed below, the layering (i.e., number of units, unit thickness, location of units) based on physical transport mechanisms is likely to be different than that based on chemical transport mechanisms. Similarly, stratigraphy derived from hydrogeologic considerations can differ from that based on solute transport. The differences in the stratigraphies arise primarily because the processes considered can depend on different types of properties. For example, when defining transport layers, both physical and chemical properties of the rock can play a role in the conceptualization, whereas, defining hydrologic layers really requires that only the physical properties of the rock be considered. Note that no attempt is made here to define a transport stratigraphy for each, specific radionuclide, but rather a general layering for all radionuclide species.

In addition to the transport-based stratigraphy, the effect of repository site hydrochemistry on transport processes will be briefly discussed in this section.

\subsection{Physical Transport Stratigraphy}

Similar to ground-water flow, the convective, dispersive, and diffusive components of radionuclide transport will be controlled directly or indirectly by the fundamental physical properties of the geologic medium. For that matter, the convective and dispersive components of transport are functions of specific flow properties (i.e., groundwater velocity). As a result, the stratigraphic layering based on convection, dispersion, and diffusion must be the same as the hydrogeologic stratigraphy discussed in Section 3.1. Sections 5.1 and 5.2 have previously presented a detailed discussion of the transport processes convection, dispersion, and diffusion in porous, fractured, unsaturated, and saturated media. 
Convective transport of a species results from the bulk flow of a fluid in which the species is contained. Thus, layering derived for this mechanism would be identical to the hydrogeologic layering. Because the mechanical dispersion component of hydrodynamic 'dispersion is caused by the flow of ground water through variable flow channels (see Section 5.1), it is assumed that dispersion would similarly be correlated to the hydrogeologic layering. Because convective and dispersive transport are directly dependent on flow, the above should be true for both fracture and matrix convective/dispersive transport.

As opposed to convection and dispersion, diffusion can occur without ground-water flowing. Nevertheless, because the effective diffusion is a function of the same underlying physical properties of the geologic medium which control ground-water flow (e.g., pore structure, pore properties), the stratigraphy for transport by diffusion would likely be the same as the hydrogeologic strata. This is because ground-water flow, convection, dispersion, and diffusion, in general, can be described as functions of macroscopic properties, such as porosity and tortuosity.

Diffusion between fractures and matrix, as a transport retardation mechanism, could also potentially influence transport stratigraphy. Matrix diffusion, as a function of fracture flow velocities and the physical properties of both fracture and matrix, would not in itself be basis for a stratigraphy different than the hydrogeologic stratigraphy. However, as a function of the sorptive properties of the geologic medium and radionuclide species, matrix diffusion may impact the need for a different stratigraphy. These geochemical considerations are discussed below in Section 7.2.

The relative contribution to stratigraphy definition by convection, dispersion, and diffusion will of course depend on the relative impact each has on overall solute transport. Using only the qualitative arguments given above, for this conceptual model, we will assume that the stratigraphic representation based on the physical radionuclide transport mechanisms is the same as the hydrogeologic stratigraphy (Section 3.1), for both the saturated and unsaturated zones. Consequently, no new layering will be defined based on the physical transport processes.

\subsection{Geochemical Transport Stratigraphy}

Geochemical and mineralogical properties of the volcanic rocks affecting radionuclide transport (specifically sorption capacity) include the degree of vitrification and the presence of secondary zeolitic and clay minerals. In the discussion that follows, the geochemical and mineralogical variations at the repository site that affect chemical 
components of transport (i.e., sorption) will be reviewed. Subsequently, a geochemicaltransport stratigraphy is proposed, based on variations in these sorptive properties. For a detailed discussion of the process of radionuclide sorption in porous geologic media, see Section 5.3.

During cooling, ash-flow tuffs at the repository site have gone through a series of crystallization stages. It is during the late stages of this crystallization that secondary minerals, such as zeolites and clays, are formed. The secondary mineralization occurs as the initial tuff components are altered during cooling. In the devitrified zones, smectites are formed by alteration of glass, feldspar, and mafic silicates. In the vitric, non-welded tuffs, many secondary zeolites are formed during alteration of glass phases. In addition to cooling-induced alterations, availability of water can induce further alteration in the formation of hydrous minerals (e.g., transition from clinoptilolite to analcime to albite; Bish and others, 1981).

Specifically, the most sorptive minerals at the repository site are the open-channel zeolites (clinoptilolite, heulandite, and mordenite) (Vaniman and others, 1984; Daniels and others, 1982). Less sorptive are those zeolites possessing a less open structure (e.g., analcime). Of the clay minerals at the site, the smectites are the most sorptive (Bish and others, 1984b). Although elemental compositions of clinoptilolite, heulandite, mordenite, and smectite are variable (Broxton and others, 1986; Caporuscio and others, 1982), and sorption is variable with composition (Rundberg and others, 1985), no attempt is made here to correlate sorptive properties with specific zeolite or clay elemental composition.

A number of studies have shown that the sorptive behavior of certain radionuclide groups is significantly affected by the presence of zeolites and clays, while other radionuclide groups exhibit poor correlation between mineralogy and sorption. Sorption ratios for the simple cations, cesium, strontium, and barium (used as an analogue of radium; Daniels and others, 1982); have been found to be as much as two orders of magnitude higher in zeolitized tuffs than in devitrified tuffs not containing zeolites (Johnstone and Wolfsberg, 1980; Vine and others, 1981; Wollenberg and others, 1983; Thomas, 1987). The increase in sorption is greatest when clinoptilolite and mordenite are considered together. An increase in sorption of cesium, strontium, and barium has also been observed in samples with high smectite content (Daniels and others, 1982).

Sorption ratios for cerium and europium are generally very high in zeolitized and clay samples (greater than $1000 \mathrm{ml} / \mathrm{g}$ and often greater than $10^{4} \mathrm{ml} / \mathrm{g}$ ) and lower on devitrified and glass samples (100's of milliliters per gram), but do not follow mineralogy 
as closely as the simple cations (Vine and others, 1981; Wollenberg and others, 1983, Thomas, 1987).

Sorption ratios for technetium, selenium, uranium, and neptunium were relatively very low across all mineralogic variations (generally less than $20 \mathrm{ml} / \mathrm{g}$, for all samples; Thomas, 1987) and generally showed little correlation with mineralogy. Technetium sorption ratios, under atmospheric and reducing conditions, were extremely low for all samples (less than $1 \mathrm{ml} / \mathrm{g}$; Ogard and Vaniman, 1985; Thomas, 1987).

Although the highest sorption ratios for plutonium were found in tuffs containing zeolites and/or clays (Thomas, 1987), ranges of values were so broad that defining a quantitative correlation of sorption ratios with mineralogy would be difficult.

No correlation with mineralogy is evident for thorium, tin, or americium (Rundberg and others, 1985; Thomas, 1987), although lanthanide and americium sorption appear to be highest on clay containing tuffs (Johnstone and Wolfsberg, 1980).

Variation in mineralogical alteration and abundance occurs both laterally and vertically at the repository site. In order to indicate lateral location of variations, an exploration block at Yucca Mountain (shown in Figure 7.1) has been designated. This is the sole purpose of the exploration block in the report. It does not necessarily coincide with the boundaries of the local or regional ground-water flow systems nor the boundary of the controlled area. The exploration block boundary encompasses the exploratory boreholes from which most of the following geochemical and mineralogical information have been gathered.

Smectite, generally found as an ubiquitous alteration, is usually in low abundance (i.e., less than 10\%; Bish and others, 1981; Bish, 1981; Bish and others, 1982); however, some zones of high abundance (as high as 50\%) are evident in the northern exploration block (Daniels and others, 1982; Bish and Vaniman, 1985). Smectite abundance has also been found to be lower in some of the zeolitized intervals than in non-zeolitized intervals (Caporuscio and others, 1982). Ion concentrations and $\mathrm{pH}$ are too low during the hydrous alteration of glass for zeolite formation unless the glass has already been altered to smectite (Hay and Sheppard, 1977). The inverse relationship therefore suggests that zeolite formation replaces smectite formation after the glass has been altered. Above the water table, primarily in the northern exploration block, zeolites are generally stratified, with clinoptilolite and mordenite most abundant (Bish and others, 1981). At greater depths, alteration of clinoptilolite to analcime, and then to albite occurs. Below the water table, within the tuffaceous aquifer, densely welded non-zeolitized tuffs and 


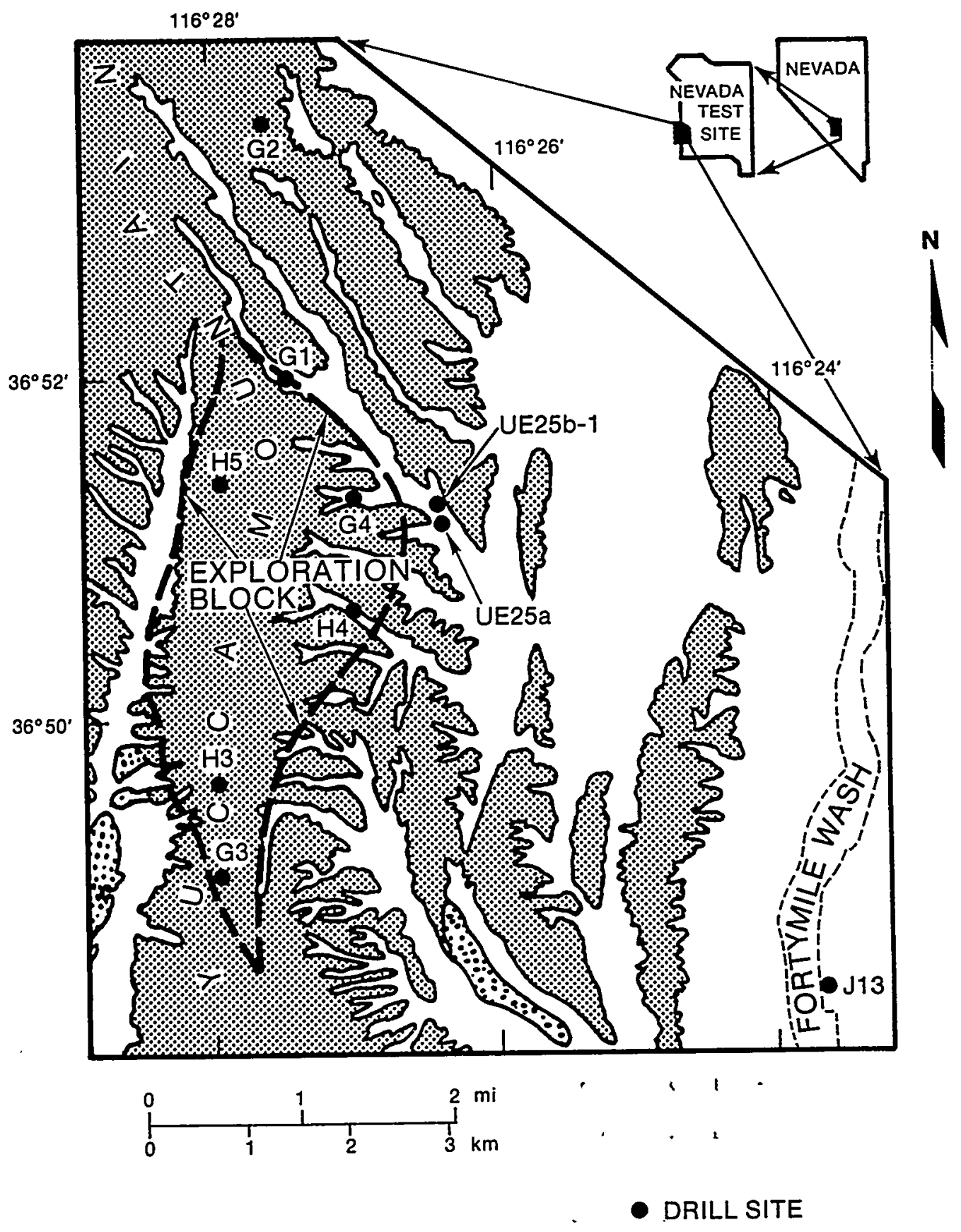

Figure 7.1. Location of Exploration Block and Exploratory Boreholes for Stratigraphy Presented in Table 7.1 (modified from Carlos, 1985) 
less densely welded zeolitized tuffs occur. Specific sorptive stratigraphy will be discussed below.

Investigations by Vaniman and others (1984) affirm that mineralogical alteration to zeolites and clays is much less in the southern part of the exploration block at Yucca Mountain than in the northern part. Secondary minerals were both less abundant and of lower grade (lower temperature of formation) than in samples from the northern block. In the southern block, both clinoptilolite and analcime were found at greater depths than in the northern block while mordenite was evident only as an infrequent fracture coating. Zones of zeolite abundance were difficult to define in that zeolite abundance was highly variable and poorly correlated with depth. Average clay abundance in the upper part (above $1000 \mathrm{~m}$ ) of the southern exploration block was found to be less than $1 \%$ with very limited smectite-to-illite transition, whereas in the northern block, abundances of $10 \%$ are common. At greater depths (below $1000 \mathrm{~m}$ ), zones of approximately $10 \%$ clay abundance become more common, but transition to illite was still less than $20 \%$ complete even at $1500 \mathrm{~m}$ depth.

Many fractures throughout the unsaturated zone are coated or lined with zeolites (mordenite and heulandite) and some smectite (Carlos, 1985). Zeolitic coatings are frequently discontinuous and do not usually seal the fractures. Smectites are often scattered across fracture faces. Zeolite coated fracture locations are not restricted to those zones adjacent to the zeolitized matrix intervals, but extend into the weldeddevitrified and glassy tuffs (Carlos, 1985).

Sorptive intervals (i.e., geochemical stratigraphic units) at the repository site, based primarily on zeolite abundance in matrix rock, have been identified (Bish and Vaniman, 1985) and defined by a number of investigators (Wolfsberg and others, 1983; Bish and others, 1984a; Bryant and Vaniman, 1984; Vaniman and others, 1984; Caporuscio and others, 1985). The number, location, and size of intervals defined by each investigation are, for the most part, consistent with one another and do not coincide with formal geologic or hydrogeologic stratigraphic definitions. Generally, most zeolite intervals are located roughly where once vitric, non-welded tuff zones existed, at the margins of devitrified tuffs (Vaniman and others, 1984). This is the result of many zeolites being alterations of vitrified tuffs. Also, transition from clinoptilolite to analcime to albite with depth has been observed (Bish and others, 1981).

Drawing from the above investigations, specific matrix, sorption-based intervals, which begin at the host rock and extend vertically downward through the saturated zone, have been defined. Defining the stratigraphy as beginning at the host rock (i.e., proposed 
repository horizon) assumes that transport occurs only downward from the repository; however, by observing lateral variations in all directions within each interval, the transport stratigraphy is not limited to one or two dimensions, and therefore does not preclude lateral movement of solutes. The units are as follows:

Host Rock - Greater than $98 \%$ of the host rock mineralogical content is made up of quartz, cristobalite, tridymite, and alkali feldspars (Bryant and Vaniman, 1984), this is considered a low-sorption interval. Sparse phenocrysts (less than $2 \%$ ) and fracture fillings also exist. Many of the fillings or linings in the older fractures are composed of silica and feldspars. The low abundance of zeolites and smectites which do occur in this unit are found primarily as relatively sparse, often discontinuous, fracture linings in more recently formed fractures (Carlos, 1985).

Zeolite Interval I - This thin interval (between 1 and $5 \mathrm{~m}$ thick) contains primarily clinoptilolite and heulandite, and some smectite. This interval exists above the water table at all boreholes sampled and is unique because it does occur within densely welded tuff of a compound cooling unit. Zeolite abundances are highest toward the north of the exploration block (as high as 15\%) and decrease to trace amounts to the south and at the crest of Yucca Mountain where little alteration has occurred.

Vitrophyre/Vitric Zone - Although this unit is composed of upper (vitrophyre) and lower (vitric) portions, it considered a single interval because of the relatively low-sorption properties throughout. The upper portion of the unit is vitrophyre primarily composed of glass ( 40 to $90 \%$ ) with thickness ranging from 10 to $30 \mathrm{~m}$. The upper portion is thickest to the south of the exploration block and along the crest of Yucca Mountain, where relatively little alteration has taken place, and is thinner to the north and east, as more alteration has occurred in these areas. Trace amounts of smectite line fractures throughout the vitrophyre, whereas zeolites can be found lining fractures at the top of the vitrophyre. The lower portion of the interval is composed of partially welded and non-welded vitric tuffs, ranging in thickness from tens of meters toward the south of the exploration block to negligible thickness in the north and east. Alteration to clay is rare and zeolites are found in highly variable abundance ( 0 to $80 \%)$ at the bottom of the interval.

Zeolite Interval II - This high-sorption interval is highly variable in mineralogical composition and thickness across the exploration block. In the zeolitized portions of the interval, clinoptilolite predominates ( 50 to $70 \%$ ), with variable occurrences of mordenite $(0$ to $20 \%)$. The occurrence of zeolites in this interval range from very thick (as high as $140 \mathrm{~m}$ ) toward the east and north of the exploration block to nonexistent in vitric 
nonzeolitized zones toward the south along the crest of Yucca Mountain. Smectite abundance is generally low, but can reach as high as $15 \%$ in thin, interbedded layers within the interval.

Central Prow Pass Member, Crater Flat Tuff - Ranging in thickness from 45 to $90 \mathrm{~m}$, this relatively low-sorption interval is composed of moderately to partially welded tuffs containing mostly alkali feldspars with some silica minerals, and silicate and oxide phenocrysts. Abundances of smectite as high as $3 \%$ can be found in this interval.

Zeolite Interval III - This high-sorption interval occurs within poorly welded and bedded tuffs. The interval is continuous across the entire exploration block, although it does vary in thickness, being thickest along the eastern margin of the exploration block (approximately 80 to $100 \mathrm{~m}$ ) and thinnest along the crest of Yucca Mountain (approximately 30 to $60 \mathrm{~m}$ ). As it down dips to the east, much of the interval lies below the static water level. Clinoptilolite predominates in the eastern part of the interval, with some mordenite occurring in lesser amounts. Only clinoptilolite exists along the Yucca Mountain crest. Alteration to smectite is scarce.

Central Bullfrog Member, Crater Flat Tuff - This relatively low-sorption unit is located in partially to densely welded tuffs, ranging in thickness from 60 to $170 \mathrm{~m}$. Slight amounts of smectite (less than 1\%) exist within the interval composed primarily of alkali feldspars with quartz, cristobalite, and silicate and oxide phenocrysts.

Zeolite Interval IV - This high-sorption interval, lying above the static water level only toward the southern part of the exploration block, is continuous across the exploration block and is relatively constant in thickness (range from 27 to $44 \mathrm{~m}$ ). Zeolite composition varies across the exploration block, ranging from being predominantly mordenite to being clinoptilolite only. Smectite abundance may reach as high as $20 \%$ in some areas of this interval.

Older Tuffs - Higher degrees of alteration occur with depth within this unit, which is continuous across the exploration block and lies completely below the static water level. Clinoptilolite and mordenite are altered to analcime between 400 and $500 \mathrm{~m}$ below the static water level and then to albite with further increase in depth.

Deeper Petrologic Zones - The carbonate rocks of the saturated zone vary from dolomite to limestone, having poorly defined sorption properties. The upper clastic rock unit (Eleana formation), an argillite, does contain more clay minerals than overlying carbonates or tuffs. The lower clastic units are composed of siltstone, shale and 
sandstone. However, although they are well-defined mineralogically, lack of sorption/retardation data for these deeper saturated-zone formations precludes further quantitative definition of discrete sorption intervals within this unit. Conservatively, this deepest geochemical unit is defined as a non-sorptive unit throughout, although local abundances of clay and zeolites exist.

The depth and thickness of the units within this stratigraphy, including their lateral variations based on borehole data, are summarized in Table 7.1. A plan view indicating location of the boreholes from which the data were gathered is shown in Figure 7.1. Note that because this stratigraphy is based primarily on zeolite abundance, it is but one possible geochemical transport stratigraphy. Considering additional mineralogy and/or chemical processes could result in alternative stratigraphies.

For a detailed summary of sorption data as a function of lithology and stratigraphic position, see Tien and others (1985) and Thomas (1987). For a detailed stratigraphic summary of the mineralogy within the tuffaceous rocks at the repository site, see Bish and Vaniman (1985), and within the deeper petrologic zones, see Winograd and Thordarson (1975).

\subsection{Stratigraphic Comparison}

A qualitative, one-dimensional, stratigraphic comparison of the depth and thickness of the geochemical transport (sorptive) units with the geologic and hydrogeologic units is given in Figure 7.2 to indicate graphically some obvious differences in each. Between the repository horizon and the upper carbonate aquifer, the geochemical transport layers are highly variable in thickness and are much finer relative to the hydrogeologic or geologic layers, whereas, below the upper carbonate, only a single geochemical transport layer is defined. The physical transport stratigraphy would be the same as the hydrogeologic stratigraphy.

For the purposes of transport modeling, a composite layering system which includes both the hydrogeologic and geochemical transport stratigraphies would be a more complete representation. In doing so, both physical and chemical transport components would be incorporated, at their appropriate locations. The composite layering would be an overlay of the geochemical stratigraphy over the hydrogeologic stratigraphy (or vice versa), resulting in a stratigraphy with thinner and greater number of units than found in either of the contributing stratigraphies. A hypothetical example is given in Figure 7.3. Both physical and chemical properties would change simultaneously at the interface between two layers only in the case where the hydrogeologic and geochemical transport layer 
TABLE 7.1

DEPTH AND THICKNESS OF SORPTION-BASED STRATIGRAPHY BENEATH EXPLORATION BLOCK AT YUCCA MOUNTAIN

\begin{tabular}{|c|c|c|c|c|c|c|c|}
\hline Unit & $\begin{array}{l}\text { USW G-1 } \\
\text { SWL=577 m }\end{array}$ & $\begin{array}{l}\text { UE-25a\#1 } \\
\text { UE-2Sb\#1 } \\
\text { SWL=471 m }\end{array}$ & $\begin{array}{l}\text { USW G-4 } \\
\text { SWL =541 m }\end{array}$ & $\begin{array}{l}\text { USW H-4 } \\
\text { SWL }=519 \mathrm{~m}\end{array}$ & $\begin{array}{l}\text { USW H-5 } \\
\text { SWL =704 m }\end{array}$ & $\begin{array}{l}\text { USW H-3 } \\
\text { SWL }=754 \mathrm{~m}\end{array}$ & $\begin{array}{l}\text { USW GU-3 } \\
\text { USW G.3 } \\
\text { SWL }=754 \mathrm{~m}\end{array}$ \\
\hline 1) Host Rock & Base: $392 \mathrm{~m}$ & Base: $385 \mathrm{~m}$ & Base: $396 \mathrm{~m}$ & Base: $357 \mathrm{~m}$ & Base: $485 \mathrm{~m}$ & Base: $367 \mathrm{~m}$ & Base: $360 \mathrm{~m}$ \\
\hline $\begin{array}{l}\text { 2) Zeolite } \\
\text { Interval I }\end{array}$ & $\begin{array}{l}z=392-393 \mathrm{~m} \\
(1 \mathrm{~m} \text { thick) }\end{array}$ & $\begin{array}{l}z=385-388 m \\
\text { ( } 3 \mathrm{~m} \text { thick) }\end{array}$ & $\begin{array}{l}z=396-401 \mathrm{~m} \\
(5 \mathrm{~m} \text { thick) }\end{array}$ & $\begin{array}{l}z=357-361 \mathrm{~m} \\
(4 \mathrm{~m} \text { thick })\end{array}$ & $\begin{array}{l}z=485 \mathrm{~m} \\
\text { (thickness } \\
\text { unknown) }\end{array}$ & $\begin{array}{l}z=367-371 \mathrm{~m} \\
(4 \mathrm{~m} \text { thick })\end{array}$ & $\begin{array}{l}z=360-364 \mathrm{~m} \\
(4 \mathrm{~m} \text { thick) }\end{array}$ \\
\hline $\begin{array}{l}\text { 3) Vitrophyre/ } \\
\text { Vitric Zone }\end{array}$ & $\begin{array}{l}z=393-425 \mathrm{~m} \\
(33 \mathrm{~m} \text { thick) }\end{array}$ & $\begin{array}{l}z=388-404 \mathrm{~m} \\
(16 \mathrm{~m} \text { thick })\end{array}$ & $\begin{array}{l}z=401-420 \mathrm{~m} \\
(19 \mathrm{~m} \text { thick) }\end{array}$ & $\begin{array}{l}z=361-400 \mathrm{~m} \\
(39 \mathrm{~m} \text { thick) }\end{array}$ & $\begin{array}{l}z=485-584 \mathrm{~m} \\
\text { (99 m thick) }\end{array}$ & $\begin{array}{l}z=371-505 \mathrm{~m} \\
(134 \mathrm{~m} \text { thick })\end{array}$ & $\begin{array}{l}z=364-495 \mathrm{~m} \\
(131 \mathrm{~m} \text { thick) }\end{array}$ \\
\hline $\begin{array}{l}\text { 4) Zeolite } \\
\text { Interval II }\end{array}$ & $\begin{array}{l}z=425-565 \mathrm{~m} \\
(140 \mathrm{~m} \text { thick) }\end{array}$ & $\begin{array}{c}-\mathrm{z}=404-556 \mathrm{~m}- \\
(152 \mathrm{~m} \text { thick })\end{array}$ & $\begin{array}{c}-\mathrm{z}=420-545 \mathrm{~m}- \\
(125 \mathrm{~m} \text { thick })\end{array}$ & $\begin{array}{l}z=400-504 \mathrm{~m} \\
(104 \mathrm{~m} \text { thick) }\end{array}$ & $\begin{array}{l}z=584-594 \mathrm{~m} \\
(10 \mathrm{~m} \text { thick })\end{array}$ & $\begin{array}{l}\text { Vitric } \\
\text { (nonzeolitized) }\end{array}$ & $\begin{array}{l}\text { Vitric } \\
\text { (nonzeolitized) }\end{array}$ \\
\hline $\begin{array}{l}\text { 5) Central Prow } \\
\text { Pass Member }\end{array}$ & $\begin{array}{c}-\mathrm{z}=565-622 \mathrm{~m}- \\
\quad(57 \mathrm{~m} \text { thick })\end{array}$ & $\begin{array}{l}z=556-636 \mathrm{~m} \\
(80 \mathrm{~m} \text { thick) }\end{array}$ & $\begin{array}{l}z=545-600 \mathrm{~m} \\
(55 \mathrm{~m} \text { thick) }\end{array}$ & $\begin{array}{l}-z=504-596 \mathrm{~m}- \\
(92 \mathrm{~m} \text { thick })\end{array}$ & $\begin{array}{l}z=594-665 \mathrm{~m} \\
(71 \mathrm{~m} \text { thick) }\end{array}$ & $\begin{array}{l}z=505-549 m \\
(44 m \text { thick) }\end{array}$ & $\begin{array}{l}z=495-557 \mathrm{~m} \\
\text { (62 m thick) }\end{array}$ \\
\hline $\begin{array}{l}\text { 6) Zcolite } \\
\text { Interval III }\end{array}$ & $\begin{array}{l}z=622-706 \mathrm{~m} \\
\text { (84 m thick) }\end{array}$ & $\begin{array}{l}z=636-710 \mathrm{~m} \\
(74 \mathrm{~m} \text { thick) }\end{array}$ & $\begin{array}{l}z=600-682 \mathrm{~m} \\
(82 \mathrm{~m} \text { thick) }\end{array}$ & $\begin{array}{l}z=596-698 \mathrm{~m} \\
(102 \mathrm{~m} \text { thick })\end{array}$ & $\begin{array}{l}z=665-689 \mathrm{~m} \\
(34 \mathrm{~m} \text { thick) }\end{array}$ & $\begin{array}{l}z=549-610 \mathrm{~m} \\
(61 \mathrm{~m} \text { thick) }\end{array}$ & $\begin{array}{l}z=557-613 \mathrm{~m} \\
(56 \mathrm{~m} \text { thick })\end{array}$ \\
\hline $\begin{array}{l}\text { 7) Central } \\
\text { Bullfrog Member }\end{array}$ & $\begin{array}{l}z=706-779 \mathrm{~m} \\
(73 \mathrm{~m} \text { thick) }\end{array}$ & $\begin{array}{l}z=710-863 \mathrm{~m} \\
(153 \mathrm{~m} \text { thick) }\end{array}$ & $\begin{array}{l}z=682-828 \mathrm{~m} \\
(146 \mathrm{~m} \text { thick) }\end{array}$ & $\begin{array}{l}z=698-765 \mathrm{~m} \\
(67 \mathrm{~m} \text { thick) }\end{array}$ & $\begin{array}{c}-\mathrm{z}=689-800 \mathrm{~m}- \\
\text { (111 m thick) }\end{array}$ & $\begin{array}{l}z=610-732 \mathrm{~m} \\
(122 \mathrm{~m} \text { thick })\end{array}$ & $\begin{array}{c}-\mathrm{z}=613-776 \mathrm{~m} \\
(163 \mathrm{~m} \text { thick })\end{array}$ \\
\hline $\begin{array}{l}\text { 8) Zeolite } \\
\text { Interval IV }\end{array}$ & $\begin{array}{l}z=779-823 \mathrm{~m} \\
\text { (44 } \mathrm{m} \text { thick) }\end{array}$ & $\begin{array}{l}z=863-890 \mathrm{~m} \\
(27 \mathrm{~m} \text { thick })\end{array}$ & $\begin{array}{l}z=828-860 \mathrm{~m} \\
(32 \mathrm{~m} \text { thick) }\end{array}$ & $\begin{array}{l}z=765-774 \mathrm{~m} \\
(9 \mathrm{~m} \text { thick })\end{array}$ & no samples & $\begin{array}{c}-z=732-760 \mathrm{~m}- \\
(28 \mathrm{~m} \text { thick })\end{array}$ & $\begin{array}{l}z=776-822 m \\
(46 \mathrm{~m} \text { thick) }\end{array}$ \\
\hline 9) Older Tuffs & Top: $823 \mathrm{~m}$ & Top: $890 \mathrm{~m}$ & Top: $860 \mathrm{~m}$ & Top: $774 \mathrm{~m}$ & Top: $830 \mathrm{~m}$ & Top: $760 \mathrm{~m}$ & Top: $822 \mathrm{~m}$ \\
\hline $\begin{array}{l}\text { 10) Deeper } \\
\text { Petrologic }\end{array}$ & \multicolumn{7}{|c|}{ Upper Carbonate Aquifer and below. } \\
\hline
\end{tabular}

Sources: Bryant and Vaniman (1984), Vaniman and others (1984)

SWL = static water level (-); $z=$ depth from surface 


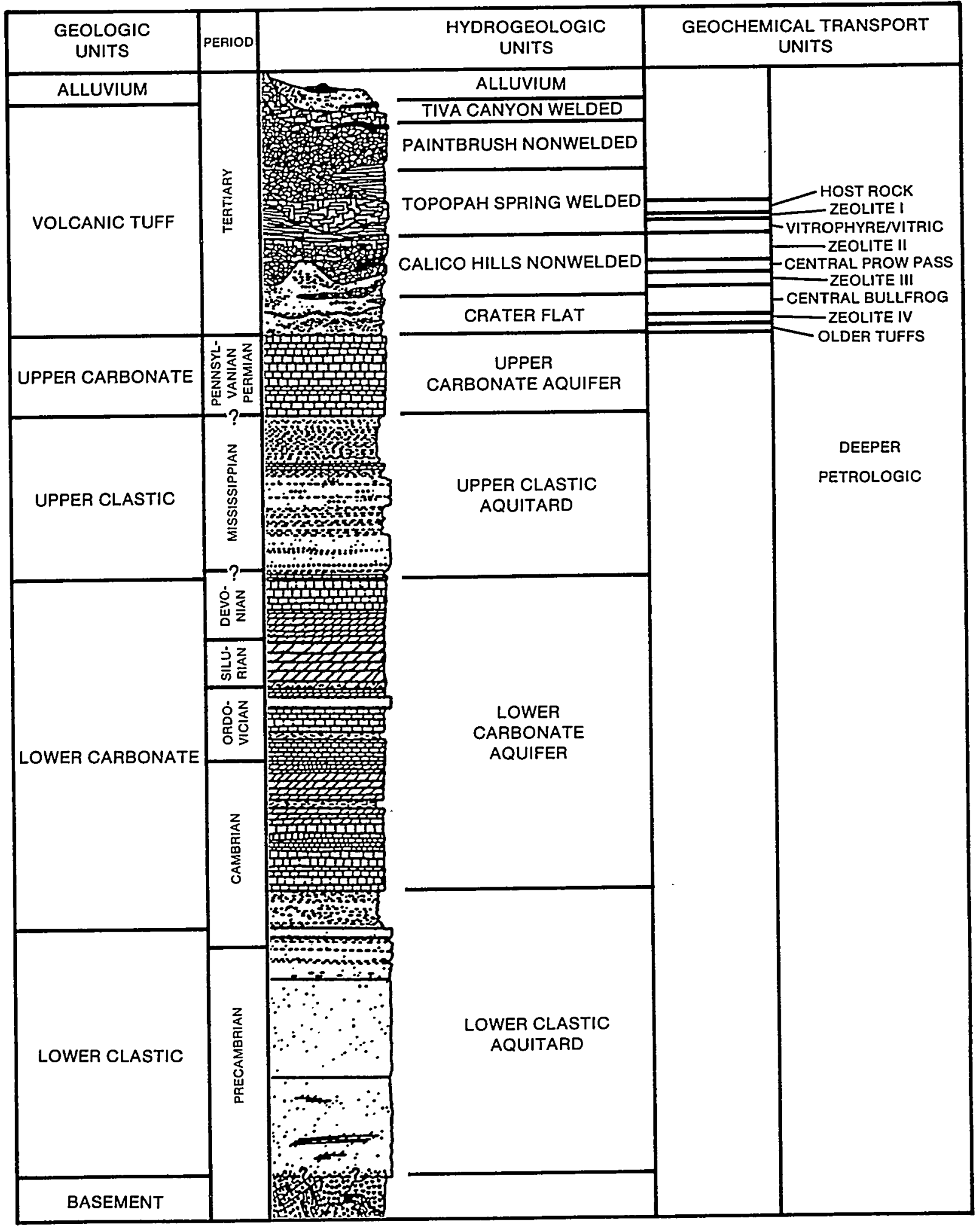

Figure 7.2. One-Dimensional Stratigraphic Comparison of Hydrogeologic, Geologic, and Geochemical-Transport Systems 


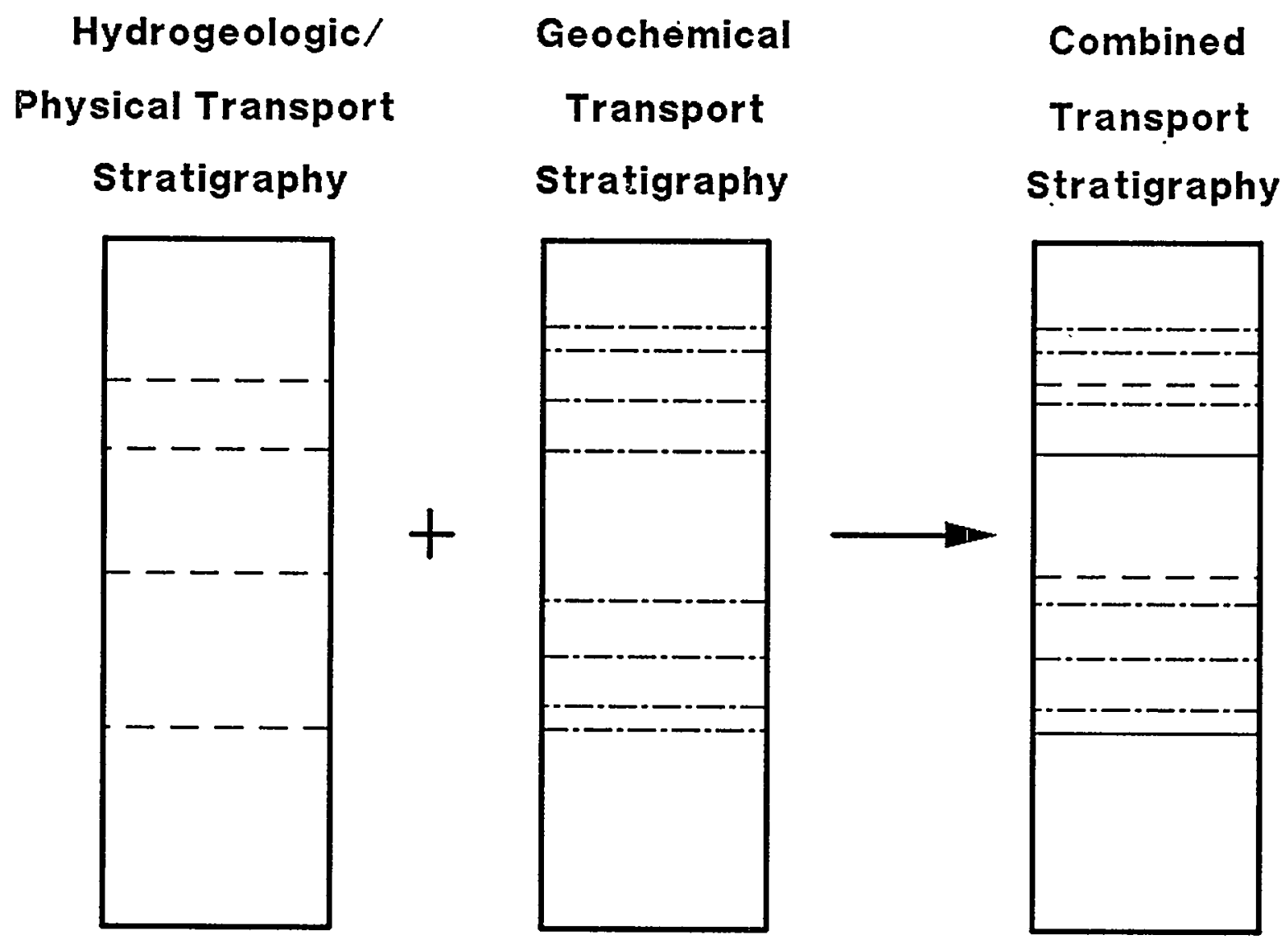

Figure 7.3. Hypothetical Example of Combined Transport Layering System 
margins coincide; otherwise, only one set of properties, physical or chemical, would change at a given interface.

From the above discussion and from Figure 7.2 it is evident that the geochemical stratigraphy defined for the purposes of transport modeling does not necessarily correspond with either the geologic or hydrogeologic stratigraphies, whereas the physical transport stratigraphy is the same as the hydrogeologic stratigraphy. Differences in depth, thickness and lateral variations of layers are due to fundamental differences in the processes considered in defining each stratigraphy. However, the respective stratigraphies should not be considered as alternatives, but rather as complements because, when defining a final transport stratigraphy, both physical and chemical components must be considered. In doing so, the resulting transport stratigraphy will be consistent with the flow assumptions made, but due to the geochemical contribution, would be a finer, more detailed layering. Uncertainty in the depth, thickness, mineralogical composition, and lateral location of each of the units should decrease as more pertinent data become available.

\subsection{Hydrochemistry Related to Radionuclide Transport}

Ground-water chemistry at the repository site can impact significantly the transport of radionuclides from the repository to the accessible environment. The discussion below is given only in the context of the effect that ground-water chemistry has on transport of radionuclides through the far-field, including nuclide solubility, speciation, and sorption. However, because reliable data for ground-water chemistry in the unsaturated zone at Yucca Mountain are sparse to non-existent, very little can be said about specific impact of hydrochemistry on transport in that zone for this conceptualization.

Water taken from the saturated zone of the tuffaceous aquifers adjacent to and below the exploration block at Yucca Mountain has been characterized to be primarily a $\mathrm{NaHCO}_{3}$ water with relatively low total elemental concentration (less than $400 \mathrm{mg} / \mathrm{l}$ ) for all samples (Benson and others, 1983; Ogard and Kerrisk, 1984). Water taken from deeper formations (i.e., carbonate aquifer) has much higher dissolved solids concentrations (greater than $1000 \mathrm{mg} / \mathrm{l}$ ). Generally, $\mathrm{Na}^{+}, \mathrm{Ca}^{2+}, \mathrm{K}^{+}$, and $\mathrm{Mg}^{2+}$ are the dominant cations present, while $\mathrm{HCO}_{3}{ }^{-}, \mathrm{Cl}^{-}, \mathrm{SO}_{4}{ }^{2-}, \mathrm{F}^{-}$, and $\mathrm{NO}_{3}{ }^{-}$are the dominant anions. Ground-water $\mathrm{pH}$ is controlled (i.e., buffered) primarily by $\mathrm{CO}_{2}$ concentration in the water and should remain in the range of 6 to 8 (Ogard and Kerrisk, 1984). A reducing environment exists in the saturated zone directly below the proposed repository site (-143 $\mathrm{mV}$ vs. $\mathrm{H}_{2}$ electrode) (Ogard and Kerrisk, 1984). An oxidizing environment, however, would be expected in the unsaturated zone because of the presence of oxygen in the gas 
phase. Naturally occurring colloid and particulate concentrations, as well as organic content have been found to be very low (Apps and others, 1982; Ogard and Kerrisk, 1984).

Spatially, ground-water composition for the local system at Yucca Mountain is relatively constant. Nevertheless, four extremes in composition have been defined based on samples taken to date (White and others, 1980; Claassen, 1983; Ogard and Kerrisk, 1984). These extremes (and their locations) are defined as follows (Ogard and Kerrisk, 1984):

- water very high in $\mathrm{NaHCO}_{3}$ content (directly below Yucca mountain, caused by $\mathrm{CO}_{2}$ reacting with vitric tuffs)

- water with higher $\mathrm{Mg}$ and $\mathrm{Ca}$ content, and lower $\mathrm{Na}$ content (eastern slopes and washes, aquifer surrounding Yucca Mountain, caused by $\mathrm{CO}_{2}$ reacting with devitrified or crystalline tuffs)

- water with high dissolved solids content (carbonate rocks of paleozoic aquifer, caused by water equilibrating with carbonate rocks)

- rain water or snow melt.

The existence of ionic species in the ground water is important because the ionic species can compete with radionuclides for sorption sites on rock surfaces (assuming physical adsorption). Crowe and Vaniman (1985) have shown that sorption ratios for the radionuclides which sorb by ion exchange mechanisms (e.g., Sr, Cs, and $\mathrm{Ba}$ ) are consistently lower in less concentrated waters (natural ion concentration) or distilled waters than in higher concentrated waters in both zeolitized and vitric tuffs. This is probably the consequence of a decrease of available sorption sites which are taken by the naturally occurring ionic species.

Ogard and Kerrisk (1984) have demonstrated that both radionuclide speciation and solubility are strong functions of ground-water composition. Particularly important are $\mathrm{Eh}, \mathrm{pH}$, and the availability of complexing anions such as hydroxyl, carbonate, sulfate, and fluoride in the ground water. For example, Ti and Eu exhibited higher apparent sorption ratios in the higher ionic strength waters. This is thought to happen because these are forming sulfate or fluoride precipitates.

Ground-water composition has been included as part of this conceptualization for the purpose of assisting in describing the transport system at the site. Ground-water composition warrants consideration because of the pronounced effect it may have on certain transport processes. Specific details of supporting investigations concerning 
ground-water chemistry and its effect on radionuclide transport can be found elsewhere (Daniels and others, 1982; Ogard and Kerrisk, 1984; Crowe and Vaniman, 1985; Rundberg and others, 1985). 


\subsection{PREVIOUS CONCEPTUAL MODELS FOR FRACTURED TUFF}

Currently, there are several conceptual models that describe the flow and transport systems in fractured tuff. None of the conceptual models to date describe flow through both the unsaturated and saturated zones. However, most of the transport system conceptual models described here consider both the saturated and unsaturated zones. Consequently, the following discussion has been divided into three sections: unsaturated ground-water flow conceptual models, saturated ground-water flow conceptual models, and transport conceptual models.

The previous conceptual models are described to illustrate the assumptions that have been made in their development. The emphasis is on the description of the conceptual model assumptions, and not on the purpose or the results of each study.

Within each section listed above, the assumptions made in each conceptual model are evaluated. This evaluation is based on the use of the model in a performance assessment of a HLW repository located in unsaturated, fractured tuff; the perceived purpose of each of these previous conceptual models.

\subsection{Unsaturated Ground-Water Flow}

Researchers have taken several different approaches to the conceptualization of the unsaturated flow system at Yucca Mountain. This section describes several conceptual models for unsaturated ground-water flow. The descriptions are followed by a discussion of the common assumptions and the appropriateness of these assumptions.

\subsubsection{Montazer and Wilson (1984)}

Montazer and Wilson (1984) developed a qualitative conceptual model of flow through the unsaturated, fractured tuff at Yucca Mountain based on their knowledge of the hydrogeological framework, application of the principles of unsaturated flow, and an interpretation of preliminary data collected in the unsaturated zone at Yucca Mountain. Montazer and Wilson describe a two-dimensional vertical cross-section through the repository site over a lateral distance of approximately $2.5 \mathrm{~km}$.

Montazer and Wilson designated six different hydrogeologic units that partially control water movement in the unsaturated zone: alluvium and five layers of welded and nonwelded tuff. The tuff layers were designated according to the degree of welding. Geometrically, the central block is structurally bound to the west by the Solitario Canyon 
Fault, a major north-striking normal fault with more than $100 \mathrm{~m}$ of offset. To the east is a zone of imbricate normal faults with vertical offsets of 2 to $5 \mathrm{~m}$. The tuff layers are laterally continuous with an overall eastward dip of 5 to 10 degrees (see Figure 8.1).

The flow system is bound at the top by the land surface, at the bottom by the water table (located 500 to $750 \mathrm{~m}$ below the land surface), and on the sides by either no-flow or constant flux boundaries. Water enters the system as precipitation from moderately intense storms which last a few days. Infiltration is spatially and temporally variable. In attempting to estimate the spatially averaged flux at these defined upper and lower boundaries, the magnitude of flux across the upper and lower boundaries is assumed to be constant. Deep percolation and recharge occur under steady-state conditions. The lateral boundaries are no-flow in the welded units (assuming that vertical flow predominates in welded tuff), while the nonwelded units are treated as a source or sink, allowing lateral flow to occur in nonwelded tuff.

Montazer and Wilson proposed several important processes that will control the liquid movement through the unsaturated zone including flow through fractured rocks (through the fractures and/or matrix), capillary barrier effects, lateral and vertical liquid flow components (which may create zones of perched water), and vapor movement due to convective and dispersive processes in the unsaturated zone. All of these processes are controlled by the amount of water present in and flowing through the system.

\subsubsection{Peters and others (1986)}

Peters and others (1986) developed a conceptual model to study the influence of the percolation rate (i.e., the water flux at depth) on the mechanism and rate of water movement in a fractured, porous medium. They calculated the water travel times using upper and lower bounds for the percolation rate.

A composite porous medium model was assumed. The model allows only onedimensional vertical steady-state flow to occur from the land surface to the water table. Peters and others assumed that the percolation rate is the same in all hydrogeologic units and that no lateral movement occurs at the interfaces between layers. If the percolation rate is greater than the matrix saturated hydraulic conductivity, then flow will occur through the both the fractures and matrix.

Peters and others used the five hydrogeologic units that were designated from the land surface to the water table (based on the stratigraphy of drillhole USW G-4 located at the eastern edge of the repository location) by Ortiz and others (1985) (see Figure 8.2). 


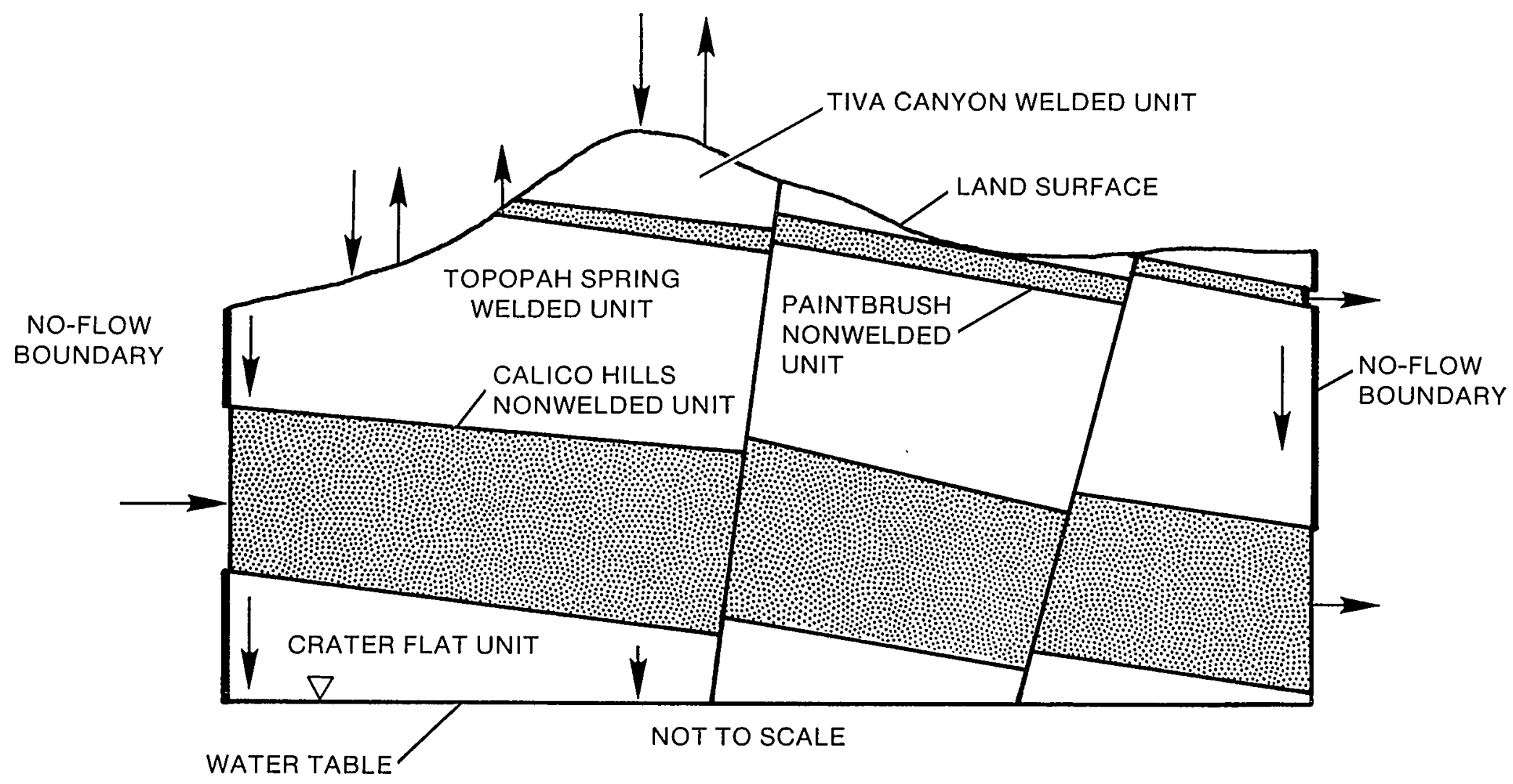

Figure 8.1. Conceptual Model Framework Assumed by Montazer and Wilson (1984) 


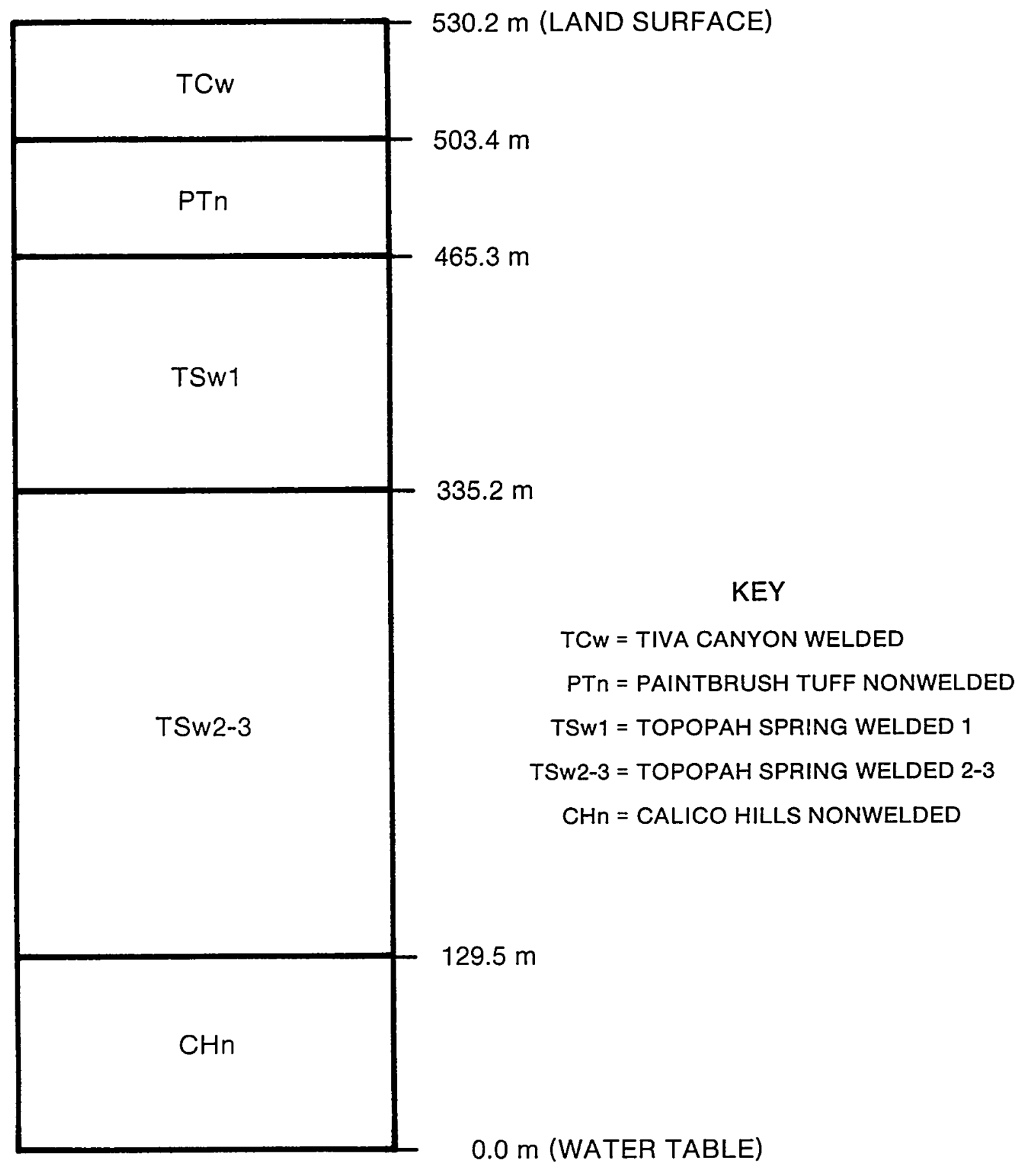

Figure 8.2. One-Dimensional Column Used in Travel Time Calculations (from Peters and others, 1986) 
Ortiz and others designated the hydrogeologic units according to variations in porosity and grain density. Peters and others assumed that each hydrogeologic unit is characterized by unit properties which are constant throughout the unit with the exception of the unit located above the water table, the Calico Hills nonwelded unit. The Calico Hills unit is assumed to be either vitric with a high conductivity, or zeolitic with a relatively low conductivity.

\subsubsection{Lin and others (1986)}

Lin and others (1986) developed a one-dimensional conceptual model for use in a probabilistic approach to calculate ground-water travel times and total radionuclide releases from the repository disturbed zone to the water table hundreds of meters directly below the repository. Their model geometry consists of a group of onedimensional vertical tubes grouped together to create a pseudo-three-dimensional geometry (see Figure 8.3). Thus, although the analysis allows only vertical flow to occur, the travel time results include the entire repository area.

Lin and others used an equivalent porous medium approach in their unsaturated flow model. They assumed that unsaturated flow occurs in the matrix only if the flux rate is less than the saturated hydraulic conductivity of the matrix. If the flux is greater than the matrix saturated hydraulic conductivity, then fracture flow was assumed to occur as Darcy flow only. Thus, for fracture flow to occur, the matrix is also saturated.

Lin and others assumed that any transient infiltration pulses that travel through fractures which may occur at the land surface are damped out by strong matrix capillary forces. Therefore, steady-state one-dimensional vertical flow was assumed to occur from the repository to the water table. In addition, Lin and others assumed a unit gradient, meaning that the unsaturated matrix flow is driven solely by gravity, with an unsaturated hydraulic conductivity equal to the flux rate of the system. The unit gradient assumption implicitly neglects capillary forces that may cause lateral flow to occur, thus increasing the amount of vertical flow that occurs.

Lin and others assumed that seven different hydrogeologic units occur from the base of the repository to the water table, which is consistent with the three-dimensional interpreted stratigraphy of Ortiz and others (1985) (see Figure 8.4). Lin and others assumed that each hydrogeologic layer behaves as a uniform porous medium. The range of data available from four boreholes were used to determine the distributions of the properties for each hydrogeologic unit (e.g., effective porosity, saturated hydraulic conductivity, unit thickness). 


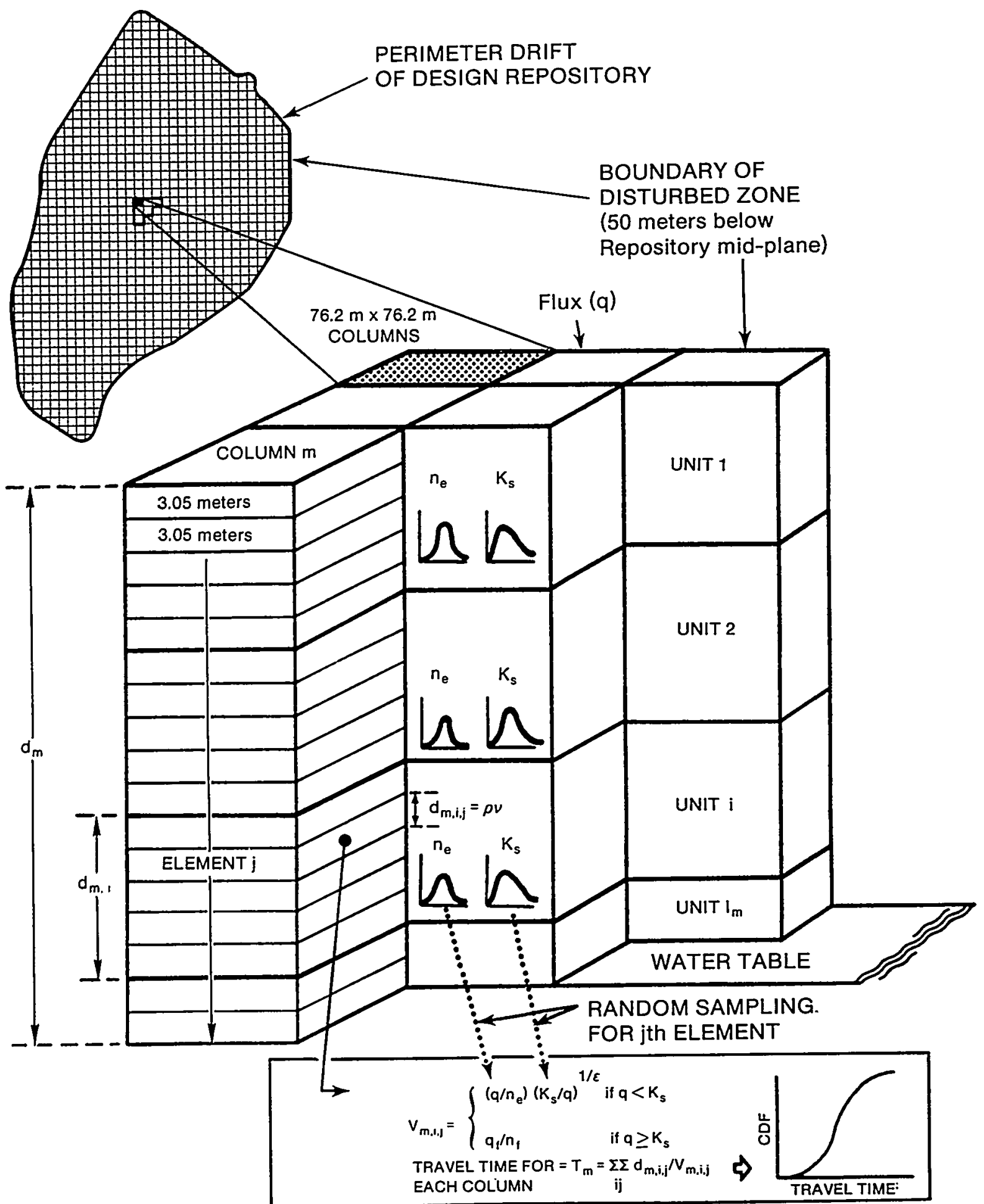

SOURCE: GE/CALMA PRODUCT NO. 0116.

Figure 8.3. Schematic Diagram Showing the Three-Dimensional Geometry for Modeling Ground-Water Travel Time (from Lin and others, 1986) 


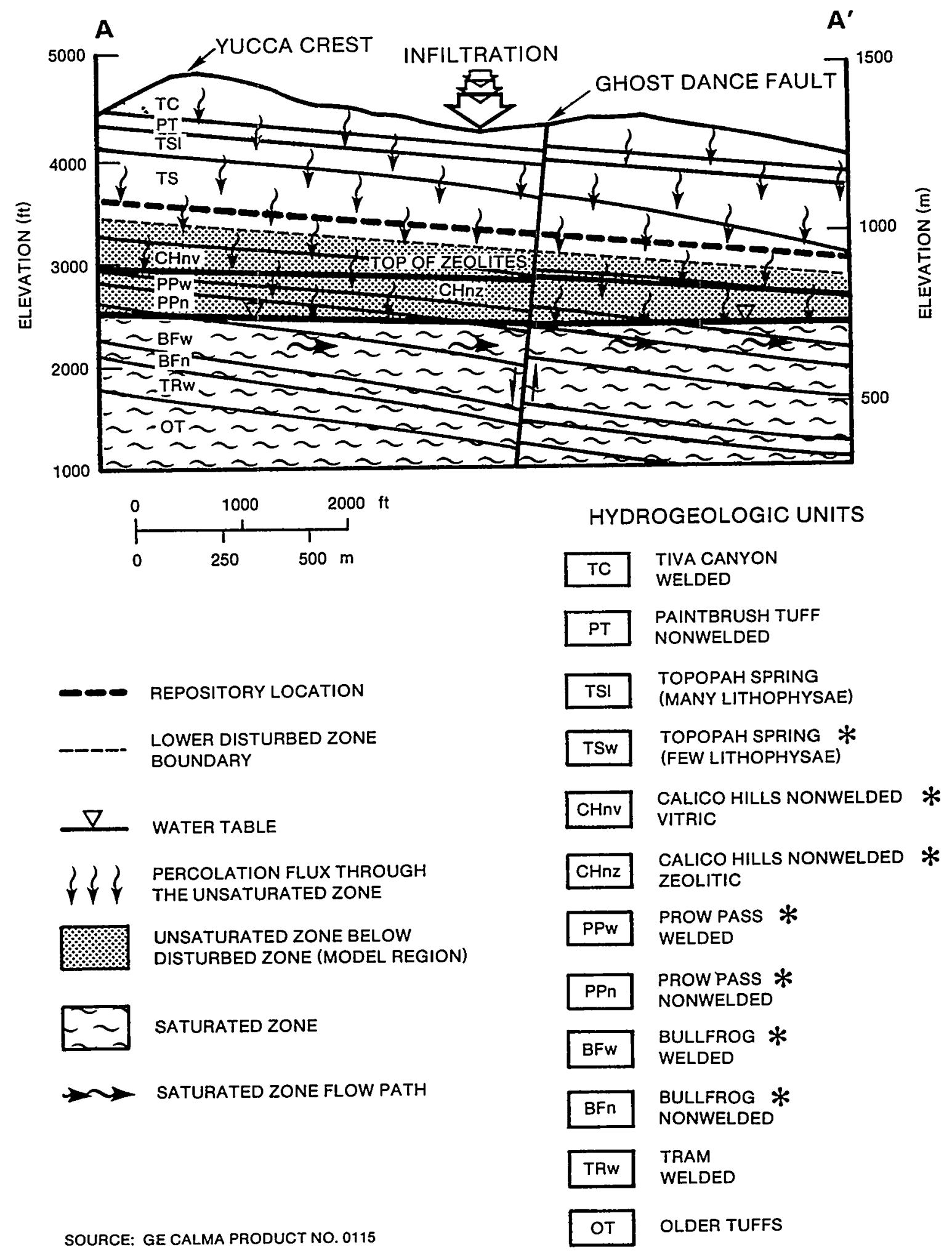

Figure 8.4. General Hydrogeologic Cross-Section at Yucca Mountain (from Lin and others, 1986) 


\subsubsection{Wang and Narasimhan (1985)}

Wang and Narasimhan (1985) developed a model to describe flow in unsaturated, fractured media on a spatial scale on the order of centimeters. Their conceptual model describes flow along and across fractures that separate unsaturated matrix blocks. Wang and Narasimhan simulated vertical drainage through a uniform column of densely welded tuff containing discrete vertical and horizontal fractures. They applied two different conceptual models to the drainage process: a discrete fracture/porous medium model, and a porous medium only model.

Wang and Narasimhan's discrete fracture/porous medium conceptual model treats the fractures in a discrete fashion. The model assumes that the fracture apertures are variable, and that the matrix pore size is several orders of magnitude less than the fracture apertures. Thus, the fractures will desaturate first upon drainage. In partially drained fractures, a relatively continuous air phase or isolated air pockets create barriers to liquid flow along the fracture. During drainage, the effective hydraulic conductivity of the fractures quickly becomes less than the effective hydraulic conductivity of the matrix. The asperities in the natural fractures may cause "islands" of water films held by capillary forces near contact points of the fracture. Therefore, water can flow across the fracture from one matrix block to another where water films in the fracture are present (see Figure 8.5).

For saturated flow along fractures, Wang and Narasimhan assumed that the cubic law applies. Tortuosity of the fractures is not taken into account.

For unsaturated flow along fractures, Wang and Narasimhan assumed that the distortion of flow paths caused by the contact areas is smaller than the flow path distortions created by air pockets. Due to capillary forces, there is a saturation cutoff aperture controlling whether the fracture can retain water or not. As desaturation of a fracture occurs, the segments of the fracture with apertures greater than the saturation cutoff aperture will become desaturated. The fracture segments with an aperture less than the saturation cutoff aperture remain saturated and contribute to flow under unsaturated flow conditions.

Under unsaturated flow conditions, the model will allow flow to occur only from the matrix to the fracture and from the fracture into the next matrix block at the zones of fracture saturation and the fracture contact points. The fracture aperture distribution was used to determine the fracture relative permeability, saturation, and effective 


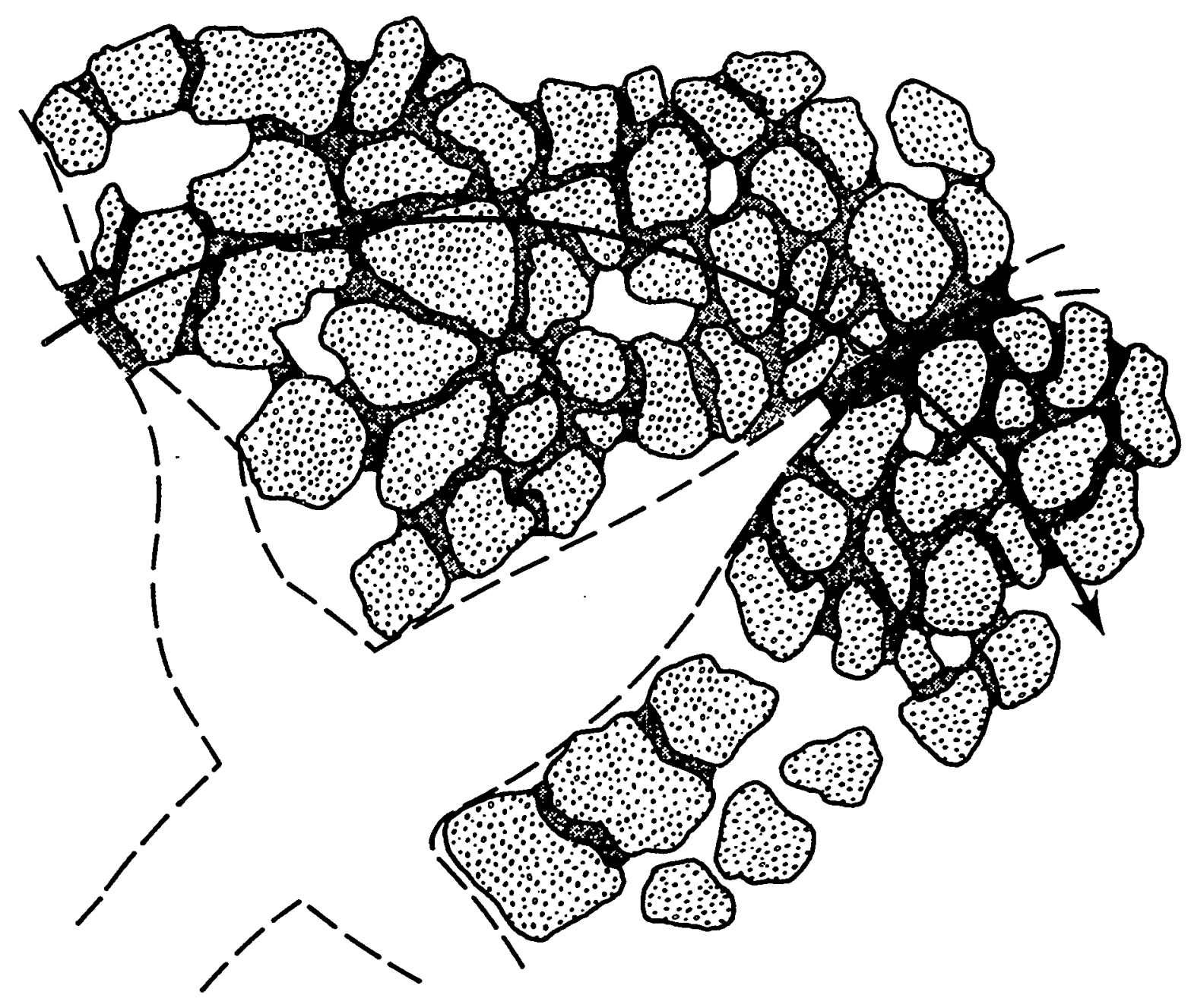

Figure 8.5. Conceptual Model of Partially Saturated, Fractured, Porous Medium Showing Schematically the Flow Lines Moving Around the Dry Portions of the Fractures (from Wang and Narasimhan, 1985) 
fracture-matrix flow area. The fracture apertures were assumed to fit a gamma distribution. Using the gamma distribution functional relationship, analytic expressions for the fracture properties were derived.

Wang and Narasimhan's model ignores film flow in the fracture, vapor flow, evaporation of isolated liquid pockets surrounded by gaseous phases, the solubility of air in water, and fracture coating effects.

\subsubsection{Wang and Narasimhan (1986)}

Wang and Narasimhan (1986) extended their analysis to study infiltration through a onedimensional column of alternating welded and nonwelded tuff. They discuss the results of two different conceptual models. Wang and Narasimhan assumed a steady-state infiltration rate in the first model and a pulse infiltration rate in the second model. They assumed a composite porous medium model for the steady-state case with a low infiltration rate so that only matrix flow occurs. For the steady-state case, infiltration occurs from the land surface to the water table through five hydrogeologic units (based on work by Montazer and Wilson, 1984; Ortiz and others, 1985; Sinnock, Lin, and Brannen, 1984; Rulon and others, 1986; Klavetter and Peters, 1985) (see Figure 8.6).

The transient case investigates situations where short-term pulses of infiltration occur at rates larger or smaller than the saturated hydraulic conductivity of the matrix. Wang and Narasimhan (1986) assume both a discrete-fracture/porous-matrix model and a composite medium model for the transient analyses. For vertical infiltration, Wang and Narasimhan (1986) designate two orthogonal vertical fracture sets in the discretefracture/porous-matrix model so that the geometry of the grid system is actually threedimensional. The composite medium model grid is strictly one-dimensional. Transient infiltration occurs through the upper three hydrogeologic units from the land surface to the upper portion of the Topopah Spring welded unit (above the top of the repository) (see Figure 8.6).

Wang and Narasimhan (1986) allow lateral movement to occur in the nonwelded units in both the steady-state and transient flow analyses. They assumed the stratigraphic units are tilted slightly such that a gravity gradient caused by the tilt may divert some water laterally. This model ignores the effects of high conductivity fault zones and the possibility of perched zones that may occur between hydrogeologic layers. The model also does not account for lateral saturation gradient, but it estimates the lateral flow component using a constant fixed-gradient approximation. The fixed-gradient approximation was set for each node in the nonwelded units for all the steady-state 


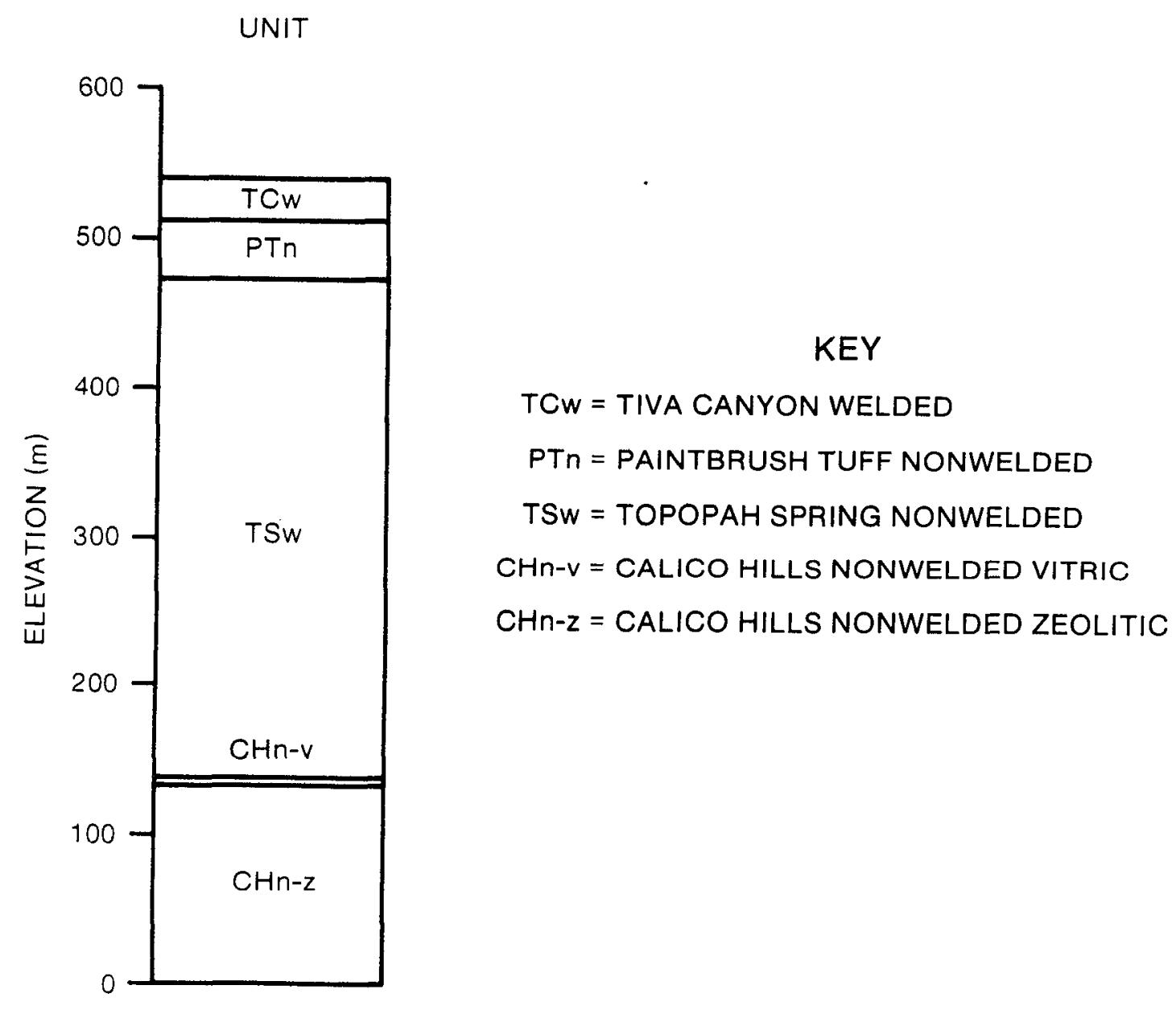

Figure 8.6. Vertical Grid of the One Dimensional Conceptual Models Assumed by Wang and Narasimhan (1986) 
simulations and the low flux cases of the transient pulse simulations. Because this is a one-dimensional model, the water that moves laterally due to the fixed gradient approximation is lost from the system and is no longer accounted for.

\subsubsection{Wang and Narasimhan (1988)}

In 1988, Wang and Narasimhan expanded their model to analyze a two-dimensional system that extends up to $1000 \mathrm{~m}$ laterally and is composed of slightly dipping welded and nonwelded tuff units bound on each side by vertical faults (Wang and Narasimhan, 1988) (see Figure 8.7). The focus of this analysis was to determine whether the fault zones act as barriers to or conduits for water movement in the unsaturated zone. The researchers assumed that there are nine hydrogeologic units of uniform thickness and constant dip (SNL, Interactive Graphics Information Services). Because the hydraulic properties of the faults are unknown, the face of the faults were treated as seepage boundaries open to the atmosphere so that the capillary force is zero and the saturated hydraulic conductivity is infinite. Various steady-state infiltration simulations, from the land surface to the water table, were performed. It appears that one-dimensional columns similar to these in their previous model (Wang and Narasimhan, 1986), constructed adjacent to each other, were used to create the two-dimensional crosssection. The assumptions for the occurrence of fracture or matrix flow (e.g., a composite porous medium, porous medium, etc.) are not clear, but the fault zone analysis is described as a continuation and extension of the previous work (Wang and Narasimhan, 1986).

\subsubsection{Travis and others $(1984 a, b)$}

The purpose of the work by Travis and others (1984a,b) was to examine the effect of lithology and the presence of fractures on water flow and radionuclide transport at the Yucca Mountain site. They present bounding flow calculations to determine to what depth a slug of water will travel through a fracture.

The conceptual model for the flow analysis involves a series of parallel equally spaced vertical fractures in a competent, homogeneous, isotropic rock. The fracture is assumed to be a uniform width that is significantly smaller than the distance between fractures (see Figure 8.8). Water is allowed to enter the fracture as a pulse. Travis and others assumed that the water flows down each fracture simultaneously as a saturated slug. That is, no film flow occurs along the fractures. The fracture flow velocity is determined by assuming the cubic law is valid for this situation. As a slug of water propagates vertically downward through a fracture due to gravitational forces, the matrix capillary 


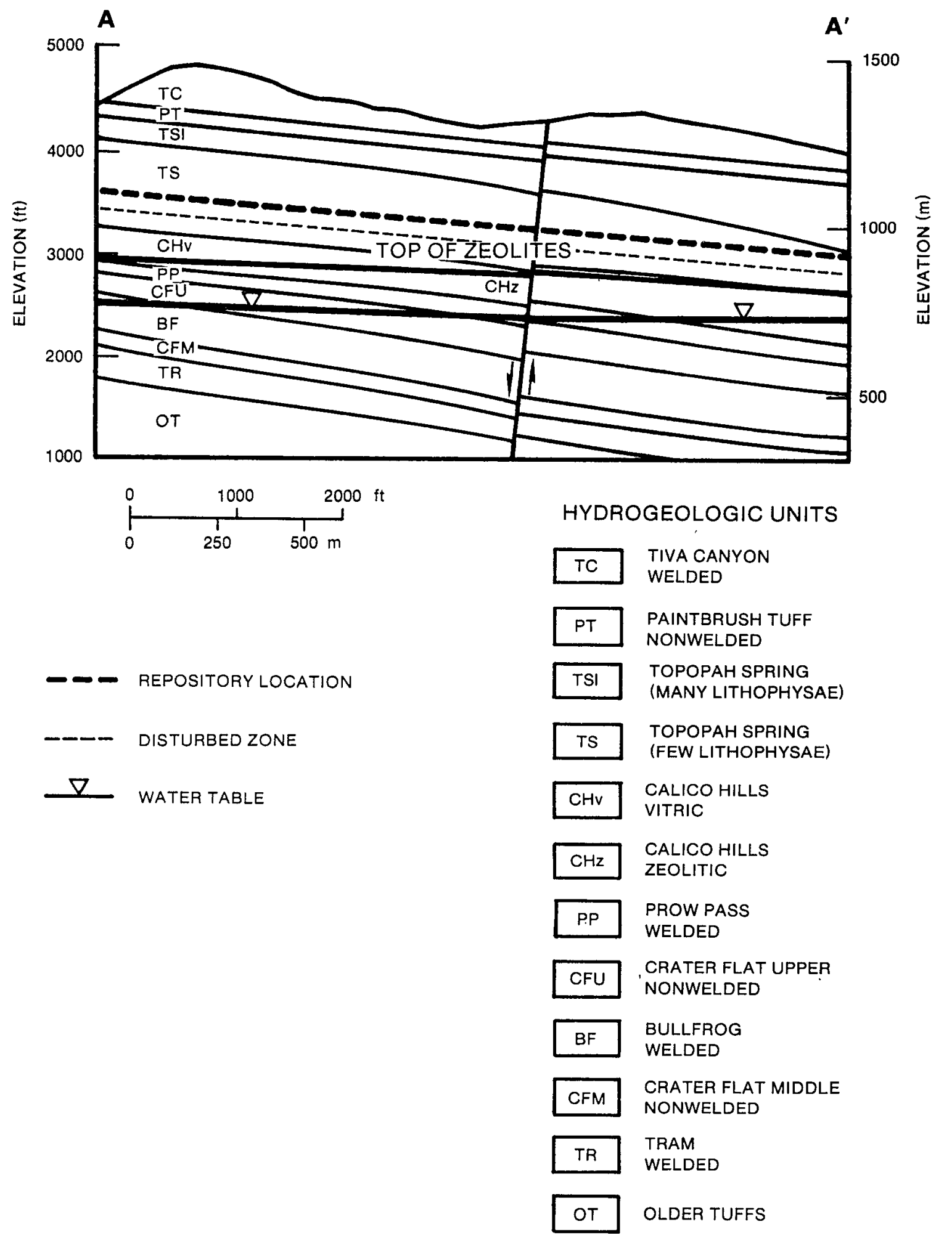

Figure 8.7. Hydrogeologic Cross-Section at Yucca Mountain Assumed in the Conceptual Model of Wang and Narasimhan (1988) 


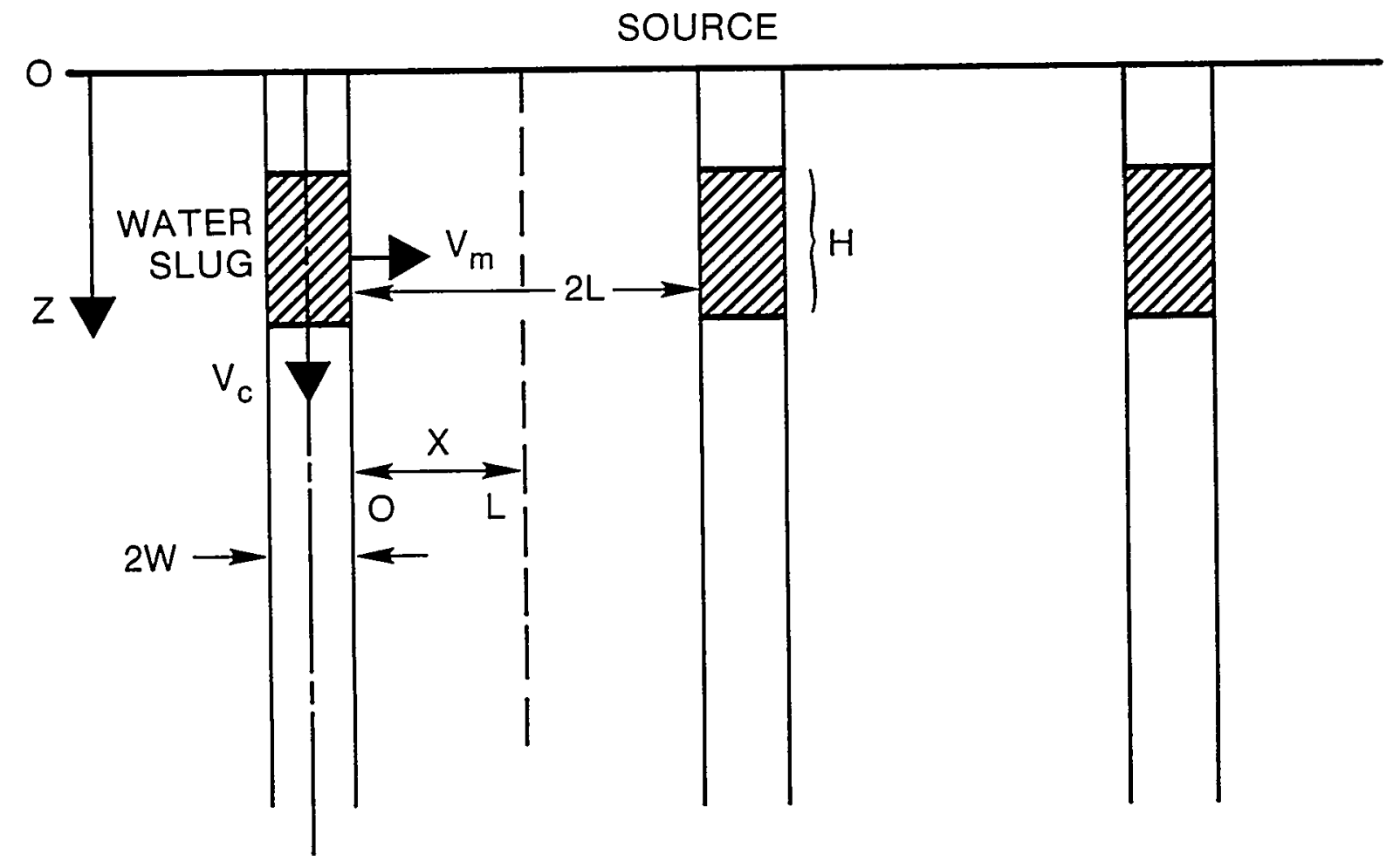

Figure 8.8. Conceptual Model Geometry Used for the Fracture Slug Flow Analysis by Travis and others $(1984 a, b)$ 
forces continually draw some of the water into the matrix. The matrix is considered for its storage capacity only and is assumed to be, initially, uniformly partially saturated. Once water has entered the matrix, it is assumed that the water does not re-enter the fracture or flow in a vertical direction. By definition, Travis and others have assumed a dual porosity system for their flow analysis.

The conceptual model developed by Travis and others for the flow analysis is not consistent with the transport analysis conceptual model in one respect. For the transport analysis, it was assumed that there is no capillary force which induces the flow into the matrix (see Section 8.3.2).

\subsubsection{Ross (1984)}

Ross (1984) developed a conceptual model for a hydrologic system that consists of an unsaturated zone hundreds of meters thick in an area of very low recharge. The purpose of the analysis was to estimate how low infiltration rates may become before additional processes (e.g., vapor movement) must be considered in a conceptual model of water flow in the unsaturated zone.

Ross conceptualized a thick section of uniform unfractured, unsaturated rocks and assumed that zero recharge occurs. There is a uniform temperature gradient at depth due to the geothermal conditions. For the water vapor analysis, Ross assumed that the gas and liquid phases are in local thermodynamic equilibrium. Ross reasoned that if conduction is the primary mode of heat transport, then a uniform temperature gradient can be assumed for a homogeneous rock mass under steady-state conditions.

The system is assumed to be under steady-state conditions. For zero net recharge, there is downward liquid movement (due to gravity) that is balanced by upward vapor movement (due to the geothermal gradient). Areally uniform steady infiltration occurs at the land surface. The model is one-dimensional and allows only vertical water and/or water vapor movement. The assumption of a unit hydraulic gradient follows from the steady-state assumption.

\subsubsection{Discussion of Unsaturated Ground-Water Flow Assumptions}

The major characteristics of each of the previously discussed unsaturated flow conceptual models and the main assumptions made by each model are summarized in Table 8.1. 
Table 8.1. Conceptual Model Assumptions for Unsaturated Flow at a HLW Repository in Fractured Tuff

Assumptions

$$
\text { Previous Conceptual Models }
$$

$\begin{array}{lllllllll}1 & 2 & 3 & 4 & 5 & 6 & 7 & 8 & 9\end{array}$

Porous Medium

(Matrix flow only)

Composite Porous

Medium

Dual Porosity

Discrete Fracture/

$\mathrm{X}$

$\mathrm{X}$

Porous Medium

Matrix Only or

Fracture Only

$\mathrm{X}$

X $\quad \mathrm{X} \quad \mathrm{X}$

$\begin{array}{llllllllll}\text { Darcy's Law Assumed } & X & X & X & X & X & X & X & X & X\end{array}$

Scale

$\begin{array}{llllllllll}\mathrm{km} & \mathrm{m} & \mathrm{m} & \mathrm{cm} & \mathrm{m} & \mathrm{m} & \mathrm{m} & \mathrm{m} & \mathrm{m}\end{array}$

$\begin{array}{llllllllll}\text { Hydrogeologic } & 6 & 5 & 7^{\mathrm{a}} & 1 & 5 & 3^{\mathrm{b}} & 9 & 1 & 1\end{array}$

Units

$\begin{array}{lllllllll}\text { Empirical Unsaturated } & X & X & X^{\mathfrak{c}} & X & X & X & X & X^{c}\end{array}$

Relationships for

Conductivity of

Fracture and Matrix

$\begin{array}{llllll}\text { Steady Infiltration } & \text { X } & \text { X } & \text { X } & \text { X } & \text { X }\end{array}$

Rate

Pulse Infiltration

Rate

$\mathrm{X}$

$\mathrm{X}$

$\mathrm{X}$

Spatially Variable

Infiltration Rate

$\mathrm{X}$ 
Table 8.1. (continued)

Assumptions

\section{Previous Conceptual Models}

$\begin{array}{lllllllll}1 & 2 & 3 & 4 & 5 & 6 & 7 & 8 & 9\end{array}$

\begin{tabular}{|c|c|c|c|c|c|c|c|c|c|}
\hline Steady-State & $\mathrm{X}$ & $\mathrm{X}$ & $\mathrm{X}$ & & $X$ & & $X$ & & $\mathrm{X}$ \\
\hline Transient & & & $X$ & & $\mathrm{X}$ & & $\mathrm{X}$ & & \\
\hline Dimensions & 2 & 1 & 1 & 3 & $1^{d}$ & $1 / 3^{d}$ & 2 & $1^{e}$ & 1 \\
\hline $\begin{array}{l}\text { Capillary Effects } \\
\text { Negligible } \\
\text { (i.e., Unit Gradient) }\end{array}$ & & $\mathrm{X}$ & & & & & & $X$ & \\
\hline Vapor Flow & $\mathrm{X}$ & & & & & & & & $\mathrm{X}$ \\
\hline
\end{tabular}

\section{INVESTIGATOR(S)}

1. Montazer and Wilson (1984) - Provided qualitative description

2. Peters and others (1986) - Investigated influence of percolation rate

3. Lin and others (1986) - Calculated ground-water travel time

4. Wang and Narasimhan (1985) - Calculated vertical drainage (uniform column)

5. Wang and Narasimhan (1986, Case1) - Calculated infiltration (layered)

6. Wang and Narasimhan (1986, Case2) - Calculated infiltration (layered)

7. Wang and Narasimhan (1988) - Investigated fault zone effects

8. Travis and others (1984) - Studied fracture slug flow

9. Ross (1984) - Investigated conditions for which vapor flow is important

a - From bottom of disturbed zone to water table

b - From ground surface to upper portion of unit where repository is located

c - For matrix only

d - Pseudo 2-dimensional system (for some cases lateral flow occurs by applying a fixed gradient approximation at each node in nonwelded units, allowing water to move laterally out of the system)

e - Pseudo 2-dimensional system (flow along a fracture and flow from fracture into matrix can occur) 
Several approaches have been used to account for fracture and matrix flow in an unsaturated, fractured tuff. A continuum approach was used in each of the conceptual models discussed previously. The first and simplest continuum approach is to treat the fracture/matrix system as a porous medium. As defined here, a porous medium model neglects fracture flow, so that only matrix flow is allowed. Such a simplification is appropriate if fracture flow is negligible.

The second continuum model applied to this system is described as a composite porous medium (Peters and others, 1986; Wang and Narasimhan, 1985, 1986, 1988). Several major assumptions are inherent in the application of a composite porous medium model. One assumption is that the fractures and the matrix both behave as an equivalent porous medium. The separate fracture and matrix hydraulic conductivity curves are combined together into what is called a composite curve (Klavetter and Peters, 1985). The result is that the system is conceptualized as an equivalent porous media, where the fracture and matrix effects have been grouped together. The pressure head (or level of saturation) then controls whether the fracture or matrix dominated portion of the composite conductivity curve is used in the flow analysis.

For the composite porous medium model, the researchers assumed that the pressure heads in the fractures and the matrix are identical in a direction perpendicular to flow. Steady-state or very slow transient flow conditions are required to make the equivalent pressure head assumption. That is, the system must either reach equilibrium very quickly following a perturbation (such as a pulse of infiltration), or it must change very slowly. If saturated fracture flow is induced, flow through the fractures would dominate. The matrix may or may not be saturated, depending on the hydraulic properties of the fracture and matrix. If the portion of the matrix adjacent to the fractures becomes saturated, it is possible to assume an equal pressure head at the fracture and matrix interface. The same assumption could be applied if film flow occurs along the sides of partially saturated fractures and the matrix is saturated near the fracture face.

Under certain conditions, however, an equilibrium between the fracture and matrix system may not be a physically appropriate assumption. Under matrix dominated flow conditions, the fractures would be almost entirely filled with air; the edge of a fracture would have a high tension while simultaneously the pressure head in the matrix may be several orders of magnitude larger (less negative) than in the fractures. Also, fracture coatings on the fracture face may impede the flow from the matrix into the fracture. In this case, a gradient could exist across the fracture and matrix interface so that the pressure head in the fracture is not equal to the pressure head in the matrix. 
A dual porosity model is the third type of continuum approach which has been used at the repository site (Travis and others, 1984a,b). The dual porosity model allows flow to occur only through the fractures. Although water may flow into the matrix, it is not allowed to re-enter the fracture. Thus, the matrix is utilized for storage and simultaneous matrix flow does not occur. The dual porosity approach may be valid for the saturated slug flow bounding calculations performed by Travis and others $(1984 a, b)$.

The fourth continuum approach used in modeling unsaturated zone flow is a discretefracture/porous-medium model as conceptualized by Wang and Narasimhan $(1985,1986$, 1988). This is the only unsaturated flow model that allows flow to occur in both the fractures and the matrix, or across a fracture. Consequently, the model includes one set of equations to describe fracture flow and another set of equations to account for matrix flow. Such processes are very likely to occur at the repository site. The fracture hydraulic properties (e.g., relative permeability, saturation, and effective fracture-matrix flow area) are determined by a statistical model that accounts for variations in fracture aperture (see Sections 8.1.4, 8.1.5, and 8.1.6 for a description of the assumptions inherent in the model). The discrete fractures are assumed to be spaced uniformly in the model when the application is on the scale of kilometers (Wang and Narasimhan, 1988). The application of a discrete-fracture/porous-medium model where the fractures are oriented in a realistic manner over this scale would not be feasible.

The fifth and last continuum approach applied to flow in the unsaturated zone is a matrix only or fracture only model (Lin and others, 1986). This model allows flow to occur in either the fracture or in the matrix, depending upon the hydraulic properties of the matrix and the infiltration rate (see Section 8.1.3).

None of the previous conceptual models describing unsaturated, fracture flow have used a dual-continuum approach which would allow flow to occur in both the fractures and matrix simultaneously with a variable resistance transfer coefficient term between the matrix and fracture. There is no substantial field or laboratory evidence to indicate that only matrix or fracture flow will occur in the unsaturated, fractured tuff at the repository site. The fact that fracture mineral coatings are present on the fracture faces at depth (Sykes and others, 1979; Spengler and others, 1984; Carlos, 1985; Crowe and Vaniman, 1985; Carlos, 1987) may suggest that fracture flow occurred at some point in time. Our current lack of knowledge indicates that we need a more robust approach to the unsaturated flow problem.

If a continuum approach is assumed, then it has been inherently assumed that Darcy's law in the form of Richard's equation may be applied to flow in the matrix and fractures. 
The validity of Darcy's law depends upon two main assumptions. First, Darcy's law assumes that the flux is linearly proportional to the hydraulic gradient. The constant of proportionality is dictated by the properties of the medium. The constant is allowed to be a function of position and pressure head, and may be a tensor. It is generally accepted that this relationship between the flux and gradient may be applied to most porous media given that the velocities do not produce turbulent flow (i.e., assume laminar flow). The second inherent assumption in applying Darcy's law is that a representative elemental volume (REV) exists (Bear, 1979). That is, for a given volume, it is appropriate to treat the system as a continuum. To date, it has not been proven that an REV exists for unsaturated, fractured media. The scale of the problem partially determines whether an REV could exist. On a large scale, it may be appropriate to treat the fractures and matrix together as a porous medium or a composite porous medium. Conversely, single discrete fractures could create discontinuities in the flow pattern so that assuming a continuum would not be valid unless the discontinuities occur on a scale smaller than the characteristic size of the averaging volume (REV).

If fracture flow dominates, the fracture network must be interconnected to assume a continuum approach. Within the unsaturated zone hydrogeologic framework at the repository site, the highly fractured welded units alternate with nonwelded units that contain very few fractures. It appears that few fractures continue vertically from one hydrogeologic unit to another. Thus, the scale over which a continuum based on fracture dominated flow could be applied may be limited to the individual highly fractured hydrogeologic units. If the fracture network is not predominantly connected from the land surface to the water table, it is not appropriate to assume a continuum for fracture dominated flow over that large a scale. However, several large faults are present at the repository site that are continuous across welded and nonwelded hydrogeologic units. It is not known at this time whether the faults behave as conduits or barriers to flow.

According to Table 8.1, the conceptual models for flow in unsaturated, fractured porous media differ in purpose and, therefore, differ in scale. The conceptual models described previously range from field scales (on the order of kilometers), to laboratory scales (on the order of centimeters). The scale differences necessitate varying degrees of detail in the conceptual model development and direct comparisons are not reasonable between all nine of the previously described conceptual models. The only large-scale models that extend from one to several kilometers laterally include the models of Montazer and Wilson (1984) and Wang and Narasimhan (1988). Five of the unsaturated flow conceptual models were developed for vertical sections that are hundreds of meters thick (Peters and others, 1986; Lin and others, 1986; Wang and Narasimhan, 1986; Travis 
and others, 1984a,b; and Ross, 1984). The analysis of Wang and Narasimhan (1985) is the only small-scale conceptual model discussed.

The number of hydrogeological units represented in the unsaturated zone conceptual models (see Table 8.1) varies. The unsaturated zone conceptual models are generally based on layers of welded and nonwelded tuff. Different hydrogeologic units with varying hydraulic properties have an important effect on flow through the unsaturated zone (see Section 4.2). Although the individual hydrogeologic units have been assumed to be homogeneous, the system is actually heterogeneous with lateral and vertical variations in hydrologic properties. The unsaturated zone conceptual models discussed previously include from one to nine hydrogeologic layers (see Table 8.1). The models that account for one hydrogeologic layer are justified by the purpose of their analysis (Wang and Narasimhan, 1985; Travis and others, 1984a,b; Ross, 1984). The investigators who designated more than one hydrogeologic unit in the unsaturated zone divided the system into layers, according to either the degree of welding (Montazer and Wilson, 1984) or the porosity and grain density (Ortiz and others, 1985). When designating the hydrogeologic stratigraphy, it may also be appropriate to incorporate additional hydrogeologic data to assist in delineating the unsaturated zone flow paths. For example, drilling characteristics, detailed lithology, fracture density, properties of lithophysae, geophysical logs (e.g., resistivity and density), in-situ moisture content, bulk density, saturated hydraulic conductivity, and moisture characteristic curves may be useful. The various number of layers in the different models is primarily because the flow was considered either from the land surface to the water table or from the bottom of the disturbed zone to the water table (see Table 8.1).

With the exception of Montazer and Wilson (1984), all the hydrogeologic stratigraphies for the unsaturated zone neglect the alluvium at the land surface. Neglecting the alluvium may be acceptable for the analyses that calculate the ground-water travel time from the repository to the water table, but it may not be appropriate when investigating the effects of infiltration. If the alluvium is neglected, episodic precipitation events are the sole mechanism by which water can enter the fractures exposed at the land surface in the uppermost welded unit. Alluvium may provide a primary source for water storage at the land surface (see Section 4.1) and a more constant source of recharge in time (but not in space) than the episodic precipitation events.

Given the assumptions of Darcian flow, the relationship between hydraulic conductivity and pressure head is necessary. However, the unsaturated hydraulic conductivity of the fractured tuff as a function of the pressure head has not been directly measured in the laboratory or the field. Instead, empirical relationships have been assumed to estimate 
the pressure head versus hydraulic conductivity curves for most of the unsaturated zone conceptual models (see Table 8.1). Peters and others (matrix and fractures, 1986) and Wang and Narasimhan (matrix only, 1985, 1986, 1988) utilized the closed form analytical solution of van Genuchten (1980). van Genuchten's model calculates the relative hydraulic conductivity from a moisture retention curve based on the pore structure model of Mualem (1976). Lin and others (matrix only, 1986) used the empirical power equation of Brooks and Corey (1966), which is also based on the moisture retention curve. Montazer and Wilson (1984) present hypothetical fracture and matrix hydraulic conductivity versus pressure head curves that could be derived from moisture retention relationships. Regardless of which empirical method is used, the relationships described above are all based on soil physics theory. However, the validity of applying soil physics principles to unsaturated, fractured rock has not been verified by field or laboratory tests. It is likely that the soil physics relationships are applicable to the matrix of the porous medium, but it may not be as reasonable to treat the fractures in this manner. For example, the moisture retention curve of a single discrete fracture has never been measured. Often, a representative moisture retention curve of an unfractured, porous medium is assigned to the fracture. For instance, Peters and others (1986) assigned moisture retention curves that are based on the hypothetical sand moisture retention curve of Freeze and Cherry (1979) to the fractures.

The infiltration rate is another component of the unsaturated zone conceptual models. At the repository site, the infiltration rate probably varies in time and space in association with episodic precipitation events. However, many of the unsaturated zone conceptual models assume a steady infiltration rate (see Table 8.1). Previous investigators justified the steady-state infiltration assumption by hypothesizing that if water infiltrated into fractures at the land surface in pulses, the water would be pulled from the fractures into the matrix, due to the strong capillary forces of the matrix. Then, due to low matrix permeabilities, the pulses are essentially dampened out, resulting in steady flux rates. Additionally, the infiltration rate at the repository site probably varies spatially according to the physical properties of the land surface (e.g, vegetation, soil cover, slope, etc). Only Montazer and Wilson (1984) account for spatial variability in the infiltration rate when comparing the three multi-dimensional unsaturated zone conceptual models.

The steady-state flow assumption has been made for most of the discussed unsaturated zone conceptual models (see Table 8.1). For describing flow through the unsaturated zone, the steady-state assumption simplifies the analysis considerably. To satisfy the steady-state condition, or near steady-state condition, the pressure head and moisture content conditions must not change throughout the time scale of interest. Most 
investigators hypothesize that any pulses of infiltration near the surface will be quickly damped out due to capillary forces pulling the water from the fractures into the matrix and that at depth the water flux is a slowly varying function of time. However, the validity of the "steady-state flow assumptions should be further quantified in the unsaturated zone prior to simplifying the system to this extent. At this time, unsaturated zone field data do not support or refute the steady-state condition. As stated previously, the steady-state assumption is not supported by field evidence (i.e., in situ pressure head measurements in the unsaturated zone). Only one borehole has been instrumented in the unsaturated zone to measure the in situ pressure head and moisture content (Montazer and Wilson, 1985). Montazer and Wilson state that there appears to be a uniform pressure head distribution in the fractured Topopah Spring unit, approximately 120 to $240 \mathrm{~m}$ ( 400 to $800 \mathrm{ft}$ ) below the land surface; however, the system may not have reached equilibrium after 2 years. The in situ pressure head field data do not suggest steady-state conditions at shallower depths to $120 \mathrm{~m}$ (400 ft) below the land surface (Montazer and Wilson, 1985).

Previous investigators have also made assumptions for the rate of water movement through the unsaturated zone (e.g., the percolation rate). Although several of the models do account for pulses of infiltration, all the unsaturated zone models that assumed steady-state flow conditions implicitly assumed that the percolation rate is constant within each hydrogeologic unit (see Table 8.1).

Dimensionality is an important assumption that governs many other simplifications of the unsaturated flow system. Flow through the unsaturated zone is conceptualized as one-dimensional in the vertical direction by most of the conceptual models discussed (Table 8.1). The vertical flow assumption implies that gravitational force dominates, any pertinent layers are situated horizontally, and capillary effects are negligible. The conceptual models presented by Montazer and Wilson (1984) and Wang and Narasimhan $(1985,1988)$ are two- or three-dimensional, thus allowing lateral flow to occur in the unsaturated zone. The one-dimensional model of Wang and Narasimhan (1986) uses a fixed gradient approximation at each node located in nonwelded tuff units which allows lateral flow to occur in those units (see Section 8.1.5). Their approach, however, neglects capillary forces. In reality, the tilted layered stratigraphy of the repository site may enhance lateral moisture movement and inhibit the vertical downward movement, particularly at an interface between a finer-grained unit overlying a coarser grained unit (see Section 4.2). Additionally, the relatively high in situ tension of the tuff units (Montazer and Wilson, 1985) may cause capillary forces to have a strong effect on moisture movement within the same hydrogeologic unit. Limiting flow to the vertical 
direction in the unsaturated zone is an oversimplification that neglects many processes that may be significant for determining the unsaturated flow paths.

The lack of spatial data is a practical factor which has been used by previous authors to explain the constrained dimensionality of conceptual models to date. Two boreholes have been drilled for collecting cores for characterizing the unsaturated zone approximately $1.5 \mathrm{~km}$ apart on the northeastern edge of the repository location boundary. A third borehole is located about $6 \mathrm{~km}$ away, south of the repository location. Additionally, there are seven boreholes for hydrologic monitoring of the unsaturated zone in the repository area located along a general north-northeastern trend about $6 \mathrm{~km}$ long (see Figure 8.9). Only one of the monitoring boreholes is located within the repository area. However, a lack of data is not an acceptable justification for ruling out a conceptual model which allows three-dimensional flow.

Assuming that steady-state, one-dimensional, vertical flow conditions occur in the unsaturated zone, the flow system could be further simplified by assuming the hydraulic gradient is equal to unity and is in the vertical downward direction. Two of the conceptual models discussed make the assumption of a unit gradient (Lin and others, 1986; Ross, 1984). This assumption allows the flux rate to be equal to the effective hydraulic conductivity and neglects effects of capillary forces. All the problems previously discussed with the assumptions of steady-state and one-dimensional vertical flow pertain to the unit gradient assumption. The unit vertical gradient assumption may be reasonable for certain sections of the repository site, but the heterogeneity of the hydrologic system and the potential for lateral flow to occur probably results in a complex distribution of the pressure head and hydraulic gradient.

Water vapor flow may be a consideration in the unsaturated zone. Only two of the previous investigators include vapor flow in their conceptual models (see Table 8.1). Montazer and Wilson (1984) discuss the possibility that vapor flow may occur due to convective and dispersive processes, but they do not state whether vapor flow is an important process for the movement of water through the unsaturated zone. Ross (1984) contends that for flux rates of greater than $0.3 \mathrm{~mm} / \mathrm{yr}$ the effects of vapor flow are not important for a system with a thick unsaturated zone.

\subsection{Saturated Ground-Water Flow}

This following section describes several conceptual models for ground-water flow in the saturated zone below a repository located in unsaturated fractured tuff. Following a brief description of each saturated, ground-water flow conceptual model is a discussion 


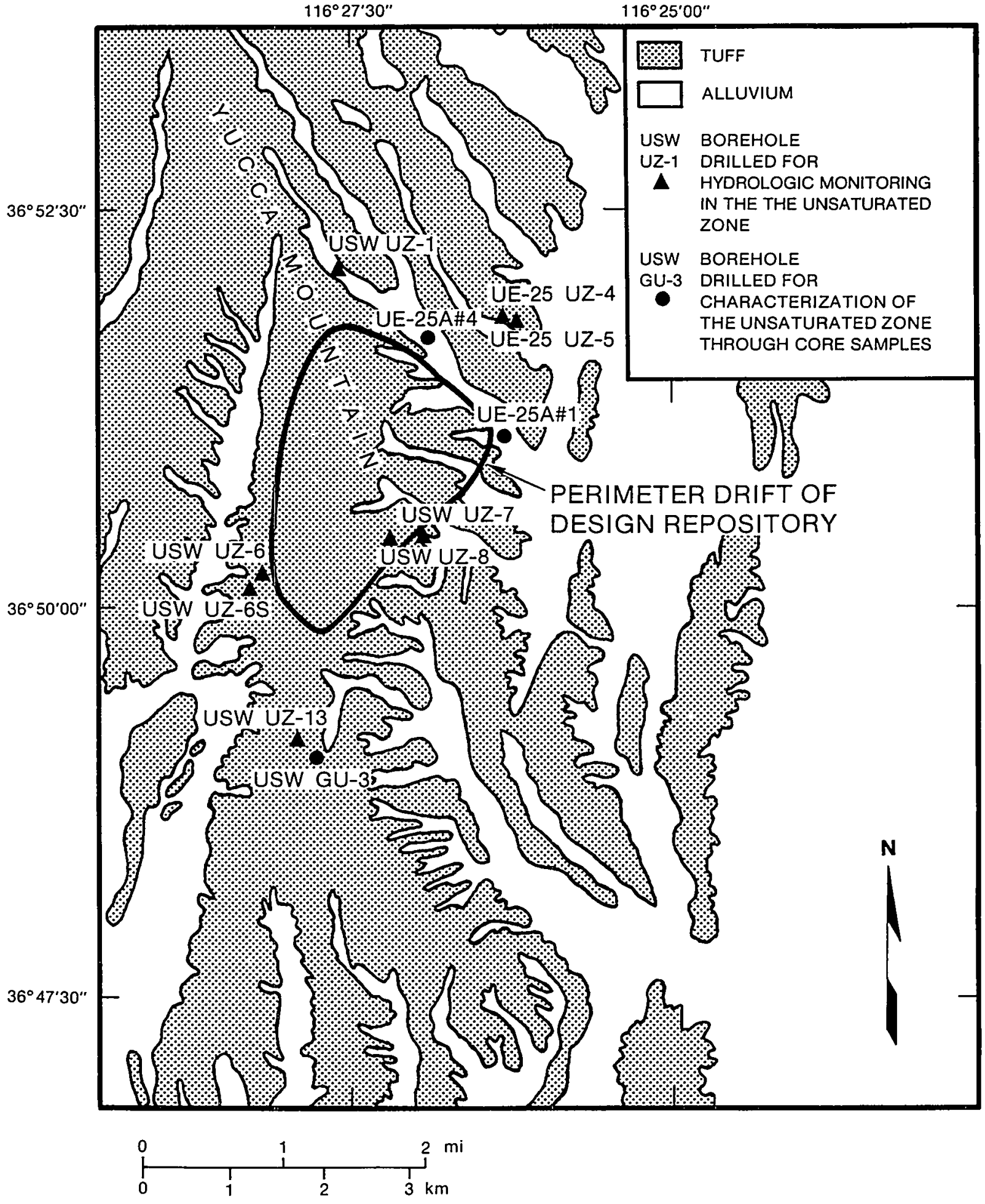

Figure 8.9. Locations of Drilled Monitoring Boreholes and Core Sampling Boreholes in the Unsaturated Zone at Yucca Mountain (modified from DOE, 1988) 
of the assumptions made by the conceptual models.

\subsubsection{Rice (1984)}

Rice (1984) developed a conceptual model for the regional saturated ground-water flow system in the Yucca Mountain area with the purpose of establishing boundary conditions for a future local model of the site. Rice modeled flow through the saturated zone over an area of approximately $230 \mathrm{~km}$ by $270 \mathrm{~km}$. Rice stated that the conceptualization of the flow system was highly simplified because of the large area of the model and the lack of detailed data.

The multilayered saturated system composed of alluvium, volcanic tuffs, and carbonate rocks was combined into one hydrogeologic unit. The lack of spatially varying hydraulic data, such as transmissivity, was given as the reason for this simplification in the geometry. At a particular location, the most transmissive unit was assumed to control the flow, and therefore, the hydraulic properties of the most transmissive unit were used for that zone. The aquifer was assumed to be homogeneous and isotropic within one of these zones.

An equivalent porous medium model was assumed to account for flow through this fractured carbonate and volcanic rock sequence. If the highly fractured units are fracture flow dominated, the fracture flow was only implicitly accounted for by using the effective transmissivity of an equivalent porous medium which include the fractures and the matrix.

Rice conceptualized the flow system as a one-layer aquifer with only two-dimensional steady-state horizontal flow. Also assumed was that the hydraulic parameters (e.g., transmissivity, hydraulic head) did not change with time and the measured hydraulic head distribution (as interpreted by the USGS, 1982) was under steady-state conditions. The measured hydraulic head distribution was used to calibrate the transmissivities so that a minimum difference occurred between the model predicted hydraulic head and the measured hydraulic head values.

Rice assumed constant head boundaries along the northern and southern edges of the region. The remainder of the lateral boundaries were set as no flow boundaries corresponding to topographical divides (see Figure 8.10). The assumption was made that the recharge rate was constant over time. Spatial variation of recharge was accounted for in the model. The variation in recharge was assumed to result from the spatial variability of precipitation, runoff, actual evapotranspiration, and soil storage. Possible 

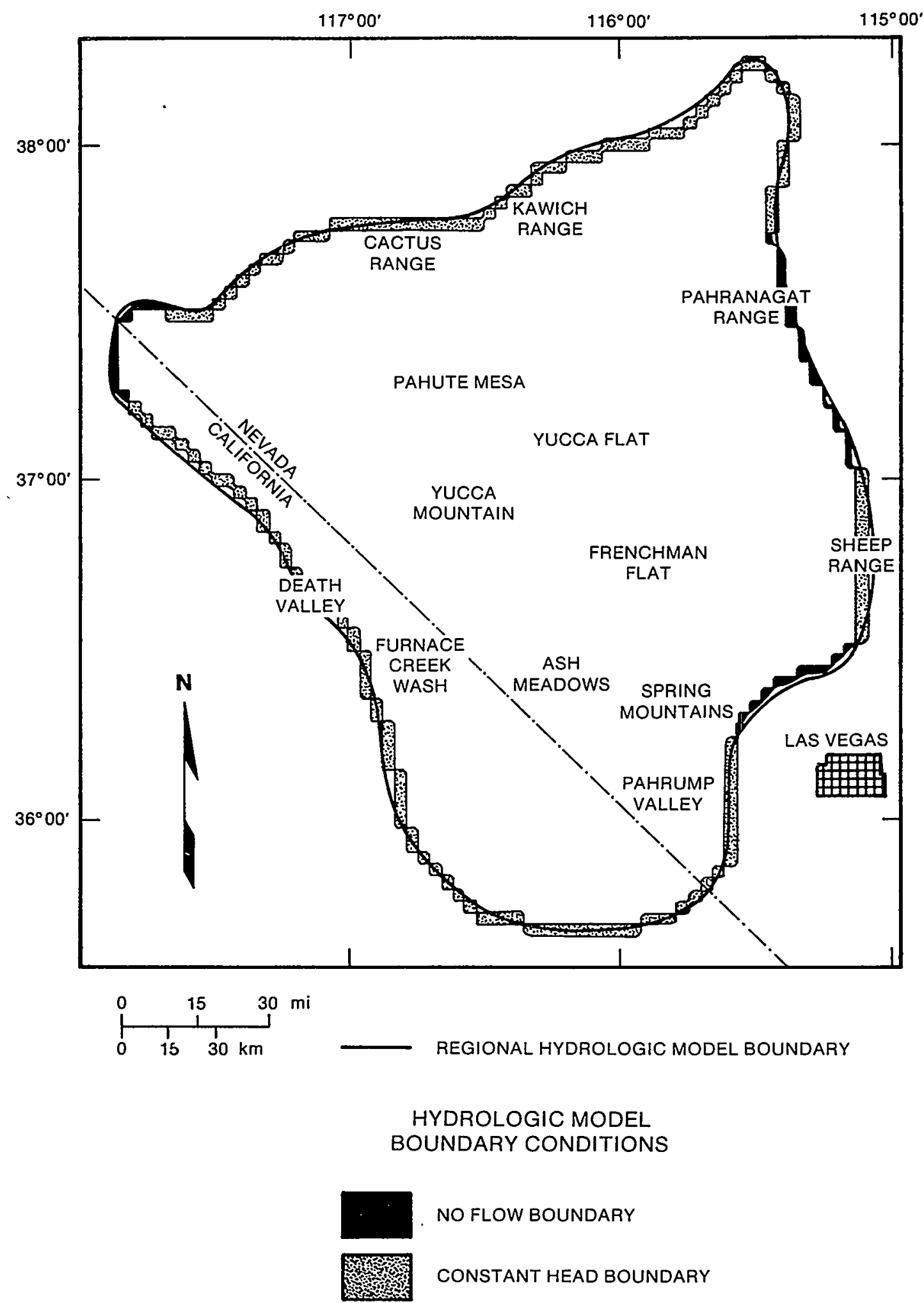

Figure 8.10. Flow Boundaries of the Regional Ground-Water Flow Model of Rice (1984) 
flow entering the system as underflow from the mountains to the north and east was unaccounted for in the recharge boundary condition and was predicted by the model. Discharge from the system was assumed to occur through springs, evapotranspiration, and pumping. Rice designated the net discharge areas as boundary conditions according to the appropriate geographic location, and the model predicted the underflow leaving the region along the southern boundary (see Figure 8.11).

\subsubsection{Waddell (1982)}

Waddell (1982) modeled the ground-water flow of the regional saturated zone flow system in the Yucca Mountain area to estimate ground-water fluxes. These estimates would be used in future radionuclide transport predictions and investigations of the effects of uncertainty in model parameters. The conceptual model was developed for an area of approximately $150 \mathrm{~km}$ by $170 \mathrm{~km}$.

The Waddell model also conceptualized the aquifer as a horizontal one-layer system that only allows two-dimensional steady-state horizontal flow. Four main hydrogeologic units, based on work by Winograd and Thordarson (1975), were assumed to control the regional ground-water flow. Therefore, the plan-view area was divided into several zones of varying transmissivity, according to the dominant lithology of each zone (carbonate, tuffaceous, clastic, or alluvial). The measured transmissivities vary by several orders of magnitude within each lithology type. The geometric mean of the measured transmissivities within each zone was assumed to be representative of the transmissivity for a particular lithology. This approach results in mean representative values that are applicable only for contrasting transmissivities of different groups, since no weighting on the size of the zones was performed. Each zone was assumed to behave in a homogeneous, isotropic manner. Some fault zones were assumed to be restrictions to flow and were assigned porous media characteristics (i.e., low values of transmissivity).

Waddell's regional model includes three ground-water subbasins which have their own recharge and discharge areas. The basin boundaries were defined by available potentiometric data, precipitation distribution, and geology. The external boundaries of the region were designated as constant flux (in and out), no flow, and one node of constant head. Internal flux boundaries were used to represent areas of recharge or discharge in seven zones. The remaining 22 zones were assigned a zero recharge or discharge (see Figure 8.12). 

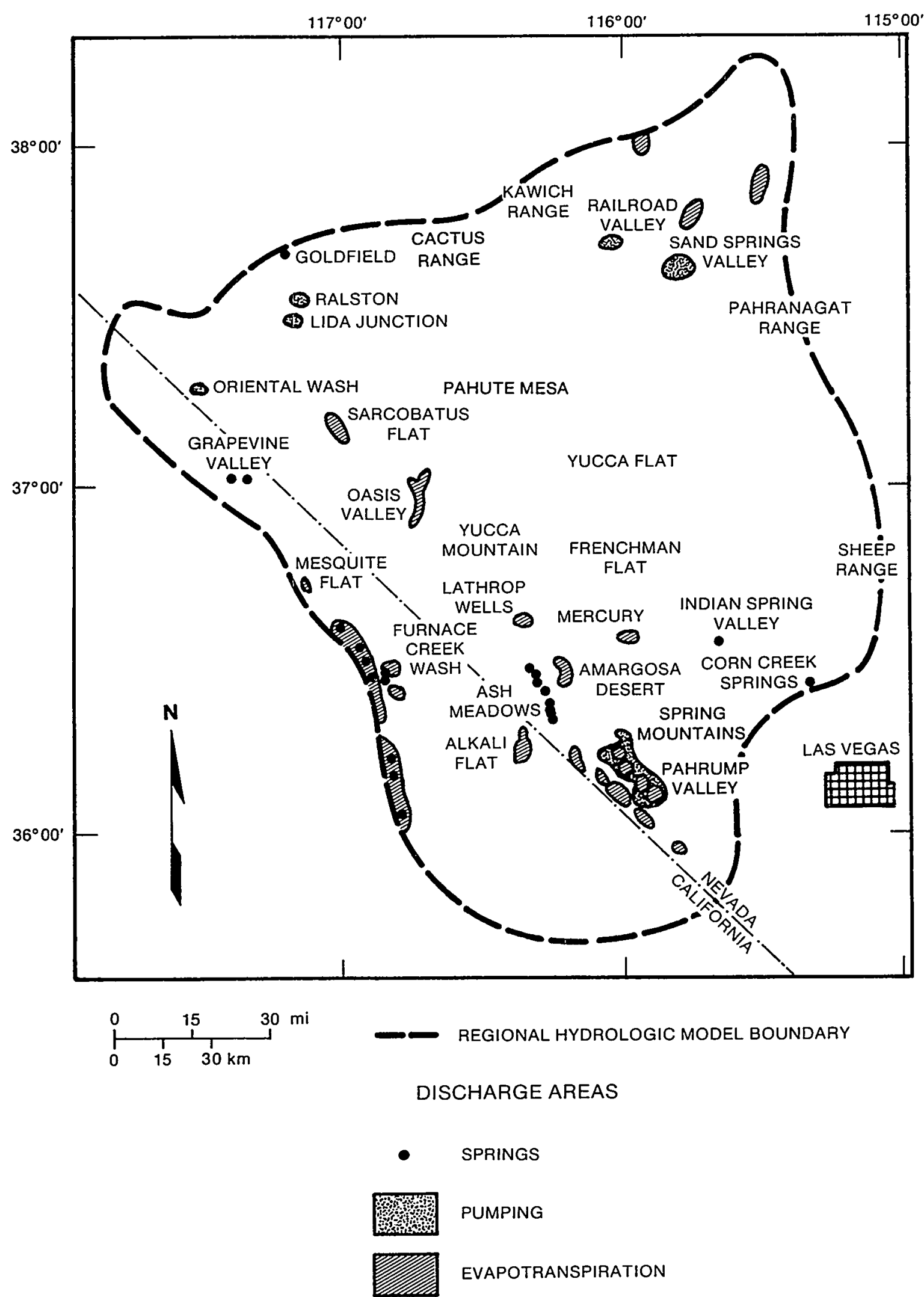

Figure 8.11. Discharge Areas of the Regional Ground-Water Flow Model of Rice (1984) 

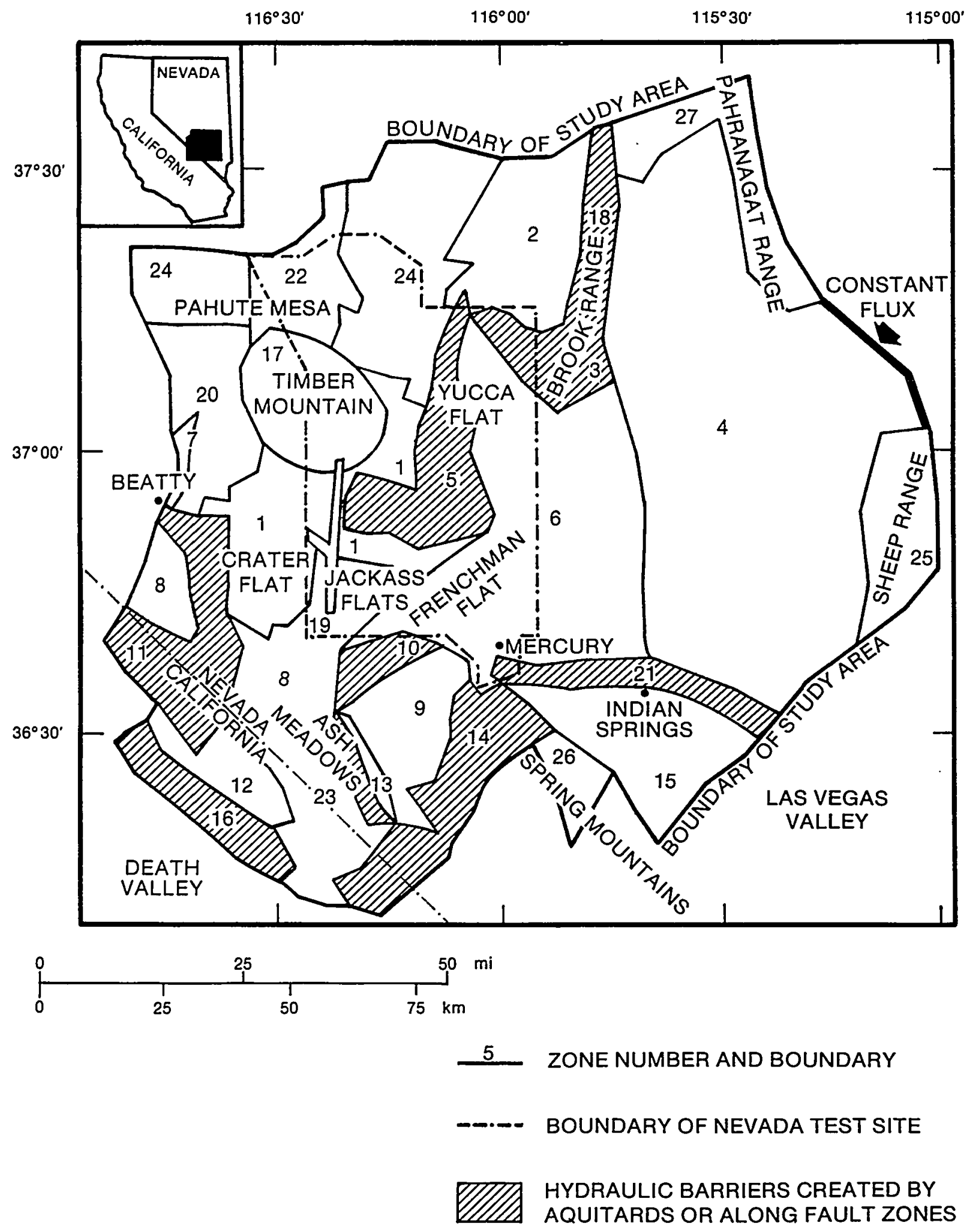

Figure 8.12. Mesh and Zones Used in Regional, Two-Dimensional Ground-Water Flow Model by Waddell (1982) 


\subsubsection{Czarnecki and Waddell (1984)}

Czarnecki and Waddell (1984) analyzed the effect of varying lateral flux boundaries within a subregional ground-water flow system in the Yucca Mountain area. Their model is equivalent to one of the basins within the regional conceptual model of Waddell (1982) and included an approximate area of $50 \mathrm{~km}$ by $100 \mathrm{~km}$ (see Figure 8.13).

Czarnecki and Waddell made the same major assumptions for their conceptual model as Waddell (1982). They assumed that the aquifer behaved as a one-layer system with only two-dimensional horizontal flow. Czarnecki and Waddell (1984) also included four different hydrogeologic units distributed areally in their model: tuffaceous, volcanic, carbonate, and alluvial rocks. The hydrogeologic units were also designated according to the regional framework described by Winograd and Thordarson (1975). Hydraulic properties of the zones were designated by the dominant lithology. Initial estimates of transmissivity values were assumed to be uniform throughout areas with similar lithologies, or where there were insufficient data available for a given area to define smaller zones. Additionally, hydraulic parameters, such as transmissivity, were assumed to be constant over time. The hydrogeologic units were also assumed to be homogeneous and isotropic.

The external boundaries of the model were based on one of the basins within Waddell's (1982) conceptual model. The external boundaries were designated as constant flux, constant head, or no flow (see Figure 8.14). The areal recharge and discharge distribution varied over the subregion. Infiltration (i.e., recharge) was assumed to occur in Forty Mile Canyon. It was assumed for model boundary conditions that evapotranspiration occurred in Alkali Flat.

\subsubsection{Czarnecki (1985)}

Czarnecki (1985) used the same conceptual model as described above (Czarnecki and Waddell, 1984) to evaluate the effects of increased ground-water recharge on the ground-water system in the Yucca Mountain vicinity. Czarnecki made some slight modifications in the designation of hydrogeologic zones and included additional boundaries of constant flux in the conceptual model. In addition, Czarnecki assumed that the aquifer is a constant thickness of $1000 \mathrm{~m}$ over the entire region, for the purpose of determining hydraulic conductivity values from previously calibrated transmissivities. Since the saturated zone thickness is not well known in this area, the resulting hydraulic conductivity is therefore suspect. That is, the variation in hydraulic conductivity may be overestimated due to the assumption that all of the observed, calibrated transmissivity 


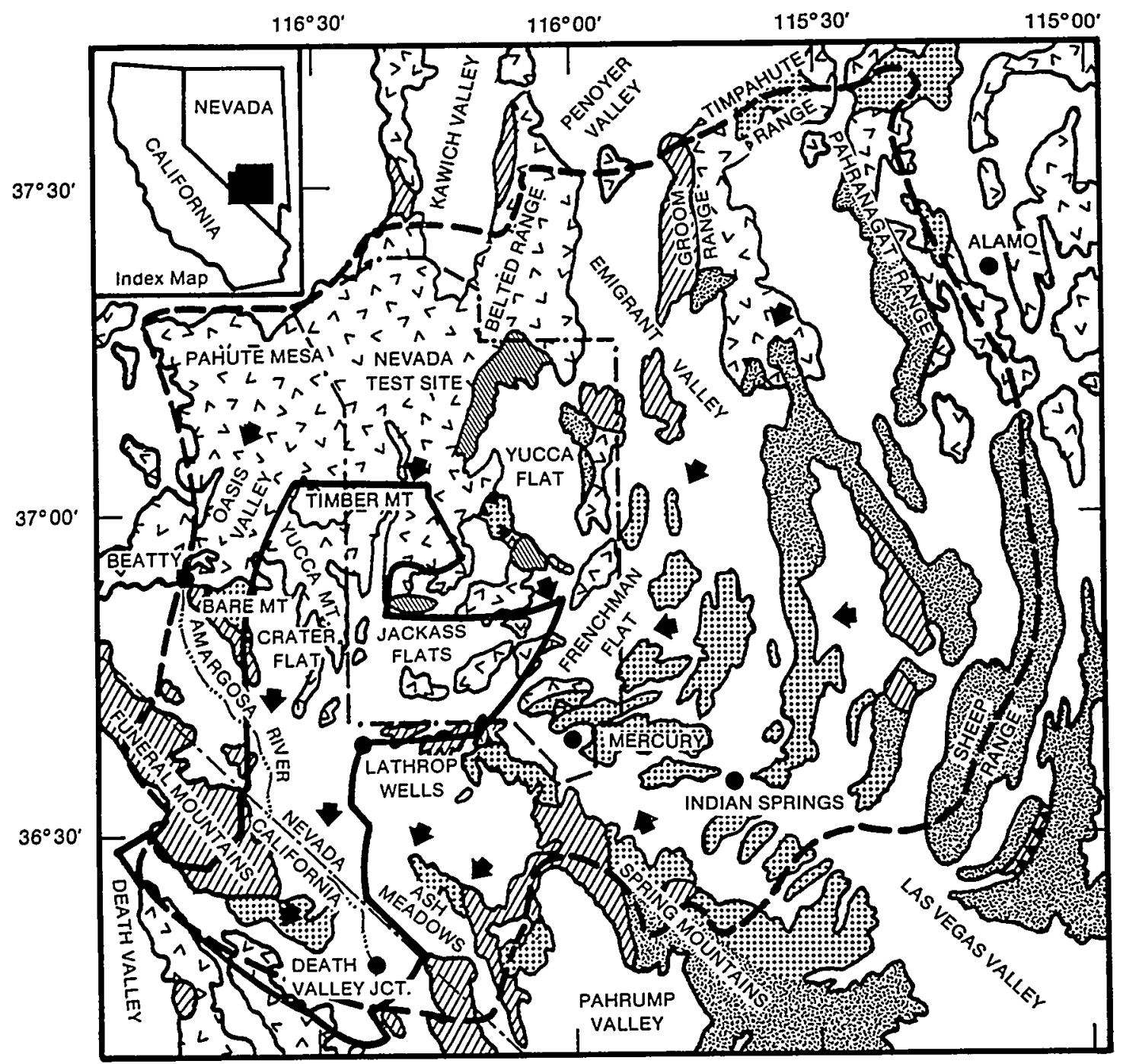

$\mathbf{N}$

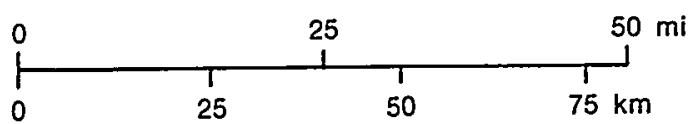

SYMBOLS

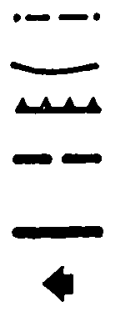

NEVADA TEST SITE

CONTACT

TRUST FAULT WITH SAWTEETH ON UPPER PLATE

REGIONAL MODEL BOUNDARY (Waddell, 1982)

(approximate boundary of groundwater system)

SUBREGIONAL MODEL BOUNDARY (Garnecki and Waddell, 1984).

APPROXIMATE DIRECTION OF GROUNDWATER FLOW
QUATERNARY

ALLUVIUM, LAKE BEDS, AND MINOR VOLCANIC ROCKS TERTIARY

[n ${ }^{2} r$ TUFF, RHYOLITE, AND ASSOCIATED VOLCANIC ROCKS MESOZOIC (Minor--not shown)

PALEOZOIC

UNDIFFERENTIATED UPPER CLASTIC AQUITARD. AND LOWER AND UPPER CARBONATE AQUIFERS

UPPER CLASTIC AQUITARD

LOWER CARBONATE AQUIFER

PALEOZOIC (CAMBRIAN)-PRECAMBRIAN

LOWER CLASTIC AQUITARD

Figure 8.13. Location of Regional and Subregional Modeled Areas, With Generalized Ground-Water Flow Directions, and Generalized Geology (Czarnecki and Waddell, 1984) 


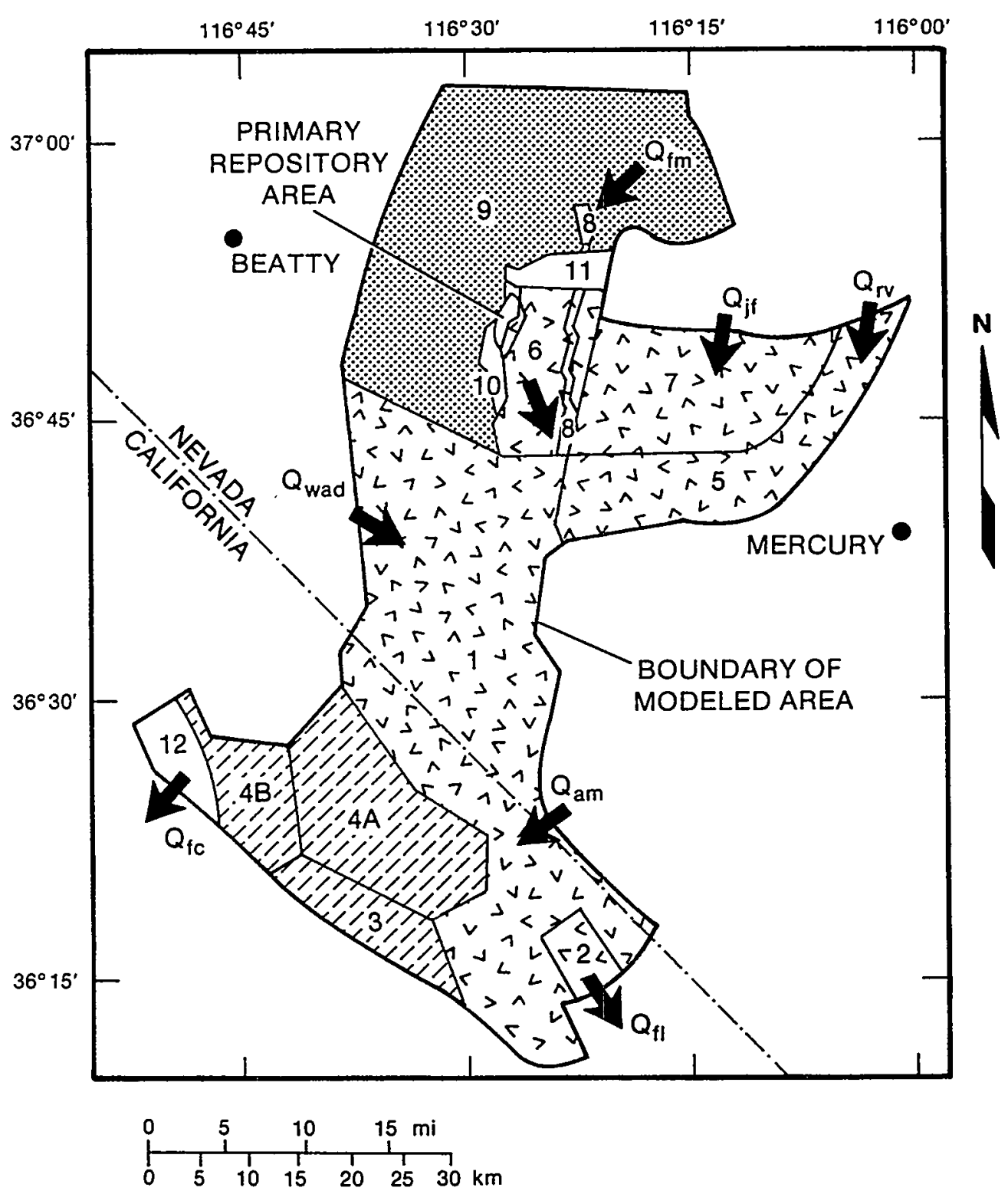

PARAMETER GROUPING SYMBOLS:

1 - 12 MODEL ZONE NUMBER
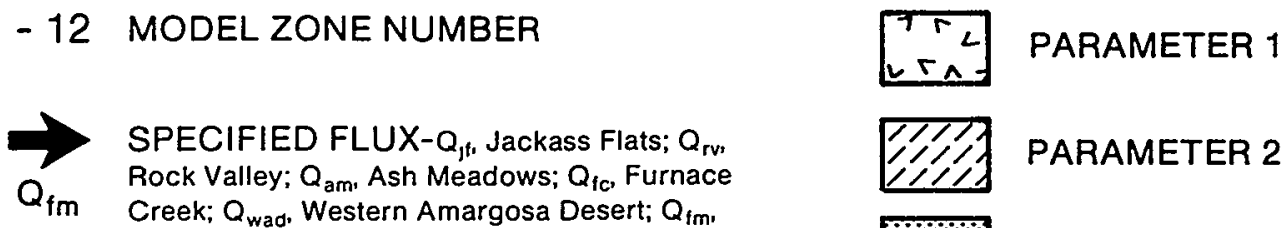

SPECIFIED FLUX- $Q_{\mathrm{ft}}$, Jackass Flats; $Q_{\mathrm{rv}}$, Rock Valley; $Q_{\mathrm{am}}$ Ash Meadows; $Q_{\mathrm{fc}}$, Furnace Creek; $Q_{\text {wad. }}$ Western Amargosa Desert; $Q_{f m}$ Fortymile Wash (Areally Distributed Over Zone 8): $Q_{f i}$ Franklin Lake Playa

PARAMETER 2

PARAMETER 3

Figure 8.14. Model Zone Numbers, Parameter Groupings, and Model Boundary Fluxes Assumed by Czarnecki and Waddell (1984) 
variability could only be attributable to variations in hydraulic conductivity in that variations in the aquifer thickness were not accounted for. Thus, when the model was used to estimate the change in water level caused by variations in recharge, the predicted water level change may be greater than or less than the true change because the hydraulic conductivity value used for the prediction is greater than or less than the true hydraulic conductivity value.

Superimposed on this effect is the fact, that if the water table rises into less transmissive units, the actual hydraulic conductivity would be less than the average hydraulic conductivity. This results in a steeper gradient and higher water table position than the model predicts. The opposite situation would occur if the water table rose into a more permeable unit than the average hydraulic conductivity (Czarnecki and Waddell, 1984).

\subsubsection{Barr and Miller (1987)}

Barr and Miller (1987) evaluated alternative interpretations of how geologic structures control the local flow system below the repository site. They assumed a two-dimensional local system over an area of approximately $8 \mathrm{~km}$ by $20 \mathrm{~km}$. Barr and Miller constrained their conceptual models to be consistent with the regional ground-water flow system interpretation of Czarnecki (1985) (see Figure 8.15).

Barr and Miller considered two different conceptual models. The first model was referred to as a "smooth" model. The smooth model ignored the effect of local structural controls. They assumed that the system behaves as a water table aquifer composed of saturated porous media. The stratigraphy was simplified into one hydrogeologic unit. A calibrated distribution of hydraulic conductivity was established for the region based on inverse calculations and a comparison of predicted hydraulic head values to the measured hydraulic head values. The assumption was made that the aquifer is a uniform thickness of $100 \mathrm{~m}$, based on the results of a tracer study (Thordarson and others, 1984). The hydraulic conductivity vector was allowed to vary in both direction and magnitude.

The second conceptual model was referred to as a "fault-controlled" model. Local structural controls, such as faults that extend to the water table, were assumed to affect the hydraulic gradient distribution of the local ground-water flow system. The fault zones were treated as a porous medium and were assumed to have higher or lower conductivity than the unfaulted zones. 

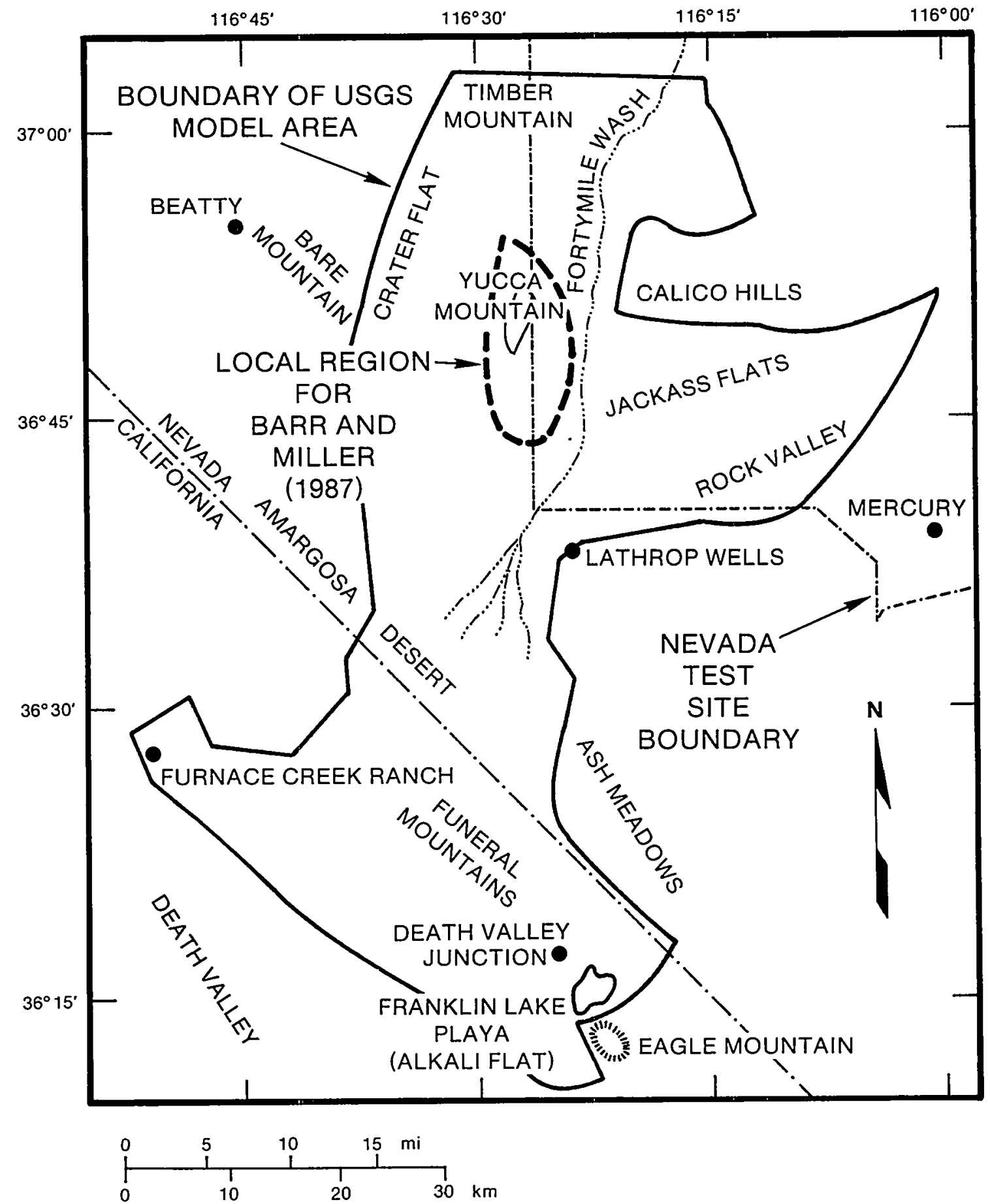

Figure 8.15. Location of the Local System Studied by Barr and Miller (1987) Compared to the Subregional System Studied by Czarnecki (1985) (modified from Barr and Miller, 1987) 
The same boundary conditions were applied to both the smooth and fault-controlled models (see Figure 8.16). Barr and Miller specified constant head boundaries along the external boundary of the local system which were consistent with the subregional model results of Czarnecki (1985). Although not explicitly stated, it appears that areal recharge is neglected in these conceptual models.

Barr and Miller also studied the effect of possible future catastrophic changes to the local ground-water flow system. They allowed the flow system to experience two different types of gross changes: alteration of the hydraulic conductivity around and along faults zones, and connection of the aquifer to new sources or sinks. Several scenarios were studied using both the smooth and fault-controlled conceptual models.

\subsubsection{Discussion of Saturated Ground-Water Flow Assumptions}

Several porous medium models have been developed based on the continuum approach for flow in the saturated zone. The simplest approach is to treat the fracture/matrix system as a porous medium. For the saturated porous medium model, the fracture and matrix flow is combined together and represented by a bulk averaged conductivity. Such a simplification is appropriate if the assumed REV is so large that the fracture/matrix system behaves as an equivalent porous medium, or for any assumed REV, the saturated fracture flow is negligible.

In all of the previously discussed saturated zone conceptual models, the researchers assume a porous medium model (see Table 8.2). Although significant fracture flow is known to occur in the saturated zone, the available hydraulic data for the saturated zone is derived primarily from aquifer tests (Bentley, 1984; Waddell, 1985; Thordarson and others, 1984). Thus, the transmissivity values determined in the field by aquifer tests measure flow through a combination of the fractures and matrix. The saturated zone models neglect fracture flow explicitly, but the models have implicitly accounted for fracture flow through the assigned hydraulic properties.

Under saturated flow conditions in a fractured medium, the fractures generally dominate the water movement. If the fracture network is relatively connected, it may be possible for one to assume that a continuum exists. On a scale of centimeters, laboratory experiments have demonstrated that the cubic law can be assumed for saturated fracture flow through a discrete fracture. However, some investigators have observed that preferential flow paths (and therefore possible discontinuities in the flow field) commonly are present within a single fracture (Chuang, 1988). On a larger scale, preferential flow paths have been observed within a fracture network. That is, the 


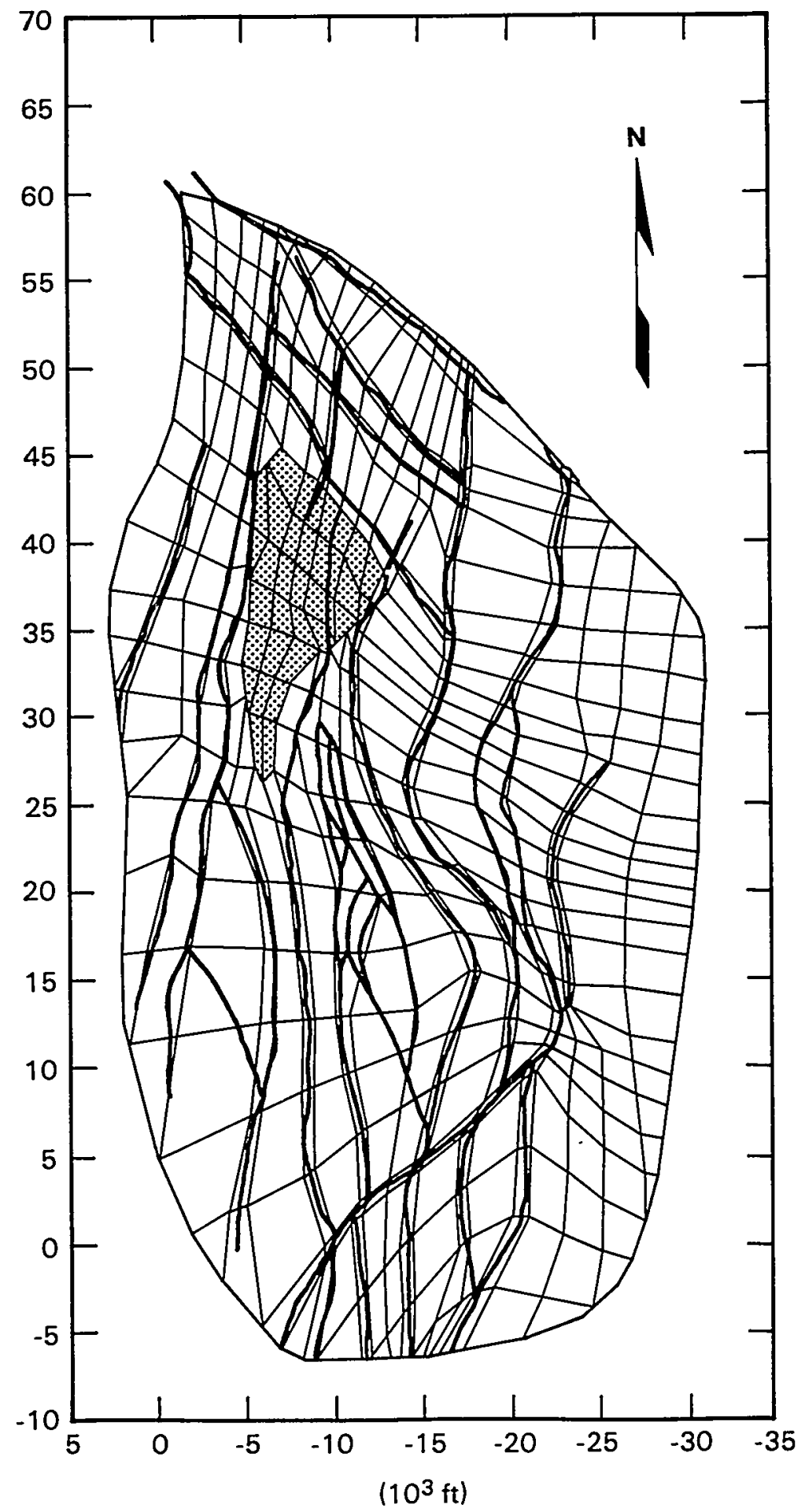

Figure 8.16. Local Region Modeled Around the Repository Block and the Grid of Elements and Nodes Assigned for Calculations in the Conceptual Model by Barr and Miller (1987) 
Table 8.2. Conceptual Model Assumptions for Saturated Flow at a HLW Repository in Fractured Tuff

Assumptions

Previous Conceptual Models

1

$2 \quad 3 \quad 4$

5

Porous Medium

$\mathrm{X}$

$\mathrm{X}$

$\mathrm{X}$

$\mathrm{X}$

$\mathrm{X}$

Composite Porous

Medium

Dual Porosity

Discrete Fracture/

$\mathrm{X}$

Porous Medium

Matrix Only or

Fracture Only

Darcy's Law Assumed

$\mathrm{X}$

$\mathrm{X}$

$\mathrm{X}$

$\mathrm{X}$

$\mathrm{X}$

Scale

$\mathrm{km}$

$\mathrm{km}$

$\mathrm{km}$

$\mathrm{km}$

$\mathrm{km}$

Hydrogeologic

1

1

1

1

1

Units

Homogeneous and

Isotropic

Steady Recharge

Rate

$\mathrm{X}$

$\mathrm{X}$

X

$\mathrm{X}$

Pulse Recharge Rate

Spatially Variable

$\mathrm{X}$

$\mathrm{X}$

$\mathrm{X}$

$\mathrm{X}$

X $\quad \mathrm{X}$

$\mathrm{X}$

$\mathrm{X}$

$\mathrm{X}$

Areal Recharge Rate 
Table 8.2. (continued)

\begin{tabular}{llllll}
\hline Assumptions & \multicolumn{5}{c}{ Previous } \\
& 1 & 2 & 3 & 4 & 5 \\
\hline $\begin{array}{l}\text { Steady-State } \\
\text { Transient }\end{array}$ & $\mathrm{X}$ & $\mathrm{X}$ & $\mathrm{X}$ & $\mathrm{X}$ & $\mathrm{X}$ \\
Dimensions & 2 & 2 & 2 & 2 & $2^{\mathrm{a}}$ \\
& & & & & \\
\hline
\end{tabular}

\section{INVESTIGATOR(S)}

1. Rice (1984) - Calculated regional ground-water flow system flux

2. Waddell (1982) - Calculated regional ground-water flow system flux

3. Czarnecki and Waddell (1984) - Evaluated sensitivity to boundary flux changes

4. Czarnecki (1985) - Estimated variations in water table elevation

5. Barr and Miller (1987) - Evaluated structural control on hydraulic gradient

a - Pseudo three-dimensional system (vertical leakage through fault zone is allowed in some cases) 
majority of the flow paths may be located within a minority of the fractures. Also, some large-scale solution caverns (with length on the order of kilometers) are present in the region (Winograd and Thordarson, 1975). The solution caverns may cause a discontinuity in the flow field for an REV that includes an area larger than the solution caverns. Conversely, continuous flow may occur in an REV that only includes the caverns. Thus, the scale over which a continuum is assumed is of utmost importance.

Another concern with assuming a continuum (and therefore Darcy's law) in the saturated zone is that the fracture flow velocities may be so large that turbulent flow occurs and Darcy's law is no longer valid. According to Bear (1972), if the dimensionless number expressing the ratio of inertial forces to viscous forces (i.e., the Reynolds number) based on an average grain diameter does not exceed some value between 1 and 10, then Darcy's law is valid. The Reynolds' number is a function of the fluid density and viscosity, the specific discharge, and a representative length dimension (i.e., average grain diameter). Because the lower carbonate aquifer is highly fractured due to tectonic and solution processes (Winograd and Thordarson, 1975), it may be possible for turbulent flow to occur in large fractures and solution cavities, thus invalidating Darcy's law.

The conceptual models describing flow through the saturated zone cover a much larger area than the unsaturated zone conceptual models. The size of all of the saturated zone models is on the order of kilometers, ranging from the largest regional model of $6 \times 10^{4}$ $\mathrm{km}^{2}$ (Rice, 1984) to the local model containing approximately $160 \mathrm{~km}^{2}$ (Barr and Miller, 1987) (see Table 8.2). The regional ground-water flow system includes a large area so that the boundary conditions can be based on actual physical boundaries as much as possible.

Most of the saturated zone conceptual models assume the hydrogeologic framework described by Winograd and Thordarson (1975), who defined aquifers based on variations in lithology. Similar to designating hydrogeologic stratigraphy in the unsaturated zone (Section 8.1.9), it may also be necessary to incorporate hydrogeologic data; this may assist in determining the saturated zone flow paths. However, the multi-layered system of alluvium, volcanic tuff, and carbonate rocks was integrated into a single layer in all of the saturated zone conceptual models (see Table 8.2). Within each designated transmissivity zone, the researchers assumed that the aquifer was homogeneous. The hydraulic properties were allowed to vary spatially, zone by zone, with the most transmissive unit present in each zone determining the designated transmissivity of that zone. This approach is not valid if vertical flow occurs. Because the most transmissive continuous hydrogeologic unit will dominate the horizontal flow, determination of 
different areal transmissivities partially accounts for hydrogeologic variations in the vertical third dimension.

The researchers attribute the assumption that the aquifer acts as one hydrogeologic unit partially to the current lack of data for the region. However, there is substantially more information available for the saturated zone than for the unsaturated zone. There are two geologic boreholes which were drilled to depths down to $1800 \mathrm{~m}$, seven hydrologic test holes, and fourteen monitoring wells in the repository area of approximately $100 \mathrm{~km}^{2}$ (see Figure 8.17).

The areal recharge rate is an important factor in the saturated zone conceptual models. As discussed previously, the amount of infiltration (and hence recharge) to the region varies over time and space. Because all the saturated zone models have assumed that steady-state flow conditions exist, the recharge rate is also assumed to be at steady-state. All the saturated zone conceptual models allowed for spatially variable recharge to occur, with the exception of the Barr and Miller model (1987) (see Table 8.2). Barr and Miller assumed that the areal recharge rate is negligible for the purpose of investigating the effects of geologic structure on the saturated flow field in their local ground-water flow system. In an arid climate, their assumption is justified because the volume of water that enters the saturated flow system as through-flow is substantially larger than the amount of areal recharge available.

The steady-state flow assumption has been made for all of the saturated zone conceptual models (see Table 8.2). The regional ground-water flow system may be in a state of hydrodynamic equilibrium, meaning that over large periods of time the input and output to the system are essentially equal. However, Brikowski (1989) suggests that it may not be appropriate to assume steady-state conditions for a regional system where the recharge rate is known to have varied considerably in the past. Brikowski suggests a valid argument, considering the regulatory time-frame of interest which includes at least $10^{4}$ years. In localized areas of the region, within a time frame which may include days or even years, the steady-state condition may be violated in areas where intense pumping has occurred. Changes in the water levels due to pumping have been documented in Ash Meadows, Pahrump Valley, and Sand Spring Valley. However, the changes in water level are small, given the range of hydraulic heads measured over the entire region and the uncertainty in the interpreted hydraulic-head distribution (Rice, 1984).

All the saturated zone conceptual models have assumed a one-layer aquifer system where only two-dimensional horizontal flow is allowed, with the exception of the Barr and Miller model (1987). Barr and Miller assumed a one-layer aquifer system where 


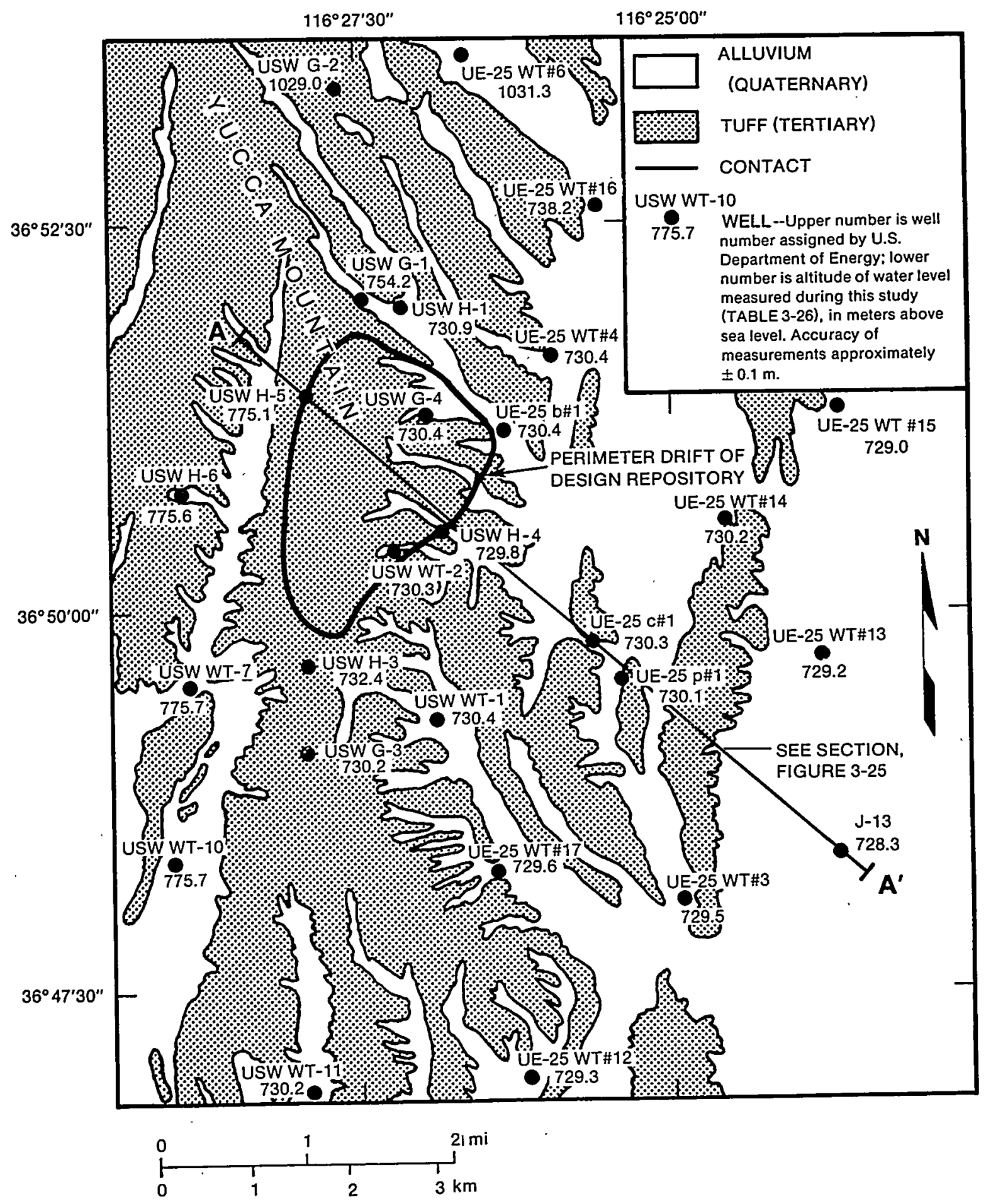

Figure 8.17. Preliminary Composite Potentiometric Surface Map of the Saturated Zone, Yucca Mountain (modified from DOE, 1988) 
vertical flow can occur (see Table 8.2). Horizontal flow occurs in a homogeneous, isotropic, confined aquifer of constant thickness. The assumption of horizontal flow is appropriate for an aquifer that is relatively thin compared to its horizontal dimensions, or if the thickness variation of the aquifer is much smaller than the average thickness (Bear and Verruijt, 1987). The horizontal flow assumption is violated if there are large vertical flow components. Overall, in a regional flow system such as this, downward flow will probably occur in the areas of major recharge, and upward flow may occur at discharge points. Vertical flow components may also be dominant in localized zones of sources or sinks. There is evidence that vertical flow occurs in both the upward and downward directions beneath the Pahute Mesa (Blankennagel and Weir, 1973). Beneath Yucca Mountain, there is evidence of an upward flow component from the lower aquifer (Czarnecki, 1989). If the saturated zone is treated as a single aquifer system, assuming horizontal flow may be reasonable for the regional flow conceptual model, although vertical flow may dominate on local scales. However, there are no definitive data in the field that support the assumption that only one aquifer system exists. In fact, according to recent work by Czarnecki (1989), there may be two nonconnected flow systems below the repository site that move in directions nearly perpendicular to each other. Further evaluation of the hydraulic gradient at the repository site is necessary to determine whether Czarnecki's hypothesis can be substantiated. Care must be taken to evaluate the hydraulic head measurements so that composite water levels are not compared to static water levels, which can represent either the upper or lower aquifer.

\subsection{Solute Transport}

The following sections summarize and discuss previous conceptual models of radionuclide transport from a high-level nuclear waste repository located in unsaturated, fractured tuff. To reiterate, the emphasis is on the description of each conceptual model and not the purpose or the results of each study. To describe each conceptual model, each assumption that is made is discussed, since assumptions, by definition, form the conceptual model. The last section evaluates the assumptions that were made with regard to assessing performance of a HLW repository located in unsaturated, fractured tuff; the perceived purpose of each study.

\subsubsection{Sinnock and others (1984)}

The purpose of the conceptual model presented by Sinnock and others (1984) was to set preliminary bounds on the expected postclosure performance of the Yucca Mountain Repository Site. It is included in this review because it is one of the first attempts to assess the suitability of a repository site in unsaturated, fractured tuff. 
Sinnock and others made several assumptions about radionuclide migration in their transport conceptual model. They assumed that all releases of waste from the repository were caused by ground water that flows through the repository and dissolves the spent fuel. Consequently, they did not consider transport of radionuclides in the gas phase.

Sinnock and others assumed that the ground-water flow path, and therefore the transport path, was vertically downward from the repository through the unsaturated zone to the water table, and then flowed horizontally through the saturated zone to the accessible environment (see Figure 8.18). Based on this migration path, they considered transient radionuclide transport in a steady-state flow field in only one dimension (vertically in the unsaturated zone and then horizontally in the saturated zone).

Sinnock and others assumed that the species velocity of any radionuclide was equal to the water velocity divided by a constant retardation factor for that radionuclide. They assumed that this retardation factor represents the combined effects of any transport process (e.g., sorption, precipitation, matrix diffusion) that can slow the net migration of the radionuclide species. Consequently, the conceptual model did not directly account for matrix diffusion and did not consider diffusion and dispersion.

The retardation factor that was used by Sinnock and others for transport in the matrix was assumed to be described by a sorption distribution coefficient, effective porosity, and bulk density. By using a distribution coefficient to define the retardation factor, they implicitly assumed that equilibrium conditions existed and considered only the chemical process of sorption for retardation. This may be inconsistent with the initial assumption that the retardation factor represented all the transport processes that may contribute to retardation in the geosphere.

For transport in the fractures, Sinnock and others assumed that the retardation factor is characterized by a sorption distribution coefficient and the ratio of surface area to void volume. They assumed that the fracture distribution coefficients were equal to the matrix distribution coefficients divided by the specific surface area. Sinnock and others assume that the fracture surfaces were planar and smooth; therefore, the ratio of surface area to void volume was equal to two divided by the fracture aperture.

In assigning retardation values to each radionuclide, Sinnock and others considered two transport paths through the unsaturated zone. The first path was through the vitric Calico Hills unit to the water table, and the second path was through the zeolitic Calico Hills unit (these units were next to each other beneath the repository). Transport through the unsaturated zone was only considered through the Calico Hills unit because 


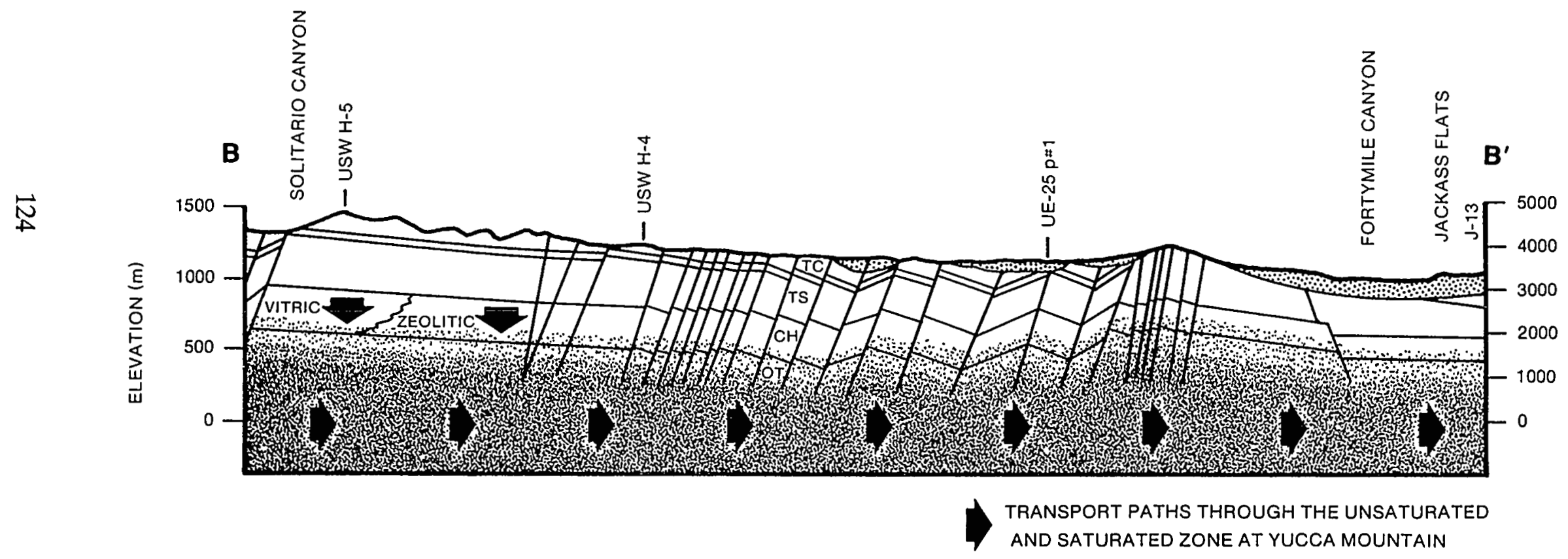

Figure 8.18. Transport Paths Assumed by Sinnock and others (1984) 
the investigators assumed that the disturbed zone extended to the edge of the Topopah Spring unit and that the Calico Hills unit extended to the water table.

Sinnock and others assigned retardation factor values to each radionuclide for matrix transport and fracture transport. Because they assumed a continuum within each unit for either matrix or fracture transport, the only difference between transport in the matrix or fractures was the value of the retardation factor. They based the determination of whether or not transport occurred through the matrix or fractures on the assumed ground-water flux. For the vitric Calico Hills unit and for all considered ranges of flux, they assumed that transport occurs only in the matrix, so they implemented the matrix retardation values. For a flux of less than $1 \mathrm{~mm} / \mathrm{yr}$, they assumed that only matrix transport occurred in the zeolitic Calico Hills unit and also used the matrix retardation values. Sinnock and others postulate that this relatively low flux $(1 \mathrm{~mm} / \mathrm{yr})$ is the likely threshold value for matrix flow based on studies done by Wang and Narasimhan (1985) and Travis and others (1984a,b). See Section 8.1 for a discussion of each of these studies. For flux values greater than $1 \mathrm{~mm} / \mathrm{yr}$, they assumed that transport occurs only in the fractures and they used fracture retardation factors for the zeolitic Calico Hills unit. For transport in the saturated zone, Sinnock and others assumed that transport occurred only in the fractures and that there was no retardation of solutes (i.e., the retardation factor for each radionuclide was equal to one).

Sinnock and others also assumed that radioactive decay occurs for contaminant transport, and considered up to five members in each decay chain. Also, for radioactive decay, they assumed that all fission products are single-member chains.

\subsubsection{Travis and others (1984a,b)}

The Travis and others (1984a,b) study examined the effect of lithology and the presence of fractures on water flow and radionuclide transport through fractured tuff. They accomplished this by conducting a sensitivity analysis using analytical and numerical techniques.

There are several assumptions that Travis and others made in developing their transport conceptual model. The radionuclide transport path that Travis and others assumed is similar to that used by Sinnock and others (1984). Travis and others assumed that the radionuclides dissolve in the ground water at the repository and travel in one dimension vertically downward through the unsaturated zone. The dissolved radionuclides then flow horizontally through the saturated zone. However, the hydrogeologic units that they considered differ somewhat from Sinnock and others. Travis and others considered 
transport through four stratigraphic units (see Figure 8.19). These units were the Topopah Spring (densely welded), bedded tuff (densely welded), and Calico Hills unit (undifferentiated tuff) in the unsaturated zone, and the Prow Pass unit (older volcanics) in the saturated zone.

Travis and others considered transient radionuclide transport in either a porous medium or in a porous medium containing a set of parallel, equidistant, vertical fractures. They assumed that a continuum exists in both the porous medium or the fractured, porous medium. The difference between fracture transport and matrix transport is determined by the properties used in the governing equations. The researchers assume matrix transport or fracture transport depending upon the stratigraphic unit through which migration is occurring. For the Topopah Spring and bedded tuff units, they assumed that only transport in the fractures occurs. The fracture apertures and spacing were assumed to be constant across each unit. They used a constant fracture flow rate for the transport through the unsaturated, densely welded units. This flow rate was based on the saturated flow rate through fractured Topopah Spring tuff that was estimated by Waddell (1983). Therefore, Travis and others assumed that the fractures were saturated and flow is continuous; which was also considered to be a conservative assumption. For their first analysis, in the Calico Hills unit, they assumed that transport in the fractures is similar to that found in the Topopah Spring and bedded tuff units. Later, Travis and others assumed that transport occurs only in the porous matrix in the Calico Hills unit. They assumed a constant flow rate that was two orders of magnitude less than the flow rate they assumed for fracture transport.

For the horizontal pathway through the saturated zone, Travis and others assumed that only fracture transport occurs, again with a constant flow rate. This flow rate value was taken from the rough estimates for flow from Pahute Mesa to Yucca Mountain reported by Blankennagel and Weir (1973).

Travis and others included convection, retardation, and diffusion for transport in the porous matrix (i.e., in the Calico Hills unit). For the fractures, the researchers assumed that only transport by convection occurs and did not consider the effects of dispersion or diffusion. For matrix transport, they used the retardation coefficients based on sorption distribution coefficients. For diffusion in the tuffaceous matrix, they assumed that the unsaturated nature of the tuff could be accounted for by multiplying porosity and diffusivity by saturation values.

For the radionuclide source, Travis and others also assumed that a decaying source was injected into a fracture at the top of a layer, and included ten radionuclides in their 


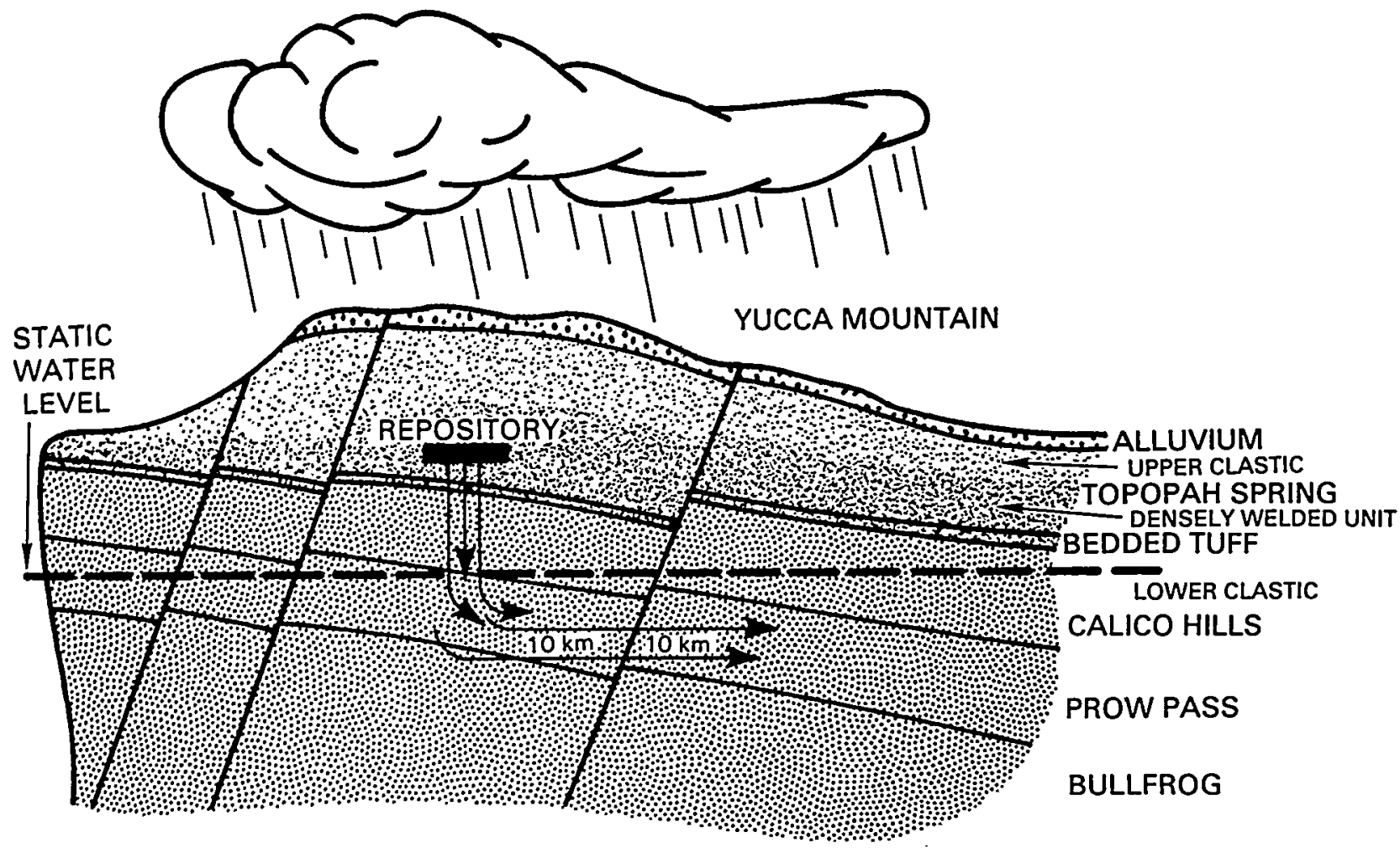

$\longrightarrow$ TRANSPORT PATH THROUGH THE UNSATURATED AND SATURATED ZONE AT YUCCA MOUNTAIN

Figure 8.19. Transport Path Assumed by Travis and others (1984a,b) 
analysis. Travis and others included the process of radioactive decay in their conceptual model but only considered single member chains.

\subsubsection{Lin and others (1986)}

The study performed by Lin and others (1986) documented analyses of ground-water travel time and radionuclide transport in support of the Environmental Assessment (EA) document of the Nevada Nuclear Waste Storage Investigations (NNWSI) Project. The ground-water travel time analysis that Lin and others conducted is discussed in Section 8.1.3.

For the radionuclide transport analysis, Lin and others incorporated all the assumptions from the ground-water travel time (flow) analysis. These assumptions included onedimensional steady state ground-water flow through the unsaturated zone to the water table. For solute migration, they assumed that time-dependent transport occurred along this same ground-water flow path starting at the repository to the water table (see Figure 8.20). Their conceptual model did not consider gas phase transport in the unsaturated zone nor transport in the saturated zone. As discussed in Section 8.1.3, they assumed that flow occurs in the matrix only if the flux is less than the saturated hydraulic conductivity, and flow occurs in the fractures if the flux is greater than the matrix saturated hydraulic conductivity. This is consistent with the transport model, where they assumed a continuum in both systems; the only difference between matrix transport and fracture transport is the ground-water travel times that are used.

Lin and others neglected diffusion because they assumed it to be small in compared to the rates of mass transport by convection. They also did not include dispersion in the traditional convective-dispersion governing equation for transport. Instead, they assumed that the physical transport process of dispersion could be represented with a distribution of ground-water travel times. Conceptually, this involves dividing the area for transport into parallel stream tubes, and then assigning each stream tube a travel time. This gives the set of tubes a distribution of ground-water travel times. They originally performed a flow analysis (see Section 8.1.3) to determine this distribution of ground-water travel times based on the uncertainty in flow parameters. From this distribution they inferred a mean and variance. They then used this mean and variance for the transport analysis assuming a normal distribution of ground-water travel times. Consequently, an inconsistency between flow and transport is apparent. Lin and others explicitly noted the approximation of the empirical ground-water travel time distribution by a normal distribution and discussed the effects of this approximation on discharge at the accessible environment. 


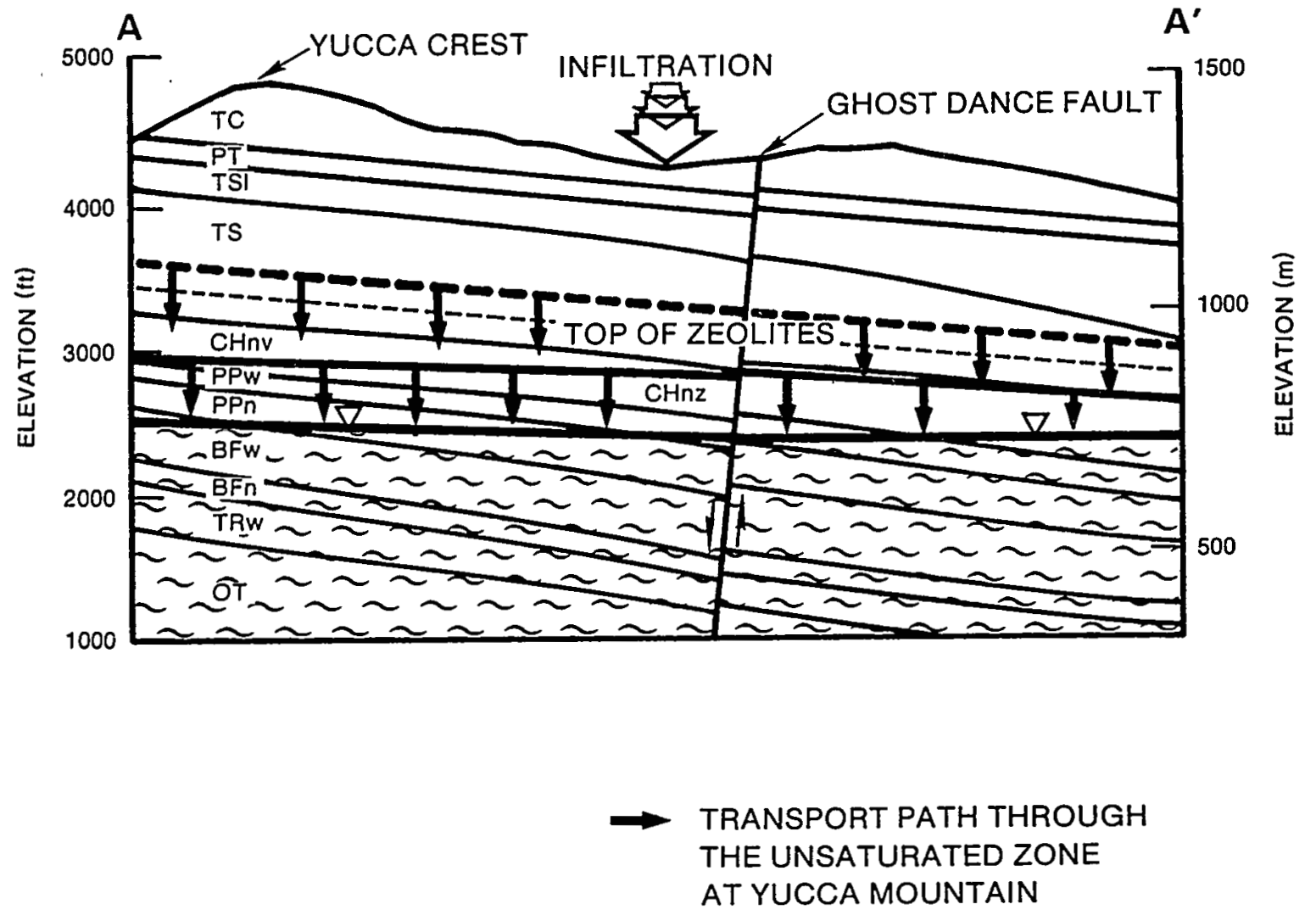

Figure 8.20. Transport Path Assumed by Lin and Others (1986) 
In their conceptual model, Lin and others limited their transport analysis to three radionuclides $\left({ }^{14} \mathrm{C},{ }^{129} \mathrm{I}\right.$, and $\left.{ }^{99} \mathrm{Tc}\right)$ that are single-member decay chains, and assumed that these radionuclides did not sorb onto the porous medium. Consequently, they did not include retardation and multi-membered decay chains in their transport conceptual model. They neglected multiple member chain elements under the assumption that these elements do not have significant contributions to the mass release on a time scale of $10^{5}$ years or less.

The source term for transport that Lin and others used was an upper-bound approximation of the radionuclide release rate from a single reference canister. Therefore, to obtain the total release rate from the nuclear waste inventory, the release rate from the single canister was multiplied by the number of waste canisters in the repository (estimated to be 21000). The failure of the canister to contain and isolate radioactive material was assumed to occur after 1000 years. Consequently, no release from the repository occurred before 1000 years. Lin and others determined the upperbound approximation by estimating a maximum rate at which water could steadily enter and leave a breached canister, and then multiplying this rate by a solubility limit and the ratio of mass of the radionuclide to the mass of the spent-fuel waste matrix for any given time. They assumed that the maximum water flow rate equals the percolation flux at the repository level multiplied by an effective water-intercept area for the canister. They assumed that this area is the projected area of the canister in a plane perpendicular to the direction of flow, ignoring the protective effects of the spent-fuel cladding and canister materials. The solubility limit was either the solubility limit for the radionuclide or the solubility limit of the spent-fuel matrix (uranium dioxide), whichever was smaller. They assumed that the mass of the radionuclide as a function of time is dependent on the decay rate of the radionuclide. Lin and others also assumed that the mass of the spent-fuel matrix at any time is constant and equal to the mass present at closure.

\subsubsection{Dudley and others (1988)}

The study performed by Dudley and others presented the basic physical model used by TOSPAC (Total System Performance Assessment Code) for calculation of radionuclide transport within ground water flowing through an unsaturated, fractured porous medium. After describing the basic physical models, Dudley and others (as an example) applied the model to a repository located in a planar horizon at Yucca Mountain. Consequently, they presented a transport conceptual model of Yucca Mountain. The corresponding flow conceptual model (Peters and others, 1986) is discussed in Section 8.1.2. 
The conceptual model for transport described by Dudley and others is similar in many respects to the transport conceptual models discussed previously. They considered only transient transport in the unsaturated zone in one dimension, and neglected gas phase transport. Dudley and others assumed that transport occurs vertically downward through the Topopah Springs welded nonlithophysal unit (TSw2-3) and the Calico Hills nonwelded unit ( $\mathrm{CHn}$ ) to the water table (see Figure 8.21). The repository was assumed to be located entirely within the TSw2-3 unit. For the flow conceptual model, they assumed five stratigraphic units from the land surface to the water table, including TSw23 and $\mathrm{CHn}$, and they assumed that the hydrologic environment is steady-state vertical flow.

The foundation for the transport conceptual model presented by Dudley and others was the basic convective-dispersion equation. They used this equation to describe transport in the matrix and in the fractures, and a matrix/fracture term coupled the two equations. Consequently, they assumed a continuum for the matrix and for the fractures. According to these governing equations, Dudley and others assumed that the following transport processes occur in both the matrix and the fractures: convection, dispersion, diffusion, sorption, precipitation and radioactive decay. They implemented the matrix groundwater flux values and the fracture ground-water flux values as calculated from the flow analysis (see Section 8.1.2 for a description of the corresponding flow conceptual model) for the convection process included in the transport conceptual model.

Dudley and others estimated hydrodynamic dispersion with a dispersion coefficient for the fractures and a dispersion coefficient for the matrix. This coefficient included the effects of both mechanical dispersion and diffusion. Dudley and others assumed that diffusion could be represented by the free diffusion coefficient in water divided by a tortuosity factor. They also assumed that the resulting effective diffusivity is a linear function of the corresponding water content. For the Yucca Mountain example, Dudley and others assumed that the free diffusion coefficient in water for all the radionuclides was a constant value. They assumed that the fracture tortuosity is unity (i.e., the path is not tortuous) based on the assumption that the tortuous path in the fractures is negligible compared to the tortuous path in the matrix. They assumed that the tortuosity for the matrix is a constant value, based on data reported by Daniels and others (1982).

Dudley and others assumed that mechanical dispersion is represented by the product of the velocity and a dispersivity. They assumed that the velocities for the matrix and fractures are equal to the corresponding ground-water flux values divided by the corresponding moisture contents. These velocities were slightly different from the ground-water velocities defined in the flow conceptual model in that, for calculating the 


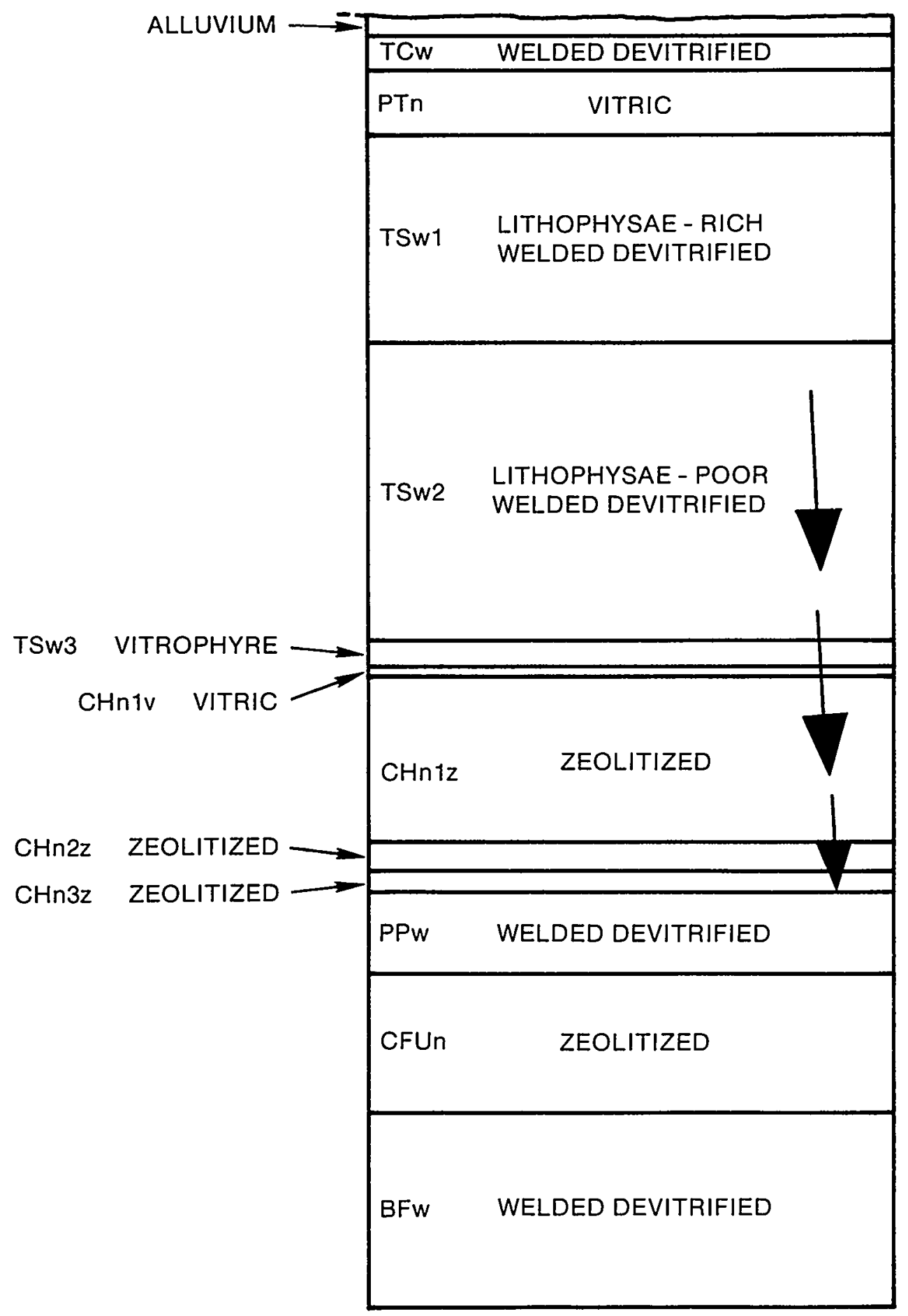
$\longrightarrow \begin{aligned} & \longrightarrow \text { TRANSPORT PATH THROUGH THE UNSATURATED } \\ & \text { ZONE AT YUCCA MOUNTAIN }\end{aligned}$

Figure 8.21. Transport Path Assumed by Dudley and Others (1988) 
flow velocity, the flux was divided by an effective moisture content. Dudley and others assumed that this effective moisture content is the total moisture content minus the residual moisture content. In effect, they assumed that the residual moisture content represented stagnant water that was not available for flow. For transport, Dudley and others assumed that this stagnant water was available because solute can diffuse into the stagnant water. However, they only used this velocity to represent mechanical dispersion which does not influence diffusion; therefore, this assumption seems inconsistent.

Dudley and others assumed that they could infer dispersivity values needed in their conceptual model of dispersion by using the stochastic approach to dispersion (see Section 5.1 and de Marsily, 1986, for a discussion of this approach). This approach assumes that hydraulic conductivities are spatially correlated, and this correlation results in dispersivities that increase over space and time. To infer dispersivity values, the conceptual model presented by Dudley and others requires statistical information (i.e., average velocity, standard deviation, correlation length) about the velocity field. Currently, the nature of dispersion in unsaturated and fractured tuff has not been addressed, and data are not available to support the stochastic approach to dispersion in unsaturated, fractured tuff.

In applying the stochastic approach, Dudley and others assumed that, within a geological unit, the dispersivity was only a function of properties of that unit; however, between two units, the dispersivity was assumed to be a weighted average. For Yucca Mountain, Dudley and others assumed correlation lengths for both the fracture and matrix system, because data needed to determine these lengths does not exist. The asymptotic values of dispersivity for each system were assumed to be $10 \%$ of the flow path length.

Dudley and others accounted for sorption in a manner similar to the sorption conceptual models discussed previously. They also assumed that the retardation factor is based on a distribution coefficient; however, instead of using porosity, they used moisture content. They assumed that the moisture content accounted for the unsaturated nature of the geologic medium. For the Yucca Mountain fractures, Dudley and others assumed that all distribution coefficients are zero and that no retardation of solutes occurs.

Dudley and others assumed that precipitation will occur if the solubility limit for the corresponding radionuclide is exceeded locally. This precipitate then becomes available for re-dissolution if the solution concentration falls below the solubility limit. This results in nonzero source contributions external to the actual repository. 
For radioactive decay, Dudley and others assumed that the radionuclides are members of a single nonbranching decay chain. The conceptual model did not limit the number of members in a chain or the number of chains allowed. For the Yucca Mountain analysis Dudley and others included only seven representative radionuclides $\left({ }^{14} \mathrm{C},{ }^{99} \mathrm{Tc}\right.$, ${ }^{129} \mathrm{I},{ }^{232} \mathrm{Th},{ }^{236} \mathrm{U},{ }^{238} \mathrm{U},{ }^{240} \mathrm{Pu}$ ). They estimated the source term from the repository by assuming that the fractional release rate of radionuclides from the spent-fuel inventory was equal to the fractional leach rate of the uranium dioxide matrix. They also assumed that the rate of waste matrix dissolution was a function of the solubility limit of uranium dioxide and the amount of water available. Dudley and others assumed that transport of the dissolved species to the source boundary was instantaneous, and that the transport behavior in the near-field region of the waste package was similar to transport in the adjacent undisturbed rock (i.e., they neglected any difference between transport in the disturbed zone and transport in the far-field region).

Dudley and others also assumed that the coupling term between the matrix and fracture system is made up of two components, an advective part and a dispersive part. They assumed that the advective component is equal to the product of the water transfer rate and the concentration at the matrix fracture boundary. They assumed that this boundary concentration is equal to the concentration in the fracture if transfer is occurring between the fractures and the matrix. For transfer between the matrix and the fractures, they assumed that the boundary concentration is equal to the matrix concentration.

The hydrodynamic dispersive component of the coupling term assumes that only diffusion occurs between the fractures and the matrix located transverse to flow. Essentially, this component accounts for the physical process of matrix diffusion discussed in Section 5.2. Dudley and others determined that the dispersive component is equal to the product of the difference between the concentration in the matrix and the fracture, the moisture content in the matrix, the effective diffusivity of the matrix, and a numerical factor, all divided by half the fracture spacing. The numerical factor in this definition indicates the magnitude of the diffusive transfer between the fractures and the matrix. If this factor is equal to unity, which Dudley and others define as the standard diffusive coupling term, then the diffusive transfer between the matrix and fractures is strong (i.e., there is hardly any resistance to transfer between the matrix and fractures). For values less than unity, diffusive transfer is weak (i.e., there is resistance to mass transfer between the matrix and fractures).

Initially, for Yucca Mountain, Dudley and others estimated this diffusive transfer factor to be one. In doing so, they assumed that there is strong coupling between the matrix and fractures, which results in equal concentrations in the matrix and fractures. 
Consequently, the two governing equations for transport in the matrix and transport in the fractures were represented by one equation. This one governing equation was similar to and consistent with the corresponding flow conceptual model of a composite porous medium (see Section 5.1). However, Dudley and others also estimated this diffusive transfer factor to be four orders of magnitude lower than the initial estimate. In doing so, they assumed that there was resistance to diffusion (i.e., possibly fracture coating), and that the concentration in the matrix and in the fractures are not equal. There is no experimental data available upon which to base this diffusive transfer factor, and any value used is questionable.

\subsubsection{Ross (1988)}

The study by Ross presented a conceptual and mathematical model of the migration of gas-phase ${ }^{14} \mathrm{C}$ from spent fuel buried at Yucca Mountain, Nevada to the land surface (i.e., accessible environment), but no analyses were conducted. Ross made several assumptions to form this conceptual model.

For the physical transport system, Ross assumed that the fractured, unsaturated tuff was a homogeneous porous medium (i.e., the fractures and matrix can be represented by a single continuum). He also assumed that gas-phase ${ }^{14} \mathrm{C}$ moved upward towards the land surface in one dimension through air-filled pores. The proposed boundary conditions for gas phase transport were the water table and the base of the root zone. Ross indicated that models of the flux at either boundary may not be possible and it is more likely that the concentrations at these boundaries will have to be set to measured values.

For his conceptual model, Ross assumed that from a model of $\mathrm{CO}_{2}$ transport a model of the transport of ${ }^{14} \mathrm{C}$ can be found. This is based on Ross assuming isotopic equilibrium between gas-phase $\mathrm{CO}_{2}$ and dissolved bicarbonate, and that no ${ }^{14} \mathrm{C}$ will be released from the dissolving calcite (i.e., the carbon atoms in the solid calcite have no ${ }^{14} \mathrm{C}$ content). Because of these assumptions, subsequent discussion about the conceptual model formulated by Ross will be for $\mathrm{CO}_{2}$ transport.

The transport processes that Ross assumed to contribute to gas movement were diffusion and convection. He assumed that the driving force for diffusion was a concentration gradient and, for convection, he assumed that gas flow was density driven. Ross assumed that the gas density was dependent on temperature and the partial pressure of water vapor. He did not assume that the density was dependent on the partial pressure of $\mathrm{CO}_{2}$; consequently, air-flow and $\mathrm{CO}_{2}$ transport were de-coupled and independent of each other. 
Ross assumed that liquid diffusion and liquid convection did not contribute to transport of $\mathrm{CO}_{2}$ in the gas. phase. $\mathrm{He}$ assumed that the carbon species that are contained in the liquid-phase (i.e., dissolved bicarbonate) are immobile relative to the mobile species in the gas phase.

Ross assumed that several chemical processes occurred in the system. This processes considered transfer between gas phase and liquid phase carbon species and between liquid and solid carbon species. The specific carbon species were gas $\mathrm{CO}_{2}$, liquid bicarbonate and solid calcite and the concentrations of each of these species are needed to estimate interphase transfer. Ross assumed that chemical equilibrium exists between gaseous $\mathrm{CO}_{2}$ and dissolved bicarbonate in the liquid phase and that calcite is the only carbonate mineral in the system that is important. To find concentrations of these species, a conceptual model of the carbonate chemistry of the system must be assumed.

Ross presented three alternative carbonate chemistry conceptual models. The first conceptual model that he presented assumed that the principal chemical reaction determining the behavior of the system was the dissolution of calcite by carbonic acid and that this reaction was at equilibrium. The second carbonate chemistry conceptual model that Ross presented assumed that the principal reaction in the system was precipitation of calcite. For this conceptual model he assumed that the calcium concentration was fixed and that the principal reaction was at equilibrium. For both of these conceptual models, Ross assumed that pore waters were saturated with calcium carbonate. The third carbonate chemistry conceptual model that Ross presented did not assume this.

\subsubsection{Discussion of Assumptions Used in Previous Solute Transport Conceptual Models}

Table 8.3 summarizes the major characteristics and assumptions of the transport conceptual models discussed previously (Sections 8.3.1 - 8.3.5). Each of these major assumptions will be discussed in the following section.

It is evident from Table 8.3 that all the conceptual models described consider transport of radionuclides in only one dimension. Obviously, this is a simplification of the physical three-dimensional system. For assessing the performance of a repository (which constitutes physical dimensions on the order of kilometers and time scales on the order of $10^{5}$ years) this simplification may be advantageous. However, due to the complexities associated with unsaturated, fractured, porous media, at least two dimensions may have to be considered for transport. There is one way to simplify the transport analysis; if the velocity field is described in detail (i.e., three dimensions), then it may be possible to 
Table 8.3. Conceptual Model Assumptions for Solute Transport at a HLW Repository in Fractured Tuff

Assumptions
Previous Conceptual Models

1
5

1

$\mathrm{X}$

$\mathbf{X}$

Gas Phase Transport

Saturated Zone

Transport

Matrix Transport

$\mathrm{X}$

$\mathrm{X}$

$\mathrm{X}$

$\mathrm{X}$

$\mathrm{X}$

Fracture Transport

$\mathrm{X}$

$\mathrm{X}$

$\mathrm{X}$

$\mathrm{X}$

$\mathrm{X}$

Matrix and Fracture

Transport

Continuum assumed

Convection

$\mathrm{X}$

$\mathrm{X}$

$\mathrm{X}$

$\mathrm{X}$

$\mathrm{X}$

$\mathrm{X}$

$\mathrm{X}$

$\mathrm{X}$

$\mathrm{X}$

Dispersion

Travel Time Based

Dispersion Coefficient

Diffusion

$\mathrm{f}$ (moisture content)
$\mathrm{X}$
$\mathrm{X}$

$\mathrm{X}$

$\mathbf{X}$
X 
Table 8.3. (continued)

Assumptions

Previous Conceptual Models

1

2

3

4

5

Retardation

$\mathrm{K}_{\mathrm{d}}$ based

$\mathrm{f}$ (moisture content)

$\mathrm{X} \quad \mathrm{X}$

$\mathbf{X}$
$\mathbf{X}$

Radioactive Decay single membered chains n-membered chains

$\mathrm{X}$

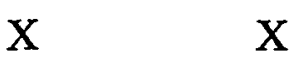

$\mathrm{X}$

INVESTIGATOR(S):

1. Sinnock and others (1984) - Set preliminary bounds

2. Travis and others (1984) - Investigated the effect of fractures

3. Lin and others (1986) - Analysis in support of the Environmental Assessment document

4. Dudley and others (1988) - Presented model used by TOSPAC

5. Ross (1988) - Presented conceptual model for ${ }^{14} \mathrm{CO}_{2}$ migration 
extract a dominant one dimensional transport path from this field. Therefore, the effects of the three-dimensional flow system would result in a one-dimensional transport path.

All the previous conceptual models discussed consider time-dependent transport. This is necessary to assess compliance with the regulations, because concentrations of contaminants as a function of time must be known. Although transient transport is considered in these conceptual models, researchers assume that the flow field, as indicated in Table 8.3, is in steady-state. This assumption of steady-state flow is discussed in Section 8.1.

Only one conceptual model (Ross, 1988, see Table 2.3) considered gas phase transport. This signifies that the path of radionuclides as dissolved solutes in the liquid ground water was usually assumed to be the dominant transport path for a repository in unsaturated, fractured tuff. It is difficult to refute or support this assumption because of the lack of experimental data concerning gas phase transport in unsaturated, fractured tuff. However, it is apparent that gas phase transport will only be important for a few radionuclides (see Section 5.7). Some researchers (Dudley and others, 1988) do acknowledge that gas phase transport will occur, but assumed that it will not be coupled with liquid-phase transport; therefore, they could implement a separate conceptual model for gas phase transport. The gas-phase conceptual model presented by Ross makes several significant assumptions and if any of these assumptions are not valid the performance of the system may change. For example, if the fractured tuff cannot be represented by a homogeneous porous medium then the system may behave significantly different.

Two of the conceptual models described (see Table 8.3) consider transport in the saturated zone (Sinnock and others, 1984; Travis and others, 1984a,b). Both of these conceptual models assumed that transport occurs in the fractures, and they do not consider retardation. These are conservative assumptions, and they indicate that all retardation of solutes was assumed to occur in the unsaturated zone.

Concerning the fractured nature of the tuff, different studies have presented several different assumptions, as indicated in Table 8.3. All of the conceptual models discussed assumed that a continuum exists in the transport system. Although some of the models assume that transport occurs predominately in either the fractures or the matrix (depending on the hydrogeologic unit) they still assume a continuum for each transport system. The only difference between fracture and matrix transport is the numerical values that were used (i.e, different values for the retardation factor, depending on whether matrix or fracture transport is assumed). It is questionable whether the 
continuum approach is appropriate for transport in fractured, porous media. When assuming a continuum, one is assuming that there are no discontinuities in the system; however the presence of fractures may constitute discontinuities. One way to conceptualize transport in fractured porous media (which none of the studies have done) is to assume that transport occurs in each discrete fracture. However, a discrete fracture model is cumbersome on large scales, and would require data that probably cannot be attained. The question that needs to be addressed is on what scale can a continuum be assumed for unsaturated, fractured media.

Dudley and others (1988) presented the only conceptual model that considers transport in the matrix and fractures simultaneously (i.e, coupled matrix and fracture transport). Again, they assumed a continuum for the fractures and for the matrix (i.e., dual continuum model). When they applied their conceptual model to Yucca Mountain for their first example, they assumed that there is strong transport coupling between the matrix and fractures. Conceptually, this is equivalent to a composite porous medium where the concentration of solute is equal in both the matrix and fractures (i.e., there is no resistance to transport between the two systems). This composite medium for transport was consistent with the corresponding conceptual model for flow discussed in Section 8.1. However, there is no experimental data to support this conceptual model of the fractured rock as a composite porous medium. In another example, Dudley and others assumed weaker transport coupling between the matrix and fractures, and, therefore, a dual continuum model was implemented (i.e., simultaneous matrix and fracture transport occurred). However, the flow results that were utilized were obtained from a equivalent porous medium model of the system. For steady-state flow this may acceptable; however, it is not clear that results from an equivalent porous medium model for flow can be used as input for a dual-continuum transport model.

As indicated in Table 8.3, convection is a transport process that researchers assume to occur in each of the conceptual models that were discussed previously. This signifies that assumptions about ground-water flow are an integral part of conceptual models for radionuclide transport. For some of the studies reviewed, a flow conceptual model was not presented; instead researchers assumed values for flow properties to be applied to the transport conceptual model.

For dispersion, which is coupled with convection, different investigators made several different assumptions (see Table 8.3). Some studies assumed that dispersion did not occur. This may be not make a difference in assessing compliance with the EPA Containment Requirement because the requirement is based on integrated discharge to the accessible environment. When the total amount of radionuclides that have reached 
the accessible environment is added over time for a specified time period, information concerning the distribution of concentration in space may not be important. There is one exception: if the contaminated plume is at the accessible environment boundary at the specified time. Concentration as a function of time and space is needed for the EPA Ground Water Protection Requirement and the EPA Individual Protection Requirement and therefore, it may be necessary to include dispersion in a transport conceptual model for a complete performance assessment.

Lin and others (1986) did not include dispersion in their governing equation for transport, but assumed that this transport process can be approximated using a distribution of ground-water travel times (GWTT) inferred from the corresponding flow analysis. The corresponding flow analysis uses a Monte Carlo approach to sample from distributions of hydraulic conductivity and porosity to find a distribution of GWTT's. For transport, this GWTT distribution was assumed to be equivalent to the physical process of dispersion. Therefore, dispersion is based on a distribution of flow parameters. This distribution of flow parameters is based on uncertainty and spatial variability. In the strictest sense this is not dispersion, since, if the flow parameters were known spatially and with certainty, solute dispersion would still occur on some scale. However, in a complicated geosphere system it may not be possible to distinguish on a macroscopic scale between the effects of uncertainty and spatial variability in flow parameters and solute dispersion.

Dudley and others (1988) conceptualized dispersion using the stochastic approach which assumes that hydraulic conductivities, among other quantities, are spatially correlated (see Section 5.1 and Gelhar and Axness, 1983). Currently, measured data does not exist that indicates spatial correlation of hydraulic conductivities for flow in unsaturated, fractured tuff and this data is needed before the stochastic approach to dispersion can be applied. One point that is not considered in any of the previous conceptual models for transport is that, by assuming one-dimensional vertical flow in the unsaturated zone, solute longitudinal dispersion may become relatively small.

Investigators assumed that diffusion occurs in three of the five transport conceptual models described, as indicated in Table 8.3. Neglecting diffusion may be justified if the rate of transport by diffusion is significantly slower than the rate of transport by convection. However, neglecting diffusion means that solute movement due to a concentration gradient is neglected, and this is one of the basic driving forces for solute movement. Some of the studies assumed that the diffusion process was a linear function of water content. This seems reasonable, because only solutes contained in the water will be available for diffusion. However, paths for diffusion can change drastically with 
changes in water content, and the relationship between diffusion and moisture content has not been established at this time.

Table 8.3 indicates that when conceptual models assumed that retardation occurs, it was based on a retardation factor. As discussed in Section 5.3, there is some question concerning the traditional definition of a retardation factor, and there is also a question about the measurement technique used to determine distribution coefficients. Some of the studies that were reviewed (see Table 8.3) assumed that the retardation factor is a function of moisture content. Conceivably, the surface area for sorption is related to the amount of water in the porous medium. However, experimental data do not exist that can confirm this relationship, and it is possible that two different rock samples that have the same water content may have different areas for sorption.

All of the conceptual models presented in Table 8.3, except the gas phase conceptual model presented by Ross (1988), assume that the process of radioactive decay occurs. Some of the conceptual models considered only single membered decay chains, while the other models considered multiple-member chains. To some extent, this was based on which radionuclides are assumed to be transported, and the validity of this assumption depends on the inventory of the nuclear waste and the relative toxicity of each radionuclide. However, for a complete description of radioactive decay, multiplemember chains and multiple chains should be included in a transport conceptual model. 


\subsection{SUMMARY AND CONCLUSIONS}

As part of the development of a HLW performance assessment methodology, a conceptualization of the geologic properties, and the ground-water flow and radionuclide transport processes at a hypothetical, HLW repository site located in unsaturated, fractured tuff has been conducted. In doing so, this report provides a foundation for the development of specific conceptual; mathematical, and numerical models that may be used in the implementation of this methodology. By evaluating and summarizing existing studies, this report reflects the current knowledge of flow and transport processes in both unsaturated and saturated, fractured tuff.

The geometry, stratigraphy, structure, and regional ground-water flow system for this conceptualization are site specific in that they are based on information from Yucca Mountain in Nevada. This was done because Yucca Mountain is the only unsaturated tuff site that has been extensively studied. However, the processes controlling groundwater flow and radionuclide transport in unsaturated and saturated, fractured tuff have been studied in the field and laboratory on tuffs from a number of different sites; therefore, in terms of process description, this conceptualization is generic.

The important processes that control the movement of ground water through the conceptualized system are described for the repository site as they apply to this topography, climate, and stratigraphy. For example, the unsaturated zone flow processes (including infiltration, percolation, recharge, and vapor/air movement), that may occur in a thick unsaturated zone consisting of fractured tuff have been discussed. A dominant flow process in the saturated zone includes saturated fracture flow.

Important mechanisms of radionuclide transport in unsaturated and saturated, fractured tuff have been identified. The primary transport processes in both the saturated and unsaturated zones are convection, dispersion, diffusion, sorption and radioactive decay. These processes were discussed for radionuclide transport as dissolved solutes in ground water through unsaturated, fractured tuff. Additional transport processes (e.g., dissolution, precipitation, complexation) were discussed in the context of their effect on the primary processes. Gas phase transport was discussed because it is a possible migration path because of the presence of the gas phase in the unsaturated zone. Colloid transport was also described because there is the possibility of radionuclide colloid transport in a ground-water flow system.

The discussion of these ground-water flow and transport processes was qualitative and no attempt was made to apply mathematical models of these processes for transport in 
unsaturated, fractured tuff because this was not the objective of this report. The discussion consisted of defining the process and identifying complexities associated with these processes for unsaturated, fractured tuff. It is evident from the discussion that there are many research questions concerning transport in unsaturated, fractured tuff that need to be addressed.

The movement of fluids through porous media is fundamentally a physical process governed by the pore geometry of the media. Therefore, the hydrogeologic stratigraphy should be defined according to physical differences in the media which affect the flow regime. Depending on which criteria are selected for defining the hydrogeologic stratigraphy, there are an infinite number possibilities for defining different layers. A possible hydrogeologic stratigraphy including the unsaturated and saturated zones was presented. The designated hydrogeologic units do not necessarily coincide with designated geologic units based on petrology and mineralogy. A three-dimensional conceptualization is highly complex due to heterogeneities, spatial variability, lack of information, and data uncertainty. However, due to the site heterogeneity, it is very important to the evaluate the performance of a three-dimensional hydrogeologic system.

The described possible hydrogeologic stratigraphy includes alluvium and five units of welded and nonwelded tuff in the unsaturated zone. The saturated zone includes an upper and lower carbonate aquifer system. The carbonate aquifers are separated by an upper clastic aquitard in some localities. The base of the hydrologic system is comprised of a lower clastic aquitard.

A regional and local ground-water flow system were defined. The regional system was delineated according to physical boundaries using potentiometric data and the results of hydrochemical studies. The regional ground-water flow system includes three topographic basins. In general, recharge occurs to the north while discharge occurs in the south. The regional ground-water flow path is directed mainly to the southwest, controlled by the lower carbonate aquifer where fracture flow dominates. The local ground-water flow system is located within the regional system. The local boundary conditions are controlled by the regional ground-water flow system. The local groundwater flow system at the repository site is characterized by a steep hydraulic gradient in the north and a fairly flat gradient in the south. It has been proposed that there is a multi-aquifer system beneath the repository site in which flow occurs through two different aquifers at nearly right angles (Czarnecki, 1989).

To define a transport system, a general stratigraphic representation of the hypothetical repository site based on geochemical and physical transport processes has been proposed. 
The units within the physical transport stratigraphy have been defined to be the same as the units within the hydrogeologic stratigraphy. The geochemical based stratigraphy is identified as only one possible alternative because the units within this stratigraphy are determined specifically by relative zeolite abundance within the rock. Alternative geochemical stratigraphies could possibly be defined based on different or more detailed mineralogy, or through the consideration of different geochemical transport processes. Zeolite abundance was chosen because of the high-sorption potential possessed by certain zeolite groups. A single stratigraphy has been proposed for all radionuclide species, although correlation of sorption to zeolite abundance ranges from very strong for certain radionuclides to almost non-existent for others.

From the host rock through the upper carbonate geologic unit, at least ten geochemicaltransport stratigraphic units can be defined. The location and thickness of the geochemical-transport units do not coincide with hydrogeologic or physical-transport units. However, a composite layering technique for transport modeling has been proposed that would incorporate both the flow and transport stratigraphic components and would therefore ensure consistency between flow and transport models. The composite layering overlays the geochemical-transport units on the physical-transport units, resulting in a more detailed stratigraphy than either of its constituents. In the composite layering, a new transport unit is defined when either the physical or the chemical properties of the rock change.

Specific, previously developed, conceptual models of ground-water flow and contaminant transport near a proposed HLW repository located in unsaturated, fractured tuff were reviewed. These previous conceptual models were described and the major assumptions that were made for each model were discussed and evaluated based on the prior discussions in this report on flow and transport processes.

This report has provided a qualitative description of a hypothetical HLW repository site in fractured tuff; however, no definitive, single conceptual model has been chosen. Instead, a basis for possible conceptual models is provided based on a description of properties and processes at the site. Given the existing data, it is recognized that multiple conceptual models are possible. Hopefully, through further research, some of the conceptual model uncertainties may be reduced and the possibilities narrowed. 


\section{REFERENCES}

Abeele, W.V., Wheeler, M.L., Burton, B.W., 1981. Geohydrology of Bandelier Tuff: Los Alamoș National Laboratories, LA-8962-MS, Los Alamos, NM.

Albers, J.P., 1967. Belt of Sigmoidal Bending and Right-Lateral Faulting in the Western Great Basin: Geologic Society of America Bulletin, vol. 78, pp. 143-156.

Amter, S., Behl, E., and Ross, B., 1988. Carbon-14 Travel Time at Yucca Mountain: report prepared for Pacific Northwest Laboratory by Disposal Safety Inc., Washington, DC.

Anderson, L.A., 1981. Rock Property Analysis of Core Samples from the Yucca Mountain UE25a-1 Borehole, Nevada Test Site, Nevada: U.S. Geological Survey, Open-File Report 81-1338, Denver, CO.

Apps, J.A., Carnshan, C.L., Lichtner, P.C., Michel, M.C., Perry, D., Silve, R.J., Weres, O., White, A.F., 1982. Status of Geochemical Problems Relating to the Burial of High-Level Radioactive Waste, 1982: U.S. Nuclear Regulatory Commission, NUREG/CR-3062, Washington, DC, and Lawrence Berkeley Laboratories, LBL15103, Berkeley, CA.

Barr, G.E., and Miller, W.B., 1987. Simple Models of the Saturated Zone at Yucca Mountain: Sandia National Laboratories, SAND87-0112, Albuquerque, NM.

Barton, 1984. Tectonic Significance of Fractures in Welded Tuff, Yucca Mountain, Southwest Nevada: Geologic Society of America, Abstracts with Programs, vol. 16, no. 6, p. 438.

Bear, J., 1972. Dynamics of Fluids in Porous Media: Am. Elsevier Publishing Co., New York.

Bear, J., 1979. Hydraulics of Groundwater: McGraw-Hill, New York.

Bear, J., and Verruijt, A., 1987. Modeling Groundwater Flow and Pollution: D. Ridel Publishing Company, Dordrecht, Netherlands.

Benson, L.V., Robinson, J.H., Blankenngel, R.K., and Ogard, A.E., 1983. Chemical Composition of Ground Water and the Locations of Permeable Zones in the Yucca Mountain Area, Nevada: U.S. Geological Survey, Open-File Report 83-854, Denver, $\mathrm{CO}$.

Bentley, C.B., 1984. Geohydrologic Data for Test Well USW G-4, Yucca Mountain Area, Nye County, Nevada: U.S. Geological Survey, Open-File Report 84-063, Denver, CO. 
Binnall, E.P., Benson, S.M., Tsao, L., Wollenberg, H.A., Tokunga, T.K., and Didwall, E.M., 1987. Critical Parameters for a High-Level Waste Repository, Volume 2: Tuff: U.S. Nuclear Regulatory Commission, NUREG/CR-4161, Washington, DC, and Lawrence Livermore National Laboratory, UCID-20092, vol. 2, Livermore, CA.

Bish, D.L., 1981. Detailed Mineralogical Characterization of the Bullfrog and Tram Members in USW-G1, with Emphasis on Clay Mineralogy: Los Alamos National Laboratory, LA-9021-MS, Los Alamos, NM.

Bish, D.L., Caporuscio, F.A., Copp, J.F., Crowe, B.M., Purson, J.D., Smyth, J.R., and Warren, R.G., 1981. Preliminary Stratigraphic and Petrologic Characterization of Core Samples from USW-G1, Yucca Mountain, Nevada: Waters, A.C., and Carroll, P.R., eds., Los Alamos National Laboratory, LA-8840-MS, Los Alamos, NM.

Bish, D.L., Vaniman, D.T., Byers, F.M., Jr., and Broxton, D.E., 1982. Summary of the Mineralogy-Petrology of Tuffs of Yucca Mountain and the Secondary Phase Thermal Stability in Tuffs: Los Alamos National Laboratory, LA-9321-MS, Los Alamos, NM.

Bish, D.L., Vaniman, D.T., Rundberg, R.S., Wolfsberg, K., Daniels, W.R., and Broxton, D.E., 1983. Natural Sorptive Barriers in Yucca Mountain, Nevada, for Long-Term Isolation of High-Level Waste: Los Alamos National Laboratory, LA-UR-83-758, Los Alamos, NM.

Bish, D.L., Ogard, A.E., Vaniman, D.T., and Benson, L., 1984a. Mineralogy-Petrology and Groundwater Geochemistry of Yucca Mountain Tuffs: in Scientific Basis for Nuclear Waste Management, VII, McVay, G.L., ed., North-Holland, Elsevier Science Publishing Co., New York, pp. 283-291.

Bish, D.L., Vaniman, D.T., Rundberg, R.S., Wolfsberg, K., Daniels, W.R., and Broxton, D.E., 1984b. Natural Sorptive Barriers in Yucca Mountain, Nevada, for Long-Term Isolation of High-Level Waste: in Radioactive Waste Management, vol. 3, pp. 415432.

Bish, D.L., and Vaniman, D.T., 1985. Mineralogical Summary of Yucca Mountain, Nevada: Los Alamos National Laboratory, LA-10543-MS, Los Alamos, NM.

Blankennagel, R.K., and Weir, J.E., Jr., 1973. Geohydrology of the Eastern Part of Pahute Mesa, Nevada Test Site, Nye, County, Nevada: U.S. Geological Survey, Professional Paper 712-B, Washington, DC.

Bonano, E.J., and Beyeler, W.E., 1985. Transport and Capture of Colloidal Particles in Single Fractures: in Scientific Basis for Nuclear Waste Management VIII, NorthHolland, New York, pp. 385-394.

Bonano, E.J., Davis, P.A., Shipers, L.R., Hall, I.J., Brinster, K.F., Beyeler, W.E., Updegraff, C.D., Shepherd, E.R., Tilton, L.M., and Wahi, K.K., 1988. Demonstration of a Performance Assessment Methodology for High-Level Radioactive Waste 
Disposal in Basalt Formations: U.S. Nuclear Regulatory Commission, NUREG/CR4759, Washington, DC, and Sandia National Laboratories, SAND86-2325, Albuquerque, NM.

Brikowski; T.H., 1989. The Steady-State Assumption in Regions of Large Hydraulic Gradient: The Potential for Conceptual Model Error: Transactions, American Geophysical Union, vol. 70, no. 15, p. 321.

Brooks, R.H., and Corey, A.T., 1966. Properties of Porous Media Affecting Fluid Flow: Journal of the Irrigation and Drainage Division, Proceedings of the American Society of Civil Engineers, pp. 61-89.

Broxton, D.E., Warren, R.G., Hagan, R.C., and Luedemann, G., 1986. Chemistry of Diagenetically Altered Tuffs at a Potential Nuclear Waste Repository, Yucca Mountain, Nye County, Nevada: Los Alamos National Laboratory, LA-10802-MS, Los Alamos, NM.

Bryant, E.A., and Vaniman, D.T., (comps.), 1984. Research and Development Related to the Nevada Nuclear Waste Storage Investigations, July 1 - September 30, 1983: Los Alamos National Laboratory, LA-10006-PR, Los Alamos, NM.

Burkholder, H.C., 1976. Methods and Data for Predicting Nuclide Migration in Geologic Media: International Symposium on Management of Wastes from the LWR Fuel Cycle, Denver, CO.

Byers, F.M., Jr., and Warren, R.G., 1983. Revised Volcanic Stratigraphy of Drill Hole $\mathrm{J}-13$, Fortymile Wash, Nevada, Based on Petrographic Modes and Chemistry of Phenocrysts: Los Alamos National Laboratory, LA-9652-MS, Los Alamos, NM.

Caporuscio, F.A., Vaniman, D., Bish, D., Broxton, D., Arney, D., Heiken, G., Byers; F., Gooley, R., and Semarge, E., 1982. Petrologic Studies of Drill Cores USW-G2 and UE25b-1H, Yucca Mountain, Nevada: Los Alamos National Laboratory, LA-9255MS, Los Alamos, NM.

Caporuscio, F.A., Warren, R.G., and Broxton, D.E., 1985. Detailed Petrologic Descriptions and Microprobe Data for Tertiary Silicic Volcanic Rocks in Drill Hole USW G-1, Yucca Mountain, Nevada: Los Alamos National Laboratory, LA-9323MS, Los Alamos, NM.

Carlos, B.A., 1985. Minerals in Fractures of the Unsaturated Zone from Drill Core USW G-4, Yucca Mountain, Nye County, Nevada: Los Alamos National Laboratory, LA-10415, Los Alamos, NM.

Carlos, B.A., 1987. Minerals in Fractures of the Saturated Zone from Drill Core USW G-4, Yucca Mountain, Nye County, Nevada: Los Alamos National Laboratory, LA-10927, Los Alamos, NM. 
Carr, W.J., 1984. Regional and Structural Setting of Yucca Mountain, Southwestern Nevada, and Late Cenozoic Rates of Tectonic Activity in Part of the Southwestern Basin, Nevada and California: U.S. Geological Survey, Open-File Report 84-854.

Carroll, P.I., Caporuscio, F.A., and Bish, D.L., 1981. Further Description of the Petrology of the Topopah Spring Member of the Paintbrush Tuff in Drill Holes UE25A-1 and USW-G1 and of the Lithic-Rich Tuff in USW-G1, Yucca Mountain, Nevada: Los Alamos National Laboratory, LA-9000-MS, Los Alamos, NM.

Champ, D.R., Merritt, W.F., and Young, J.L., 1982. Potential for Rapid Transport of Plutonium in Groundwater as Demonstrated by Core Column Studies: in $\underline{\text { Scientific }}$ Basis for Nuclear Waste Management V, North-Holland, New York, pp. 745-754.

Chuang, Y., 1988, Solute Transport Measurement by Ion-Selective Electrodes in Fractured Tuff: M.S. Thesis, Department of Hydrology and Water Resources, University of Arizona, Tucson, AZ.

Claassen, H.C., 1983. Sources and Mechanisms of Recharge for Ground Water in the West-Central Amargosa Desert, Nevada - A Geochemical Investigation: U.S. Geological Survey, Open-File Report 83-542, Denver, CO.

Claassen, H.C., and Cordes, H.E., 1975. Two-Well Recirculating Tracer Test in Fractured Carbonate Rock: Nevada Inst. Assn. Hydrol. Sci., Hydrol. Sci. Bull., vol. 20 , no. 3 , pp. $367-382$.

Claassen, H.C., and White, A.F., 1979. Application of Geochemical Kinetic Data to Ground-Water Systems: in Chemical Modeling in Aqueous Systems, Amer. Chem. Soc. Sympos. Ser. no. 93, pp. 771-793.

Clebsch, A., 1961. Tritium Age of Groundwater at the Nevada Test Site, Nye County, Nevada: U.S. Geological Survey, Professional Paper 424-C, Washington, DC.

Cox, W.B., 1988. A Field Study of Stream Infiltration and Recharge: M.S. Thesis, New Mexico Institute of Mining and Technology, Socorro, NM.

Crowe, B.M., and Vaniman, D.T., 1985. Research and Development Related to the Nevada Nuclear Waste Storage Investigations, January 1 - March 31, 1984: Los Alamos National Laboratory, LA-10154-PR, Los Alamos, NM.

Czarnecki, J.B., 1985. Simulated Effects of Increased Recharge on the Ground-Water Flow System of Yucca Mountain and Vicinity, Nevada-California: 'U.S. Geological Survey, Water-Resources Investigations Report 84-4344, Denver, CO.

Czarnecki, J.B., 1989. Preliminary Simulations Related to a Large Horizontal Hydraulic Gradient at the North End of Yucca Mountain, Nevada: Transactions, American Geophysical Union, vol. 70, no. 15, p. 321. 
Czarnecki, J.B., and Waddell, R.K., 1984. Finite-Element Simulation of Ground-Water Flow in the Vicinity of Yucca Mountain, Nevada-California: U.S. Geological Survey, Water-Resources Investigations Report 84-4349, Denver, CO.

Daniels, W.R., Wolfsberg, K., Rundberg, R.S., 1982. Summary Report on the Geochemistry of Yucca Mountain and Environs: Heiken, J., ed., Los Alamos National Laboratory, LA-9328-MS, Los Alamos, NM.

Day, J.A., 1964. Production of Droplets and Salt Nuclei by the Bursting of Air-Bubble Films: Quarterly Journal of the Royal Meteorological Society, vol. 90, no. 72.

de Marsily, G., 1986. Quantitative Hydrogeology, Groundwater Hydrology for Engineers: Academic Press, New York.

Dieulin, A., Matheron, G., and de Marsily, G., 1981a. Growth of the Dispersion Coefficient with the Mean Travelled Distance in Porous Media: Sci. Total-Environ., vol. 21, pp. 319-328.

Dieulin, A., Matheron, G., and de Marsily, G., 1981b. Time Dependence of an "Equivalent Dispersion Coefficient" for Transport in Porous Media: Proc. Euromech. 143, Delft, 1981, Verruijt, A., and Barends, F.B.J., eds., pp. 199-202, Balkema, Rotterdam, The Netherlands.

DOE (Department of Energy), 1988. Site Characterization Plan, Yucca Mountain Site, Nevada Research and Development Area, Nevada: Office of Civilian Radioactive Waste Management, Washington, DC.

Drever, J.I., 1982. The Geochemistry of Natural Waters: Prentice-Hall, Englewood Cliffs, NJ.

Dudley, A.L., Peters, R.R., Gauthier, J.H., Wilson, M.L., Tierney, M.S., and Klavetter, E.A., 1988. Total System Performance Assessment Code (TOSPAC) Volume 1: Physical and Mathematical Bases: Sandia National Laboratories, SAND85-0002, Albuquerque, NM.

Dykhuizen, R.C., 1988. Transport of Solutes Through Unsaturated Fractured Media, NNWSI Project: Sandia National Laboratories, SAND86-0940, Albuquerque, NM.

Eakin, T.E., 1966. A Regional Interbasin Groundwater System in the White River Area, Southeastern Nevada: vol. 2, no. 2, pp. 251-271.

Eakin, T.E., Maxey, G.B., Robinson, T.W., Fredericks, J.C., and Loeltz, O.J., 1951. Contributions to the Hydrology of Eastern Nevada: Nevada Department of Conservation and Natural Resources, Water Resources Bulletin 12, pp. 14-16.

Ehlers, E.G., and Blatt, H., 1982. Petrology: Igneous, Sedimentary, and Metamorphic, W.H. Freeman and Company, San Francisco, CA. 
EPA (Environmental Protection Agency), 1985. Environmental Standards for the Management and Disposal of Spent Nuclear Fuel, High-Level, and Transuranic Radioactive Wastes: Code of Federal Regulations, Title 40, Part 191, U.S. Government Printing Office, Washington, DC.

Evans, D.D., and Rasmussen, T.C., 1988. Unsaturated Fractured Rock Flow Model Calibration for a Tuff Site: Proceedings of the International Conference and Workshop on the Validation of Flow and Transport Models for the Unsaturated Zone, Ruidoso, NM.

Ferris, J.G., Knowles, D.B., Brown, R.H., and Stallman, R.W., 1962. Ground Water Hydraulics: U.S. Geological Survey, Water-Supply Paper 1536E, p. E84, Washington, DC.

Fogler, H.S., 1986. Elements of Chemical Reaction Engineering: Prentice-Hall, Englewood Cliffs, NJ.

Freeze, R.A., and Cherry, J.A., 1979. Groundwater: Prentice-Hall, Englewood Cliffs, NJ.

Gelhar, L.W., Gutjar, A.L., and Naff, R.L., 1979. Stochastic Analysis of Macrodispersion in a Stratified Aquifer: Water Resources Research, vol. 15, no. 6, pp. 1387-1397.

Gelhar, L.W., and Axness, C.L., 1983. Three-dimensional Stochastic Analysis of Macrodispersion in Aquifers: Water Resources Research, vol. 19, no. 1, pp. 161-180.

Green, R.T., and Evans, D.D., 1987. Radionuclide Transport as Vapor Through Unsaturated Fractured Rock: U.S. Nuclear Regulatory Commission, NUREG/CR4654, Washington, DC.

Grove, D.B., Rubin, M., Hanshaw, B.B., and Beetem, W.A., 1969. Carbon-14 Dates of Ground Water from a Paleozoic Carbonate Aquifer, South Central Nevada: in Geological Survey Research 1969, U.S. Geological Survey, Professional Paper 650-C, Washington, DC.

Hay, R.L., and Sheppard, R.A., 1977. Zeolites in Open Hydrologic Systems: in Mineralogy and Geology of Natural Zeolites, Mumpton, F.A., ed., Mineralogical Society of America Short Course Notes, vol. 4, pp. 93-102.

Helfferich, F., 1962. Ion Exchange: McGraw-Hill, New York.

Heiken, G.H., and Bevier, M.L., 1979. Petrology of Tuff Units from the J-13 Drill Site, Jackass. Flats, Nevada: Los Alamos National Laboratories, LA-7563-MS, Los Alamos, NM.

Hillel, 1980a. Applications of Soil Physics: Academic Press, New York. 
Hillel, 1980b. Fundamentals of Soil Physics: Academic Press, New York.

Johnstone, J.K., and Wolfsberg, K., eds., 1980. Evaluation of Tuff as a Medium for a Nuclear Waste Repository: Interim Status Report on the Properties of Tuff: Sandia National Laboratories, SAND80-1464, Albuquerque, NM.

Klavetter, E.A, and Peters, R.R., 1985. Fluid Flow in a Fractured Rock Mass: Sandia National Laboratories, SAND85-0855C, Albuquerque, NM.

Lallemand-Barres, A., and Peaudecerf, P., 1978. Research of Relations Between the Measured Values of the Macroscopic Dispersivity for an Aquifer Medium, Its Other Characteristics, and the Measurement Conditions. A Bibliographic Study: Bull. Bur. Rech. Geol. Min. Ser 2, Sec. III, 4-1978, pp. 277-284.

Lappin, A.R., Thomas, R.K., and McVey, D.F., 1981. Eleana Near-Surface Heater Experiment Final Report: Sandia National Laboratories, SAND80-2137, Albuquerque, NM.

Lin, Y.T., and Tierney, M.S., 1986. Preliminary Estimates of Groundwater Travel Time and Radionuclide Transport at the Yucca Mountain Repository Site: Sinnock, S., ed., Sandia National Laboratories, SAND85-2701, Albuquerque, NM.

Malmberg, G.T., and Eakin, T.E., 1962. Hydrology of the Valley-Fill and CarbonateRock Reservoirs, Pahrump Valley, Nevada-California: U.S. Geological Survey, Water-Supply Paper 1832, Washington, DC.

Maxey, G.B., and Mifflin, M.D., 1966. Occurrence and Movement of Ground Water in Carbonate Rocks of Nevada: National Speleological Society Bulletin, vol. 28, no. 3, pp. 141-157.

McWhorter, D.B., and Sunada, D.K., 1977. Ground-Water Hydrology and Hydraulics: Water Resources Publications, Fort Collins, CO.

Miller, D.E., and Gardner, W.H., 1962. Water Infiltration into Stratified Soil: Soil Sci. Soc. Am. Proc., vol. 26, pp. 115-118.

Montazer, P., and Wilson, W.E., 1984. Conceptual Hydrologic Model of Flow in the Unsaturated Zone, Yucca Mountain, Nevada: U.S. Geological Survey, WaterResources Investigations Report 84-4345, Denver, CO.

Montazer, P., and Wilson, W.E., 1985. Hydrogeology of the Unsaturated Zone, Yucca Mountain, Nevada: in Proceedings of the NWWA Conference on Characterization and Monitoring of the Vadose (Unsaturated) Zone, November 19-21, 1985, Denver. CO, National Water Well Association, Worthington, OH, pp. 396-412.

Morel, F.M., 1983. Principles of Aquatic Chemistry: John Wiley and Sons, New York. 
Mualem, Y., 1976. A New Model for Predicting the Hydraulic Conductivity of Unsaturated Porous Media: Water Resources Research, vol. 12, no. 3, pp. 513-522.

Neretnieks, I., 1980. Diffusion in the Rock Matrix: An Important Factor in Radionuclide Retardation?: J. Geophysical Research, vol. 85, no. B8, pp. 4379-4397.

Nichols, W.D., 1987. Geohydrology of the Unsaturated Zone at the Burial Site for LowLevel Radioactive Waste near Beatty, Nye County, Nevada: U.S. Geological Survey, Water-Supply Paper 2312, Washington, DC.

Nichols, W.D., and Akers, J.P., 1985. Water-Level Declines in the Amargosa Valley Area, Nye County, Nevada, 1962-1984: U.S. Geological Survey, Water-Resources Investigations Report 85-4273, Denver, CO.

Norris, A.E., Wolfsberg, K., and Gifford, S.K., $1985 .{ }^{36} \mathrm{Cl}$ Measurements of the Unsaturated Zone Flux at Yucca Mountain: in High-Level Nuclear Waste Disposal, Burkholder, H.C., Batelle Press, pp. 381-388.

NRC (Nuclear Regulatory Commission), 1984. Draft Generic Technical Position on Licensing Assessment Methodology for High-Level Waste in Geologic Repositories: U.S. Nuclear Regulatory Commission, Washington, DC.

NRC (Nuclear Regulatory Commission), 1986. Disposal of High-Level Radioactive Waste in Geologic Repositories: Code of Federal Regulations, Title 10, Part 60, U.S. Government Printing Office, Washington, DC.

Ogard, A.E., and Kerrisk, J.F., 1984. Groundwater Chemistry Along Flow Paths Between a Proposed Repository Site and the Accessible Environment: Los Alamos National Laboratory, LA-10188-MS, Los Alamos, NM.

Ogard, A.E., and Vaniman, D.T. (comps.), 1985. Research and Development Related to the Nevada Nuclear Waste Storage Investigations, July 1 - September 31, 1984: Los Alamos National Laboratory, LA-10299-PR, Los Alamos, NM.

Ogard, A.E., Wolfsberg, K., and Vaniman, D.T., 1983. Research and Development Related to the Nevada Nuclear Waste Storage Investigations, April 1 - June 30, 1983: Los Alamos National Laboratory, LA-9846-PR, Los Alamos, NM.

Ortiz, T.S, Williams, R.L., Nimick, F.B., Whittet, B.C., and South, D.L., 1985. ThreeDimensional Model of Reference Thermal/Mechanical and Hydrological Stratigraphy at Yucca Mountain, Southern Nevada: Sandia National Laboratories, SAND84-1076, Albuquerque, NM.

Palmquist, W.N., and Johnson, A.I., 1962. Vadose Flow in Layered and Non-Layered Materials: U.S. Geological Survey, Professional Paper 450-C, pp. C142-C143, Washington, DC. 
Pfankuch, H.O., 1963. Contribution to a Study of Miscible Fluids Displacements in a Porous Medium: Rev. Inst. Fr. Pet., vol. 2, no. 18, pp. 215-270.

Peters, R.R., Gáuthier, J.H., and Dudley, A.L., 1986. Effect of Percolation Rate on Water-Travel Time in Deep, Partially Saturated Zones: Sandia National Laboratories, SAND85-0854, Albuquerque, NM.

Peterson, D.W., 1968. Zoned Ash-Flow Sheet in the Region Around Superior, AZ: Titley, S.R., ed., Southern Arizona Guidebook III, Geological Society of America, pp. 215-222.

Polzer, W.L., Fuentes, H.R., Raymond, R., Bish, D.L., Gladney, E.S., and Lopez, E.A., 1987. Characterization of Crushed Tuff for the Evaluation of the Fate of Tracers in Transport Studies in the Unsaturated Zone: U.S. Nuclear Regulatory Commission, NUREG/CR-4875, Washington, DC and Los Alamos National Laboratory, LA10962-MS, Los Alamos, NM.

Quiring, R.F., 1983. Precipitation Climatology of the Nevada Test Site: U.S. Department of Commerce, National Weather Service, WSNSO 351-88, Las Vegas, NV.

Reynolds, 1969. Stratigraphy and Structural Geology of the Titus and Titanothere Canyons Area, Death Valley, California: Ph.D. Dissertation, University of California, Berkeley.

Rice, W.A., 1984. Preliminary Two-Dimensional Regional Hydrologic Model of the Nevada Test Site and Vicinity: Sandia National Laboratories, SAND83-7466, Albuquerque, NM.

Robison, J.H., Stephens, D.M., Luckey, R.R., and Baldwin, D.A., 1988. Water Levels in Periodically Measured Wells in the Yucca Mountain Area, Nevada, 1981-1987: U.S. Geological Survey, Open-File Report 88-468.

Ross, B., 1984. A Conceptual Model of Deep Unsaturated Zones with Negligible Recharge: Water Resources Research, vol. 20, no. 11, pp. 1627-1629.

Ross, B., 1988. Gas-Phase Transport of Carbon-14 Released from Nuclear Waste Into the Unsaturated Zone: Mat. Res. Soc. Symp. Proc., vol. 122, pp. 273-283.

Rulon, J., Bodvarsson, G.S., and Montazer, P., 1986. Preliminary Numerical Simulations of Groundwater Flow in the Unsaturated Zone, Yucca Mountain, Nevada: Lawrence Berkeley Laboratory, LBL-20553, Berkeley, CA.

Rundberg, R.S., Ogard, A.E., and Vaniman, D.T., 1985. Research and Development Related to the Nevada Nuclear Waste Storage Investigations, April 1 - June 30, 1984: Los Alamos National Laboratory, LA-10297-PR, Los Alamos, NM. 
Rush, F.E., Thordarson, W., and Bruckheimer, L., 1983. Geohydrologic and Drill-Hole Data for Test Well USW H-1, Adjacent to Nevada Test Site, Nye County, Nevada: U.S. Geological Survey, Open-File Report 83-141.

Sahimi, M., Davis, H.T., and Scriven, L.E., 1983. Dispersion in Disordered Porous Media: Chem. Eng. Commun., vol. 23, pp. 329-341.

Sandia National Laboratories, Interactive Graphics Information Services, NNWSI Product Numbers CAL0115 and CAL0119, Albuquerque, NM.

Sass, J.H., and Lachenbruch, A.H., 1982. Preliminary Interpretation of Thermal Data from the Nevada Test Site: U.S. Geological Survey, Open-File Report 82-973, Denver, CO.

Sass, J.H., Lachenbruch, A.H., and Mase, C.W., 1980. Analysis of Thermal Data from Drill Holes UE24a-3 and UE25a-1, Calico Hills and Yucca Mountain, Nevada Test Site: U.S. Geological Survey, Open-File Report 80-826, Denver, CO.

Satterfield, C.M., 1970. Mass Transfer in Heterogeneous Catalysis: MIT Press, Cambridge, MA.

Schoff, S.L., and Moore, J.E., 1964. Chemistry and Movement of Ground Water, NTS: U.S. Geological Survey, Trace-Elements Investigations Report 838.

Scott, R.B., and Bonk, J., 1984. Preliminary Geologic Map of Yucca Mountain with Geologic Sections, Nye County, Nevada: U.S. Geological Survey, Open-File Report 84-494, Denver, CO.

Scott, R.B., and Castellanos, M., 1984. Stratigraphic and Structural Relations of Volcanic Rocks in Drill Holes USW GU-3 and USW G-3, Yucca Mountain, Nye County, Nevada: U.S. Geological Survey, Open-File Report 84-491, Denver, CO.

Scott., R.B., Spengler, R.W., Diehl, S., Lappin, A.R., and Chornack, M.P., 1983. Geologic Character of Tuffs in the Unsaturated Zone at Yucca Mountain, Southern Nevada: in Role of the Unsaturated Zone in Radioactive and Hazardous Waste Disposal, Mercer, J.W., Rao, P.S.C., and Marine, I.W., eds., Ann Arbor Science Publishers, Ann Arbor, MI, pp. 289-335.

Shaw, D.J., 1970. Introduction to Colloid and Surface Chemistry: Butterworths, Boston, MA.

Sinnock, S., 1982. Geology of the Nevada Test Site and Nearby Areas, Southern Nevada: Sandia National Laboratories, SAND82-2207, Albuquerque, NM.

Sinnock, S., Lin, Y.T., and Brannen, J.P., 1984. Preliminary Bounds on the Expected Postclosure Performance of the Yucca Mountain Repository Site, Southern Nevada: Sandia National Laboratories, SAND84-1492, Albuquerque, NM. 
Sinton, P.O., 1989. Characterization of the Large Hydraulic Gradient Beneath the North End of Yucca Mountain, Nevada: Transactions, American Geophysical Union, vol. 70 , no. 15 , p. 321.

Smiles, D.E., Perroux, K.M., Zegelin, S.J., and Raats, P.A.C., 1981. Hydrodynamic Dispersion During Constant Rate Absorption of Water by Soils: Soil Sci. Soc. of Am. Proc., vol. 45, pp. 453-458.

Smith, D.M., 1988. Pore Structure Properties of Tuff: A Preliminary Study of Experimental Methodology: in Proceedings of Workshop IV on Flow and Transport Through Unsaturated Fractured Rock -- Related to High-Level Radioactive Waste Disposal, pp. 127-148, Tucson, AZ.

Smith, D.M., Updegraff, C.D., Bonano, E.J., and Randall, J.D., 1986. Assessment of Radionuclide Vapor-Phase Transport in Unsaturated Tuff: U.S. Nuclear Regulatory Commission, NUREG/CR-4693, Washington, DC, and Sandia National Laboratories, SAND86-1598, Albuquerque, NM.

Smith, R.L., 1960. Ash Flows: Geologic Society of America Bulletin, vol. 71, no. 6, pp. 795-841.

Spengler, R.W., Chornack, M.P., Muller, D.C., and Kibler, J.E., 1984. Stratigraphic and Structural Characteristics of Volcanic Rocks in Core Hole USW G-4, Yucca Mountain, Nye County, Nevada: U.S. Geological Survey, Open-File Report 84-789, Denver, CO.

Stewart, J.H., 1978. Basin-Range Structure in Western North America: A Review: in Cenozoic Tectonics and Regional Geophysics of the Western Cordillera, Smith, R.B., and Eaton, G.P., eds., Geological Society of America Memoir 152, pp. 1-31.

Stewart, J.H., 1985. East-Trending Dextral Faults in the Western Great Basin: An Explanation for Anomalous Trends of Pre-Cenozoic Strata and Cenozoic Faults: Tectonics, vol. 4, no. 6, pp. 547-564.

Swadley, W.C., Hoover, D.L., and Rosholt, J.N., 1984. Preliminary Report on Late Cenozoic Faulting and Stratigraphy in the Vicinity of Yucca Mountain, Nye County, Nevada: U.S. Geological Survey, Open-File Report 84-788.

Sykes, M.L., Heiken, G.H., and Smyth, J.R., 1979. Mineralogy and Petrology of Tuff Units from the UE25a-1 Drill Site, Yucca Mountain, Nevada: Los Alamos National Laboratory, LA-8139-MS, Los Alamos, NM.

Taylor, Sir, G., 1953. Dispersion of Soluble Matter in Solvent Flowing Slowly Through a Tube: Proc. R. Soc., London, Ser. A, vol. 219, pp. 186-203.

Thoma, S.G., Gallegos, D.P., and Smith, D.M., 1990. Effect of Mineral Layers on Capillary Uptake from Fracture Surfaces: Implications for Waste Disposal in 
Unsaturated, Fractured Rock: Letter report submitted to U.S. NRC Office of Nuclear Regulatory Research, July 1990.

Thomas, K.W., 1987. Summary of Sorption Measurements Performed with Yucca Mountain, Nevada, Tuff Samples and Water from Well J-13: Los Alamos National Laboratory, LA-10960-MS, Los Alamos, NM.

Thordarson, W., Rush, F.E., Spengler, R.W., and Waddell, S.J., 1984. Geohydrologic and Drill-Hole Data for Test Well USW H-3, Yucca Mountain, Nye County, Nevada: U.S. Geological Survey, Open-File Report 84-149.

Tien, P., Siegel, M.D., Updegraff, C.D., Wahi, K.K., and Guzowski, R.V., 1985. Repository Site Data Report for Unsaturated Tuff, Yucca Mountain, Nevada: U.S. Nuclear Regulatory Commission, NUREG/CR-4110, Washington, DC and Sandia National Laboratories, SAND 84-2668, Albuquerque, NM.

Toth, J., 1963. A Theoretical Analysis of Groundwater Flow in Small Drainage Basins: J. Goephys. Res., vol. 68, pp. 4795-4812.

Travis, B.J., Hodson, S.W., Nuttall, H.E., Cook, T.L., and Rundberg, R.S., 1984a. Numerical Simulation of Flow and Transport in Fractured Tuff: in Scientific Basis for Nuclear Waste Management VII, North-Holland, New York.

Travis, B.J., Hodson, S.W., Nuttall, H.E., Cook, T.L., and Rundberg, R.S., 1984b. Preliminary Estimates of Water Flow and Radionuclide Transport in Yucca Mountain: Los Alamos National Laboratory, LA-UR-84-40, Los Alamos, NM.

Travis, C.C., and Etnier, E.C., 1981. A Survey of Sorption Relationships for Reactive Solutes in Soil: Journal of Environmental Quality, vol. 10, pp. 8-17.

Tsang, C.F., and Mangold, D.C., 1984. Panel Report on Coupled Thermo-MechanicalHydro-Chemical Processes Associated with a Nuclear Waste Repository: Lawrence Berkeley Laboratory, LBL-18250, Berkeley, CA.

U.S. Geological Survey (USGS), 1982. Hand-Contoured Ground-Water Elevation Map of the Nevada Test Site: Transmitted from the Denver, CO, USGS Office to Pacific Northwest Laboratory, Richland, WA on March 31, 1982.

U.S. Geological Survey (USGS) (comp.), 1984. A Summary of Geologic Studies through January 1, 1983, of a Potential High-Level Radioactive Waste Repository Site at Yucca Mountain, Southern Nye County, Nevada: U.S. Geological Survey, Open-File Report 84-792, Denver, CO.

Vaniman, D.T., Bish, D., Broxton, D., Byers, F., Heiken, G., Carlos, B., Semarge, E., Caporuscio, F., and Gooley, R., 1984. Variations in Authigenic Mineralogy and Sorptive Zeolite Abundance at Yucca Mountain, Nevada, Based on Studies of Drill 
Cores USW GU-3 and G-3: Los Alamos National Laboratory, LA-9707-MS, Los Alamos, NM.

van Genuchten,'M.Th., 1980. A Closed-Form Equation for Predicting the Hydraulic Conductivity of Unsaturated Soil: Soil Science Society of America Journal, vol. 44, pp. 892-898.

van Konynenburg, R.A., Smith, C.F., Culham, H.W., and Otto, C.H., Jr., 1985. Behavior of Carbon-14 in Waste Packages for Spent Fuel in a Repository in Tuff: Mat. Res. Soc. Symp. Proc., vol. 44, pp. 405-412.

van Olphen, H., 1977. Introduction to Clay Colloid Chemistry: John Wiley \& Sons, New York.

Vine, E.N., Bayhurst, B.P., Daniels, W.R., DeVilliers, S.J., Erdal, B.R., Lawrence, F.O., and Wolfsberg, K., 1981. Radionuclide Transport and Retardation in Tuff: in Scientific Basis for Nuclear Waste Management III, Moore, J.G., ed., Plenum Press, New York, pp. 483-490.

Vogt, G.T., 1988. Porosity, Pore-Size Distribution and Pore Surface Area of the Apache Leap Tuff Near Superior, Arizona Using Mercury Porosimetry: M.S. Thesis, Department of Hydrology and Water Resources, Univ. of Arizona.

Waddell, R.K., 1982. Two-Dimensional Steady-State Model of Groundwater Flow, Nevada Test Site and Vicinity, Nevada-California: U.S. Geological Survey, WaterResources Investigations Report 82-4085, Denver, CO.

Waddell, R., 1983. from Minutes of NNWSI Performance Assessment Working Group Meeting, Sandia National Laboratories, Albuquerque, NM, April 21-22, 1983.

Waddell, R.K., 1984. Solute-Transport Characteristics of Fractured Tuffs at Yucca Mountain, Nevada Test Site - A Preliminary Assessment: GSA Abstracts with Programs, vol. 16, no. 6, p. 684.

Waddell, R.K., 1985. Hydrologic and Drill-Hole Data for Test Wells UE-29a No. 1 and UE-29a No. 2, Fortymile Canyon, Nevada Test Site: U.S. Geological Survey, OpenFile Report 84-142, Denver, CO.

Waddell, R.K., Robison, J.H., and Blankennagel, R.K., 1984. Hydrology of Yucca Mountain and Vicinity, Nevada-California, Investigative Results Through Mid-1983: U.S. Geological Survey, Water-Resources Investigations Report 84-4267, Denver, CO.

Walker, G.E., and Eakin, T.E., 1963. Geology and Ground Water of Amargosa Desert, Nevada-California: Nevada Department of Conservation and Natural Resources, Ground-Water Resources Reconnaissance Series Report 14, Carson City, NV. 
Walters, G.R., 1982. Theoretical and Experimental Determination of Matrix Diffusion and Related Solute Transport Properties of Fractured Tuffs from the Nevada Test Site: Los Alamos National Laboratory, LA-9471-MS, Los Alamos, NM.

Wang, J.S.Y., and Narasimhan, T.N., 1985. Hydrologic Mechanisms Governing Fluid Flow in a Partially Saturated, Fractured, Porous Medium: Water Resources Research, vol. 21, no. 12, pp. 1861-1874.

Wang, J.S.Y., and Narasimhan, T.N., 1986. Hydrologic Mechanisms Governing Partially Saturated Fluid Flow in Fractured Welded Units and Porous Non-Welded Units at Yucca Mountain: Sandia National Laboratories, SAND85-7114, Albuquerque, NM.

Wang, J.S.Y., and Narasimhan, T.N., 1988. Hydrologic Modeling of Vertical and Lateral Movement of Partially Saturated Fluid Flow Near a Fault Zone at Yucca Mountain: Sandia National Laboratories, SAND87-7070, Albuquerque, NM.

Waters, A.C., and Carroll, P.R., eds., 1981. Preliminary Stratigraphic and Petrologic Characterization of Core Samples from USW-G1, Yucca Mountain, Nevada: Los Alamos National Laboratory, LA-8840-MS, Los Alamos, NM.

Weeks, E.P., 1987. Effect of Topography on Gas Flow in Unsaturated Fractured Rock: Concepts and Observations: in Flow and Transport Through Unsaturated Fractured Rock, Geophysical Monograph 42, Evans, D.D., and Nicholson, T.J., eds., American Geophysical Union, Washington, DC, pp. 165-170.

Weeks, E.P., and Wilson, W.E., 1984. Preliminary Evaluation of Hydrologic Properties of Cores of Unsaturated Tuff, Test Well USW H-1, Yucca Mountain, Nevada: U.S. Geological Survey, Water-Resources Investigations Report 84-4193, Denver, CO.

White, A.F., Claassen, H.C., and Benson, L.V., 1980. The Effect of Dissolution of Volcanic Glass on the Water Chemistry in a Tuffaceous Aquifer, Ranier Mesa, Nevada: U.S. Geological Survey, Water-Supply Paper 1535-Q, Washington, DC.

Winograd, I.J., and Friedman, I., 1972. Deuterium as a Tracer of Regional GroundWater Flow, Southern Great Basin, Nevada and California: Geological Society of America Bulletin, vol. 83, pp. 3691-3708.

Winograd, I.J., and Thordarson, W., 1968. Structural Control of Ground-Water Movement in Miogeosynclinal Rocks of South-Central Nevada: in Studies of Geology and Hydrology, Eckel, E.B., ed., Geological Society of America Memoir 110, pp. 35-48.

Winograd, I.J., and Thordarson, W., 1975. Hydrogeologic and Hydrochemical Framework, South Central Great Basin, Nevada-California, with Special Reference to the Nevada Test Site: U.S. Geological Survey, Professional Paper 712-C, Washington, DC. 
Wolfsberg, K., Vaniman, D.T., and Ogard, A.E., (comps.), 1983. Research and Development Related to the Nevada Nuclear Waste Storage Investigations, January 1 - March 31, 1983: Los Alamos National Laboratory, LA-9793-PR, Los Alamos, NM.

Wollenberg, H.A., Wang, J.S.Y., and Korbin, G., 1983. An Appraisal of Nuclear Waste Isolation in the Vadose Zone in Arid and Semi-Arid Regions, Emphasis on the Nevada Test Site: U.S. Nuclear Regulatory Commission, NUREG/CR-3158, Washington, DC.

Yariv, S. and Cross, H., 1979. Geochemistry of Colloid Systems: Springer-Verlag, New York. 


\begin{tabular}{|c|c|}
\hline $\begin{array}{l}\text { U.S. NUCLEAR REGULATORY COMMISSION } \\
\text { BIBLIOGRAPHIC DATA SHEET } \\
\text { (See instructions on the reverse) }\end{array}$ & $\begin{array}{l}\text { 1. REPORT NUMBER } \\
\text { (Asslgned by NRC. Add Vol.s Supp.. Rev., } \\
\text { and Addendum Numbers, it any.) } \\
\text { NUREG/CR-5495 } \\
\text { SAND89-2965 }\end{array}$ \\
\hline \multirow{4}{*}{$\begin{array}{l}\text { 2. TITLE AND SUBTITLE } \\
\text { Conceptualization of a Hypothetical High-Level Nuclear Waste } \\
\text { Repository Site in Unsaturated, Fractured Tuff }\end{array}$} & \\
\hline & 3. DATE REPORT PUBLISHED \\
\hline & \begin{tabular}{|c|c|} 
MONTH & YEAR \\
January & 1991 \\
\end{tabular} \\
\hline & $\begin{array}{c}\text { 4. FIN OR GRANT NUMBER } \\
\text { A1266 }\end{array}$ \\
\hline \multirow[t]{2}{*}{$\begin{array}{l}\text { 5. AUTHOR(S) } \\
\text { A. M. Parsons, N. E. 01 ague, D. P. Gallegos }\end{array}$} & $\begin{array}{l}\text { 6. TYPE OF REPORT } \\
\text { Technical } \\
\end{array}$ \\
\hline & 7. PERIOD COVERED (Inclusive Dates) \\
\hline \multicolumn{2}{|c|}{$\begin{array}{l}\text { 8. PERFORMING ORGANIZATION - NAME AND ADDRESS (II NRC, provide Division, Office or Region, U.S. Nuclear Regulatory Commission, and mailing address, if contractor, provide } \\
\text { name ond malling address.) }\end{array}$} \\
\hline \multicolumn{2}{|c|}{$\begin{array}{l}\text { Sandia National Laboratories } \\
\text { Albuquerque, NM } 87185\end{array}$} \\
\hline \multicolumn{2}{|l|}{$\begin{array}{l}\text { Division of Engineering } \\
\text { Office of Nuclear Regulatory Research } \\
\text { U.S. Nuclear Regulatory Commission } \\
\text { Washington, D.C. } 20555\end{array}$} \\
\hline \multicolumn{2}{|l|}{ 10. SUPPLEMENTARY NOTES } \\
\hline \multicolumn{2}{|l|}{ 11. ABSTRACT 1200 words or less) } \\
\hline \multicolumn{2}{|c|}{$\begin{array}{l}\text { Under the sponsorship of the U.S. Nuclear Regulatory Commission (NRC), Sandia National Laboratories (SNL) is } \\
\text { developing a performance assessment methodology for the analysis of long-term disposal and isolation of high-level } \\
\text { nuclear waste (HLW) in alternative geologic media. As part of this exercise, SNL created a conceptualization of ground- } \\
\text { water flow and radionuclide transport in the far field (i.e., outside the disturbed zone) of a hypothetical HLW repository } \\
\text { site located in unsaturated, fractured tuff formations. This study provides a foundation for the development of conceptual, } \\
\text { mathematical, and numerical models to be used in this performance assessment methodology. This conceptualization } \\
\text { is site specific in terms of geometry, the regional ground-water flow system, stratigraphy, and structure in that these are } \\
\text { based on information from Yucca Mountain located on the Nevada Test Site. However, in terms of processes in } \\
\text { unsaturated and saturated, fractured, porous media, the model is generic. This report also provides a review and } \\
\text { evaluation of previously proposed conceptual models of unsaturated and saturated flow and solute transport. This report } \\
\text { provides a qualitative description of a hypothetical HLW repository site in fractured tuff. However, evaluation of the } \\
\text { current knowledge of flow and transport at Yucca Mountain does not yield a single conceptual model. Instead, multiple } \\
\text { conceptual models are possible given the existing information. }\end{array}$} \\
\hline \multirow{6}{*}{$\begin{array}{l}\text { high-level nuclear waste } \\
\text { geologic repositories } \\
\text { unsaturated, fractured tuff } \\
\text { ground-water flow and transport }\end{array}$} & $\begin{array}{l}\text { 13. AVAILABILITY STATEMENT } \\
\text { Unl imited }\end{array}$ \\
\hline & 14. SECURITY CLASSIFICATION \\
\hline & $\begin{array}{l}\text { (This Pagel } \\
\text { Unclassified }\end{array}$ \\
\hline & $\begin{array}{l}\text { (This Report) } \\
\text { Unclassified }\end{array}$ \\
\hline & 15. NUMBER OF PAGES \\
\hline & \\
\hline
\end{tabular}

